\title{
EL DELME COM A FONT PER A LA HISTORIA RURAL
}

ELENA CATALÁN MARTÍNEZ GABRIEL JOVER AVELLÀ ENRIQUE LLOPIS AGELÁN (EDS.)




๑ :三

$<$

$>$ 


\section{EL DELME}

COM A FONT PER A LA HISTÒRIA RURAL

Elena Catalán Martínez

Gabriel Jover Avellà

ENRIQUe Llopis Agelán

(ed.) 
Dades CIP recomanades pel Servei de Biblioteques de la UdG

CIP 001.891 DEL

El Delme com a font per a la història rural / Elena Catalán Martínez,

Gabriel Jover Avellà, Enrique Llopis Agelán (ed.). - Girona : Associació

d'Història Rural : Centre de Recerca d'Història Rural (Institut de Recerca

Històrica) de la Universitat de Girona : Documenta Universitaria, 2020. -

276 pàgines : il.lustracions, mapes, taules, gràfics $; 20 \mathrm{~cm}$. - (Biblioteca

d'història rural. Col-lecció estudis ; 21). - Bibliografia: pàgines 237-276

ISBN 978-84-9984-540-1

I. Catalán Martínez, Elena, 1963- editor literari II. Jover i Avellà, Gabriel, editor literari III. Llopis, Enrique 1960- editor literari 1. Delmes

2. Història - Fonts

Qualsevol forma de reproducció, distribució, comunicació pública o transformació d’aquesta obra només pot ser realitzada amb l’autorització dels seus titulars, llevat excepció prevista per la llei. Dirigiu-vos a CEDRO (Centro Español de Derechos Reprográficos) si necessiteu fotocopiar o escanejar algun fragment d’aquesta obra (www. conlicencia.com; +34917021970/ +349327204 47).

Amb el suport de


Edita: Associació d'Història Rural, Centre de Recerca d'Història Rural (Institut de Recerca Històrica) de la Universitat de Girona i Documenta Universitaria

Disseny de coberta: Quim Español

Correcció lingüística: Berta Crous

ISBN: 978-84-9984-540-1

DOI: $10.33115 / \mathrm{b} / 9788499845401$

(C) dels textos: els autors

(C) de la Biblioteca d'Història Rural: Associació d'Història Rural

(c) de l'edició: Documenta Universitaria

Girona, 2020

La Biblioteca d'Història Rural s'autofinança, en part, amb les quotes aportades pels socis de l'Associació d'Història Rural. Els socis reben puntualment els llibres editats, així com informació periòdica de les activitats de l'Associació (a través del seu butlletí Mestall, de periodicitat semestral). Podeu obtenir la butlleta d'inscripció a www.ddgi. cat/historiarural o a l'Arxiu Històric de Girona (plaça de Sant Josep, 1, 17004 Girona) 


\section{ÍNDEX}

INTRODUCCIÓ:

EL DELME COM A FONT PER A LA HISTÒRIA RURAL ......................

1. DEL DIEZMO AL PRODUCTO AGRARIO: ¿PODEMOS MEDIR LO INVISIBLE? ¿PODEMOS IGNORARLO? .......................................15

2. EL DIEZMO COMO BASE DEL SISTEMA BENEFICIAL .................49

3. La producció agrària al País VAlencià durant L'EDAT MODERNA. APROXIMACió al SEU ESTUdi A PARTIR

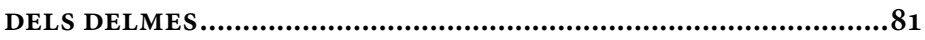

4. LA RECAPTACIÓ I EL REPARTIMENT DEL DELME a la Catalunya Vella. El cas del bisbat de Girona, SEGLES XIII-XIV

5. Els ARRENDAMENTS DE LES CAPELlanies de LA SEU DE GIRONA (1503-1705). UN INDICADOR DE LA RENDA AGRÀRIA DELS SEGLES XVI I XVII? ............................................167

6. Delmes, trullades i preus de loli a Mallorca, 1684-1835 
๑ :三

$<$

$>$ 


\title{
INTRODUCCIÓ: EL DELME COM A FONT PER A LA HISTÒRIA RURAL
}

\author{
Elena Catalán Martínez, Gabriel Jover \\ Avellà i Enrique Llopis Agelán
}

La documentació decimal fou emprada pels coetanis per aproximar-se a la dimensió, composició i variacions del producte agrari, especialment del cerealista. Al segle xviı la monarquia espanyola va començar a fer un ús relativament sistemàtic de la documentació decimal per esbrinar el volum de les collites. En diverses ocasions, en el transcurs d'aquesta centúria, el Govern o el Consell de Castella van sol-licitar a intendents i corregidors o a arquebisbes, bisbes, capítols catedralicis i col-legiates, dades precises sobre la producció de cereals en les seves respectives jurisdiccions (Anes, 1970: 59-63). Però la profunda crisi del sistema decimal (Canales, 1982) va interrompre aquest procediment per conèixer els nivells i les fluctuacions de les collites.

Foren els historiadors els que reprengueren l'ús d'aquesta font per estimar la producció agrària, particularment dels cereals, per a les etapes medieval i moderna. L'edat d'or de la utilització dels delmes com a indicadors del creixement agrari data de les dècades de 1960 i 1970. El creixent interès en la quantificació del creixement econòmic del passat preindustrial no es pot deslligar del seu context socioeconòmic. Durant els decennis de 1950 i 1960 el PIB dels països de l'Europa occidental va créixer de manera molt ràpida i sostinguda. L'eufòria que provocava l'expectativa d'un creixement sostingut i una 
millora continuada del benestar induí molts economistes i historiadors a mesurar i definir les diferents etapes del desenvolupament europeu. L'objectiu era contrastar el creixement del capitalisme industrial, ràpid i sostingut, amb el creixement econòmic preindustrial, lent $\mathrm{i}$ irregular (Rostow, 1960).

En la dècada de 1960 l'Escola dels Annals es trobava en una situació privilegiada per liderar aquells estudis per l'etapa preindustrial. La tradició de la geografia històrica i la història econòmica franceses es conjuminaren en un projecte de reconstrucció i estudi regional de la població, la producció agrària, els rendiments, els preus i les rendes. En aquell projecte els delmes es convertiren en una de les fonts més utilitzades i apreciades pels historiadors, perquè eren un indicador continu i comparable de la producció agrària. Les primeres impressions dels especialistes van ser relativament optimistes. Molts autors van considerar que a partir dels delmes resultava possible reconstruir els moviments del producte agrari en diverses regions europees, almenys durant bona part de l'edat moderna.

El resultat foren dos congressos internacionals liderats pels historiadors econòmics francesos de l'Escola dels Annals, entre d'altres, Emmanuel Le Roy Ladurie, Joseph Goy i Ernest Labrousse. El seu objectiu era impulsar a escala internacional un estudi comparatiu de la trajectòria del producte agrari a través de les fonts decimals. Probablement, el moment culminant d'aquell esforç investigador fou la trobada internacional celebrada a París, entre el 30 de juny i el 2 de juliol de 1977, i titulada Peasant dues, tithes and trends in agricultural production in preindustrial societies. Es tractava d'una reunió preparatòria d'una de les principals sessions del VII Congrés Internacional d'Història Econòmica, que s'havia de celebrar a Edimburg l'any següent, en què van participar 66 investigadors de 17 països europeus i americans. La presència espanyola va ser molt nombrosa: ni més ni menys que 13 de les 58 comunicacions presentades versaven sobre diversos territoris espanyols. Dos factors contribueixen a explicar aquest protagonisme dels historiadors econòmics espanyols en aquesta onada de treballs sobre els moviments del producte agrari a les societats preindustrials: l'abundància i alta qualitat, almenys en termes relatius, de les fonts decimals en aquest país i els estrets vincles de les grans figures de la història econòmica 
espanyola de les dècades de 1960 i 1970 amb l'Escola dels Annals o $\mathrm{amb}$ altres eminents historiadors econòmics francesos.

Abans i després d'aquella trobada internacional parisenca es van publicar nombrosos treballs de reconstrucció de la trajectòria de collites i esplets, sustentats en els delmes, per a la major part de les regions espanyoles. Però la qualitat dels delmes com a indicadors de la trajectòria del producte agrari varia notablement en el temps i en l'espai. En general, els delmes no permeten un bon acostament a aquesta trajectòria quan s'arrendaven en metàl-lic, quan la diversificació de cultius reduïa significativament el pes relatiu dels cereals en el conjunt de collites o quan els drets decimals es cobraven conjuntament amb altres drets senyorials, com ara censos, herbatges i altres rendes. D’aquí que l'ús i la confiança en les fonts decimals per conèixer l'evolució del producte agrari en l'edat moderna hagin estat diferents en els diversos territoris espanyols.

A finals de la dècada de 1970 ja eren bastant clares les llums i les ombres de l'esforç de quantificació que s'havia efectuat en els darrers vint anys. D'una banda, les sèries decimals construïdes, al costat de les de baptismes, defuncions, matrimonis, preus, salaris i rendes territorials, havien contribuït decisivament a conèixer molt millor les diferents conjuntures econòmiques en nombrosos territoris europeus per l'etapa preindustrial (Le Roy Ladurie, 1982). Ara bé, també resultava llavors ja evident que l’objectiu més ambiciós, la reconstrucció de la trajectòria del producte agrari europeu entre finals de l'edat mitjana i l'últim tram de l'edat moderna, no podria aconseguir-se. L'explotació de la voluminosa documentació decimal havia despertat, potser, unes il.lusions excessives i els rendiments proporcionats per l'ús d'aquestes fonts, tot i que eren rellevants, no estaven sovint a l'alçada de les optimistes expectatives generades entre no pocs dels historiadors que s'havien aventurat en la quantificació de diverses variables agràries. Finalment, la temptativa de reconstruir la trajectòria del producte agrari mitjançant els registres decimals havia provocat, ja en els seus inicis, un intensa polèmica sobre la validesa i la fiabilitat d'aquesta font (Ruwet, 1964).

Què va impedir la reconstrucció anual del producte agrari europeu entre el segle XV o inicis del XVI i finals del XVIII? Els obstacles havien estat diversos i de no poca envergadura: 1) en alguns països, com 
Itàlia, Alemanya i Polònia, els registres decimals conservats eren relativament escassos; 2) en diversos territoris, el delme es pagava barrejat amb altres drets senyorials, rendes i impostos, i no resultava possible esbrinar quina quantitat se satisfeia exactament per aquest concepte; 3 ) a vegades, la taxa decimal que gravava un territori variava en el transcurs del temps; 4) en algunes regions les proporcions en què els ingressos decimals es dividien entre els diferents partícips van patir alteracions al llarg dels segles (Marcos Martín, 1983: 121); 5) la informació sobre delmes de cereals era bastant abundant, però la relativa a la dels restants fruits i esplets sovint resultava clarament insuficient; 6) les diferents cronologies de les sèries provincials o regionals i les llacunes que hi havia dificultaven la seva agregació; 7) en algunes àrees, per exemple en la de París, el delme es pagava per unitat de superfície i, per tant, no era proporcional a la collita; 8) en nombrosos casos, els drets decimals s'arrendaven en metàllic per un o diversos anys, cosa que obligava a construir deflactors, tasca complicada, laboriosa i no sempre possible, i, 9) en diverses regions europees, l'augment significatiu del frau en el pagament del delme afeblia la fiabilitat d'aquest tribut eclesiàstic com a indicador de la producció agrària; aquest fenomen es generalitzà i augmentà a la segona meitat del segle XVIII (Lorcin, 1973; Rives, 1976; Nicolas, 1982). Davant d'aquest cúmul de problemes, és lògic que l'explotació de diverses i voluminoses masses de documentació decimal no culminés en la reconstrucció del moviment del producte agrari en diversos països i regions d'Europa (Goy, 1982: 14-64). A mitjan dècada de 1980, les col-leccions decimals més prometedores ja havien estat explotades i aquest tipus d'historiografia havia entrat en una fase de rendiments decreixents. Després de 1985 es van seguir realitzant treballs d'història agrària sustentats, en part, en els delmes, però el seu protagonisme en la historiografia va minvar enormement. L'aguda febre pels delmes de les dècades de 1960 i 1970 ja era història. Del furor es va transitar, en relativament poc temps, a l'oblit gairebé total d'aquesta font.

Aquest volum proposa una nova mirada sobre aquesta font. En el primer capítol, el treball d’Enrique Llopis Agelán i José A. Sebastián Amarilla reprèn l'anàlisi dels esforços realitzats a través d'altres mètodes per reconstruir el creixement agrari preindustrial, tot observant-ne les insuficiències i els problemes. Per ço proposen 
recuperar la via d'estimació del creixement agrari a través del producte. La nova metodologia ens torna a les velles fonts decimals, en particular als llibres de les averiguaciones de veros valores. El seu propòsit era establir el repartiment del delme entre els partícips, base del sistema beneficial de l'Església catòlica. En aquest sentit, les averiguaciones de veros valores per al pagament del subsidi i l'excusat resulten imprescindibles per utilitzar amb garanties la documentació parcial procedent de parròquies o capítols catedralicis, ja que detallen la quantitat i els productes que percep cada un d'ells, i també els productes de les terres privatives del clergat i d'aquelles que pertanyen als monestirs, les quals estaven exemptes de tributació. Tanmateix, la font palesa dos grans inconvenients. El primer afecta la seva cronologia: només es van realitzar per a dos quinquennis: el primer, 1588-1592, a fi d'actualitzar la base imposable de les rendes del clergat i establir un nou repartiment, i un altre de més tardà només trobat per algunes diòcesis (Zamora); el segon, 1771-1775, quan es va iniciar l'administració directa del subsidi i l'excusat. El segon inconvenient és el seu abast geogràfic: als avatars propis de la història o a les deficiències de catalogació dels arxius eclesiàstics, cal sumar-hi diferències territorials en la percepció de l'impost que per diferents raons deixaren fora la Corona d'Aragó i el País Basc (Bilbao i Fernández de Pinedo, 1984). No obstant això, aquests dos períodes documentats es poden utilitzar per determinar els canvis estructurals produïts entre les dues dates. Els resultats d'aquesta anàlisi mostren una imatge diferent de la que transmetia l'anàlisi senzilla de les sèries decimals i de les estimacions del producte agrari a partir de la demanda. El creixement agrari d'aquelles regions de les quals es disposa d'aquesta font, les diòcesis d'Àvila, Burgos, Salamanca, Segòvia, Zamora i La Rioja (Llopis et al., 2018; Catalán, 2018), presenten un creixement més robust i una major diversificació dels cultius, cosa que era difícil de copsar amb l'anàlisi només de les percepcions decimals.

Una altra virtut de les averiguaciones de los veros valores, com mostra Elena Catalán en el segon capítol, és que permet determinar amb exactitud el repartiment del producte decimal entre els seus beneficiaris. A diferència de la documentació sistematitzada i ordenada de les sèries procedents dels capítols catedralicis, de les taules episcopals o de la comptabilitat parroquial, que només 
recull la informació corresponent a la fracció dels delmes que percebia cada partícip, les averiguaciones mostren una completa distribució de la percepció del delme. Així, la font obre una via per conèixer bé l'estructura beneficial de cada bisbat, així com el repartiment de la quantitat i la tipologia de les espècies que percep cada partícip. Aquesta estructura de distribució del delme fou resultat de l'organització dels bisbats heretada de la tradició medieval, i la configuració de la xarxa parroquial. La qualitat i la quantitat de la informació que proporciona aquesta font, dependrà en gran mesura de la capacitat administrativa i comptable d'aquelles institucions. Les possibilitats d'anàlisi dels veros valores encara no han estat prou explotades. D’una banda, cal estudiar l'estructura i la composició de les rendes del clergat parroquial; analitzar la distribució de la renda entre els diferents estrats de partícips eclesiàstics, i finalment, entre els nivells de rendes dels capellans i el de les famílies pageses de les que s'extreia el delme. És a dir, aquesta és una excelllent finestra per estudiar la distribució desigual de la renda en l'Església moderna.

La Corona d'Aragó no disposa d'aquesta extraordinària font, perquè va contribuir per separat a l'impost del subsidi $i$ excusat (1561), gaudint de múltiples exempcions i rebaixes en commutació dels serveis militars que havien de prestar els bisbes catalans. A més, la noblesa propietària dels delmes (majoritària al nord de Catalunya) va aconseguir quedar exempta del pagament del subsidi i excusat, al contrari del que succeïa amb els laics amb dret a delme a Castella. A més, la distribució dels delmes tenia una enorme complexitat en els territoris de la Corona d'Aragó, particularment a la Catalunya Vella, com mostra Elvis Mallorquí en el capítol quart. L’autor presenta les possibilitats i les mancances de les fonts decimals a la diòcesi de Girona. La minuciosa descripció de les pràctiques ocultes rere el verb delmar i de totes les instàncies i persones implicades en el procés, el condueix a una detallada anàlisi sobre la distribució del delme a la regió de Girona i les diferents modalitats de recaptació. La percepció del delme implicava una estructura jeràrquica i un control que exercia el bisbe de la diòcesi sobre la resta de partícips. Les pràctiques dels perceptors del delme a la Catalunya Vella difereixen enormement de les de la resta de la Hispània conquerida als musulmans a partir de la fi del segle xi. Tanmateix, com assenyala l'autor a les conclusions, resten moltes qüestions sense resposta, particularment el pes de 
les comunitats pageses en la distribució del delme, ja fos per fer complir la seva finalitat de mantenir el culte, o bé l'interès dels pagesos benestants en la seva gestió amb el propòsit d'enriquir-se.

En el capítol cinquè Pere Gifre comença amb un exhaustiu balanç dels estudis sobre el producte decimal a Catalunya a l'edat moderna. La complexa distribució dels delmes, les modalitats de gestió — sovint eren arrendats per un període de 3 o 4 anys i per un preu en metàl-lic-, l'agregació de diverses rendes en l'arrendament dels delmes i la primerenca resistència al seu pagament, en dificulten extremadament l'ús com a indicador del producte agrari. Potser aquestes prevencions condueixen l'autor a analitzar les rendes decimals de les capellanies de la diòcesi de Girona durant els segles XVI i XVII com a ingrés senyorial, més que no pas com a indicador del producte. Després de l'expansió de la renda al segle XVI, a cavall de l'augment de la producció i el repoblament dels camps, el segle XviI fou solcat per la llarga Guerra dels Segadors (1640-1652) i els conflictes bèl-lics amb França (1684, 1692-1695). Malgrat les dificultats, a final del segle Xvir la renda havia recuperat els nivells d'inicis de la centúria. Com diu l'autor, l'esmolada maquinària administrativa i judicial permetria als perceptors mantenir els nivells de sostracció al llarg del període estudiat.

L'expansió colonial de la Corona aragonesa cap al sud, el que seria el regne de València (1238), i cap al mar, el regne de Mallorca (1229), confegí noves realitats decimals. En el capítol tercer Lluís Torró ofereix un balanç dels resultats dels estudis sobre l'evolució de la producció agrària del País Valencià fets a partir de la documentació decimal, i en particular de l'obra de Manuel Ardit. L'autor, malgrat reconèixer les aportacions d'aquests estudis, en destaca les insuficiències i els problemes que té la documentació decimal pel que fa a l'avaluació de la magnitud i la composició del producte agrari, particularment a la segona meitat del segle xviII. Per ço suggereix, d'una banda, recuperar l'anàlisi local i comarcal i, de l'altra, eixamplar el ventall documental, particularment a partir de les fonts disponibles en els arxius Diocesà i Capitular.

Al darrer capítol, Gabriel Jover Avellà tracta de discutir la fiabilitat de les rendes decimals i dels escrutinis de les collites per a una de les produccions més importants de Mallorca: l'oli. Primer, l'autor proposa una descripció i anàlisi de les fonts emprades: els escrutinis de les 
collites d'olives (manifests de trullades), els preus de l'oli confeccionats a partir de les compres dels convents en el mercat de Palma i les rendes decimals de l'oli del capítol de la catedral de Mallorca. A continuació, contrasta la fiabilitat i el significat històric dels diferents indicadors. Dels resultats d'aquesta anàlisi, en destaquen dues conclusions: el delme de l'oli planteja nombrosos problemes com a indicador físic de la producció olivarera, però sembla un bon indicador dels ingressos i la distribució de la renda en el sector olivarer; l'estudi proposa mantenir la diferenciació analítica entre la producció i els ingressos del sector oleícola per tal d'entendre les inèrcies i els canvis que es produïren en el sector al llarg dels segles XVI-XVIII. 


\title{
1. DEL DIEZMO AL PRODUCTO AGRARIO: ¿PODEMOS MEDIR LO INVISIBLE? ¿PODEMOS IGNORARLO?
}

\author{
Enrique Llopis Agelán \\ José Antonio Sebastián Amarilla
}

\section{INTRODUCCIÓN}

Los registros decimales pueden usarse para distintos fines: entre otros, estimar el producto agrario, su composición y su evolución en el tiempo; acercarse a la estructura de cultivos y sus cambios; estudiar el tamaño de las granjas y su trayectoria; aproximarse a los niveles de desigualdad en la generación de la producción agraria; examinar la productividad agraria por unidad familiar; conocer la distribución de una parte sustancial del excedente agropecuario; analizar los conflictos sociales en torno al pago del diezmo y al reparto de la masa decimal entre los partícipes en la misma, así como el impacto de tales enfrentamientos sobre el crecimiento agrario.

Las reflexiones siguientes se ciñen esencialmente al primero de los propósitos enumerados: su empleo para estimar el crecimiento agrario. Como los registros decimales que mejor conocemos son los castellanos y andaluces de la Edad Moderna, nuestras valoraciones se refieren preferentemente a esos territorios y a dicho marco temporal. 
Los juicios sobre el uso de los diezmos para reconstruir el producto agrario y sus movimientos no deberían ser absolutos: han de efectuarse con relación a la magnitud de los problemas que suscita el empleo de fuentes y metodologías alternativas para alcanzar dicho objetivo en espacios y periodos concretos. Eso sí, conviene plantear explícitamente, en cada caso, los márgenes de error que se asumen al estimar la cuantía, la composición y la trayectoria del producto agrario.

En este ensayo se abordan tres asuntos. Primero, sintetizaremos el modo en el que los historiadores económicos han medido el crecimiento agrario preindustrial; luego, realizaremos algunos comentarios sobre el tipo de registros decimales más adecuados para abordar determinados fines; $y$, por último, comprobaremos lo que pueden dar de sí los más completos y examinaremos cómo y por qué una parte creciente del producto agrario se tornó cada vez más invisible para las fuentes decimales en el transcurso de la segunda mitad del siglo XVIII. Finalizaremos, como es lógico, con unas breves conclusiones.

\section{2. ¿CÓMO HEMOS MEDIDO EL CRECIMIENTO AGRARIO Y ECONÓMICO EN LA EDAD MODERNA?}

¿Cómo han estimado los especialistas el crecimiento agrario en la época preindustrial? Desde la década de 1960 hasta la actualidad, los trabajos dedicados a medir el crecimiento agrario y/o económico entre finales de la Edad Media o inicios de la Moderna y las postrimerías del siglo XviII pueden agruparse en cuatro oleadas. ${ }^{1}$

La primera la protagonizó la Escuela de los Annales y se sustentó en los diezmos. ${ }^{2}$ La segunda fue impulsada por Angus Maddison. ${ }^{3}$

1 En Llopis, Sebastián, Abarca, Bernardos y Velasco (2016) hemos tratado de manera más detallada este tema.

2 Véanse especialmente Le Roy Ladurie y Goy (1982); Goy y Le Roy Ladurie (1982).

3 Aunque Maddison llevaba ya años trabajando en la reconstrucción del producto agrario y, sobre todo, del PIB de algunos países, su proyecto se internacionalizó y recibió un fuerte impulso a raíz de la celebración en Milán, 
La tercera ha tratado y está tratando de estimar el crecimiento de la producción agraria mediante funciones de consumo en las que los salarios, los precios de los productos agrarios y no agrarios y las elasticidades precio y renta de demanda constituyen las variables independientes, empleándose los salarios como proxy de la renta por habitante. Tras obtener el consumo agrario por habitante, los datos de población y el supuesto de que, en los periodos analizados, los saldos de las balanzas comerciales agrarias eran poco relevantes, permiten transformar aquel en cifras de producto agrario. ${ }^{4} \mathrm{Y}$ la cuarta, bastante reciente, ha supuesto el retorno a la vía del producto y se ha sustentado en fuentes distintas en los diversos países donde ha sido ensayada.

En las décadas de 1960 y 1970 muchos investigadores llegaron a la convicción de que la explotación extensiva e intensiva de los diezmos permitiría reconstruir el movimiento del producto agrario en bastantes regiones europeas entre finales de la Edad Media y los últimos compases de la Moderna. Este ambicioso objetivo no se alcanzó porque los registros decimales escasean en no pocos territorios y son casi siempre complejos, heterogéneos e incompletos; y porque en bastantes ocasiones este tributo eclesiástico no constituye un buen indicador del movimiento del producto agrario, entre otras razones por el considerable y relativamente temprano fraude en el pago del mismo. En el caso de las fuentes decimales, los historiadores económicos pasamos del furor al olvido en un corto periodo de tiempo. En España, Gonzalo Anes, quien había completado estudios en París con algunos de los grandes maestros de la Escuela de los Annales en 1959 y 1960, ${ }^{5}$ y su libro Las crisis agrarias en la España moderna $a^{6}$ fueron los principales impulsores del uso de los diezmos, sobre todo de las tazmías, para reconstruir las tendencias

en septiembre de 1994, de la Sesión B.13 del XI Congreso Internacional de Historia Económica, coordinada por él y por Herman van der Wee, titulada «Economic Growth and Structural Change. Comparative Approaches over the Long Run». En este encuentro, el caso castellano lo abordó Bartolomé Yun (1994), quien utilizó fuentes de diversa índole para estimar el crecimiento económico castellano entre 1500 y 1800.

$4 \quad$ Allen (2000: 13-18).

5 Pérez Moreda (2015: 15-21).

6 Anes (1970). 
y las fluctuaciones del producto agrario en nuestro país en la Edad Moderna.

La segunda oleada de trabajos de reconstrucción de macromagnitudes económicas de la época preindustrial la impulsó Angus Maddison, cuyo titánico y osado proyecto consistía en estimar el PIB y el PIB per cápita del mundo, de los distintos continentes y de numerosos países, en diferentes cortes temporales, desde el inicio de la era cristiana hasta el presente. Para acometer este plan tuvo que recurrir a fuentes y metodologías muy dispares, no siempre suficientemente explícitas y que variaban según las épocas y los territorios. ${ }^{7}$

La tercera oleada la han protagonizado historiadores económicos muy atrevidos que han recurrido a la denominada vía de la demanda para estimar el crecimiento agrario. Este modo de proceder ha tenido una rápida difusión en los primeros quince años del siglo XXI. ${ }^{8}$ Ello ha obedecido a que se trata de una alternativa relativamente poco intensiva en información y trabajo de archivo, a que posibilita las comparaciones internacionales y a que aprovecha la disponibilidad de series largas de precios y salarios de varias ciudades europeas de los siglos XVI, XVII y XVIII. ${ }^{9}$

$7 \quad$ Van Zanden y Van Leeuwen distinguen, según los márgenes de error en que Maddison incurre, entre estimaciones sólidas, buenas, burdas y conjeturas (Zanden y Leeuwen, 2012: 122). Es muy probable que la mayoría de las cifras de PIB y PIB per cápita que Maddison propone para fechas anteriores a 1750 constituyan meras conjeturas (guestimates).

8 Federico y Malanima (2004); Malanima (2003, 2006 y 2011); Álvarez-Nogal y Prados (2007 y 2013); Pfister (2011); Buyst (2011); Schön y Krantz (2012); Zanden y Leeuwen (2012); Freire Costa, Palma y Reis (2013); Palma y Reis (2014 y 2019).

9 En 1929, en un periodo en el que la economía internacional registraba una fuerte inestabilidad, que se había iniciado con el desencadenamiento de la I Guerra Mundial y que se prolongaría hasta el inicio de la década de 1950, se constituyó el International Scientific Committee on Price History (ISCPH). El apoyo de esta institución y la honda preocupación que gobernantes y economistas sentían por el tema de la inestabilidad económica permiten explicar el notable protagonismo que las investigaciones sobre la evolución de precios y salarios en el largo plazo tuvieron en la historiografía europea en las décadas de 1930, 1940 y 1950. Entre los trabajos más destacados impulsados por el ISCPH figuran los de Hamilton (1934, 1936 y 1947), Posthumus (1946 y 1964), Phelps Brown y Hopkins (1955 y 1956), Pribram (1938) y Elsas (1936-1940). 
Sin embargo, la vía de la demanda, a nuestro juicio, no es un procedimiento adecuado para medir el crecimiento agrario en la Europa moderna. Y ello por varios motivos. ${ }^{10}$

Primero, porque las rentas salariales no constituían la principal fuente de ingresos de la mayor parte de las familias rurales, las predominantes en la Europa moderna. En numerosas zonas de este continente, un alto o muy alto porcentaje de tales familias poseía una explotación agraria, cuyos ingresos netos, en especie y en metálico, componían el grueso o una parte relevante de sus rentas. Por tanto, la variable proxy de la renta por habitante empleada en las funciones de consumo, los jornales, los salarios anuales o, incluso, un índice de rentas laborales y territoriales no puede reflejar de modo satisfactorio las variaciones en el ingreso por habitante.

Segundo, porque en economías en las que el autoabastecimiento familiar absorbía un alto porcentaje de los frutos y esquilmos obtenidos en las granjas, las funciones de consumo no constituyen una herramienta adecuada para estimar el crecimiento debido a que solo pueden captar las alteraciones de parte del producto agrario.

Y, tercero, porque la determinación de las rentas salariales anuales de las familias, que sería en todo caso la variable proxy apropiada, constituye un objetivo casi quimérico. Exige conocer los jornales de diversos tipos de trabajadores urbanos y, sobre todo, rurales, la evolución del número de días laborados al año, la tasa de actividad femenina e infantil y sus respectivas trayectorias, y los salarios de las mujeres y de los menores de 16 años. Y solo disponemos de buena información sobre jornales urbanos de hombres adultos de un reducido número de profesiones.

En suma, ni los ingresos salariales son un buen indicador de la renta por habitante en las economías preindustriales, ni contamos con información adecuada y suficiente para medir las rentas del trabajo de las familias. Por esto último, los usuarios de la vía de la demanda se han visto forzados a introducir muchos e importantes supuestos que acarrean márgenes de error muy amplios.

10 Este tema se aborda más ampliamente en Llopis, Sebastián, Abarca, Bernardos y Velasco (2016: 4-16) y en Calderón, García Montero y Llopis (2017: 333-339). 
Casi todas las investigaciones que han utilizado la vía de la demanda han concluido que el producto agrario por habitante descendió considerable o muy considerablemente en distintos países europeos en la época moderna. ${ }^{11}$ También Álvarez-Nogal y Prados para el caso español. ${ }^{12}$ En su último ensayo utilizando esta vía, publicado en 2013, estos autores estiman que el producto agrario por habitante retrocedió en España un 34 \% entre 1500-1510 y 1790-1800 y un $24 \%$ entre $1585-1595$ y $1790-1800 .^{13}$

Sin embargo, una apreciable contracción del producto agrario por habitante en la Europa moderna, en especial en los países noroccidentales, no encaja nada bien con el comportamiento de otras variables. Es difícil aceptar que la tasa de urbanización hubiese podido aumentar, y la mortalidad descender, en un contexto de considerable retroceso del producto agrario per cápita y de escasa contribución, todavía, de las importaciones al consumo nacional de alimentos. De ahí que especialistas cualificados hayan promovido nuevos proyectos de investigación con el propósito de estimar el crecimiento agrario en la Europa moderna por la vía del producto. ${ }^{14}$

Tanto para Inglaterra como para Holanda, las estimaciones del crecimiento agrario en la Edad Moderna por la vía del producto han arrojado balances bastante más positivos del sector primario que los ofrecidos por la vía de la demanda. ${ }^{15}$

Sin embargo, para el caso español, Álvarez-Nogal, Prados y Santiago-Caballero, utilizando fuentes decimales para ensayar la vía del producto, han seguido ofreciendo un balance muy negativo: según ellos, el producto agrario per cápita habría caído en nuestro

11 Por ejemplo, Allen (2000: 19); Federico y Malanima (2004: 459-460); Malanima (2003).

12 Álvarez-Nogal y Prados (2007 y 2013).

13 Carlos Álvarez-Nogal y Leandro Prados nos facilitaron amablemente las series anuales de PIB y de PIB por habitante del referido ensayo. Ello nos ha permitido realizar tales cálculos.

14 Broadberry, Campbell, Klein, Overton y Leeuwen (2011); Zanden y Leeuwen (2012: 120).

15 Broadberry, Campbell, Klein, Overton y Leeuwen (2015: 233-234 y 242); Zanden y Leeuwen (2012: 125-126). 
país un $24 \%$ entre $1500-1519$ y $1780-1799$, y un $23 \%$ entre $1550-1569$ y $1780-1799 .{ }^{16}$

¿Son fiables las estimaciones efectuadas por dichos colegas? En nuestra opinión, no lo son porque Álvarez-Nogal, Prados y SantiagoCaballero no han realizado un examen crítico suficiente de las muy heterogéneas fuentes decimales que sustentan su investigación. Su ensayo plantea importantes problemas.

Primero, los registros decimales de una diócesis o de un grupo de dezmatorios constituyen un indicador deficiente de sus cosechas y esquilmos cuando no recogen fielmente una notable porción del producto agrario y esta tiende a crecer de manera significativa en el tiempo. Esto ocurre en Valencia, Cataluña y, probablemente, en casi todas las regiones donde la diversificación y/o los nuevos cultivos cobraron una creciente importancia desde mediados o finales del siglo XVII. ${ }^{17}$ En consecuencia, es muy probable que las cifras de ÁlvarezNogal, Prados y Santiago-Caballero infravaloren de manera notable el crecimiento agrario en las regiones mediterráneas.

Segundo, al no tener en cuenta los cambios efectuados por la Real Hacienda en la administración del excusado desde $1761^{18}$, los citados autores introducen un considerable sesgo a la baja en las cifras atribuidas a las cuatro últimas décadas del siglo XVIII. ${ }^{19}$

Tercero, las muestras de localidades empleadas tienen deficiencias importantes en su cobertura temporal y subsectorial, tamaño y representatividad espacial. ${ }^{20}$

Y, cuarto, no pueden darse por buenas las series que se prolongan hasta 1800 sin intentar, cuando menos, vislumbrar la magnitud del

16 Álvarez-Nogal, Prados y Santiago-Caballero (2016: 476).

17 Manuel Ardit, excelente historiador, nos advirtió de este problema hace ya muchos años.

18 Hasta esa fecha el excusado fue un impuesto de cupo que las congregaciones de iglesias de las Coronas de Castilla y Aragón repartían entre sus diversos obispados y que estos, a su vez, prorrateaban entre los distintos partícipes en las rentas decimales de sus respectivas diócesis (Catalán, 1997: 184-197).

19 Llopis, Sebastián, Bernardos, Velasco y Abarca (2018: 73).

20 Como reconocen los propios autores. 
crecimiento del fraude en el pago del diezmo en las últimas décadas del siglo XVIII. ${ }^{21}$

Por consiguiente, consideramos que los cálculos de ÁlvarezNogal, Prados y Santiago-Caballero infravaloran notablemente el crecimiento agrario en la España moderna, sobre todo en la segunda mitad del siglo XVIII.

En suma, el crecimiento agrario no puede estimarse a partir de salarios, precios, elasticidades y rentas territoriales, pero tampoco a partir de registros decimales heterogéneos sin haber realizado previamente un análisis crítico de los mismos, sin haber homogeneizado todas las series y sin haber separado el trigo de la paja.

\section{3. ¿QUÉ PUEDEN APORTAR LOS DISTINTOS REGISTROS DECIMALES?}

Si queremos realizar una aproximación lo más precisa posible a la cuantía del producto agrario a partir de registros decimales, necesitamos tener información sobre: 1) la totalidad de la masa decimal que entraba en el acervo común y que luego se distribuía entre los partícipes en el diezmo en cada parroquia; 2) el producto de la casa mayor dezmera de cada cilla, en los periodos en que el excusado fue administrado directamente por la Real Hacienda; ${ }^{22} 3$ ) los diezmos privativos que percibían los párrocos u otras personas e instituciones; 4) la producción no sujeta total o parcialmente al pago del diezmo en fincas rústicas pertenecientes al clero regular y secular; 5) los frutos exentos de dicho pago o por los que se satisfacía, de hecho o de derecho, una tasa inferior al $10 \%, y, 6)$ los niveles de fraude de los cultivadores directos al diezmar. ${ }^{23}$ Ninguna fuente

21 García Sanz (1986: 451-457); Muñoz Dueñas (1994: 155-165); Rodríguez López-Brea (1995: 286-287); Robledo (2002: 211-213); Barrio (2004: 59); Llopis y González Mariscal (2010: 21).

22 Sobre la documentación generada por la administración de la casa mayor dezmera en Galicia, véase Fernández González (1994: 365-395).

23 El real noveno, establecido mediante la Real Cédula de 26 de enero de 1801 con el propósito de contribuir al sostenimiento del crédito público, introduce, a partir de dicha fecha, heterogeneidad en las series decimales de partícipes en el reparto del llamado acervo común. En cualquier caso, los diezmos no 
decimal proporciona una información íntegra y satisfactoria sobre todos estos extremos. Ahora bien, las que aportan más información, y mejor, son las averiguaciones de diezmos para el reparto del subsidio y el excusado en cada obispado ${ }^{24}$ y algunas tazmías que suministran datos en especie de casi todo lo diezmado.

Especialmente ricas son las averiguaciones de diezmos del quinquenio 1771-1775, efectuadas en varios obispados castellanos en 1776, cuando estaba a punto de finalizar o acababa de concluir un primer periodo de administración directa del excusado por la Real Hacienda. Estas incluyen un interesante interrogatorio sobre diversos, relevantes y, a veces, conflictivos asuntos relativos al diezmo. Por ejemplo, el realizado a los párrocos de la diócesis de Burgos. ${ }^{25}$

Una pesquisa muy similar conforma la encuesta de justificación de diezmos de 1788, verificada en la diócesis de Sigüenza para el quinquenio 1783-1787. ${ }^{26}$ Es probable que la Congregación de Iglesias de la Corona de Castilla, que era la encargada de distribuir el subsidio y el excusado entre los distintos obispados en las etapas en las que estos fueron impuestos de cupo, ordenase que tal cuestionario fuese repartido y cumplimentado por los párrocos, al menos en las diócesis en cuyos dezmatorios se acostumbraba a confeccionar tazmías anuales.

Estas averiguaciones de diezmos proporcionan una información muy completa y fiable, pero tienen dos problemas. Uno, su pérdida o su sobrevivencia incompleta para numerosos cortes temporales y/o circunscripciones de las distintas diócesis: solo se tornan abundantes en varios obispados castellanos para los quinquenios 1588-1592 y 1771-1775. Dos, aportan datos sobre periodos relativamente cortos, casi siempre un quinquenio. Teniendo en cuenta la magnitud de las fluctuaciones interanuales y cíclicas de las cosechas en los siglos

permiten, como es bien conocido, una buena reconstrucción de la trayectoria del producto agrario en las primeras décadas del siglo Xix.

24 Han utilizado esta fuente Bilbao y Fernández de Pinedo (1984: 83-198); Catalán (2018: 82-93); Llopis, Sebastián, Abarca, Bernardos y Velasco (2016: 12-26); Llopis, Sebastián, Bernardos, Velasco y Abarca (2018: 69-81).

25 Abarca (2015: 286-310).

26 Archivo de la Catedral de Sigüenza (ACSi), Encuesta de justificación de diezmos de 1788. 
modernos, hubiese sido deseable que las pesquisas abarcasen nueve o más años para estar plenamente seguros de que los promedios anuales obtenidos fuesen representativos del nivel de producción agraria de la correspondiente fase histórica.

Las tazmías anuales, aunque permiten abarcar periodos más amplios y suelen proporcionar información fiable sobre las cantidades diezmadas en especie de diversos frutos y esquilmos en cada parroquia, no ofrecen, salvo excepciones, una información tan completa. A diferencia de las averiguaciones de diezmos del lapso 1771-1775, pocas veces aportan suficientes datos sobre diezmos privativos, sobre productos no sujetos al pago del diezmo y sobre tierras exentas, total o parcialmente, de satisfacer dicho tributo. En cualquier caso, el principal problema de las tazmías también radica en su relativa escasez, sobre todo para fechas anteriores a 1700. De ahí que solo en contadas ocasiones dispongamos de información suficientemente completa de un aceptable número de cillas que posibilite realizar estudios sobre el movimiento del producto agrario regional, provincial o comarcal que arranquen del siglo Xvir o de antes.

¿Qué permiten, entonces, las fuentes decimales que proporcionan una información más detallada y fiable? Las averiguaciones de diezmos para el reparto del subsidio y el excusado, cuando se explotan cuidadosamente y sus cifras se cruzan con otras de bautizados, defunciones, nupcias y/o precios en los mismos espacios y periodos, sustentan comparaciones bastante sólidas entre los niveles de producto agrario y los de producto agrario per cápita en varias provincias o diócesis castellanas en los últimos compases del siglo XVI y en la segunda mitad del xviII. Por su parte, las tazmías, entre otras aplicaciones, posibilitan aproximarse a los cambios en la cuantía y en la composición del producto agrario en buena parte del setecientos y resultan de enorme valor, tanto por lo que incluyen como por lo que omiten, para analizar los conflictos en torno al pago del diezmo y a la administración y reparto de la masa decimal en el último tercio de dicha centuria y en los primeros años de la siguiente.

Los libros de diezmos o cuentas generales de los cabildos catedralicios constituyen en ocasiones la mejor fuente para analizar las tendencias a largo plazo del producto agrario en la Castilla de 
los siglos XVI, XVII y XVIII. Las grandes ventajas de estas fuentes radican en su amplia cobertura temporal y espacial. No obstante, su grado de idoneidad para cubrir satisfactoriamente dicho objetivo depende, entre otros extremos, del modo de administrar los derechos decimales elegido por el cabildo en cuestión. Estas fuentes permiten construir un aceptable indicador de la trayectoria de la producción agraria cuando los cabildos optaron por la administración directa de sus derechos decimales, esta se mantuvo en el tiempo y la parte del producto agrario que sus registros de diezmos no consienten visibilizar no registró graves alteraciones. Lamentablemente, los cabildos que permanecieron fieles a la administración directa de sus derechos decimales de forma ininterrumpida fueron pocos y la porción del producto agrario invisible para los registros de diezmos catedralicios aumentó significativamente en el interior peninsular en la segunda mitad del siglo XvirI.

¿Pueden los arrendamientos de derechos decimales de los cabildos servirnos de indicador del movimiento del producto agrario en el largo plazo? En nuestra opinión, no cuando se efectuaban en metálico, máxime si los mismos se hacían por dos o más años. Y ello por varios motivos. En primer lugar, porque el grado de concurrencia a las subastas de tales derechos variaba en el tiempo; en segundo lugar, porque no puede descartarse que algunos allegados a los canónigos con más peso lograsen ventajas a la hora de realizar las pujas y de hacerse con tales derechos decimales; en tercer lugar, porque los agentes que intervenían en estas subastas, pese a tener presentes los errores que habían cometido en el pasado, podían equivocarse en sus predicciones y expectativas acerca de los siguientes años; $y$, por último, porque la construcción de deflactores adecuados resulta casi siempre muy costosa o imposible. Además, es probable que las tasas efectivamente pagadas por los cultivadores directos, cuando los derechos decimales se hallaban arrendados en metálico por varios años, no fuesen del $10 \%$ y tendiesen a descender, sobre todo en el caso de los productos no cerealistas.

Los diezmos de granos arrendados anualmente en especie, $a$ cosecha vista, comparten algunos de los problemas indicados, pero, en su caso, el margen de error de las previsiones de los correspondientes agentes era significativamente menor y su uso no requiere recurrir a deflactores. Las series construidas con fuentes de este tipo permiten 
desvelar las principales tendencias de la producción de cereales hasta, aproximadamente, 1760. Después de esta fecha, sin embargo, plantean problemas crecientes por los cambios en la administración del excusado, que no siempre fueron coincidentes en las diferentes diócesis, por el aumento en la defraudación en el pago del diezmo y por el alza de la masa decimal percibida privativamente por párrocos y vicarios a costa de la ingresada en el acervo común.

En suma, en la mayoría de los territorios españoles, la reconstrucción de las tendencias del producto agrario en la Edad Moderna a partir de fuentes decimales se ve dificultada, entre otros factores, por el frecuente arrendamiento de los derechos correspondientes. Pese a ello, en el caso de que los diezmos mayores se arrendasen en especie, la vía del producto permite trabajar con márgenes de error menores que la vía de la demanda, siempre que se consiga formar series homogéneas y que las porciones de los partícipes no variasen en el periodo objeto de estudio. En cualquier caso, es preciso relacionar las cifras decimales con otras variables demográficas y económicas -bautizados, defunciones, nupcias, precios, rentas territoriales, etc.- para contrastar el grado de coherencia y verosimilitud de las primeras. Y también conviene cruzar los datos macroeconómicos con los de microcosmos mejor conocidos del área estudiada para verificar si lo que acontece en estos últimos refrenda, o no, lo que apuntan las cifras de las muestras territoriales más amplias.

\section{CRECimiento agrario y diversificación PRODUCTIVA. EL INCREMENTO DE LO INVISIBLE EN LA SEGUNDA MITAD DEL SIGLO XVIII}

Los registros decimales, como indicadores del producto agrario, tendieron a empeorar en el interior peninsular durante la segunda mitad del siglo XviII por dos motivos que se solaparon. Por un lado, porque la porción de dicho producto que habitualmente mejor captaban, la relativa a los diezmos mayores, pasó a anotarse en las tazmías de modo más defectuoso; y, por el otro, porque la peor recogida desde antiguo, la concerniente a frutos y esquilmos distintos de los cereales, se registró de modo aún más deficiente a la par que tendió a crecer. Este doble movimiento lo originaron tres fenómenos 
cuya capacidad perturbadora creció en las cuatro últimas décadas del siglo xviII. Uno, la nueva forma de administrar el excusado desde 1761 que, en cada dezmatorio, sustrajo del acervo común los frutos de la primera casa dezmera, una magnitud no desdeñable, ${ }^{27}$ durante lapsos de esos cuatro decenios distintos según las diócesis. ${ }^{28}$ Dos, el incremento de los diezmos privativos, desviados en su provecho por los párrocos antes de que entrasen en el acervo común; aunque su cuantía relativa es difícil de establecer porque en su ámbito, obviamente, primaba la opacidad, nuestros cálculos indican que, aun siendo muy variable, en absoluto era nimia y que gravitaba más sobre el producto agrario no cerealista que sobre los granos. ${ }^{29} \mathrm{Y}$ tres, el creciente fraude en el pago del diezmo por parte de los cultivadores. Por tanto, la parte del producto agrario que los registros decimales apenas permiten atisbar aumentó desde mediados del setecientos, a nuestro juicio de forma significativa. Ello implica que muchas de las series decimales disponibles, construidas sin una suficiente consideración de estos

27 Entre el 8,4 y el 10,6 \% de la masa decimal en los obispados de Ávila, Burgo de Osma, Burgos y Segovia (Cuervo, 2015: 394-396; Pérez Romero, 2009: 77; Abarca, 2015: 332; Llopis, Sebastián, Abarca, Bernardos y Velasco, 2016: 28). El 6,7 \% del total de la cosecha de cereales, en 1759, en una muestra de 43 localidades de la Mancha y la Serranía conquenses. Archivo Capitular de Cuenca (ACC), Tazmías.

28 En el obispado de Burgo de Osma, la casa mayor dezmera permaneció en manos de la Hacienda y fuera del acervo común de cada cilla de 1761 a 1799 (Pérez Romero, 2009: 76). En el de Sigüenza, ello ocurrió en dos periodos: 1761-1787 y 1796-1799; entre 1788 y 1791, tras un nuevo acuerdo con la Hacienda, la casa excusada tornó al acervo común, situación que, al parecer, se prorrogó para el lapso 1792-1795 (Archivo Diocesano de Sigüenza (ADSi), Libros de Tazmías de Hijes, Trillo y Miedes de Atienza). En el obispado de Cuenca, la administración directa por la Hacienda se extendió de 1761 a 1775, se volvió al sistema de concordias entre 1776 y 1793, y se retornó a la primera en 1794 (ACC, Tazmías).

29 En una muestra de 47 dezmatorios segovianos, en 1771-1775, los diezmos privativos absorbieron el 2,9\% del diezmo completo (esto es, de la suma de acervo común, casa excusada y privativos); no obstante, mientras que implicaron el 1,7 \% del diezmo de cereales, supusieron el 5,4 \% del de frutos y esquilmos ajenos a estos (Llopis, Sebastián, Abarca, Bernardos y Velasco, 2016: 29). En otra muestra de 21 enclaves del arciprestazgo de Molina de Aragón, diócesis de Sigüenza, en 1783-1787, las relevantes porciones de los diezmos de avena, leguminosas, miel, cera, pollos, lechones y menudos en dinero que distraían del acervo común, implicaban, reducidas a dinero, el 13,9 \% del valor del conjunto del producto agrario (ACSi, Encuesta de justificación de diezmos de 1788). 
tres fenómenos (y nosotros mismos somos responsables de algunas) ${ }^{30}$ infravaloran, y no en poca medida, el crecimiento agrario en el siglo xviII y en el conjunto de la Edad Moderna.

Estamos persuadidos, sin embargo, de que la segunda mitad del setecientos fue una etapa de crecimiento y diversificación productiva en el mundo rural del interior peninsular, y que dicho crecimiento superó las probables cotas máximas de finales del siglo XVI, previas a la intensa y larga depresión subsiguiente. ${ }^{31}$ Emplearemos, a continuación, las mejores fuentes decimales disponibles (las averiguaciones y encuestas de diezmos para el reparto del subsidio y el excusado y los libros de tazmías) de tres ámbitos castellanos (el obispado de Salamanca, el arzobispado de Burgos y el obispado de Sigüenza) para, en primer lugar, calcular con la mayor precisión posible el crecimiento agrario entre finales de la década de 1580 y comienzos de la de 1770; en segundo lugar, comprobar que dicho crecimiento, luego de 1775, prosiguió hasta los últimos años del setecientos, y, finalmente, explorar las razones y vicisitudes que incrementaron la porción sumergida del producto agrario y tiñeron de opacidad su aumento entre los decenios de 1760 y 1790.

En el cuadro 1 se contrastan los niveles medios de cosechas y esquilmos reconstruidos para una muestra de 218 localidades y/o dezmatorios salmantinos en 1588-1592 y 1771-1775, en cantidades físicas y reales constantes de 1773, a partir de las cuantías registradas en el acervo común de cada cilla y de la estimación de las relativas a los diezmos privativos, la producción no sujeta al pago de diezmos y la casa mayor dezmera en los años del segundo quinquenio en que el excusado estuvo directamente administrado por la Real Hacienda. ${ }^{32}$

30 Por ejemplo, Sebastián (1991).

31 Llopis (2010); Sebastián (2013).

32 Dicha muestra representa bastante bien al conjunto de la provincia actual, aunque falte en ella la comarca de Ciudad Rodrigo, perteneciente al obispado del mismo nombre y no al de Salamanca: se distribuye equilibradamente entre las cuatro comarcas restantes, que suponen más del $80 \%$ del territorio provincial, y tiene un tamaño suficiente, albergando una elevada proporción de la población salmantina, por demás muy similar en 1591 (21,6\%) y en 1787 $(22,8 \%)$. Para más detalles sobre los cálculos realizados y las características de los quinquenios comparados, Llopis, Sebastián, Abarca, Bernardos y Velasco (2016: 24-33). 
Hubiese sido demasiado arriesgado introducir cualquier estimación acerca del fraude en el pago del diezmo, mayor sin duda al inicio del último cuarto del siglo XviII que a finales del xvi, y no lo hemos hecho. Considérese, por tanto, que las cifras atribuidas al quinquenio 1771-1775 suponen un umbral mínimo del producto agrario obtenido en las poblaciones de la muestra en bastante mayor medida que las calculadas para 1588-1592.

Cuadro 1. El producto agrario en la provincia de Salamanca en 1588-1592 y 1771-1775. Muestra de 218 localidades y/o dezmatorios

\begin{tabular}{|c|c|c|c|c|c|}
\hline \multirow[b]{2}{*}{ Productos y esquilmos } & \multicolumn{3}{|c|}{ Cantidades físicas } & \multicolumn{2}{|c|}{ Dinero (reales de 1773) } \\
\hline & 1588-1592 & $1771-1775$ & Medidas & 1588-1592 & $1771-1775$ \\
\hline Trigo & 309.664 & 302.924 & Fanegas & 6.482 .001 & 6.340 .930 \\
\hline Centeno & 85.290 & 169.554 & Fanegas & 1.338 .998 & 2.661 .883 \\
\hline Cebada & 42.632 & 70.999 & Fanegas & 535.426 & 891.709 \\
\hline Avena & 790 & 1.998 & Fanegas & 9.922 & 25.086 \\
\hline Cereales & 438.376 & 545.475 & Fanegas & 8.366 .347 & 9.919 .608 \\
\hline Leguminosas ${ }^{*}$ & 19.745 & 57.219 & Fanegas & 350.494 & 1.098 .537 \\
\hline Patatas & 0 & 3.641 & Arrobas & 0 & 9.528 \\
\hline Hortalizas y frutos ${ }^{\star *}$ & -- & --- & Varias & 31.008 & 37.517 \\
\hline Cultivos no cerealistas & --- & --- & Varias & 381.502 & 1.145 .582 \\
\hline Miel, cera y linaza & --- & --- & Varias & 11.498 & 1.070 \\
\hline Lino & 12.681 & 18.182 & Cuarentales & 172.536 & 247.388 \\
\hline Mosto & 399.116 & 214.254 & Cántaras & 1.670 .899 & 896.974 \\
\hline Vino & 0 & 82.345 & Cántaras & 0 & 689.473 \\
\hline Uva tinta & 0 & 8.873 & Arrobas & 0 & 27.528 \\
\hline Aceite & 1.292 & 5.644 & Cántaras & 49.080 & 214.459 \\
\hline Alguna transformación & --- & --- & Varias & 1.904 .013 & 2.076 .892 \\
\hline Lana & 2.413 & 7.780 & Arrobas & 83.348 & 268.702 \\
\hline Queso & 954 & 1.220 & Arrobas & 31.920 & 40.831 \\
\hline Corderos & 27.439 & 39.169 & Cabezas & 344.612 & 491.934 \\
\hline Pollos & 610 & 14.841 & Cabezas & 638 & 15.532 \\
\hline Pavos & 0 & 12.352 & Cabezas & 0 & 25.855 \\
\hline
\end{tabular}




\begin{tabular}{lcrrrr} 
& \multicolumn{3}{c}{ Cantidades físicas } & \multicolumn{2}{c}{ Dinero (reales de 1773) } \\
\hline Otros $^{* * *}$ & 0 & 3.879 & Cabezas & 0 & 38.264 \\
\hline Esquilmos ganaderos & --- & --- & Varias & 460.518 & 881.118 \\
\hline Menudos en dinero & --- & --- & --- & 1.543 .634 & 849.969 \\
\hline Producto cerealista & --- & --- & --- & 8.366 .347 & 9.919 .608 \\
Producto no cerealista & --- & --- & --- & 4.289 .668 & 4.953 .561 \\
Producto total & --- & --- & --- & 12.656 .015 & 14.873 .169 \\
\hline
\end{tabular}

* Garrobas y garbanzos en el siglo xvi. Garrobas, garbanzos, arvejas, guisantes y judías en el XVIII.

${ }^{* *}$ Higos secos, nueces, castañas y aceitunas en el siglo xvi. Higos secos, nueces, castañas, aceitunas, ajos, cebollas, berzas, peras, melocotones y manzanas en el xviII.

*** Chivos, cabritos, cerdos y gansos en el siglo xviII.

Fuentes. Archivo de la Catedral de Salamanca (ACSa), Libro de veros valores de 1596 y Averiguaciones y certificaciones de rentas para la contribución de subsidio y excusado de 1771-1775.

La primera y principal observación que permite hacer el cuadro 1 es la relativa a que los niveles de producción agraria en Salamanca en la década de 1770, lejos de ser inferiores a los de 1588-1592, eran claramente superiores, en concreto un $17,5 \%$. La ausencia de cualquier caída del producto agrario entre los intervalos comparados se aprecia, igualmente, en términos per cápita. Considerando los 39.848 habitantes de las localidades de la muestra calculados a partir del Vecindario de 1591 y los 40.669 que hemos estimado hacia 1773, gracias a un amplio conjunto de series de bautismos y a las cifras del Censo de $1787,{ }^{33}$ el producto agrario por persona habría pasado de 317,6 a 365,7 reales constantes, un aumento del $15,1 \%$, significativo $y$, seguramente, inferior al real.

La producción agraria por habitante habría crecido en Salamanca tanto en lo que atañe al producto cerealista (de 210,0 a 243,9 reales constantes, un 16,1\%) como al no cerealista (de 107,7 a 121,8 reales constantes, un 13,1\%). Es probable, sin embargo, que el mayor incremento relativo correspondiese, en realidad, al segundo. El cuadro

33 Magra diferencia que da idea de la intensidad y duración de la depresión del siglo XVII en tierras salmantinas. Para más detalles sobre tales estimaciones, Llopis, Sebastián, Abarca, Bernardos y Velasco (2016: 31-32). 
1 revela que, entre los quinquenios estudiados, el valor de las nuevas producciones y de los frutos y esquilmos que habían ido saliendo de los diezmos menudos en dinero, ${ }^{34}$ conforme fueron adquiriendo entidad suficiente como para que su recolección en especie fuese aconsejable, supera por mucho a la subsiguiente reducción del citado monto en metálico, pero en absoluto es seguro que tales producciones (las patatas y diversas leguminosas, por ejemplo) diezmasen al $10 \%$, a la par que existen múltiples indicios de que eran objeto predilecto de defraudación por parte de los cultivadores.

Si en el cuadro 1, junto a valores, se observan cantidades, los aspectos más relevantes del contraste que incluye son los siguientes.

Primero, un destacable aumento (del 24,4 \%) de las cosechas de cereales - concentrado en las de centeno (que prácticamente se duplicaron) y en las de cebada y avena (que crecieron dos tercios largos), del que no participaron las de trigo, que se redujeron algo (un 2,2 \%)-, el cual elevaría un 21,8 \% la cantidad de grano disponible por persona (de 11,0 a 13,4 fanegas). El volumen de cereales panificables per cápita creció un $17,2 \%$, pero el aumento relativo más intenso correspondió al de los granos destinados preferentemente a consumo animal, máxime si se tiene en cuenta que el centeno solía ser un alimento estratégico para el vacuno de labor durante los fríos inviernos castellanoleoneses. ${ }^{35}$

Segundo, al hilo de ese intenso aumento de la producción de cereales-pienso, un progreso sustancial (al menos del 91,3\% en reales constantes) del producto ganadero, el cual arroja relevantes avances, tanto en volumen como en valor, en todos y cada uno de sus renglones, más allá de la incertidumbre que causa ignorar su grado de presencia en los menudos en dinero y ser uno de los ramos productivos siempre peor captados por las fuentes decimales.

Tercero, la casi triplicación de la producción de leguminosas, que pasaría en términos per cápita de 0,5 a 1,4 fanegas, y la precoz

34 Integrados por los de una variada gama de producciones que, bien por su reducida cuantía en especie, bien por costumbre arraigada en la lógica de aquella agricultura (como ocurría con el ganado mayor que, en vez de diezmo, pagaba una reducida tasa en metálico por cría), acababa en dicho cajón de sastre. 
aparición, en cuantías no desdeñables, de las patatas, responsables unas y otras de que sea el apartado de cultivos no cerealistas sin mayor transformación el que registre el aumento en valor más importante entre ambos intervalos.

Y, cuarto, un ligero aumento (del 9,1 \%) del valor de las producciones agrícolas sujetas a alguna transformación, resultante de un descenso de la vitivinícola de pocas consecuencias traducido en dinero - al diezmarse en vino en el siglo XVIII una porción de lo que en el XVI se diezmaba en mosto- y del aumento de las de lino y aceite.

En suma, crecimiento del producto agrario, cierta diversificación del mismo, sin que los cereales, en su conjunto, perdiesen un ápice de su primacía, e indicios de orientaciones productivas que, por una parte, mejoraban el monótono panorama del autoconsumo de alimentos de los campesinos salmantinos (leguminosas, patatas, quizá algo más de carne) y, por otra, favorecían una mayor vinculación al mercado (la transformación en vino de una parte del mosto obtenido, el significativo aumento de diversas producciones ganaderas y de las de cereales-pienso, lino y aceite). Y todo ello con la convicción de que, aun ensayando el mejor acercamiento posible a la cuestión por la vía del producto, la reconstrucción no es completa.

Los promedios de cosechas y esquilmos que recoge el cuadro 2 para una muestra de 225 núcleos y/o dezmatorios del arzobispado de Burgos en 1592-1594, 1771-1775 y $1793-1797^{36}$ se han reconstruido de forma análoga a los de la muestra salmantina del cuadro 1, pero con una diferencia: incluyen el acervo común, la estimación de la producción que no pagaba diezmos que entrasen en aquel y la de los frutos de la primera casa dezmera de cada cilla en los años de los dos periodos del setecientos en que fueron percibidos directamente por la Real Hacienda, pero no los diezmos privativos. La diócesis de Burgos fue uno de los primeros espacios en que ensayamos nuestras

36 La cual consideramos representativa de la provincia burgalesa por iguales motivos que en el caso salmantino: cubre adecuadamente la mayoría de su espacio (siete comarcas de ocho, faltando la de La Ribera, dependiente del obispado de Burgo de Osma) e incluye el 16,0 \% de la población provincial en 1591 y el 16,9 \% en 1787. Véase, Abarca (2015: 311 y ss.) y Llopis, Sebastián, Abarca, Bernardos y Velasco (2016: 19-24). 
estimaciones del producto agrario ${ }^{37} \mathrm{y}$, a fin de simplificar las cálculos, optamos por trabajar con muestras de dezmatorios en los que, en apariencia, los diezmos privativos o no existían o apenas tenían importancia. Hoy, luego de nuestras experiencias en los obispados de Ávila, Salamanca, Segovia, Sigüenza y Zamora, actuaríamos de otra forma: estamos persuadidos de que la falta de datos sobre diezmos privativos en cualquier demarcación decimal prueba más la interesada opacidad que rodeaba a estos que su inexistencia. Por tanto, es probable que las cifras burgalesas del setecientos pequen por defecto más que las salmantinas, sobre todo en cuanto al producto no cerealista, y en grado creciente al pasar del decenio de 1770 al de 1790. Añádanse, al respecto, en cuanto a la defraudación en el pago del diezmo, sobre la que tampoco hemos hecho estimación alguna, los numerosos indicios que apuntan a su aumento en Burgos entre comienzos del último cuarto del setecientos y la última década de dicha centuria.

Cuadro 2. El producto agrario en la provincia de Burgos en 1592-1594, 1771-1775 y 1793-1797.

Muestra de 225 localidades y/o dezmatorios

\begin{tabular}{crrrlrrrr} 
& \multicolumn{3}{c}{ Cantidades físicas } & \multicolumn{3}{c}{ Dinero (reales de 1773) } \\
\hline & $1592-1594$ & $1771-1775$ & $1793-1797$ & Medidas & $1592-1594$ & $1771-1775$ & $1793-1797$ \\
\hline Trigo & 305.208 & 276.081 & 303.268 & Fanegas & 8.833 .599 & 7.964 .397 & 8.853 .004 \\
Comuña & 13.337 & 24.713 & 50.094 & Fanegas & 339.312 & 561.788 & 1.155 .048 \\
Centeno & 59.540 & 85.555 & 92.592 & Fanegas & 1.237 .238 & 1.744 .690 & 1.852 .034 \\
Cebada & 171.750 & 195.471 & 207.481 & Fanegas & 2.431 .336 & 2.803 .718 & 3.001 .104 \\
$\begin{array}{c}\text { Avena } \\
\text { Mijo, borona y } \\
\text { maíz }\end{array}$ & 18.517 & 53.943 & 61.014 & Fanegas & 171.811 & 473.374 & 528.309 \\
\hline $\begin{array}{c}\text { Producto } \\
\text { cerealista }\end{array}$ & 1.340 & 1.325 & 1.888 & Fanegas & 33.508 & 31.651 & 45.011 \\
\hline $\begin{array}{c}\text { Leguminosas } \\
\text { ( }\end{array}$ & 12.873 & 49.692 & 637.088 & 716.337 & Fanegas & 13.046 .804 & 13.579 .618 & 15.434 .510 \\
\hline
\end{tabular}

37 Con la participación central de Vanesa Abarca en el equipo investigador, como se aprecia en Abarca (2015). Al respecto, Llopis, Sebastián, Abarca, Bernardos y Velasco (2016: 29). 


\begin{tabular}{|c|c|c|c|c|c|c|c|}
\hline & $1592-1594$ & 1771-1775 & $1793-1797$ & Medidas & 1592-1594 & $1771-1775$ & $1793-1797$ \\
\hline $\begin{array}{c}\text { Hortalizas y } \\
\text { frutos }^{\star *}\end{array}$ & --- & --- & --- & Varias & 15.407 & 60.837 & 15.046 \\
\hline $\begin{array}{l}\text { Cultivos no } \\
\text { cerealistas }\end{array}$ & --- & --- & --- & Varias & 304.347 & 1.098 .780 & 1.096 .734 \\
\hline Miel y cera & 40 & 17.603 & 13.751 & Libras & 279 & 27.596 & 25.294 \\
\hline Lino & 23.098 & 84.613 & 82.090 & Mañas & 36.809 & 112.003 & 101.066 \\
\hline Cáñamo & 0 & 2.880 & 13.326 & Mañas & 0 & 3.615 & 14.217 \\
\hline Vino & 201.090 & 115.518 & 80.488 & Cántaras & 1.050 .810 & 632.205 & 473.061 \\
\hline Uva & 0 & 30.456 & 1.164 & Arrobas & 0 & 91.368 & 3.492 \\
\hline $\begin{array}{c}\text { Alguna } \\
\text { transformación }\end{array}$ & --- & --- & --- & Varias & 1.087 .898 & 866.787 & 617.130 \\
\hline Lana & 3.430 & 15.808 & 15.576 & Arrobas & 92.385 & 453.860 & 433.182 \\
\hline Queso & 2.535 & 4.225 & 3.764 & Arrobas & 63.371 & 104.359 & 93.473 \\
\hline Corderos & 25.457 & 52.015 & 39.269 & Cabezas & 282.131 & 549.934 & 423.837 \\
\hline Cabritos & 0 & 2.302 & 4.626 & Cabezas & 0 & 18.437 & 41.206 \\
\hline Pollos & 10.978 & 21.366 & 9.546 & Cabezas & 10.978 & 20.281 & 8.652 \\
\hline Otros ${ }^{* * *}$ & --- & --- & --- & Varias & 23.820 & 105.739 & 80.786 \\
\hline $\begin{array}{l}\text { Esquilmos } \\
\text { ganaderos }\end{array}$ & --- & --- & & Varias & 472.685 & 1.252 .610 & 1.081 .136 \\
\hline $\begin{array}{l}\text { Menudos en } \\
\text { dinero }\end{array}$ & --- & --- & & --- & 1.005 .954 & 292.336 & 303.549 \\
\hline $\begin{array}{l}\text { Producto } \\
\text { cerealista }\end{array}$ & --- & --- & & --- & 13.046 .804 & 13.579 .618 & 15.434 .510 \\
\hline $\begin{array}{l}\text { Producto no } \\
\text { cerealista }\end{array}$ & --- & --- & & --- & 2.870 .884 & 3.510 .513 & 3.098 .549 \\
\hline Producto total & --- & --- & & --- & 15.917 .688 & 17.090 .131 & 18.533 .059 \\
\hline
\end{tabular}

* Garbanzos, titos, arvejas, lentejas, habas, alubias, alholvas, yeros y ricas.

** Ajos, cebollas, nabos, manzanas, frutas y nueces.

*** Lechones, pichones, pavos, gansos, leche, pies de colmena y yerbas y alcaceres.

Fuentes. Archivo de la Catedral de Burgos (ACB), Relaciones de veros valores de 1592-1594, Libros de averiguaciones de frutos decimales de 1776, y Abarca (2015).

En lo que al contraste entre 1592-1594 y 1771-1775 se refiere, tampoco se aprecia en Burgos, pese a lo anterior, desplome alguno de los niveles de producción agraria, aunque sí un mayor apuro que en Salamanca en seguir el paso a los efectivos demográficos: el valor del producto agrario, en su conjunto, habría crecido un 
$7,4 \%$, pero, en términos per cápita, habría disminuido un 3,6\%, de 478,3 reales constantes a $460,9 .{ }^{38}$ Las cosechas de cereales habrían aumentado un $11,8 \%$ pero, en dinero, el alza apenas sería del $4,1 \%$, al protagonizar dicho avance los granos de menor valor unitario (el volumen de centeno y comuña creció un $51,3 \%$ y el de cebada y avena, un 31,1 \%) y al descender la producción de trigo (un 9,5\%). Ello supondría un progreso muy notable del monto con destino preferente a la alimentación animal, mayor que el que indican las cifras si se considera la parcial dedicación a tal fin del centeno, frente a un avance muy escaso, del 2,2 \%, del volumen panificable. El producto no cerealista, por su parte, se habría ampliado un $22,3 \%$ en valor gracias, sobre todo, al intenso crecimiento del producto ganadero - que se habría multiplicado por 2,6 en reales constantes y registraría, en cantidades, alzas elevadas en todos sus renglones- - y al aumento del valor de los frutos de los cultivos no cerealistas sin transformación - que se habría multiplicado por 3,6- sostenido por la casi cuadruplicación de las cosechas de leguminosas. Solo en el capítulo de productos agrícolas sometidos a alguna transformación se registraría un comportamiento contrario: en su seno, la fuerte contracción de la producción vitivinícola (del 31,1 \% en valor) no se vería compensada por el destacable avance de las de lino, cáñamo, miel y cera.

En suma, en Burgos, como en Salamanca, todos los componentes del producto agrario crecieron entre finales del quinientos e inicios del último cuarto del setecientos excepto dos, la producción vitivinícola y la triguera, pero, eso sí, en proporciones muy diferentes: si en Salamanca, la primera, en valor, se redujo un 3,4\%, en Burgos se desplomó más de un $30 \%$; si la segunda, en Salamanca, en volumen, mermó un 2,2 \%, en Burgos su descenso bordeó el $10 \%$. Los dos movimientos sugieren ciertos cambios en las orientaciones productivas de la agricultura castellanoleonesa, pero da la impresión de que las cifras burgalesas los exageran, quizá, junto a la ausencia de los diezmos privativos, por un precoz aumento del fraude en el pago del diezmo. Sobre la trayectoria de la producción vitivinícola pudo

38 Hemos estimado para la muestra burgalesa 32.278 habitantes en 1591, 37.079 hacia 1773 y 40.712 hacia 1795 . Véanse, Abarca (2015: 304 y ss.) y Llopis, Sebastián, Abarca, Bernardos y Velasco (2016: 31-32). 
influir un fenómeno en absoluto negativo, vigente en el último tramo del siglo XVIII en mayor medida que a finales del xvi: el aumento del tráfico comercial pudo facilitar a las poblaciones salmantinas y burgalesas un acceso asequible a vinos algo mejores que los producidos por ellas en condiciones naturales poco favorables; ello impulsaría que menguase la superficie plantada de viñedo. ${ }^{39}$ El cambio relativo en el seno de la producción cerealista castellana durante los siglos XVII y XVIII a favor del centeno y, en menor medida, de la cebada y la avena, y en contra del trigo, lo hemos observado en todos los espacios del interior peninsular sobre los que hemos trabajado. ${ }^{40}$ Pero supone una notable diferencia que ese doble movimiento no impidiese que, en Salamanca, el volumen de cereales panificables per cápita creciese un 17,2 \% entre 1588-1592 y 1771-1775, mientras que, en Burgos, entre 1592-1594 y 1771-1775, caía un 8,8 \%. Cabe recordar, al efecto, que el detallado interrogatorio al clero local que, en la archidiócesis burgalesa, acompañó a la averiguación de diezmos de 1771-1775, se llevó a cabo doce años antes que el análogo, efectuado en 1788, en la diócesis de Sigüenza, lo que sugiere más tempranos signos de desasosiego respecto de la percepción íntegra de los diezmos por parte de sus autoridades eclesiásticas; que dicha pesquisa revela, ya por entonces, que eran muchas las localidades burgalesas en las que los colectores que debían supervisar el arqueo de las cosechas de granos para cobrar el diezmo no estaban presentes en las eras al tiempo de realizarse esa operación, ${ }^{41}$ y que, en punto a defraudar, el incentivo más alto concernía al cereal de mayor valor unitario. En todo caso, y pese a los claroscuros que, al respecto, apuntan las cifras, ${ }^{42}$ consideramos que el contraste burgalés no modifica sustancialmente las conclusiones obtenidas del salmantino: con todos

39 Añádase, en el caso de Burgos, la ausencia en la muestra de la comarca más meridional, la de La Ribera, la mejor dotada, seguramente, para el aprovechamiento vitivinícola.

40 Baste como ejemplo, Llopis, Sebastián, Abarca, Bernardos y Velasco (2016: 39).

41 Abarca (2015: 303).

42 Por citar alguno más entre 1592-1594 y 1771-1775: descenso del 6,6 \% del producto cerealista per cápita en valor, pero sostenimiento del mismo en volumen (17,1 fanegas en un caso, 17,2 en el otro) y, a la par, aumento del $9,7 \%$ del valor del producto no cerealista por habitante. 
los matices de rigor, crecimiento agrario y diversificación productiva entre finales del siglo XVI y comienzos del último cuarto del XVIII.

¿Se mantuvo dicho crecimiento en Burgos hasta el final del setecientos? El cuadro 2 ofrece, al respecto, una certeza y varias evidencias discordantes. La primera, la ausencia de un retroceso generalizado entre 1771-1775 y 1793-1797, pese a las crecientes deficiencias del registro decimal, la consideramos muy significativa. Opinamos así, en concreto, de un aumento del 13,7 \% del valor del producto cerealista (si bien, solo del 3,5\% en términos per cápita) que, en volumen, supondría un alza del 15,4 \% del capítulo de granos panificables, con una clara recuperación de la producción de trigo, y otra del 7,7 \% del de cebada y avena. Entre las segundas destaca un crecimiento, en valor, del conjunto de producto agrario del $8,4 \%$ que vendría acompañado de un descenso del 1,2\% de dicho producto por persona; de este sería responsable, en exclusiva, una notable caída del valor del producto no cerealista, del 11,7 \% (del 19,6 \%, nada menos, en términos per cápita). Semejante contracción de los frutos y esquilmos ajenos a los granos nos parece, sin embargo, poco verosímil porque varios de sus componentes casan mal entre sí y con las trayectorias de otras variables. De un lado, no parece muy compatible una relevante caída del producto ganadero (del $13,7 \%$ en valor) con un crecimiento continuado de la producción de cereales-pienso, y más cuando aquella incluye la reducción de algunos esquilmos por debajo, incluso, de los niveles de finales del siglo XVI y, en cuanto al ovino, un leve descenso de la producción de lana (del 1,5\% en volumen) junto a un auténtico desplome de la de corderos (próximo al $25 \%$ ). De otro, el práctico estancamiento de las cosechas de leguminosas entre las décadas de 1770 y 1790, cuando las proteínas que aportaban debían de haberse hecho un hueco en la dieta de las poblaciones burgalesas al menos desde mediados del siglo, no encaja con la continuidad del crecimiento demográfico en la provincia, que indica la trayectoria de los bautismos, ni con la disminución, según todos los indicios, de la mortalidad en la misma. ${ }^{43}$

En suma, consideramos que la pérdida de calidad de los registros decimales, incluso de los mejores, en el tramo final del setecientos, 
sobre todo por el creciente fraude en el pago del diezmo, impediría que aquellos hiciesen plena justicia al aumento del producto cerealista en Burgos en las cuatro últimas décadas de la centuria y sería la principal responsable de la aparentemente severa contracción de la producción no cerealista. Sin la continuidad del crecimiento agrario en tierras burgalesas hasta el final del siglo no resultarían verosímiles, ni el avance del número de bautizados, cuyo promedio anual se incrementó un 14,3 \% entre 1771-1775 y 1793-1797, ${ }^{44}$ ni la caída registrada por la mortalidad, la cual, según la ratio defunciones totales / bautizados, alcanzaría el 5,2 \% entre 1774-1782 y 1792-1800. ${ }^{45}$

En el interior castellano, las alteraciones en las prácticas decimales que deterioraron la calidad de tales fuentes fueron a más, como hemos indicado, en las cuatro últimas décadas del siglo XVIII. Ello acaeció en un contexto de crecimiento económico y de cambio político y social; de aumento de las cosechas y esquilmos y, a la par, de incremento de las fricciones entre el bajo y el alto clero diocesano, entre el clero regular y el secular, y entre la facción reformista de la clase dirigente y la más conservadora; de cierto reforzamiento económico y político de los pequeños y medianos productores agrarios, y de una lenta secularización de la sociedad española. ${ }^{46}$

La diócesis de Sigüenza ofrece un microcosmos donde se acumulan indicios en todos los sentidos citados. En ella, el cobro de diezmos estaba firmemente asentado, al menos desde finales del siglo XVII, cuando el cabildo catedralicio y el obispo habían diseñado con claridad los oportunos procedimientos administrativos (en las Constituciones Sinodales de 1660, ampliadas en dicha materia por las órdenes de 1678 y 1690, que añadían detallados formularios impresos) a partir de la red de parroquias y de la obligación de cada párroco de

44 Abarca (2015: 383-384; 2017). Sobre la base 100 del promedio del tramo 1770-1774, los índices de bautizados de los cinco quinquenios posteriores, de 1775-1779 a 1795-1799, son 105,5, 107,0, 107,8, 111,4 y 117,6.

45 Abarca (2015: 171 y 177; 2017). En Burgos, como en otras provincias castellanas, se aprecia una reducción de la mortalidad total entre la primera y la segunda mitad del siglo XVIII, así como entre 1750-1774 y 1775-1799: según la ratio citada, en el primer caso aquella sería del 6,9 \% y, en el segundo, del 5,9\%. 
efectuar tazmías anuales y llevar al día los libros pertinentes según modelos muy precisos. ${ }^{47}$

No obstante, los numerosos libros de tazmías del siglo XVIII subsistentes muestran, por parte de los párrocos, omisiones significativas (sobre todo, respecto del producto agrario no cerealista) y resistencias a facilitar información; $y$, por parte de las autoridades diocesanas, crecientes suspicacias sobre los diezmos privativos que no se incluían en las tazmías y los abusos en el modo de diezmar de los que no se daba puntual noticia. Estas tensiones, que ya se aprecian en las advertencias escritas en los libros por los visitadores del cabildo a finales del decenio de 1740 (por ejemplo, en Maranchón, Villaseca de Henares, Miedes de Atienza y Ledanca) ${ }^{48}$ crecieron durante la segunda mitad del siglo Xvin, lo que amplió los márgenes de actuación de los cultivadores directos que, de su usual reticencia a pagar diezmos, pasaron a infringir el abono íntegro de los mismos.

Pero, más allá de comportamientos puntuales en una etapa de dificultades como los años 40 del setecientos, ${ }^{49}$ lo que se observa en las décadas siguientes en tierras seguntinas es una confluencia entre los intereses del clero local y los de los campesinos; estos y aquel percibieron con claridad las ventajas derivadas de un cierto entendimiento. El crecimiento agrario vigente en tierras alcarreñas desde mediados de la centuria implicaba, en parte, diversificación de cultivos y aumento del producto agrario no cerealista, fuente esencial de diezmos privativos. A los párrocos les beneficiaba obviar su registro, en todo o en parte, en las tazmías, escondiendo el aumento

47 ADSi, Constituciones Sinodales del obispado de Sigüenza. Los formularios que incluyen las órdenes de 1678 y 1690 se encuentran cosidos al inicio de muchos de los libros de tazmías que se custodian en este archivo, sobre todo de los que abarcan las primeras décadas del setecientos.

48 En Ledanca (y en otros núcleos, al parecer), en 1747, ciertos cuestores de limosnas habían difundido la falsa doctrina de que las abonadas por los cultivadores podían deducirse de los diezmos, lo que algunos hicieron; el cura del lugar, sin embargo, declaró no ser noticioso de abuso alguno. En Maranchón, en 1748, el párroco, solo tras un serio interrogatorio por parte del visitador, reconoció quererse introducir por los cosecheros de este pueblo no diezmar de los granos a no llegar a una media [fanega] el diezmo (es decir, de las cosechas inferiores a 10 medias o 5 fanegas), ADSi, Libros de Tazmías de Ledanca y Maranchón. 
de su cuota decimal frente al resto de partícipes; y, a cambio del silencio, al efecto, de los cultivadores, los curas consintieron que estos pagasen con menos rigor los diezmos correspondientes.

¿Qué motivos explicarían semejante proceder del clero rural del obispado de Sigüenza en la segunda mitad del setecientos? De entrada, no cabe reducirlo a razones genéricas, como la codicia, ni a motivaciones exclusivamente seguntinas, si bien ciertas características de la diócesis (pobreza relativa de la misma, ${ }^{50}$ pequeño tamaño de las feligresías aldeanas, modestos ingresos y congruas del clero parroquial) pudieron favorecerlo. Lo más probable es que unas y otras se viesen influidas por acontecimientos de ámbito general que, durante la segunda mitad del siglo XVIII, acrecentaron el desapego de los curas respecto de las autoridades diocesanas y aumentaron su afinidad con las comunidades vecinales que regían espiritualmente.

El clero rural del setecientos vivía en un mundo de fidelidades cruzadas $;{ }^{51}$ su piedra angular era un sistema beneficial sostenido por un entramado de intereses en el que los derechos de presentación de los beneficios parroquiales (o de otro tipo), amén de en manos de obispos y cabildos, podían estar en las de nobles, monasterios, comunidades locales e, incluso, ciertos linajes de tales comunidades, trayendo consigo el derecho a participar en los diezmos. Si la fidelidad al patrono de turno podía menoscabar la esperable respecto de la autoridad diocesana, la lealtad a la propia feligresía podía ser notable desde el principio, en especial en diócesis donde, aun siendo el obispo quien elegía, se aplicaba la prelación de los naturales de una parroquia a la hora de acceder a un beneficio que radicase en ella. ${ }^{52}$

50 La diócesis de Sigüenza no figura entre aquellas que Barrio (2007: 330-331) destaca por contar con un clero secular, en promedio, rico (las de Cartagena, Orihuela, Valencia, Cuenca, Toledo, Tarragona, Zaragoza y Jaén) o mediano (las de Barcelona, Lérida, Tortosa, Tarazona, Pamplona, Santiago, Ávila, Segovia, Zamora y Osma).

51 Lo que sigue es tributario, especialmente, de Saavedra (2016) y Barrio (2007, 2011).

52 Saavedra (2016: 356) afirma que dicha condición de patrimonialidad o vecindad motivaba que los curas fuesen una suerte de prolongación de la comunidad o, al menos, de sus miembros más influyentes, e indica que se aplicaba, al menos, en las diócesis de Burgos, Palencia, Valladolid, Pamplona, Tarazona, Lérida, Granada y parte de la de Calahorra. Desconocemos, no obstante, si también estaba vigente en la de Sigüenza. 
En una situación definida por enormes desigualdades en ingresos y nivel de vida del clero secular, las reformas iniciadas por el Consejo de Castilla a raíz del Concordato de 1753, junto a objetivos religiosos, ${ }^{53}$ tenían fines materiales: incluían una reforma beneficial que aumentase la dotación de los párrocos y vicarios más pobres, la cual sería fácil que acabase afectando, entre otras cosas, a la parte de los diezmos que percibían los patronos. Pero el concordato respetaba la notable diversidad de poseedores de derechos de presentación, y el intento se saldó con una aplicación muy desigual de la citada reforma, cuando no con su completo fracaso. Saavedra (2016: 360-369) enfatiza que ello hizo que muchos párrocos en situación material precaria se tornasen más críticos y exigentes con los patronos y otros perceptores de diezmos, como los cabildos e, incluso, con los mismos prelados. ${ }^{54}$ No parece difícil, en este contexto, que numerosos párrocos $\mathrm{y}$ vicarios adquiriesen, junto a una mayor consciencia de su dignidad y trabajo, la convicción de que merecían ampliar su participación en los diezmos. Tales convencimientos avalarían actitudes, por su parte, menos dóciles que en el pasado respecto de la autoridad diocesana y más cercanas al bienestar material de sus feligreses, cada vez más vinculado al propio.

De vuelta al obispado de Sigüenza, la creciente opacidad que se aprecia en muchos libros de tazmías desde comienzos de la década de 1760 o algo antes resulta ilustrativa. En los de Trillo, por ejemplo, de una masa decimal compuesta, de 1753 a 1761, por diezmos granados (de trigo, cebada y avena), diezmos de uva y menudos (de

53 Reforzar la asistencia espiritual a los fieles, mejorar la formación de los curas y afirmar la centralidad de la parroquia y la posición de los párrocos frente a la fronda de regulares y clérigos beneficiados, capellanes, minoristas y tonsurados de diverso tipo (Saavedra, 2016: 362).

54. Tomaron conciencia de la dignidad de su ministerio y se convencieron de que, dentro de un clero muy numeroso y heterogéneo, eran los únicos que realmente trabajaban y resultaban imprescindibles para atender las necesidades de los fieles (Saavedra, 2016: 366). Este autor recoge ejemplos de quejas, al respecto, de los párrocos del obispado de Segovia en la década de 1770; de diatribas de los curas navarros, en 1789, sobre la mezquindad de los perceptores de diezmos, y de duras críticas de los párrocos orensanos, en 1792, sobre la opulenta vida de los canónigos de su cabildo catedralicio: descansan casi todo el día, por lo que no parecen dignos de su salario (Saavedra, 2016: 367 y 368). 
18 producciones no cerealistas), en 15 de los 24 años que median entre 1762 y 1787 tan solo se recogieron los primeros. En los de Ledanca, los registros de diezmos de uva, miel y cera se omitieron desde 1753, los diezmos menudos solo dieron cuenta de lana, corderos y minucias de 1768 a 1782, y desaparecieron del todo entre 1783 y 1787, quedando únicamente los diezmos granados. ${ }^{55}$

Ante la extensión de tales prácticas en la diócesis en las décadas de 1770 y 1780, el cabildo reaccionó mediante circulares y órdenes dirigidas a los párrocos. ${ }^{56} \mathrm{La}$ del provisor y vicario general de julio de 1785 , les exigía, bajo pena de excomunión mayor, que formasen

las tazmías que llaman de marzo, las de menudos y mencales que por él y meses siguientes se acostumbran a diezmar [...], compeliendo con todo rigor a los feligreses para que hagan las declaraciones competentes; [...] y cuiden y celen de evitar cualquier intrusión, particularmente en los diezmos de aquellas semillas que de pocos años a esta parte se han principiado a sembrar.

En junio de 1788, el provisor, tras informarles de la nueva concordia alcanzada con la Real Hacienda sobre el excusado para el lapso 17881791, que suponía el retorno de la casa mayor dezmera de cada cilla al acervo común, del que faltaba desde 1761, les ordenaba que expresen en certificación separada todos y cualesquiera diezmos que en sus parroquias no se lleven a la cilla común o se perciban privativamente. Esta orden no debió surtir el efecto esperado porque, en septiembre, les informaba de que se había comisionado a un notario público por arciprestazgo para que efectuase una encuesta sobre justificación de

55 ADSi, Libros de Tazmías de Trillo y Ledanca. Otra forma de oscurecer los registros de tales libros consistía en omitir las sumas de las cuantías anuales diezmadas de cada especie, como exigían las constituciones sinodales, anotando solo largos y prolijos listados de cosecheros y cantidades individuales. En Ledanca, los curas seguían sin incluirlas en la década de 1780, pese a la advertencia que habían recibido, al respecto, por parte de los visitadores, en 1747.

56 Copias de las cuales figuran en la mayoría de los libros de tazmías que hemos consultado en el ADSi, correspondientes a 35 localidades distintas. Es significativo, sin embargo, que no todas fuesen insertadas por los curas en todos los casos. 
excusado y privativos (muy similar, como dijimos, a la ejecutada en el arzobispado de Burgos en 1776) para que, bajo juramento, manifiesten qué especies de diezmos se causan en sus respectivos territorios, cuántos de ellos perciben privativamente y a cuánto ascenderán anualmente, para el quinquenio 1783-1787, bajo multa de 20 ducados sin excusa ni dilación. ${ }^{57}$ Por último, les ordenaba que desde hoy en adelante, $y$ anualmente, formen con toda distinción y claridad tazmía de los diezmos que (ellos) o cualquiera otra persona, comunidad, iglesia $u$ hospital percibiese privativamente y la remitan a su debido tiempo a la contaduría general.

Pese a la insistencia de las autoridades diocesanas, la colaboración de los curas fue reticente y se ciñó a la duración de la pesquisa. Esta, a la vez, puso de manifiesto que los cultivadores estaban desarrollando otras prácticas especialmente dañinas para los intereses decimales del alto clero, cuya difusión solo era posible con la anuencia del clero local: las dirigidas a eludir la presencia de los colectores en las eras al tiempo de medir el volumen de cereales cosechado sobre el que recaía el diezmo. A la pregunta 10 del cuestionario (idéntica a la que figura con igual número en el interrogatorio burgalés realizado doce años antes), ¿Se alzan los montones de las eras sin llamar al colector de diezmos, que según constitución debe hallarse presente?, la respuesta más habitual de los pueblos seguntinos consistió en que sí avisaban al colector, pero todos los cultivadores a una; este, claro está, no podía asistir a la medición de la cosecha porque es imposible que a un mismo tiempo pueda hallarse presente al levante de los montones de todos los cosecheros $y$, si no acude, meten el grano en sus casas y luego le pagan allí. Una variante de esta declaración sugiere que, por el procedimiento descrito, muchos productores habían empezado a descontar la simiente y otros gastos del producto bruto teóricamente gravado por el diezmo: los de Sotodosos señalaban: Antes de levantar los montones de las eras avisan al colector de ellos y, no acudiendo a tiempo, los levantan en parte aunque no en el todo, hasta que satisfacen

57 En el ACSi hemos localizado un número considerable de cuadernillos de esta Encuesta de justificación de diezmos de 1788, concernientes a más de 100 localidades del obispado. Conviene indicar que, a diferencia del interrogatorio burgalés, el seguntino, amén de a los curas, se dirigió a un grupo de vecinos, cuyas respuestas como peritos servían de contraste a las de aquellos. 
el diezmo que han adeudado. ${ }^{58}$ Es probable que esto equivalga a lo que en Burgos se llamaba, ante la ausencia de terceros en muchos dezmatorios en 1771-1775, diezmar en conciencia..$^{59}$ En todo caso, teniendo en cuenta que, en el interior castellano, la porción del terrazgo cerealista con rendimientos medios por unidad de semilla sembrada superiores a la ratio 1 a 5 era minoritaria, solo la deducción de la simiente suponía un fraude de gran dimensión en los diezmos granados, por encima del $20 \%$.

Más allá de los cereales, algunos párrocos seguntinos ofrecen ocasionalmente en los libros de tazmías, por presiones y motivos diversos, ciertos datos sobre la composición y la cuantía de sus diezmos privativos y de otros frutos y esquilmos que habitualmente quedaban en la penumbra. El mosaico resultante no es fácil de armar, pero la dirección de las piezas parece clara: el aumento y la diversificación del producto agrario no cerealista en la segunda mitad del siglo XVIII.

Los apuntes cualitativos abundan más que los cuantitativos. Así, en 1783, al comienzo de un nuevo libro de tazmías, el cura de Miedes de Atienza copió las advertencias insertas al inicio del anterior, en 1741, sobre sus diezmos privativos; luego de aludir a los de arroturas e inovados añadió, asimismo viene a ser de tiempo inmemorial a esta parte privativo del cura el diezmo de la heredad del curato, de las frutas de las huertas, los pollos y lechones, y garbanzos; con tinta más oscura y otra letra, antes de la firma, aparece interlineado y las papas de los huertos y alubias. En 1790, en el libro correspondiente de Rillo de Gallo, pese a que el párroco jamás añadió dato alguno al respecto, puede leerse:

En este año de la fecha hice recurso al tribunal eclesiástico de la ciudad de Sigüenza para que los vecinos del lugar de Rillo me pagasen el diezmo de patatas que algunos de ellos habian sembrado en sus huertos, por ser fruto nuevo y aunque se

58 ACSi, Encuesta de justificación de diezmos de 1788.

59 Abarca (2015: 302-304). En conciencia, según la de los propios campesinos. Barrio (1983: 135), subraya el sentimiento, muy difundido entre los cultivadores segovianos, de que una notable porción de su cosecha de granos había diezmado ya el año anterior como simiente, siendo legítima su deducción. 
resistieron a ello, el Señor Provisor, en vista de la justificación que hice, los condenó a la paga de dicho diezmo, de todos los años que las habian sembrado, como efectivamente me lo pagaron.

En Villares de Jadraque, en 1789 en exclusiva, el cura se avino a incluir una detallada tazmía de sus privativos: destacan, junto a ciertas cantidades de centeno, lana, pollos, corderos y fruta, 7,4 arrobas de leguminosas y 81,2, de patatas; en ese año, 38 de los 55 cosecheros de cereal de la localidad también cultivaron el tubérculo americano. En Villaseca de Henares, el protagonismo era para las leguminosas. Un pleito, sustanciado en 1783, informa de que el cultivo de judías en el término, quizá desde 1780, había rebasado las lindes de los cuatro predios en que, por tradición, estaba exento de diezmar y que los campesinos se resistían a hacerlo. El fallo en su contra los condenó a pagar el diezmo de las cosechas obtenidas fuera de los términos exentos, si bien, se les perdonaron los concernientes a 1781, 1782 y 1783. La primera tazmía de judías inserta en el libro oportuno es de 1786, año en que abonaron dicho diezmo 46 cosecheros de los 50 que diezmaron granos, sumando 49,7 arrobas de judías. De los apuntes que el cura siguió incluyendo entre 1786 y 1794 se obtiene una media de 27,7 arrobas de judías diezmadas y otra de 41 cosecheros sobre 49 de cereales, promedios que nunca incluyen las producciones y los productores de los cuatro predios exentos. ${ }^{60}$

Por último, juzgamos muy significativo que, en los raros casos en que puede efectuarse un contraste cuantitativo más adecuado, en un contexto tan desfavorable para la integridad de los registros decimales, el resultado sea el crecimiento. En Trillo, la reaparición en las tazmías de los diezmos de uva y de los menudos entre 1787 y 1797 permite apreciar cuantías más elevadas de ciertos frutos ajenos a los granos que las diezmadas en el decenio de 1750. Estimada la casa excusada en los años en que falta del acervo común y considerados los datos que cabe reunir sobre privativos, entre 1753-1761 y 17871797, los promedios anuales diezmados de uva pasaron de 1.146 a

60 ADSi, Libros de Tazmías de Miedes de Atienza, Rillo de Gallo, Villares de Jadraque y Villaseca de Henares. 
1.491 arrobas; los de leguminosas, de 19,2 a 27,3; los de cáñamo, de 13,7 a 15,3 , y los de patatas, de cero a $78,7 .{ }^{61}$

Los aumentos que reflejan cálculos como estos han de interpretarse como un mínimo. Considérese que aprovechan cifras ocasionales sobre actividades agrícolas sumergidas en todo o en parte durante la segunda mitad del siglo XVIII, sobre diezmos que siempre se pagaron con menos rigor que los granados, sobre momentos en que el control acerca de su cobro por parte del clero local, en la medida en que engrosasen sus privativos, cedió, y, en casos como los de patatas y judías, sobre cultivos nuevos o desacostumbrados, cuyas décimas los cultivadores procuraban no pagar o bien hacerlo en proporciones inferiores al $10 \%$ de la cosecha.

El testimonio definitivo sobre la magnitud que la defraudación en el pago del diezmo había adquirido en la diócesis de Sigüenza a finales del siglo xvin lo aporta la circular que, por orden del obispo, remitió en 1794 el contador mayor de rentas decimales, no ya a los párrocos, sino a los mayordomos y oficiales del cabildo. ${ }^{62}$ Organizada en seis puntos con un tono tan directo como severo, revela que las autoridades diocesanas asumían el fraude por parte de los cultivadores como un fenómeno generalizado, que su confianza en los curas era casi nula y que, quizá convencidas de que sin la colaboración del clero local no podían salir airosas de semejante pugna, en su ánimo, la preocupación iba dando paso a la impotencia: al fin y al cabo, lo que invocaban una y otra vez en la circular de 1794 era que se cumpliera lo prescrito en el título De Decimis de las Constituciones Sinodales de $1660 .^{63}$

61 ADSi, Libros de Tazmías de Trillo.

62 Son pocos los libros de tazmías que la recogen, lo que es sintomático.

63 ADSi, Libros de Tazmías de Bañuelos e Hijes. Basta citar parte de los puntos 3, 5 y 6. 3: Que cuiden dichos mayordomos saber e informarse de si se siembran nuevas especies de frutos en los pueblos como es judias, garbanzos, cáñamo, lino, papas $u$ otros cualesquiera para que entren en la cilla común y no se apropien privativamente por los curas ni que se dejen de diezmar... 4: Que los mayordomos no permitan que en casa de algún interesado como cura o beneficiado se recojan diezmos [...] por evitar el abuso de que quieren valerse [...] o acaso otros mayores los curas es a saber: apropiárselo todo privativamente... 5: Que hagan presente a los curas dichos mayordomos que luego que se levanten los montones hagan las tazmías con arreglo a la constitución 26 y que estos y los camareros no permitan que levanten los montones antes de pagar el 
¿Resultan representativas las alteraciones de las prácticas decimales detectadas en el obispado de Sigüenza (y en el arzobispado de Burgos) de lo acontecido, al respecto, en otras diócesis castellanas y andaluzas en la segunda mitad del siglo XviII? Consideramos que sí. El grado de desafección de los párrocos respecto del alto clero podía ser más reducido en otras partes, y menor la afinidad de estos con sus feligreses, pero conviene resaltar que, en tierras seguntinas y burgalesas, la obligación de hacer tazmías anuales estaba consolidada, que las diferencias de fortuna entre los vecinos de sus pequeñas localidades no debían de ser muy grandes, que sus suelos no eran especialmente feraces y que la relativa lejanía a grandes mercados debía suponer estímulos mercantiles reducidos. En otros espacios del interior peninsular, una mejor dotación de recursos agrarios, una estructura social más polarizada y una mayor proximidad a mercados relevantes pudieron generar condiciones incluso más favorables para el incremento de la defraudación en el pago del diezmo.

En suma, las evidencias que ofrecen las mejores fuentes decimales disponibles sobre tres amplios territorios castellanos indican un notable aumento de la porción sumergida del producto agrario, en el interior peninsular, en la segunda mitad del siglo xviII: más velos, y más tupidos, se interpusieron entre la producción agraria y los registros decimales. De ahí que las series decimales publicadas, que en su mayoría obvian este fenómeno, infravaloren el crecimiento de dicho producto agrario y no permitan observar muchos de los cambios operados en su composición en la segunda mitad del setecientos y, si el contraste arranca del siglo Xvi, en el conjunto de la Edad Moderna.

\section{Conclusiones}

1. Consideramos que la vía de la demanda constituye un procedimiento inapropiado para medir el crecimiento agrario en la Edad Moderna. 
2. Opinamos que la vía del producto es, al efecto, preferible con diferencia, pero su empleo adecuado requiere conocer a fondo una fuente tan compleja y repleta de problemas como los registros de diezmos. Solo estos permiten, cuando se trabaja con cuidado sobre los mejores existentes, lograr acercamientos con márgenes de error asumibles a la cuantía, trayectoria y composición del producto agrario en distintas fases de los siglos modernos.

3. Desde 1760, las fuentes decimales que, hasta entonces, habían transmitido una imagen relativamente precisa de la trayectoria del producto agrario, sobre todo del cerealista, en distintas regiones españolas, fueron perdiendo calidad conforme una parte creciente de aquel se tornó invisible para las mismas y registró un aumento significativo en las últimas décadas del setecientos. La insuficiente consideración de este fenómeno ha implicado que, durante mucho tiempo, hayamos infravalorado el crecimiento agrario en el siglo XviII y en la Edad Moderna en su conjunto.

4. Esa infravaloración ha sido actualizada, recientemente, a través de un acercamiento inadecuado a la vía del producto, insistiéndose en la caída del producto agrario por persona entre las décadas de 1750 y 1790 y, a su vez, entre las últimas del siglo Xvi y las postreras del XVIII, siendo mucho más probable en uno y otro caso que, con todos los matices que se quiera, hubiese crecimiento de esa magnitud y diversificación productiva.

5. ¿Podemos establecer la cuantía exacta de ese sesgo a la baja? Obviamente, no. Pero lo que sí podemos hacer es estimar umbrales mínimos de la misma y atisbar los cambios registrados en la composición de la producción agraria en la segunda mitad del setecientos, a partir de las mejores fuentes decimales disponibles (las averiguaciones de diezmos y los libros de tazmías) en los territorios donde estas se hayan conservado.

La pregunta pertinente quizá no sea ¿podemos medir lo invisible?, sino ¿podemos ignorarlo?, ¿podemos dejar el campo libre a estimaciones que consideramos erróneas, cuando es posible que en muchos archivos diocesanos y catedralicios españoles estén aguardando pesquisas sobre diezmos y reparto de subsidio y excusado, así como libros de tazmías, de calidad similar a la de los utilizados en este trabajo? 


\section{EL DIEZMO \\ COMO BASE DEL SISTEMA BENEFICIAL ${ }^{1}$}

Elena Catalán Martínez

\section{INTRODUCCIÓN}

El diezmo eclesiástico ha sido, y aún lo sigue siendo, una de las fuentes fundamentales para analizar la economía de la época preindustrial. Su carácter de impuesto directo y su universalidad en el mundo católico lo convierten en un referente inexcusable para conocer la estructura de los cultivos, las fluctuaciones agrarias y la distribución del excedente agrícola entre sus perceptores; además, cuenta con el valor añadido de que permite el análisis en el largo plazo y una perspectiva comparada tanto en Europa como en América. La contabilidad decimal ha sido utilizada por los historiadores económicos fundamentalmente para analizar cuestiones relacionadas con la producción agraria - estructura de cultivos, productividad, producto agrario bruto $(\mathrm{PAB})$ - y sus implicaciones en la renta campesina. Sin embargo, su análisis desde el punto de vista de los perceptores se ha abordado de manera superficial, centrándose por

1 Este trabajo ha sido realizado bajo el patrocinio del Gobierno Vasco a través de la pertenencia de su autora al Grupo Consolidado de InvestigaciónCliobasque IT-897. 
lo general en las élites eclesiásticas y relegando a un segundo plano al clero parroquial.

Se puede afirmar que en las décadas de 1970 y 1980 se vivió un importante movimiento historiográfico que analizaba las sucesivas coyunturas agrarias tomando como base documental la contabilidad decimal. No es mi propósito dar cuenta de toda esta producción. Baste señalar que la contribución española fue destacada ya que se reconstruyeron las tendencias de la producción campesina en la mayor parte de las regiones españolas. ${ }^{2}$ De manera subsidiaria, pero no por ello menos importante, estos trabajos pusieron de manifiesto la necesidad de conocer las diferentes formas de diezmar de cada diócesis para poder paliar las dificultades que se encontraban los historiadores en el reconocimiento de la tipología decimal. ${ }^{3}$ Como consecuencia, empezaron a aflorar estudios en los que se analizaban las peculiaridades de la distribución del diezmo en cada circunscripción, centrándose fundamentalmente en la parte que recibían obispos y cabildos catedralicios, ya que, aunque en teoría el diezmo iba destinado a los ministros de culto, en la práctica los grandes beneficiarios fueron las élites diocesanas (Morgado, 2000: 80). ${ }^{4} \mathrm{El}$ interés por esta fuente fue decayendo en la década de 1990, quedando circunscrita a trabajos cuyo principal objetivo era el análisis socioeconómico de las élites, tanto religiosas como laicas, dejando en un segundo plano al clero parroquial. ${ }^{5}$

2 Le Roy Ladurie y Goy (1982) recogen las aportaciones de series decimales de varias regiones españolas: Segovia (García Sanz), Galicia (Eiras Roel), País Vasco (Bilbao y Fernández de Pinedo), Málaga (Benítez Sánchez-Blanco), Murcia (Lemeunier), Valencia (Palop Ramos) y Granada (Garzón Pareja).

3 Unos años antes Anes y Le Flem (1965: 6-7) ya habían señalado esta necesidad.

4 Así conocemos bastante bien la distribución decimal de la mayoría de las diócesis castellanas y, algo peor, la de las de la corona de Aragón: Málaga (Benítez Sánchez-Blanco, 1978), Segovia (Barrio Gozalo, 1982), Calahorra (Ibáñez, 1999), Córdoba (Muñoz Dueñas, 1988), Galicia (Burgo López, 1993; Rey Castelao, 1992 e Iglesias, 2012), Salamanca (García Figuerola, 1989), Zamora (Álvarez Vázquez, 1984), Huesca (Latorre, 1992), Teruel (Latorre, 1990), Lleida (Castillón, 1988) y Mallorca (Juan, 1989).

5 En este sentido, cabe destacar los trabajos de Barrio Gozalo (1983-2003; 1988a y b, 2010b, 2014 y 2015) sobre las rentas de la mayoría de los obispos españoles. 
En la actualidad, el interés por el diezmo se ha revitalizado como indicador esencial para calcular el PIB per cápita vía producto, metodología que ofrece mayores garantías que la que utiliza funciones de demanda. ${ }^{6}$ Algunos de estos trabajos han rescatado las series decimales publicadas en los 80 con el fin de construir una estimación nacional y establecer un análisis comparativo con otras regiones europeas. Esto ha puesto de manifiesto la dificultad de homogeneizar series procedentes de diversos perceptores, y a las que no se puede aplicar el estándar tridentino de reparto del diezmo, basado en el del arzobispado de Toledo, ya que no se cumple en la mayoría de las diócesis.

En este capítulo se abordan aquellos aspectos esenciales del sistema beneficial necesarios para comprender la distribución del diezmo, tanto a nivel territorial como profesional, con el fin de ofrecer una guía a los investigadores que se acerquen a la documentación eclesiástica, en general, y decimal, en particular. El conocimiento de la estructura diocesana y de los mecanismos de redistribución del diezmo entre sus beneficiarios constituye un pilar esencial para utilizar series procedentes de contabilidades parroquiales y catedralicias, ya que estas solo ofrecen datos parciales de la producción agraria. Antes de enfrentarse a este tipo de documentación se debe tener en cuenta a qué porción del diezmo se está teniendo acceso, puesto que, salvo en el caso de las tazmías, siempre se trata de la contabilidad de alguno de los partícipes. Asimismo, se debe considerar a qué especies tiene derecho la porción que analizamos ya que hay determinados productos que son privativos del clero parroquial o, al contrario, solo son percibidos por la jerarquía diocesana. La cantidad y tipología de las especies que percibe cada una de las partes depende tanto de la estructura organizativa del obispado y su red parroquial, como de todo aquello que atañe a la composición, valor y gestión de la producción agraria. También debe tenerse en cuenta la incidencia del excusado, la existencia de diezmos privativos, tierras exentas de su pago o con reducciones importantes, como sucede con la mayoría de

6 Entre los trabajos que están estimando el crecimiento del sector agrario vía producto cabe destacar: a nivel europeo, Van Zanden y Van Leeuwen (2012); Broadberry et al. (2015) y, en el ámbito nacional, Álva-rez-Nogal et al. (2016); Latorre (2010); Llopis et al. (2018) y Catalán (2018). 
las propiedades de los conventos y monasterios. No tener en cuenta las disparidades regionales existentes en este sentido puede llevar a incurrir en errores de sub- o sobreestimación del PAB.

El diezmo tampoco ha sido suficientemente analizado como elemento fundamental para explicar los desequilibrios de renta dentro de la Iglesia, especialmente entre el llamado bajo clero. La acumulación de propiedades, rentas y privilegios por parte de la institución, nos lleva con frecuencia a minimizar el hecho de que lo que define cada beneficio y el lugar que ocupa en el escalafón del sistema beneficial es precisamente la porción que percibe del excedente agrario. Las diferencias entre un cura de pueblo y un canónigo de la catedral son obvias tanto por la extensión de sus dezmatorios como por la diferente capacidad de comercialización o almacenamiento de lo percibido. Sin embargo, no están tan claras las diferencias entre el clero parroquial, cuya capacidad económica solemos tender a homogeneizar estableciendo, como mucho, una leve diferenciación de acuerdo con las características agronómicas de cada región. Un análisis detallado de la distribución del diezmo entre los servidores, atendiendo a su categoría profesional, a las características geomorfológicas y a los derechos históricos que pesan sobre cada dezmatorio, permitiría profundizar en los mecanismos de distribución de la renta y en el origen de las desigualdades existentes, tanto a nivel estamental como regional. En la segunda parte de este capítulo se plantea una reflexión metodológica para nuevas vías de investigación que permitan precisar los niveles de renta de los servidores parroquiales, los mecanismos que regulan la distribución del ingreso en un colectivo tan heterogéneo y la distancia que media entre una familia campesina o de artesanos y los curas que sirven en su parroquia. ${ }^{?}$

$7 \quad$ Hasta el momento, este trabajo solo ha sido realizado para el obispado de Calahorra y La Calzada (Catalán, 2010), aunque sería necesario realizar estudios similares para el resto de las diócesis españolas. 


\section{EL DIEZMO COMO BASE DEL SISTEMA BENEFICIAL}

El diezmo es un impuesto directo que grava con un $10 \%$ todas las actividades productivas, fundamentalmente la producción agraria - granos, ganado y otros productos agrícolas que requerían una manipulación como vino, queso, lana, aceite, miel, cera, etc.- pero también el trabajo y la renta. Los cereales, junto con el vino y los corderos, comprendían los llamados diezmos mayores o pontificales mientras que el resto de productos, por su menor volumen, formaban parte de los llamados diezmos menores o minucias junto con las cantidades monetarias acordadas como pago de la actividad artesanal o comercial. Durante el Antiguo Régimen, esta renta sirvió como base para articular el sistema beneficial de la Iglesia católica, ya que su percepción constituía la recompensa por el desempeño del oficio, sea cual fuere la posición del perceptor en el organigrama eclesiástico.

El concilio de Trento (sesión 25, capítulo 12) institucionalizó el reparto del diezmo en tres partes cuyos beneficiarios eran el rey, como patrono universal de todas las iglesias de España; el obispo, como cura universal de su diócesis; y los beneficiados, como parte de su retribución por su servicio en la parroquia. Sin embargo, esta disposición conciliar no conseguiría romper con la herencia medieval en la organización y distribución de la masa decimal. A este respecto, los obispados españoles presentaban una gran heterogeneidad derivada de la pervivencia de los derechos de patronato en los que se sustentaba la Iglesia medieval y de la propia configuración de las diócesis en el contexto de la Reconquista (Catalán, 2004a).

\subsection{La formación de los obispados y distribución del producto decimal}

La historiografía medieval señala un acusado proceso de feudalización en la formación de la estructura eclesiástica, cuyo objetivo prioritario era la formación y consolidación de un señorío territorial, siendo el diezmo una exacción señorial más. Así, la fundación y posesión de una iglesia -iglesias propias - se convirtió en un elemento estratégico para los monarcas, la nobleza, los obispos, grandes monasterios e incluso para las comunidades de campesinos quienes dotarían al concejo o a la behetría de un templo que sirviese 
de centro espiritual y de percepción de rentas. De esta manera, las iglesias propias se extendieron por los territorios comprendidos al norte de los ríos Duero y Ebro, así como en las cuencas medias del Tormes y Eresma. En la zona oriental, la mayor presencia de estructuras eclesiales visigóticas favoreció la configuración de señoríos episcopales; en el área cantábrica, con muchos elementos arcaizantes y una estructura eclesial débil, la iniciativa corrió a cargo de los nobles; mientras que, entre la cordillera cantábrica y el Duero, predominaron las iglesias de abadengo y las erigidas por las comunidades de campesinos. En todos los casos, la propiedad del templo otorgaba el derecho de percepción de oblaciones, diezmos, primicias y la obligación de mantener el culto. Así, si el dueño de la iglesia era laico delegaba en un clérigo todo lo referente a la asistencia espiritual de los fieles, reservándose la administración de los bienes; si era eclesiástico se constituía a sí mismo como ministro de culto, asegurando la continuidad del servicio designando a un sucesor a quien dejaba en herencia su patrimonio, que era el de la iglesia. Todos ellos debían garantizar que el servidor de la parroquia se pudiera dedicar a su oficio de forma exclusiva por lo que debían proporcionarle medios suficientes para su sustento material.

Este sistema organizativo generaba numerosos problemas como la injerencia de los poderes laicos en la provisión eclesial, el amancebamiento de los clérigos o el nombramiento de cargos eclesiásticos sin la adecuada formación. Si bien estos males aquejaban a todo el Occidente cristiano, en la Península Ibérica tuvieron un desarrollo peculiar por el cariz de cruzada que se le dio a la expansión territorial de los reinos cristianos.

A partir de que el diezmo se hiciera obligatorio, los prelados cambiaron su estrategia relegando la posesión territorial a un plano secundario en favor del control de la fiscalidad parroquial (Fuente Cimino, 2014: 102). Según los cánones gregorianos, la parroquia, unidad administrativa básica, era el único ámbito en el que se podían administrar los sacramentos o cobrar el diezmo. En este contexto, se otorgó al obispo la potestad de conceder a un templo la autorización para poseer pila bautismal, lo que equivalía a la concesión de la parroquialidad y, por lo tanto, a la percepción de la renta decimal. Este hecho en sí mismo implicaba la aceptación de su autoridad y el reconocimiento de su señorío a través del pago de una parte del diezmo - tercia episcopal. 
En líneas generales, los monarcas apoyaron la integración de las iglesias señoriales y monasteriales en la estructura diocesana e impulsaron un movimiento de donación de iglesias propias a los obispos, con desigual resultado. En Galicia, León y el norte de Castilla se produjo un trasvase masivo de iglesias hacia los prelados y los grandes cenobios, lo que favoreció la formación de grandes señoríos episcopales y monásticos (Loring, 1997: 105). La gran extensión territorial de estos patrimonios propició que las parroquias más alejadas del cenobio o de la iglesia catedral fuesen cedidas a concejos o particulares laicos en régimen de arrendamiento o a censo perpetuo. En la práctica, serían los arrendatarios, en ocasiones descendientes de los primitivos propietarios, quienes se hiciesen cargo del nombramiento y la retribución del clérigo, mantenimiento del templo y pago de los impuestos debidos a la Corona (Diago, 1997: 634-635). Esto causaría en el futuro graves problemas de titularidad de los derechos inherentes a la posesión de la iglesia. En los obispados de Pamplona y Huesca, los propietarios de las iglesias reconocieron al obispo como su señor natural siguiendo fórmulas diversas: en unos lugares solo pagaban una cantidad fija de frutos decimales en especie; en otros, la parte del obispo quedó reducida a la cuarta u octava parte de los diezmos anuales; y en otros, percibía la totalidad del diezmo, deducida la parte del beneficiado, por el hecho de ser abad de ellos (Barrio Gozalo, 1988a: 49; Latorre, 1992: 36-38).

El País Vasco y Cataluña constituyen la excepción a este flujo de trasvase de titularidad privada hacia la Iglesia. Las campañas de donaciones con derecho a percibir rentas y diezmos tuvieron escasa repercusión entre los vascos ya que solo se transfirieron un puñado de templos a los monasterios de San Millán de la Cogolla, San Salvador de Oña, San Juan de la Peña y San Salvador de Leyre (Curiel, 2009: 244-249). El motivo fundamental de la oposición de los señores vizcaínos y guipuzcoanos a ceder sus propiedades al episcopado fue económico: la posesión de una iglesia garantizaba la percepción del excedente agrario en una tierra de pobres recursos, y permitía gestionar el enorme capital social derivado del derecho de presentación, asiento y enterramiento preferente. Además, ninguno de los tres territorios reconoció la autoridad de su obispo, y en consecuencia no pagarían la tercia. En Vizcaya y las parroquias de Guipúzcoa pertenecientes al obispado de Calahorra 
la autoridad episcopal era considerada un contrafuero y, por tanto, solo se reconoció la figura del arcipreste como suministrador de los santos óleos. En cambio, el prelado de Pamplona sí percibió la parte correspondiente a las iglesias guipuzcoanas bajo su jurisdicción porque sus fundadores lo reconocieron como señor natural. El caso de Álava es un tanto especial ya que el patronato laical apenas estaba implantado en su territorio. Su clero hizo valer las prerrogativas que le correspondían como antigua sede episcopal, ${ }^{8} \log$ rando que se le conmutase la tercia por una cuota fija en trigo y cebada - tasaciones alavesas - (Sainz de Ripa, 2001: 65). En el caso de Cataluña, las donaciones fueron forzosas ya que se dispuso que todo laico que poseyese una iglesia debía cederla a las autoridades eclesiásticas a su muerte, anulando el derecho de herencia. Sin embargo, el diezmo continuó siendo percibido por los señores al quedar vinculado a la posesión del dominio eminente, siendo parte esencial de la renta feudal (Mallorquí, 2009b: 284-285).

Durante la crisis del siglo xiv, la contracción demográfica y la caída de las rentas señoriales revalorizaron la posesión de una iglesia, debido a la alta rentabilidad económica y social que se derivaba de su posesión. ${ }^{9}$ Como consecuencia, se produjo un proceso de usurpación de patronatos en aquellos lugares en los que no estaban claros los derechos de propiedad y percepción de rentas de las iglesias. ${ }^{10} \mathrm{De}$ forma simultánea, la inestabilidad política llevó a los Trastámara a ceder el usufructo de parroquias de las que el rey era titular para asegurar la fidelidad de determinados linajes y reforzar el poder real frente al señorial. Esta política favoreció la concentración y el fortalecimiento del patronato laical en las diócesis de Burgos, Palencia, Calahorra y Pamplona. En Cataluña también salieron fortalecidos ya que la Sentencia arbitral de Guadalupe (1486)

8 La antigua sede de Armentia, primer obispado vasco y sede de su catedral, fue anexionada por Calahorra a finales del siglo XI.

9 Según Díaz de Durana (1998: 505), en Guipúzcoa los diezmos derivados de la posesión de una iglesia constituyeron más de la mitad de los ingresos señoriales.

10 Todavía en 1609, en la averiguación que realizó Felipe II sobre los patronatos de sus reinos y su naturaleza, los beneficios usurpados constituían el $35 \%$ del total, concentrados fundamentalmente en las diócesis de Oviedo, Astorga y Orense. Archivo de la Real Academia de la Historia, sig. 97-4r-12/9/1.139. 
establecía la obligatoriedad del pago del diezmo y otros derechos señoriales a los propietarios del dominio eminente como parte del reconocimiento del mismo. ${ }^{11}$

La reforma eclesiástica llevada a cabo durante el reinado de los Reyes Católicos dejó intacta la esencia del régimen patrimonial. Estas iglesias fueron integradas en la estructura diocesana aceptando sus peculiaridades como algo específico de las zonas de montaña. Por tanto, durante la Edad Moderna, en los obispados del norte peninsular encontramos una gran profusión de parroquias cuyos derechos de propiedad y rentas eran ostentados por laicos, grandes órdenes monásticas y señoríos episcopales. La retribución de sus servidores quedaba al libre albedrío de sus propietarios que unas veces cedieron una parte variable del diezmo, otras solo un puñado de casas dezmeras que garantizaran su supervivencia y, otras, una renta fija monetaria que iría devaluándose con el paso del tiempo. Poco importa si el propietario era laico o eclesiástico. El resultado final fue un clero parroquial muy abundante y con una retribución muy desigual que no siempre garantizaba los mínimos de subsistencia. Solo escaparon de esta situación las iglesias erigidas en villas y ciudades de realengo, o las que se fundaron a partir del siglo xiII, ya que no tuvieron más remedio que integrarse en la estructura diocesana, manteniendo los derechos decimales intactos.

Al sur del Duero, la situación de las iglesias y sus servidores fue bien distinta. La erección de las diócesis y la organización eclesiástica estuvieron desde un principio supervisadas por la Corona y bajo el control de obispos u órdenes militares. En estas diócesis, aunque existieron iglesias fundadas por legos en señoríos muy extensos, la autoridad episcopal en materia de presentación de clérigos o de reparto de diezmos estuvo fuera de toda duda. Por una parte, el derecho canónico había establecido desde el siglo xiII que la administración de una iglesia no podía competer de ninguna manera a los seglares ya que estos no estaban investidos de poderes espirituales (Bidagor, 1933: 151-153). Por otra parte, la Corona reforzó

11 Durante los siglos xvi y xvir, el principal conflicto que enfrentaría a los campesinos, detentadores del dominio útil, y a los diezmeros sería la heterogeneidad de la tasa de exacción del diezmo, tanto en su proporcionalidad como en los productos que gravaba (Gifre, 2011: 43-45 y 191-192). 
el poder material de las nuevas diócesis ya que jugaban un papel fundamental en la integración territorial de la Monarquía. Así, se les concedió extensos territorios, que se encontraban entre los más productivos de la Península, y reservaron para los obispos la cura de almas de muchas de sus parroquias, lo que les daba derecho a percibir además de la tercia episcopal la parte del diezmo correspondiente a los servidores.

Quintín Aldea (1973: 17-20), tomando como ejemplo el arzobispado de Toledo en 1499, ilustra las transformaciones sufridas en la distribución decimal como consecuencia del creciente protagonismo que la Corona fue otorgando a los obispos como parte fundamental de articulación y control de su territorio (figura 1).

En un principio, se estableció una división teórica del diezmo en tres porciones para poder hacer frente al mantenimiento de la parroquia, sus servidores y del aparato burocrático necesario para el funcionamiento de la diócesis: una de ellas se destinaba a sufragar los gastos de la fábrica del templo parroquial y sus ornamentos; otra se repartía entre los clérigos residentes en la parroquia, y la última se destinaba al obispo y cabildo catedralicio. Esta distribución del diezmo fue alterada a partir de 1247 con la concesión papal al rey de una tercera parte del diezmo como ayuda financiera en el asedio de Sevilla. A cambio, la Monarquía reforzó la autoridad de la Iglesia regulando la cobranza de los diezmos en sus territorios, poniendo al servicio de la Corona su aparato administrativo para la organización fiscal del Reino (Ladero Quesada, 1982: 34). Finalmente, la tercia real se detrajo de la parte correspondiente a los servidores y a la fábrica, sin tocar la del obispo, lo que suponía $2 / 9$ del total —es decir, el 22,2 \%. A medida que se iba ampliando el territorio y, por tanto, aumentando la feligresía, se decidió aumentar la parte correspondiente a los servidores con un tercio de lo que le correspondía a la fábrica, por lo que su parte quedó reducida a 1/9 -11,1\%. Por otra parte, la nueva dimensión pastoral y fiscal de las diócesis obligó a configurar nuevas estructuras administrativas: los arcedianatos, que facilitaban la gestión de los recursos y el repartimiento de las tercias debidas a la mesa episcopal, y los arciprestazgos, que coordinaban cuestiones doctrinales. El obispo debió asumir con su parte el mantenimiento de la estructura burocrática de su diócesis: al arcediano y arcipreste le correspondió un 3,33 \%, mientras que a los canónigos de la catedral 
Figura 1. Evolución del reparto del diezmo en el arzobispado de Toledo
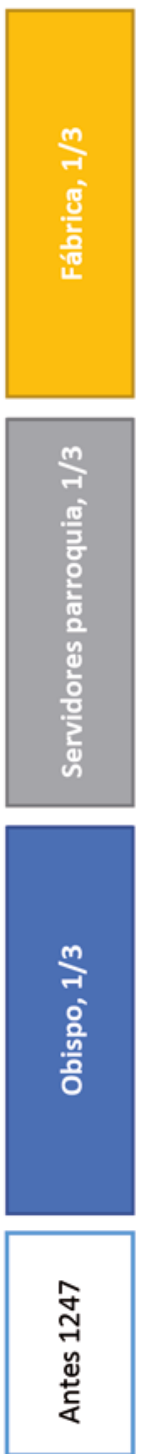
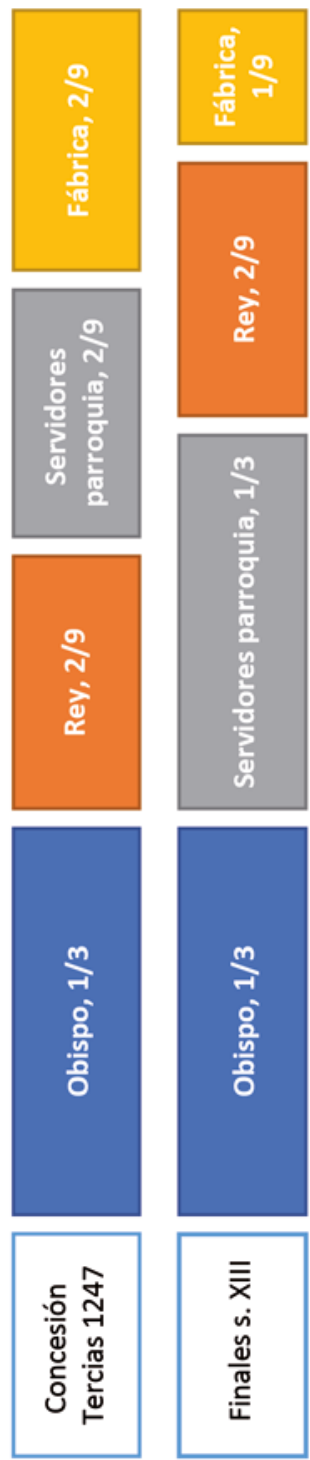
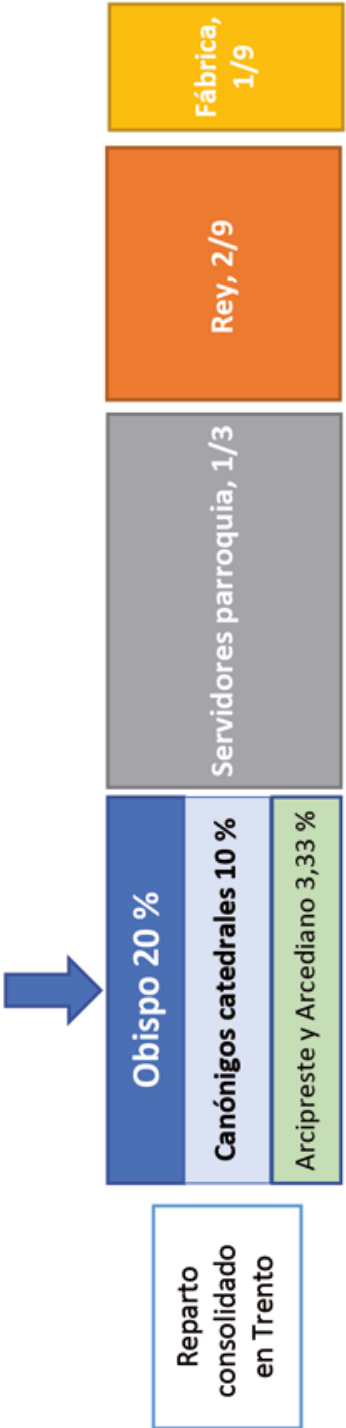

FUENTE. Elaboración propia basada en Aldea (1973: 17-20). 
el $10 \%$ de los diezmos de pan y vino. Con ello, la parte del obispo quedó reducida del 33,3 al $20 \%$.

Esta distribución del diezmo fue la que consagró Trento como modelo general, con alguna pequeña variación referida al pago del personal administrativo de cada diócesis. Sin embargo, pocas veces se aplicó de esta manera debido a la heterogeneidad en el número de pilas o parroquias, y en consecuencia la abundancia o escasez de beneficiados, así como a la pervivencia de derechos particulares en las iglesias del norte y a los derechos adquiridos por la jerarquía eclesiástica sobre las del sur. Aunque como colectivo fue el clero parroquial (incluida la fábrica) el que se llevó la mayor parte del diezmo $-46 \%$-, sin duda fueron los obispos los mayores beneficiarios, ya que una sola persona percibía un promedio del $8 \%$ de lo recaudado, seguidos de los canónigos que componían los cabildos catedralicios. Tampoco hay que menospreciar las cantidades que permanecieron en manos de laicos un $-12 \%-\mathrm{y}$ de monasterios y conventos —un 7 \%-(Ibáñez, 1999: 341-343).

\subsection{El reparto del diezmo en el sistema beneficial}

La posición que cada clérigo ocupaba en el organigrama de la Iglesia católica llevaba aparejado el desempeño de una función específica y el derecho a una renta que fuera acorde con la importancia de la misma. Hoy diríamos que por la labor realizada cobraba un salario que en la terminología eclesiástica se denomina beneficio y, por asimilación, beneficiados a los que lo percibían. La fuente principal de retribución del oficio fue el diezmo y, en consecuencia, la base sobre la que se articuló toda la estructura del clero diocesano. El reparto del diezmo no obedeció a criterios de equidad, sino que atendía a principios de jerarquía y privilegio, por lo que la desigualdad fue la nota dominante.

La diversidad en la tipología de los beneficios fue tan variada como la de los oficios a los que dio soporte. ${ }^{12}$ De esta forma, cuando servían en una catedral, colegiata o abadía se denominaban mayores, mientras que si lo hacían en una parroquia eran menores. Ambos podían

12 Sobre la tipología y las características de los beneficios, véanse Barrio Gozalo (2010) y Catalán (2004a). 
tener aneja la cura de almas, jurisdicción, dignidad o administración eclesiástica de cualquier tipo. Junto a estos se encuentran los llamados simples cuya única obligación era la asistencia diaria al coro para rezar el oficio divino como miembros de pleno derecho del cabildo y celebrar determinado número de misas vinculadas a perpetúales y aniversarios. Sobre esta estructura básica se podían añadir múltiples variaciones que tenían que ver con la residencia o con la manera en la que los beneficios habían sido instituidos. Los había que exigían exclusividad y, por lo tanto, obligaban a la residencia, y otros que se podían compatibilizar con el disfrute de otros de naturaleza análoga. En este último caso, se debía garantizar el servicio mediante sustitutos que recibían el beneficio en encomienda o custodia temporal. ${ }^{13}$ Desde Trento, todos los beneficios debían ser aprobados por la autoridad del ordinario (obispo) aunque había categorías en función de quién los propusiera para el cargo: colativos por el obispo; patronato por el propietario de la iglesia o quien la usufructuara en ese momento; y electivo, en el caso de los cargos a los que se accedía por elección.

En las parroquias, colegiatas y catedrales de toda España existía otro tipo de clérigos que no tenían derecho a percibir el diezmo, pero que convivían con los beneficios propiamente dichos. Estos habían sido fundados y dotados por particulares - laicos y eclesiásticospor lo que su retribución económica y sus funciones quedaban establecidas por la propia fundación. Así mismo, no exigían la ordenación sacerdotal, sino que bastaba con estar en posesión de la prima tonsura. En algunos casos servían de título de ordenación, siendo con frecuencia el paso previo para poder acceder a un beneficio simple. En la corona de Castilla, este tipo de fundaciones se denominan capellanías, mientras que en la de Aragón son beneficios personados, lo que lleva a confundirlos con los anteriores (Barrio Gozalo, 2010a: 54). Todos ellos permitían la integración plena en la estructura eclesiástica en cualquiera de sus niveles, constituyendo una pieza fundamental en las estrategias hereditarias de la pequeña nobleza territorial y de todos aquellos que, con un cierto nivel

13 Trento estableció la obligatoriedad de residencia para todos los curatos. La figura del sustituto no desapareció, sino que se regularizó transformándose en vicario, teniente o coadjutor (Barrio Gozalo, 2010a: 19). 
económico, quisieran compensar a las líneas secundarias con el acceso al estado eclesiástico (Saavedra, 2016: 351).

\subsubsection{Obispos, canónigos y racioneros}

El obispo, nombrado y presentado por la Corona, era la dignidad máxima de la diócesis. Como se ha visto, recibía una parte de todos los diezmos de las parroquias de su diócesis - tercia episcopal-con la que debía hacer frente a los gastos de mantenimiento de la catedral y retribuir al cuerpo de canónigos que lo acompañaban en el gobierno y la administración de su sede. ${ }^{14}$

El gobierno de la catedral y el de la circunscripción requería una organización administrativa compleja que sufrió múltiples variaciones en número, funciones y privilegios. ${ }^{15}$ No existía ninguna norma que regulara el número de capitulares que debía tener una iglesia catedral, por lo que su número y retribución estuvieron en relación directa con el poder económico de la diócesis y sus necesidades de culto. ${ }^{16}$

Los cabildos catedralicios estaban compuestos por canónigos y racioneros que asistían juntos al coro, a las distribuciones canónicas y a las reuniones capitulares donde se tomaban las decisiones que afectaban el gobierno de la diócesis.

Las canonjías - denominadas capellanías en la corona de Aragón $-{ }^{17}$ tenían derecho, como retribución de su oficio, a

14. Los obispos de diócesis particularmente ricas o extensas tenían la dignidad arzobispal. Muchos de ellos son también los responsables de la provincia eclesiástica en la que se localiza su archidiócesis. En Castilla había 7 arzobispados (León, Oviedo, Santiago, Burgos, Toledo, Granada y Sevilla), mientras que en la corona de Aragón solo eran tres (Tarragona, Valencia y Zaragoza).

15 En la descripción de la jerarquía de los cabildos catedralicios seguimos a Barrio Gozalo (2010a: 49-54).

16 La composición de cada cabildo catedralicio fue adecuándose a las diversas coyunturas económicas y a las sucesivas reformas de la estructura diocesana acometidas por la Monarquía, para acabar por estabilizarse a comienzos del siglo XVIII.

17 Toda la terminología utilizada es fundamentalmente castellana. En la corona de Aragón, e incluso en cada uno de sus reinos, estas figuras pueden recibir otras denominaciones, lo que puede llevar a confusión. 
participar junto al obispo de la tercia episcopal. Dentro del cuerpo de canónigos existía una jerarquía de oficio que solía ser retribuida con la posesión privativa de los diezmos de ciertas heredades, con pensiones o con otro tipo de renta, lo que les confería el estatus de dignidad catedralicia. En la cúspide del organigrama se encontraba el deán, que era quien presidía el coro y sustituía al obispo en su ausencia, y los cargos fijos necesarios para el gobierno de la catedral chantre, tesorero, maestrescuela, etc. Por su parte, la administración de la diócesis recaía en arciprestes y arcedianos cuyo número será variable en función de la extensión del obispado y de las divisiones territoriales que comprendiera. Ambos solían recibir, además de la parte que les correspondía de la tercia, una cantidad fija en trigo y cebada de todas las parroquias de su jurisdicción, lo que hacía que estos cargos fuesen económicamente muy rentables. Además, existían otras canonjías desprovistas de dignidad que presentaban mayor heterogeneidad tanto en función como en número. Las más comunes estaban vinculadas a un oficio (lectoral, doctoral, magistral, penitenciario), mientras que las que no tenían un cargo específico se regulaban en función de su antigüedad (presbiterales, diaconales y subdiaconales).

Además, en todas las catedrales existían otros clérigos de menor categoría - raciones - encargados de atender el culto y asistir al coro, como si se tratase de una iglesia parroquial. A ellos les correspondía íntegramente el diezmo de la localidad en la que se encontraba la sede episcopal y el de sus poblaciones anejas, pero no solían participar de la tercia a menos que los capitulares les hubieran cedido de manera específica una parte. Estas raciones podían ser enteras, medias o cuartas por lo que el reparto del diezmo parroquial se realizaba en la misma proporción. La posesión de una ración en sede episcopal constituía un punto de partida privilegiado para acceder a una canonjía ya que tenían preferencia a la hora de promocionar. Este grupo de beneficiados catedralicios fue consolidando su posición en el cabildo y aumentando sus competencias hasta llegar a asimilarse en todo a los canónigos, excepto en la procedencia de sus rentas.

Por último, este grupo tampoco se debe confundir con el elevado número de clérigos privados - beneficios a título de patrimonio y capellanes- que prestaban sus servicios en el recinto de la catedral. Estos no tenían derecho ni al disfrute de los diezmos ni a los ingresos 
devengados de la celebración de misas, perpetúales o funerales, sino que vivían de la renta establecida en su fundación.

Las colegiatas tenían un organigrama similar al de las catedrales, aunque con número de dignidades inferior y mayor diversidad en la casuística de la participación decimal. Por regla general, se les adjudicaban los diezmos de una determinada área próxima al templo, aunque a veces se les asignaba un pequeño porcentaje del diezmo de las principales especies en algunas localidades en calidad de préstamos realizados por el resto de la clerecía. ${ }^{18}$

Durante el siglo xviI, las congregaciones del clero de Castilla realizaron varias valoraciones económicas de sus ingresos decimales con objeto de reclamar a la Corona una reducción de la presión fiscal que pesaba sobre ellos. Gracias a ellas se puede conocer la estructura de la jerarquía de cada obispado y el montante líquido de sus rentas (tabla 1).

Por provincias eclesiásticas, destaca el poderoso arzobispado de Toledo que abarcaba un amplísimo territorio que se extendía por el centro de la Península desde Valladolid y Osma, al norte, hasta Córdoba, Jaén y Cartagena, al sur. A pesar de no presentar una gran densidad parroquial, su enorme extensión territorial le permitía mantener 87 dignidades, 227 canónigos y 214 raciones con las rentas medias más altas de la clerecía castellana. En orden descendente por nivel de renta le sigue el arzobispado de Sevilla, que con un territorio mucho más reducido consigue unos promedios de renta muy similares. También merece destacarse el caso del arzobispado de Santiago, que agrupaba 13 obispados a lo largo del camino de la plata, concentrando el mayor número de capitulares y parroquias de la Península. Sea cual fuere su número o dotación económica, es de destacar que, en todos los casos, el valor de las rentas de los obispos castellanos equivalía aproximadamente al $10 \%$ de las que

18 En muchas diócesis, a los beneficiados con derecho a diezmo, pero sin ocupación pastoral concreta, se les denomina préstamos o beneficios prestimoniales. En origen, se utilizaron por obispos y cabildos para premiar la fidelidad y confianza de un clérigo; pero finalmente se utilizaron para primar a un clero clientelar afín a quien lo otorgaba. En la diócesis de Toledo los arcedianos obtienen préstamos como complemento de sus ingresos. En la de Cuenca existían muchos préstamos sin adjudicar de manera personalizada por lo que el cabildo los arrendaba a terceros (Ayllón, 2010: 193). 
Tabla 1. Número y retribución media del alto clero castellano en 1630

\begin{tabular}{|c|c|c|c|c|c|c|c|c|}
\hline \multirow{2}{*}{$\begin{array}{c}\text { Provincias } \\
\text { eclesiásticas } \\
\text { (archidiócesis) }\end{array}$} & \multirow{2}{*}{$\begin{array}{c}\text { Pilas* }^{*} \\
\text { N.o }\end{array}$} & \multicolumn{2}{|c|}{$\begin{array}{c}\text { Obispos } \\
\text { (a) }\end{array}$} & \multirow{2}{*}{$\begin{array}{c}\text { Dignidades y } \\
\text { canónigos } \\
\text { N. }\end{array}$} & \multirow{2}{*}{$\begin{array}{c}\text { Raciones } \\
\text { N.o }\end{array}$} & \multicolumn{2}{|c|}{$\begin{array}{l}\text { Cabildos } \\
\text { Catedrales } \\
\text { (b) }\end{array}$} & \multirow[t]{2}{*}{$\begin{array}{c}\text { Renta } \\
\text { b/a }\end{array}$} \\
\hline & & N. ${ }^{\circ}$ & $\begin{array}{l}\text { Renta } \\
\text { duc. }\end{array}$ & & & N. ${ }^{\circ}$ & $\begin{array}{c}\text { Renta } \\
\text { duc. }\end{array}$ & \\
\hline León & 1.020 & 1 & 12.000 & 95 & 20 & 115 & 120.000 & 10,0 \\
\hline Oviedo & 1.000 & 1 & 12.000 & 33 & 12 & 45 & 120.000 & 10,0 \\
\hline Santiago & 5.781 & 13 & 21.231 & 440 & 153 & 593 & 201.538 & 9,6 \\
\hline Burgos & 4.743 & 4 & 27.500 & 198 & 92 & 290 & 292.500 & 10,6 \\
\hline Toledo & 2.912 & 9 & 57.111 & 314 & 214 & 528 & 466.667 & 9,8 \\
\hline Granada & 291 & 3 & 17.333 & 43 & 26 & 69 & 153.333 & 9,2 \\
\hline Sevilla & 406 & 4 & 44.000 & 116 & 56 & 172 & 412.500 & 9,6 \\
\hline
\end{tabular}

Nota. ${ }^{\star}$ Pilas equivalen a parroquias, aunque existen algunas que poseen dos o más pilas.

FuENTE. Elaboración propia sobre datos citados por Aldea (1973: 23)

percibían las dignidades, canónigos y racioneros de su catedral. En la corona de Aragón este porcentaje debió ser menor si atendemos a la distribución decimal del País Valenciano en la que la parte del obispo suponía la mitad del tercio (Torró, 2018).

Todos los autores que han analizado la renta de los obispos están de acuerdo en señalar que al menos el $80 \%$ de estas procedía de la parte del diezmo que les correspondía de las parroquias que estaban en los límites de su jurisdicción. Solo quedan por debajo de este porcentaje el obispado de Calahorra y La Calzada, que está en torno al $65 \%$ al no percibir tercias del País Vasco (Catalán, 2004a y 2010); los obispados gallegos, cuyas rentas decimales oscilan entre el $54 \%$ de Mondoñedo y el 10 \% de Santiago de Compostela (Rey Castelao, 1992); y la mayoría de los catalanes ya que la mayor parte de los diezmos o eran propiedad de legos o los derechos devengados por la comercialización de los granos tenían mucho peso (gráfico 1).

En el reparto del diezmo entre los capitulares encontramos dos modelos básicos, que pueden presentar variaciones. En el primero, los canónigos y el obispo participaban de todas las cillas de su circunscripción en porcentajes variables; en el segundo, a cada uno de ellos se le adjudicaba de manera específica la tercia de determinadas 
Gráfico 1. Porcentaje que representa el diezmo en las rentas de los obispos



Fuente. Elaboración propia según los datos que ofrece Ibáñez (1999: 244).

localidades. En cualquiera de estos casos se debe prestar especial atención a la calidad, cantidad y especies que le corresponden a cada beneficiario, ya que bajo una aparente distribución igualitaria se esconden grandes diferencias que marcan el lugar que ocupa el individuo en el organigrama de la diócesis.

José Manuel Latorre (1990: 33-34), en su análisis del obispado de Teruel, advertía que los porcentajes locales que correspondían a cada canónigo podían inducir a engaño puesto que no era lo mismo percibir el $50 \%$ del diezmo en un pueblo con una producción de 1.000 fanegas de cereal que la misma proporción de otro cuyo rendimiento fuese de 200 fanegas. De manera similar, no será lo mismo percibir la tercia de una localidad con tierras de primera calidad o cultivos con alto valor añadido como el vino, que en otra con suelos pobres y economía de montaña. Cabe suponer que el reparto porcentual o geográfico se debió establecer teniendo presentes los datos reales de recaudación decimal en el momento en el que se realizó la distribución y que, sin duda, tuvo que atender a consideraciones de tipo edafológico, calidad y productividad de los suelos. Sin embargo, hay que tener en cuenta que, en la mayoría de los obispados, esta 
se estabilizó en tiempos de los Reyes Católicos o, como muy tarde, durante la reorganización eclesiástica del reinado de Felipe II. Por tanto, las variaciones estructurales que se produjeron en los cultivos durante los siglos XVII y XVIII debieron afectar de manera importante la valoración de los diezmos y, por tanto, la retribución de los eclesiásticos.

El caso del área riojana del obispado de Calahorra y La Calzada puede ilustrar este problema. El obispo llevaba entre el 8 y el $9 \%$ de los diezmos de la diócesis como resultado de su participación en porciones variables de muchos hórreos. Su cuota era mayor en las zonas cerealistas y ganaderas que en las vinateras, más alejadas de la sede episcopal, siendo frecuente que tomase distintas proporciones en un mismo pueblo, en cuyo caso siempre percibía mayor cantidad de cereal que de vino. La parte del obispo se veía menguada por la cuota fija en cereal que debía ceder al arcediano más los gastos de almacenaje, contaduría y distribución de los diezmos que eran más onerosos que los de las parroquias (Ibáñez, 1999: 245-246). En cuanto a los canónigos, su renta variaba enormemente según estuviesen adscritos a la catedral de Calahorra o a la de La Calzada, ya que esta diócesis tenía doble sede con cargos intercambiables. A los que componían el cabildo de La Calzada les correspondía una cuarta parte del diezmo de las iglesias cerealistas de La Rioja alta, aunque en realidad su participación global estuvo en torno al $23 \%$ debido a que en esta zona se encontraban los monasterios de San Millán, Valvanera o Nájera que percibían directamente los diezmos de sus propiedades o pagaban una cantidad simbólica. Por su parte, los de la catedral de Calahorra tenían derecho a un tercio - que finalmente supuso entre el 25 y el $29 \%$ - de los diezmos de las principales localidades vinateras del valle del Ebro, de las ganaderas de la sierra de Cameros y de las cerealistas de La Rioja media y baja. Las desigualdades en el reparto también afectaban las especies que componían su acerbo decimal. Obispo y canónigos no participaban de los llamados menudos ni de algunas especies menores por ser privativas del clero parroquial. Tampoco tenían derecho a aquellos productos que presentaban problemas de partición y almacenamiento y que, por tanto, se acostumbraba a ceder a los beneficiarios locales. Esta distribución afectó directamente la importancia que tuvo la renta decimal en cada una de las sedes catedrales: el $84 \%$ de la retribución 
para los canónigos de Calahorra y el 66 \% para los de La Calzada. A estas desigualdades de origen se deben añadir las producidas por las variaciones en la estructura de los cultivos del siglo xvin y que afectaron de manera diferente cada uno de los cabildos catedralicios. El viñedo había sido abandonado en el entorno de Santo Domingo de la Calzada, siendo sustituido en muchos casos por cebada, mientras que en la ribera alta del Ebro se había convertido en monocultivo con destino a los mercados castellanos y vascos. Esta especialización productiva afectó profundamente las rentas del obispo, que percibía una porción insignificante del diezmo de vino, y a los canónigos de La Calzada; mientras que los que servían en Calahorra salieron beneficiados (Catalán, 2010 y 2018).

En líneas generales, y a pesar de las desigualdades, las rentas que percibían los canónigos de las catedrales fueron más que suficientes para llevar una vida de acuerdo con su estado, o al menos eso fue lo que transmitieron los obispos electos al informar sobre el estado económico de las prebendas de sus diócesis (Barrio Gozalo, 2010a: 164). Sin embargo, en la segunda mitad del siglo XVIII, la crisis agraria propició el fraude y las ocultaciones a la hora de pagar el diezmo afectando de forma negativa los ingresos del clero de las diócesis con mayor dependencia del diezmo como las andaluzas, las de la Mancha o las de Valencia.

\section{2. 2. El clero parroquial}

Las diferencias numéricas y económicas entre el bajo clero son mucho más acusadas que las observadas entre los miembros de los cabildos catedralicios debido a la disparidad en la ratio de feligreses por cura y a la diversidad en la porción del diezmo que les corresponde. No debemos olvidar que, al igual que sucede en las catedrales o colegiatas, en las parroquias, sean urbanas o rurales, conviven dos realidades que se superponen, se mimetizan y a menudo se confunden por su similitud semántica: los clérigos que tienen derecho a la percepción de una parte del diezmo y aquellos cuya dotación económica procede de una fundación particular. Solo los primeros forman parte stricto sensu del clero parroquial ya que son la capacidad económica de la parroquia — composición y calidad del 
dezmatorio-y sus necesidades de culto - tamaño de la poblaciónlos factores que determinan su número y la calidad de los beneficios. Normalmente, era el obispo el que establecía la composición de los cabildos de cada parroquia y el número de estas, aunque también los hubo que, por diversas razones, tuvieron autonomía plena en esta cuestión o aquellos que se configuraron según la voluntad del propietario o usufructuario de la iglesia. ${ }^{19}$ No obstante, unos y otros fueron variando a lo largo del tiempo, ajustándose a las diferentes coyunturas.

A partir del siglo $\mathrm{xv}$, el crecimiento de la población disparó la demanda de servicios religiosos, problema que se solucionó de muy diversas maneras. En aquellas diócesis en las que los derechos decimales de los obispos eran compartidos, se tendió a desmembrar las parroquias más extensas en varias unidades autónomas de menor tamaño. ${ }^{20}$ En cambio, en aquellas en las que la jerarquía percibía un porcentaje importante del diezmo, las nuevas necesidades de culto se cubrieron con la creación de anejas, llamadas también sufragáneas, con las mismas funciones que una parroquia - poseían un dezmatorio, estaban abiertas al culto y, la mayoría, tenían pila bautismal y enterramiento- con la salvedad de que sus clérigos formaban parte del cabildo de la iglesia más antigua o matriz. Esto explica que muchas diócesis de la mitad sur de la Península tuvieran un número tan bajo de parroquias y que solo el $26 \%$ de los beneficiados tuvieran asignada la cura de almas. ${ }^{21}$ El caso más extremo lo encontramos en la diócesis hispalense donde no hay registrado ningún cura ya que era el arzobispo el único que tenía asignadas funciones pastorales, y cumplía su función por delegación,

19 En el obispado de Calahorra se las denominaba receptivas - sujetas a la regulación del obispo-, numeradas - número fijo establecido por el cabildoy de patronato - el patrón nombra a los clérigos que quiere. Véanse Catalán (2015) e Ibáñez (1994).

20 En la Constitución sinodal de Vitoria de 1410, se obliga a las iglesias urbanas con jurisdicción en las aldeas a dotar específicamente a un clérigo en los lugares que tuvieran 10, 15 ó 25 pobladores casados o más, citado en MAÑARICÚA (1950: 168).

21 En la provincia de Burgos había 1 párroco por cada 360 feligreses; en la de León, 1 por cada 213; en Álava, 1 por cada 154; en Córdoba la proporción era de 1 por 1.990, y en Canarias se llegó a la cifra de 1 por 6.000 (Domínguez Ortiz, 1981: 533). 
a través de clérigos designados a voluntad - amoviles. Estos no tenían derecho a diezmo y su única retribución procedía de los derechos devengados por su trabajo - pie de altar y funerales- (Barrio Gozalo, 2010a: 59; Candau, 1994)

El concilio de Trento dispuso que en todas las parroquias tenía que haber al menos un clérigo residente con cura de almas para garantizar la asistencia espiritual de los fieles. Para las parroquias que eran servidas por delegación se determinó la promoción de uno de los beneficios simples. Esta medida no tuvo mucho éxito. En algunas diócesis, como la de Córdoba, adujeron falta de candidatos debido a la cortedad de las rentas y, en otras, como la de Sevilla, esta medida contó con la oposición de los perceptores de los diezmos ya que consideraban lesionados sus derechos históricos (Barrio Gozalo, 2010a: 60) En las diócesis del norte, especialmente las de Burgos, Calahorra, Palencia y Valladolid, los beneficios instituidos y dotados con cura de almas eran más abundantes pero debían ser patrimoniales, es decir, el candidato o su familia tenía que ser oriundo de la parroquia en la que pretendía servir. Normalmente, el curato era ejercido por uno de los beneficios que componían el cabildo parroquial, y se designaba de varias maneras: por el de mayor antigüedad y jerarquía, de forma rotatoria; o por designación del obispo, entre aquellos que estuvieran más capacitados por el puesto. Sirva como ejemplo la forma de proceder en el obispado de Calahorra y La Calzada en que la cura de almas la ejercía el beneficiado más antiguo y, por ello, percibía una sexta parte del diezmo de lo que le hubiese correspondido al beneficiado entero, aunque no siempre incluía todas las especies del dezmatorio.

En paralelo, la mayoría de los cabildos necesitaron ampliar su capacidad para dar respuesta al fortísimo incremento en la demanda de misas y perpetúales, pero sin alterar la dotación económica de cada beneficio. Para hacerlo posible, se recurrió a una práctica que había sido frecuente durante la Edad Media pero que había caído en desuso durante la crisis del siglo xiv: la creación o provisión de beneficios con la mitad o la cuarta parte de la renta que le hubiera correspondido de haberse instituido normalmente (Martín 2005: 697 y Catalán, 2004a: 152-162). Así por el coste de un beneficiado entero se obtenía el servicio de dos clérigos que solo percibían la mitad de los diezmos, pie de altar y derechos funerales. Algunas 
diócesis, especialmente las del sur del río Duero, abusaron de este sistema generando beneficios simples sin carga de residencia ni de servicio, fraccionando la participación del diezmo hasta límites ridículos - sextas, novenas o dozavas de ración. De esta manera, la mayor parte de las obligaciones de los beneficiados enteros eran cubiertas por los de menor rango y, más frecuentemente, por los expectantes o aspirantes que no tenían ningún derecho sobre las misas y oficios, ni tampoco entraban en el reparto de los diezmos mayores; tan solo percibían un pequeño salario y la parte que les correspondía del acervo común cuando todas las necesidades de los miembros capitulares estaban cubiertas. Esta situación produjo un notable desequilibrio entre las rentas percibidas y el trabajo realizado sin que el producto de los diezmos llegase a cubrir los gastos del clero parroquial. ${ }^{22}$ La incongruidad de los beneficios se toleraba, y aun justificaba, por el hecho de que percibían los ingresos inherentes a su oficio que se suponía les reportaban una cantidad similar e incluso superior a la del diezmo (Morgado, 2000: 82).

Este sistema de gradación beneficial propició una gran acumulación de beneficios, lo que en ocasiones se ha confundido con un alto nivel de absentismo. Un eclesiástico podía poseer y servir dos o más beneficios, siempre y cuando lo permitiese la constitución del mismo y, obviamente, la proximidad geográfica. Sin embargo, lo más frecuente era que ocupase personalmente uno de ellos, y no necesariamente el de mayor renta, y delegara el servicio del resto a un tercero al que debía pagar un salario o ceder una parte de la renta correspondiente al beneficio ocupado. Desde un punto de vista práctico, este sistema no afectó el correcto funcionamiento de las parroquias, siempre y cuando el servicio fuese cubierto por una persona cumplidora y capaz. Sin embargo, contribuyó al crecimiento desmedido de clérigos mal retribuidos, con escasa formación y muy

22 Los gastos más importantes de un párroco provienen de la alimentación y el vestido; personal de servicios (un criado y un ama), caballerías, etc. Todo ello ascendía en Segovia a mediados del siglo xvin a unos 5.000 reales de vellón (Barrio Gozalo, 1982: 433-435) y a unos 6.600 en Cádiz (Morgado, 2000: 92). 
dependientes de las élites locales, especialmente en los lugares donde predominaba el clero patrimonial. ${ }^{23}$

El gráfico 2 muestra las consecuencias económicas de este sistema beneficial: en la mayor parte de las diócesis, la retribución del clero parroquial queda muy por debajo del tercio que se había estipulado en Trento para los servidores. En líneas generales, se puede afirmar que, en el reparto teórico del diezmo, la retribución del clero parroquial guarda una relación inversamente proporcional a la destinada al mantenimiento de la élite diocesana: los beneficios que servían en las diócesis que se configuraron en la última etapa de la Reconquista percibieron un porcentaje menor de diezmo que los que pertenecían a sedes más antiguas.

Gráfico 2. Distribución porcentual de los diezmos correspondientes al clero parroquial (siglo xVIII)

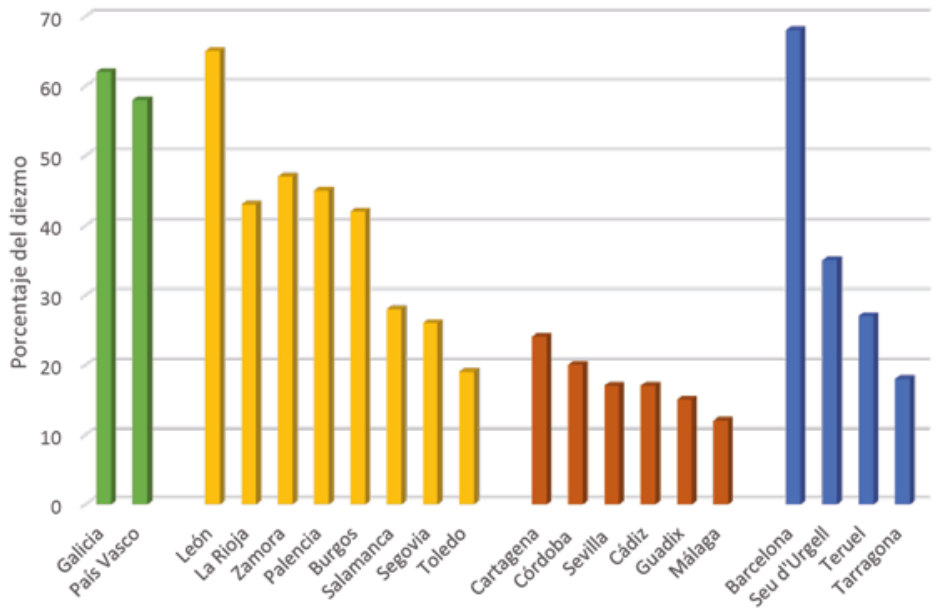

Fuente. Elaboración propia. Véanse las notas del texto.

23 A mediados del siglo xvi, en la diócesis de Calahorra y La Calzada, la renta de estos beneficios era tan pequeña que era necesario acumular al menos dos raciones para alcanzar el mínimo de 12.000 maravedís estipulados por el obispado como estipendio de la ración entera servida (Catalán, 2013: 57). 
En los obispados gallegos, el clero parroquial percibía un promedio del $60 \%$ de la masa decimal, aunque este porcentaje esconde grandes diferencias internas: en un extremo se encontraban los clérigos orensanos que percibían el $75 \%$, y en el otro, los de las parroquias del litoral cantábrico, con una participación menor al $10 \%$ (Rey Castelao, 1992: 149). La razón de esta disparidad la encontramos en las reservas de cupos de diezmos, e incluso de parroquias enteras, realizadas por los arcedianos de las iglesias catedrales o sus cabildos, especialmente el de Santiago de Compostela.

En el norte del país, en una franja que abarca desde Asturias a Gerona, el clero parroquial tuvo una escasa participación en la masa decimal debido a la pervivencia de los derechos de patronato laical. Este fenómeno fue mucho más acusado en las parroquias vascas pertenecientes al obispado de Calahorra ya que no se integraron plenamente en la estructura diocesana y, por tanto, no contribuían al mantenimiento de su jerarquía. Sin embargo, la pervivencia de derechos señoriales motivó que, en la práctica, el clero vasco estuviera desigualmente retribuido: en Vizcaya, los patrones se beneficiaron de casi la mitad de los diezmos, mientras que en Guipúzcoa este porcentaje estuvo en torno al $35 \%$. Tanto en las diócesis de Burgos como en la de Calahorra, los clérigos que no estuvieron sujetos al régimen laical tenían unas condiciones de vida mucho mejores al corresponderles en torno al 40 \% de lo diezmado (Fonseca, 1992: 120-121; Ibáñez, 1994: 216). En el obispado de Pamplona se vivía una situación similar ya que, en este caso, el obispo era propietario de muchas iglesias de las que detraía la totalidad del diezmo y otras las había donado a los respectivos municipios para el mantenimiento del clero parroquial. Del resto, percibía una cantidad variable que oscilaba entre la cuarta y la octava parte o una cantidad fija de frutos decimales en especie (Barrio Gozalo, 1988: 49 y 199).

En Castilla, solo los curas leoneses se beneficiaron ampliamente del diezmo. En León, existió una estrecha relación entre el poder concejil, y su control sobre la parroquia, y el nivel de participación de los curatos en los diezmos. El 65 \% del clero local percibía la totalidad de los diezmos mayores, cobertura que se extendía al $100 \%$ en el caso de los diezmos menores (Rubio, 2013: 153). A medida que se desciende hacia el sur, el porcentaje de diezmo destinado a mantenimiento del clero parroquial va reduciéndose en la misma proporción en la que 
aumenta la cantidad detraída por obispos y canónigos. Así, en Segovia el tercio se repartió de manera desigual entre los beneficios curados, quienes percibieron en torno al $26 \%$, y los simples, a los que solo les correspondió el $8 \%$; en Toledo, los curados apenas alcanzaron el 18,6\%, mientras que en muchos pueblos de Castilla la Nueva ni siquiera se mencionan entre los beneficiarios del diezmo (Barrio Gozalo, 1982: 398; Donézar, 1984; Salomon,1982: 225-227). Una situación especial se vivía en las diócesis extremeñas, de Coria y Badajoz, cuyo clero se tuvo que enfrentar con los miembros de las órdenes militares y grandeza de España que poseían amplios derechos sobre el territorio (Melón Jiménez, 1987 y Rodríguez Cacho et al., 2004).

En Andalucía la situación del clero parroquial fue más precaria si cabe ya que algunos obispos, como el de Sevilla, disfrutaron en exclusiva de la cura de almas, aunque de facto la ejerciera un clérigo con licencia de confesión. A estos se les reservaba el usufructo de las primicias, algo más del $2 \%$, y el estipendio de las limosnas que ofrecían los fieles durante los oficios, que rara vez alcanzaban para llevar una vida digna (Barrio Gozalo, 2010a: 84). Por contra, los beneficios simples percibían un exiguo $15 \%$, lo que era mucho si lo comparamos con las condiciones de los curados. En el resto de Andalucía la situación del clero parroquial era similar: en Córdoba recibía el 20 \% de los diezmos; en Cádiz, el 17 \%, y en Málaga, tan solo el 12 \% (Muñoz Dueñas, 1988; Morgado, 1996; Benítez Sánchez-Blanco, 1978).

En la corona de Aragón, la participación del bajo clero en el diezmo también tiene fuertes desigualdades geográficas. En Barcelona percibían el $68 \%$, mientras en la Seu d'Urgell o el norte de Lleida, su porción quedaba reducida al $35 \%$, con fuertes desigualdades internas que derivaban de la presencia de numerosas parroquias de patronato laical en las que el patrón o percibía la totalidad del diezmo o lo compartía con los beneficiados en distintas proporciones (Castillón, 1988). Ya en el Mediterráneo, los curas de Tarragona apenas participaban en $18 \%$ de los diezmos mientras que, en Mallorca, los rectores solo llevaban un $19 \%$ del cuarto parroquial que les correspondía, siendo el $6 \%$ restante para los beneficios simples (Saavedra, 2009: 64 y Juan, 1989: 811) En el arzobispado de Zaragoza, la mayoría de los curatos dependían de un tercero para cobrar su estipendio: del Conde de Aranda y del convento de Trasovares, en sus dominios; de los canónigos de la Seo y del Pilar en el valle del 
Ebro; de la ciudad de Daroca al sur y de la Orden de San Juan de Jerusalén en la parte oriental. Con esta diversidad de propietarios no existió una tendencia homogénea para dotar a sus vicarios. Así, conventos, órdenes militares y dignidades zaragozanas abonaron el importe de la congrua preferentemente en metálico, mientras que los patrones laicos y las iglesias de Daroca pagaron en especie y solo en casos muy puntuales se les cedió una parte de la producción decimal (Catalán 2004b: 383). José Manuel Latorre (1990: 32) estima que, en estos casos, el clero rural de los obispados turolenses percibiría en torno al 27 \% de lo recolectado (Latorre, 1990: 32).

\section{LAS RENTAS DEL CLERO PARROQUIAL: UNA PROPUESTA DE CATEGORIZACIÓN}

Como acabamos de explicar, en el sistema beneficial es el derecho a participar de la masa decimal lo que dota de contenido económico al oficio. Por tanto, la cuantificación del valor de un beneficio constituye un elemento esencial para establecer los diferentes niveles de renta del clero secular ya que es este aspecto el que condiciona el acceso a determinados cargos eclesiásticos, la extracción social de sus aspirantes y las posibles estrategias clientelares que se generan en torno a ellos. Esta labor se ha realizado en buena medida para las élites económicas de la Iglesia, pero sigue pendiente para los niveles inferiores. Es cierto que en los últimos años se ha avanzado mucho en el conocimiento del bajo clero con excelentes monografías a nivel regional y trabajos que abordan el mundo rural desde una perspectiva holística, pero sigue pendiente una síntesis nacional que aborde la cuestión de la retribución del clero parroquial teniendo en cuenta tanto la diversidad regional como profesional. ${ }^{24} \mathrm{Mi}$ propuesta pasa por la elaboración de un ranking beneficial a escala nacional en el que se tengan en cuenta todas aquellas cuestiones que determinan la renta de los servidores: estructura de la red parroquial, alcance

24 No es mi intención citar aquí los trabajos que se han publicado en los últimos años sobre el clero secular español, entre otras cosas porque la mayoría de ellos se han ido desgranando a lo largo de este trabajo. No obstante, remito al lector al estado de la cuestión que publicó en 2016 el profesor Pegerto Saavedra. 
de los derechos de patronato, cuantificación y categorización de los servidores de cada parroquia, acumulación de beneficios, así como la estructura, composición y valoración monetaria de sus rentas. A priori, podría pensarse que un análisis exhaustivo de la documentación de una muestra seleccionada de parroquias de cada obispado nos permitiría llevar a cabo este trabajo. Sin embargo, una documentación tan atomizada hace casi imposible la labor de sistematización y análisis de la información en ella contenida. Afortunadamente, contamos con las averiguaciones de veros valores para el pago del subsidio y el excusado, realizadas con motivo de la inclusión de la Iglesia como contribuyente regular de la Hacienda Real. ${ }^{25}$ La homogeneización de los datos parroquiales de todas las diócesis permite una radiografía completa y certera del entramado del sistema beneficial y sus retribuciones, atendiendo a la diversidad administrativa y geoeconómica de cada una de las parroquias. ${ }^{26}$ Las visitas pastorales también ofrecen una información similar, aunque más atomizada, que puede servir de complemento, cuando no de sustituto, de las averiguaciones de veros valores.

El primer paso deberá ir encaminado a definir la estructura de la red parroquial, densidad y cohesión de un territorio determinado. El cálculo básico de parroquias por $\mathrm{km}^{2}$ nos permite una primera aproximación a la densidad parroquial, pero no es suficiente. Será necesario determinar el porcentaje de anejas y de matrices, porque es en estas últimas en las que reside el cabildo parroquial. Cuanto mayor sea la proporción de anejas, menor será la cohesión del territorio y peor la retribución de los servidores.

Por otra parte, será necesario completar el mapa real de los derechos de patronato a nivel nacional, ya que, de facto, esta figura no es privativa de los obispados norteños. La manera más eficiente de cuantificarlo es a través del análisis de la retribución de los

25 Sobre la concesión del subsidio y excusado, negociaciones y formas de pago, puede verse Catalán (1997).

26 Las averiguaciones han sido utilizadas fundamentalmente para estimar el producto agrario bruto: Bilbao y Fernández de Pinedo (1984) para el País Vasco; Llopis et al. (2018) para Ávila, Burgos y Salamanca, y Catalán (2018) para La Rioja. En todos estos trabajos se explicita la naturaleza y las características de esta fuente. 
servidores parroquiales. Cuando existen derechos de patronato, los servidores solo llevan una pequeña porción del diezmo, un puñado de explotaciones agrícolas o un porcentaje pequeño de algunos productos específicos, y más frecuentemente la primicia o una cantidad fija en dinero; mientras que los propietarios percibirán la mayor parte de los diezmos mayores de la localidad analizada. No hay que dejarse confundir por el hecho de que esta sea percibida por otros miembros del estamento eclesiástico, ya que como hemos visto, monasterios y sedes episcopales mantuvieron sus derechos sobre las iglesias durante toda la Edad Moderna, siendo la causa fundamental de la desigual retribución del clero parroquial en la Península.

En segundo lugar, es imprescindible cuantificar la variable demográfica ya que solo así podremos estimar la renta per cápita de los diferentes estratos del estamento eclesiástico. Para ello no solo hay que contabilizar el número total de clérigos, sino establecer con precisión la categoría beneficial a la que pertenecen. Las fuentes parroquiales y las averiguaciones de veros valores especifican el número de beneficiados de entera, media, cuarta y fracciones inferiores de cada parroquia; si sirven o no y dónde lo hacen —en la matriz o en las anejas-, y el número de beneficios simples, préstamos y capellanías que ofrecen sus servicios en el templo parroquial. Aunque en teoría el origen, la retribución y las funciones están perfectamente definidos, la posibilidad de acumular varios beneficios simples y la no obligatoriedad de residencia favorecieron que los cabildos los utilizasen para ampliar la asignación de las medias y cuartas raciones e incluso para poder promocionar a enteros (Catalán 2004a: 164). Esta práctica, que fue muy frecuente durante el siglo XVI, hay que tenerla en cuenta tanto para contabilizar el número de clérigos por parroquia como para determinar con exactitud la renta real de cada uno de ellos. Las visitas pastorales, y las averiguaciones, especifican no solo el nombre y los apellidos de los propietarios de la ración sino también el de los sustitutos, en caso de que no la sirvan personalmente, y el de los beneficios simples y capellanes. Cruzando estos datos es posible identificar a los clérigos con más de una ración en propiedad y a los que prestan su servicio en más de un beneficio. Esta operación resulta indispensable para asignar una renta real al clérigo y delimitar con exactitud el grado de absentismo 
o de acumulación de beneficios. También permitirá comparar las diferencias de renta entre el clero oficial y el privado.

Una vez que esta información está convenientemente cuantificada se pueden efectuar los cálculos pertinentes para establecer la ratio que guardan con respecto a la feligresía a la que sirven. En este sentido, hay que ser cuidadoso ya que la elección de la tipología de clérigos dependerá de lo que queramos medir. Si lo que se pretende es ver el grado de evangelización y la asistencia espiritual de los fieles, se deberá tener en cuenta únicamente a aquellos que están investidos con cura de almas ya que son los únicos que tienen potestad de administrar los sacramentos o ejercer funciones pastorales. En las diócesis en las que esta responsabilidad estaba en manos de los prelados, se debe incluir a los beneficiados en los que se delegaba esta misión, aunque no tengan específicamente esta categoría. Si lo que queremos saber es la ratio total de clérigos por parroquia o por habitante, tendremos que considerar a todas las personas con órdenes sagradas, sea cual sea su categoría profesional, pero sin incluir a los clérigos privados. Estos, aunque comparten espacio con los beneficiados en iglesias parroquiales y catedrales, no guardan relación ni con el número de habitantes ni con sus posibilidades económicas ya que responden a las condiciones de la fundación que les sustenta. Finalmente, para calcular la renta per cápita y lo que le cuesta a la comunidad mantener a su clerecía, entonces habrá que tener en cuenta únicamente el número de raciones enteras ya que este es el baremo que utiliza la Iglesia tanto para el reparto interno de diezmos y rentas como para distribuir los gastos de administración y el pago de los impuestos. Por tanto, hay que contabilizar dos raciones medias como una entera, y así sucesivamente con todas las fracciones de ración.

En tercer lugar, es necesario elaborar de manera sistemática rankings beneficiales de cada obispado que nos permitan establecer comparaciones precisas sobre los niveles de renta de las raciones enteras siguiendo criterios geoeconómicos. Solo así se obtendrá la base con la que elaborar una síntesis nacional sobre los niveles de renta del clero. ${ }^{27}$ Las averiguaciones permiten saber la composición

27 Hasta ahora, los estudios sobre niveles de renta del bajo clero son fragmentarios y muy heterogéneos en cuanto a la metodología y las bases documentales utilizadas. Solo existen estudios sistemáticos para Galicia (Rey Castelao, 1992), 
y cuantía de la renta percibida por una ración entera, así como deducir el valor de los beneficios de menor categoría. En este cálculo habrá que incluir, además del diezmo en su valoración monetaria a precios de tasa, todos los ingresos percibidos por el clérigo. Se da la circunstancia de que en los lugares donde los servidores tienen una menor participación del diezmo, los ingresos por los derechos funerales, explotación del entorno o rendimiento de censos son mucho más importantes que lo percibido por la producción agraria, tanto en términos absolutos como relativos. También tiene la ventaja de que nos permite cuantificar los ingresos de los clérigos sometidos a la jurisdicción de un patrón y cuyo estipendio se realiza con una aportación anual en dinero. Agrupando la valoración de las raciones en una distribución de frecuencias, se puede determinar cuál es el tramo más habitual y la dispersión que existe con respecto a las rentas superiores e inferiores. También podremos establecer la cantidad de clérigos que se encuentran en los límites del mínimo vital establecido por las constituciones sinodales de cada obispado y, por tanto, la necesidad de acumular beneficios o compaginarlos con fundaciones privadas para llegar a un estándar de vida aceptable.

Este cálculo no está exento de problemas. El primero es la valoración de los productos decimales a precios tasa cuando lo idóneo sería calcularla con precios de mercado. La Iglesia utilizó tanto las tasas oficiales como las sinodales, y rara vez las sobrepasó, para la valoración de sus rentas, ya que de no haberlo hecho hubieran tenido un incremento de la carga impositiva que pesaba sobre ellas. A nosotros, nos sirven para homogeneizarlas, independientemente del tipo de gestión y la capacidad de negociación en la comercialización del diezmo, hecho que constituía uno de los factores diferenciales entre los colectivos que estamos estudiando. El segundo deriva de la propia naturaleza estática de la fuente ya que solo nos muestra una foto fija del momento en el que se realiza la averiguación o la visita pastoral, lo que nos priva de conocer las fluctuaciones en el largo plazo.

Segovia (Barrio Gozalo, 1982) y el País Vasco-La Rioja (Catalán, 2010). Este último es el único que ofrece un ranking beneficial por áreas geoeconómicas con una metodología mucho más sistematizada. 
Por último, el estudio diferencial de las rentas del clero debería completarse con una estimación comparativa de su poder adquisitivo. Para ello, habría que establecer con exactitud las necesidades de gasto que tenía cada una de las categorías profesionales, tanto en lo que respecta al vestido y alimento como todo lo referente al mantenimiento y servicio de su casa. ${ }^{28}$ En este sentido, no son tan interesantes las diferencias entre alto y bajo clero sino las que se establecen entre beneficiados de similar categoría en diferentes ámbitos geoeconómicos o las que mantienen en relación con la feligresía a la que sirven.

En definitiva, el uso del diezmo como fuente documental no está agotado ni muchísimo menos. La Iglesia reproducía relaciones de dependencia que regían en la sociedad civil generando una fuerte desigualdad interna cuyos límites son difíciles de definir precisamente por la diversidad de situaciones y derechos en la percepción del excedente agrario. Por ello, el análisis de la distribución de la renta decimal en el seno de la institución permitirá establecer un parámetro homogéneo en función de la categoría profesional de cada individuo, el área geográfica en la que sirva, y el número de feligreses a los que asista.

28 Las contabilidades de conventos pueden servir como referencia para construir una cesta de consumo básica ya que ofrecen información detallada del gasto diario. 


\title{
3. LA PRODUCCIÓ AGRÀRIA AL PAÍS VALENCIÀ DURANT L'EDAT MODERNA. APROXIMACIÓ AL SEU ESTUDI A PARTIR DELS DELMES ${ }^{1}$
}

\author{
Lluís Torró Gil
}

A Manuel Ardit, in memoriam

El creixement econòmic és un dels objectes d'estudi més recurrents historiogràficament. ${ }^{2}$ El coneixement de l'evolució de variables tan significatives com la població, la producció o els preus és necessari per a la comprensió del funcionament de les societats i dels processos històrics que han anat formant-les. Tanmateix, abans de l'època estadística resulta extraordinàriament complex disposar de dades fiables que faciliten la reconstrucció de les dimensions i

1 Vull agrair la col-laboració rebuda per part de Jesús Millán i Claudio Cremades, per la seua orientació bibliogràfica sobre el bisbat d'Oriola. Així mateix, he de fer constar l'infinit agraïment acumulat durant anys amb Manuel Ardit, mestre i amic, que se'n va anar massa prompte. La redacció d'aquest text no hauria estat possible sense la seua obra i la seua ajuda, en més d'un sentit.

2 Qualsevol aproximació a aquesta qüestió hauria de partir de l'extensa contribució que va fer Pierre Vilar (1980) en el Primer Congrés d'Història Econòmica de 1960. 
l'evolució d'aquestes realitats. Per aquesta raó, els historiadors i els economistes que s'han dedicat al seu estudi han tractat d'obtenir fonts d'informació que, si més no indirectament, permeten assajar la reconstrucció de sèries d'indicadors. Per al cas de la producció agrària, els delmes - una sèrie de càrregues sobre el producte agrari, normalment proporcionals a les collites, que tenien com a destinatari original i principal l'Església- han resultat ser una font d'informació privilegiada al llarg de l'època feudal (Le Roy Ladurie i Goy, 1982).

Les recerques sobre la producció agrària valenciana abans dels voltants de 1830 han emprat, de fet, aquesta font com a base per al seu estudi. Els primers treballs sobre la qüestió al País Valencià són, com a molts altres indrets d'Europa, relativament recents. A diferència de la història dels preus, per exemple, que compta amb les aportacions de Hamilton encetades als anys 30 del segle $\mathrm{xx}$, l'estudi de l'agricultura valenciana mitjançant les fonts decimals va començar fa ara uns cinquanta anys. Atès que al territori valencià no s'han assajat reconstruccions per la via de la demanda - emprant indicadors com els preus i els salaris- $-{ }^{3}$ i que sols disposem d'algunes estimacions sobre la producció agrària fetes per contemporanis per a finals del segle XviII (Peris, 1995: 486-487), l'estudi dels delmes sembla l'alternativa més raonable per continuar aprofundint en els nostres coneixements sobre la qüestió.

El present treball pretén oferir un panorama d'allò que sabem hui sobre l'agricultura valenciana a partir de l'estudi dels delmes, i suggerir vies de recerca que puguen millorar i eixamplar aquest coneixement. Per això el text s'estructura en cinc apartats. En primer lloc, presentaré críticament la historiografia que ha emprat els delmes com a font d'informació, almenys aquella més rellevant i influent. Seguidament, dedicaré un apartat a considerar l'aportació més completa i destacada que va ser portada a terme pel malaguanyat Manuel Ardit. Continuaré amb una anàlisi sobre les potencialitats de la informació derivada de les recaptacions del delme, tractant de valorar també aquelles fonts que encara no han estat explorades o

3 Es tracta d'una metodologia definida per Allen (2000: 13-18) que parteix de la reconstrucció del consum aparent per habitant. Vegeu una breu descripció i una valoració crítica dels resultats obtinguts a partir d'aquesta metodologia a Llopis i Sebastián (2018: 2-8). 
ho han estat de manera insuficient. Abans de finalitzar, exposaré els resultats de la recerca d'abast local que jo mateix he assajat com a model de contrast. Al darrer epígraf, i a mode de conclusió, intentaré sintetitzar quines són les limitacions d'aquesta tipologia documental en el cas valencià i quines podrien ser les futures línies de recerca.

\section{L'ESTUDI DELS DELMES VALENCIANS A L'EDAT MODERNA. UNA APROXIMACIÓ HISTORIOGRÀFICA}

Probablement el primer autor que va estudiar les dades procedents del delme va ser Álvaro Castillo (1969), emprant informació obtinguda dels registres del terç delme de tres ciutats. Com observaria posteriorment Eugeni Císcar (1977), l’aproximació de Castillo resultava metodològicament molt deficient. Les seues principals debilitats es trobaven en el fet d'haver emprat xifres d'arrendaments en brut sense cap tipus de deflació i d'extrapolar els resultats de tan sols tres espais geogràfics reduïts a l'àmbit del conjunt del país.

De forma quasi paral-lela, l'historiador britànic James Casey va emprar els registres del delme en la seua important recerca sobre el País Valencià al segle XviI. ${ }^{4} \mathrm{~A}$ més de la informació recollida $\mathrm{i}$ exposada en el llibre (Casey, 1981: 78-92), va participar en l'enquesta proposada per Joseph Goy i Emmanuel Le Roy Ladurie en el Setè Congrés d'Història Econòmica celebrat a Edinburgh el 1978 (Le Roy Ladurie i Goy, 1982). Encara que no va ser l'única contribució sobre l'agricultura valenciana que utilitzava com a font els delmes — també hi va participar José Miguel Palop (1982) amb un estudi fet sobre l'agregació de les sèries de 10 delmaris entre 1600 i 1800_, va resultar sens dubte la més completa i influent (Casey, 1982).

El treball de Casey es va recolzar, d'una banda, en la informació recollida de l'Arxiu de la Catedral de València (ACV) sobre els arrendaments de les parts bisbals del delme, i, d'una altra, en els registres del terç delme conservats a l'Arxiu del Regne de València

$4 \quad$ La seua recerca va ser objecte de publicació el 1979 sota el títol de The Kingdom of Valencia in the Seventeenth Century (Casey, 1981), però prèviament ja havia esbossat algunes de les seues conclusions més cridaneres en un parell d'articles publicats amb antelació (Casey, 1971; 1976). 
(ARV). Com la de Palop, la contribució de Casey era un treball rigorós que va eludir els barroers errors que havia comès Castillo amb anterioritat. ${ }^{5}$ L'estudi dels arrendaments deflactats de les parts bisbals va servir per descobrir les grans línies d'evolució de la producció agrària i ramadera, i la documentació, menys general però puntualment més completa, del terç delme, li va permetre dibuixar l'estructura de la producció, així com l'establiment d'una clara diversitat regional dins del mateix país.

El treball es va limitar als segles XVI i XVII, amb una especial incidència en aquest darrer. Les conjuntures dibuixades pels arrendaments deflactats dels delmes de l'arquebisbat de València mostraven un fort auge des de 1500 fins a 1570. Al llarg d'aquesta dècada semblava produir-se una crisi que provocaria la neutralització del creixement a les dècades següents. El veritable punt d'inflexió, però, es va situar el 1609 amb l'expulsió dels moriscos. Des d'aquesta data es constata una forta caiguda, intensificada des de 1620, que no es va aturar fins als voltants de 1650. La resta del sis-cents va estar marcada per una recuperació que, tanmateix, el 1700 encara no havia tornat a assolir els nivells màxims observables abans de 1610. De la mateixa manera, la conjuntura ramadera mostrava les mateixes tendències de l'agrícola però amb una sensible diferència pel que fa a la seua intensitat. La ramaderia creixeria a un ritme molt més dèbil que l'agricultura durant el cinc-cents, per a recuperar-se més d'hora i més intensament durant la centúria següent. El balanç final, però, mostrava un retrocés relatiu a llarg termini de la ramaderia respecte a les produccions obtingudes del conreu directe de la terra.

Pel que fa a l'estructura de la producció, la principal conclusió de Casey va ser la constatació d'un aclaparador pes dels cereals en el conjunt del valor agrari, al voltant d'un $70 \%$, sense massa diferències ni en el temps ni en l'espai. Això va conduir l'autor britànic a afirmar que, sauf en céréales, l'agriculture du Levant espagnol (pourtant réputé si fertile) était assez pauvre (Casey, 1982: 333). Tanmateix, a les seues taules regionalitzades (Casey, 1982: 332-333) s'apreciava certa especialització i diversificació. Així, el vi hi destacava amb claredat

5 De tota manera, vegeu les crítiques d'Ardit (1987: 291) a aquests autors, particularment adreçades a alguns errors comesos per J. M. Palop. 
a les zones que ell anomenava Plaine de Sagunto - 20,23\% del valor total- i al Centre-Ouest -12,87 \%—; a la Plaine de Sagunto, també s'hi podia veure la importància del cànem -9,56\%—; l'arròs tenia un pes considerable a Játiva et vallée d'Albaida - 16,52\%— i a la Ribera del Júcar -11,38 \%-; aquesta darrera destacava també per la seda -20,41 \%—; les ametlles sobresortien a La Marina -12,48 \%—, i, finalment, resultava cridanera la presència generalitzada de la dacsa, que assolia una proporció significativa al Sud-Ouest -6,09\%.

Junt amb el mensyteniment d'aquestes evidències que conduïa a una interpretació força esbiaixada, el treball de Casey també mostra algunes debilitats metodològiques. La més important és que, tot i reconéixer l'existència de taxacions diverses segons els delmaris i les produccions, no sembla haver-les pres en consideració per als càlculs. No hi ha res als seus treballs que ens aclarisca aquest extrem, que podria haver conduït a subvalorar collites tan importants com la fulla de morera per a criar els cucs de seda. ${ }^{6}$

La idea d'una agricultura relativament endarrerida també es trobava subjacent a l'altra gran contribució que, gairebé simultàniament, va veure la llum als darrers anys de la dècada de 1970: la d'Eugeni Císcar (1977: 43-55). La seua anàlisi, limitada al s. XVI i les primeres dècades del XVII, es va basar en la informació extreta d'una mostra dels arrendaments de 10 delmaris de pa e vi de l'arquebisbat de València. Va recollir 9 talls temporals entre $1503 \mathrm{i}$ 1609 i en va oferir el valor dels arrendaments sense deflactar, però els va comparar amb l'evolució dels preus. Aquesta informació ratificava la impressió obtinguda d'altres fonts sobre el creixement del segle XVI. Paral-lelament, l'ús d'una mostra de la gestió directa del terç delme del rei a 20 localitats entre 1590 i 1627 li va permetre aproximar-se a l'estructura de la producció en termes de valor i, en el cas dels cereals, en espècie. D’aquesta observació en deduïa conclusions semblants a les de Casey sobre una agricultura endarrerida: per a ell, l'enorme pes dels cereals — i del forment, dins d'aquests — i la relativa diversificació complementària significaven que ens trobàvem davant d'una agricultura caracteritzada aclaparadorament per l'autoconsum.

6 La fulla de morera sols contribuïa amb 1/30 del seu valor; això significa que si els càlculs de Casey no han tingut en compte aquesta qüestió caldria augmentar-ne el pes en prop del doble. 
Tots aquests treballs —així com els d'Ardit que comentaré més avant-s'han basat, per a l'estudi de les parts bisbals, en la informació obtinguda de l'Arxiu de la Catedral de València. Això significa deixar de banda una part significativa del territori valencià: les comarques del sud -l'Alacantí, les Valls del Vinalopó i el Baix Segura-, Aiora i pràcticament totes les comarques situades al nord de Sagunt. ${ }^{7}$ Els registres de les batllies reials de la gestió del terç delme, per les seues característiques, que també comentarem després, no permeten cobrir totalment aquesta deficiència. Això deixa fora d'observació les comarques del nord, repartides entre la petita diòcesi de Sogorb i la de Tortosa - molt més gran-a l'època moderna, atès que no disposem d'estudis que hagen emprat les fonts decimals d'aquests bisbats.

La situació millora certament a les comarques del sud, on els delmes de la diòcesi d'Oriola — separada de Cartagena el 1564- sí que han estat objecte d'estudis. La principal font ha estat el treball de Juan Antonio Ramos (1980) que va publicar els valors en brut dels arrendaments i, agrupada per quinquennis, la recaptació en espècie d'ordi - la principal collita de la zona - i forment (Ramos, 1980: 82-298). La seua anàlisi conté greus errors metodològics i la forma de presentació de les dades en brut dificulta extraordinàriament una reconstrucció fiable sobre la qual estudiar l'evolució de la producció. D’una altra banda, Gregorio Canales $(1981,1988)$ ha emprat rigorosament les recaptacions en espècie de cereals provinents de la mateixa documentació. L'altra font emprada ha estat l'anomenat tercio de fábricas, que era el terç delme cedit pel rei a diverses parròquies de la zona per al seu manteniment; Armando Alberola (1984: 253-257) en va fer ús per al seu treball sobre Alacant, així com va utilitzar els delmes cedits per l'Església al rei per a la construcció $i$

$7 \quad$ Els poc més de $13.000 \mathrm{~km} 2$ que aplega actualment l'arquebisbat equivalen al $56 \%$ del total del territori valencià. Les demarcacions han sofert importants modificacions - particularment el 1957- però el balanç entre pèrdues i guanys no resulta gaire significatiu en termes territorials, encara que probablement sí en termes demogràfics i econòmics - particularment per la cessió de l'arxiprestat de Xixona i els de la Marina Baixa a la diòcesi d'Alacant-Oriola. De les dades del Cens de Floridablanca (https://www.ine. es/prodyser/pubweb/censo_floridablanca/tomo6.pdf; consultat el 30/7/2019) se'n desprén que el territori que cobreix la informació decimal de la diòcesi de València deixa fora d'observació un terç del conjunt de la població del País Valencià de 1787. 
el manteniment del pantà de Tibi. ${ }^{8}$ De tots aquests estudis se’n desprén que l'evolució conjuntural no mostra grans diferències amb el que s'ha anat coneixent per al conjunt del País Valencià.

\section{L'EVOLUCIÓ DE LA PRODUCCIÓ AGRÀRIA VALENCIANA DURANT ELS SEGLES XVI, XVII I XVIII: LA RECERCA DE Manuel Ardit}

A l'hora de presentar una síntesi sobre el que s'ha avançat en l'estudi de les fluctuacions generals i territorials de la producció agrària valenciana a l'edat moderna, cal recórrer als estudis de Manuel Ardit, que va començar a treballar amb aquesta font ja en el marc de la seua tesi doctoral (Ardit, 1975; 1977: 20-24). La seua recerca s'ha centrat en els registres de l'ACV sobre els arrendaments de les parts bisbals, així com en bona part de la documentació de plets sobre la recaptació dels delmes - a partir dels registres conservats a l'Arxiu del Regne de València- al segle XviII. A través de diferents publicacions va anar exposant la seua recerca (Ardit, 1989; 1993; Ardit i Pérez García, 1988), destacant des del punt de vista interpretatiu i metodològic el seu article «Expulsió dels moriscos i creixement agrari al País Valencià» (Ardit, 1987).

Aquest treball suposa un trencament amb les interpretacions tradicionals que veien l'agricultura valenciana moderna com un sector endarrerit i entorpidor del procés de transició cap al capitalisme industrial. Per a posar dempeus la seua proposta, Ardit va començar per aplicar una metodologia rigorosa en el tractament de les dades procedents dels arrendaments dels delmes. El seu objectiu era la construcció de diverses sèries agregades per tal d'aproximar-se a dues realitats: l'evolució global i les disparitats regionals. Les claus de la reconstrucció rauen, en primer lloc, en una extrema cautela a l'hora de fer les agregacions, prenent en compte les variacions dels delmaris - agregacions, desagregacions, introducció de noves contribucions, etc. En segon lloc, a més, calcula les agregacions a

8 José Ojeda (Ojeda Nieto, 1997) també ha estudiat el terç de fàbriques de la diòcesi d'Oriola, com comentaré després. 
partir d'índexs que li permeten minimitzar les distorsions generades pels buits existents a la documentació. Finalment, presenta totes les dades deflactades amb els índexs de les mitjanes mòbils dels preus del forment de València ciutat.

La hipòtesi bàsica de la qual parteix Ardit és que l'expulsió dels moriscos no va ser la responsable del fracàs de la industrialització valenciana i que, més encara, la recuperació d'aquest esdeveniment traumàtic va suposar canvis en la distribució de la població i dels seus recursos, que enceten o reforcen la concentració de la riquesa a les planes litorals - un procés que, com reconeix el mateix Ardit, s'allarga fins al present- (Ardit, 1987: 274-275). Els canvis suposarien la creació d'un nou model agrari, progressivament diversificat i orientat al mercat (Ardit, 1996). Així mateix, va tractar de demostrar que el debilitament del creixement observable mitjançant les fonts decimals des del darrer terç del segle xviII responia a un problema social amb importants repercussions econòmiques: el creixent frau en la recaptació (Ardit, 1989).

El conjunt de les seues contribucions mostra un panorama prou clar pel que fa a les grans tendències, que difícilment podrà ser objecte de grans modificacions en el futur, tret d'algunes matisacions o esmenes, preferentment d'àmbit local o comarcal. Entre 1500 i 1700, l'evolució observada per Ardit confirmava la descripció de Casey, tot i que la interpretació diguem-ne pessimista de l'autor anglès era substituïda per una altra força més optimista. El creixement del segle XVI era incontestable i l'única diferència entre les visions dels dos autors es referia a la conjuntura posterior a la crisi agrària dels anys 1570: el que Casey descrivia com a situació d'estancament era per a Ardit una de creixement moderat fins a 1609 -de prop d'un 30 $\%$-, impulsat per la població morisca. Aquest ha estat un dels grans descobriments de l'historiador valencià. Molt més que Casey, i en un sentit oposat a les primeres afirmacions de Císcar, Ardit constatava un comportament demogràfic i econòmic clarament diferenciat de les comunitats morisques respecte a les de cristians vells. ${ }^{9} \mathrm{La}$ importància d'aquesta divergència raïa en el fet que el peculiar sistema

9 Vegeu la darrera contribució d'aquest autor, publicada pòstumament (Ardit, 2018). Cal aclarir que tant Casey (1987) com Císcar (1993) van modificar notablement les seues interpretacions inicials. 
demoeconòmic de les poblacions morisques, sotmeses a un règim de punció de renda heretada de la conquesta feudal del segle XIII i que podríem qualificar de colonial (Torró Abad, 2009), sí que podria haver estat un fre a les transformacions agràries. ${ }^{10}$

La recuperació a partir dels anys 30 del segle xviI, després de la forta crisi provocada per l'expulsió, hauria situat la producció agrària en el seu conjunt prop dels nivells màxims de finals del XVI ja abans de la Guerra de Successió. També, com Casey, Ardit va observar com la ramaderia aniria perdent pes en les activitats del món rural valencià; primer, creixent a un ritme menor que el conjunt de l'agricultura al llarg del cinc-cents i amb una recuperació feble que, de nou, va caure per sota del ritme del creixement agrari des de 1650 i que es va aturar cap a 1750 sense assolir els màxims de finals del segle Xvi. Per contra, l'agricultura es recuperaria ràpidament dels efectes de la guerra i creixeria a un ritme molt intens fins a 1770. L'alentiment d'aquest ritme des d'aquesta data és atribuit per Ardit, en una proporció decisiva, a la progressiva extensió del frau al delme.

Com he assenyalat abans, aquestes tendències no van ser uniformes geogràficament ni tampoc pel que respecta als conreus practicats. Des del punt de vista territorial, la presència d'una significativa minoria morisca - quasi un terç de la població en el moment de la seua expulsió- suposaria l'existència de dos ritmes diferents de creixement agrari i demogràfic. Fins a 1570 el creixement està impulsat per les comunitats de cristians vells, mentre que entre aquesta data i l'expulsió l'estancament d'aquelles es veu compensat per un avivament del creixement de les comunitats morisques. Aquesta tendència es veu irremissiblement alterada des de 1610, moment a partir del qual el creixement demogràfic i agrícola se sosté per l'impuls de les poblacions situades a les zones no repoblades. L'explicació sembla evident, atès que els moriscos ocupaven generalment zones marginals muntanyenques, freqüentment menys fèrtils i en les quals resultava més complex adoptar el nou model agrari que es va consolidar. Un model caracteritzat, entre altres qüestions, per una major diversificació i una clara tendència al progrés de conreus no

10 Crec que és necessari remarcar que Ardit va ser molt reticent a escriure de manera contundent aquestes proposicions que, de tota manera, estan subjacents de forma clara a les seues contribucions. 
cerealístics, l'exemple més clar dels quals és la morera i la producció de seda.

Tot i constituir la millor aproximació des del punt de vista metodològic $\mathrm{i}$, consegüentment, el punt de partida obligat de qualsevol aproximació a l'estudi de la producció agrària durant l'edat moderna, la recerca d'Ardit també mostra alguns punts febles. En primer lloc, per basar la seua explicació exclusivament en arrendaments. Aquesta debilitat és reconeguda pel mateix Ardit, que va indicar que caldria un estudi més detingut i profund de la documentació de l'arxiu catedralici. ${ }^{11}$ Això suposa considerar que les proporcions en què es contribuïa no van variar ni espacialment - Ardit considera que l'agregació minimitzaria aquest problema - ni al llarg del temps uns canvis que semblen clars almenys pel que toca a l'excusat. Resulta evident que el marge d'incertesa és considerable; tornaré sobre aquest tema més avant.

En segon lloc, l'operació de deflactar amb els preus del forment de la ciutat de València també afecta la fiabilitat de les sèries. Com també reconeix el mateix autor, hauria estat millor disposar d'un índex ponderat de preus que tingués en compte la varietat de collites que es recollien sota un mateix epígraf. És evident que les postures dels arrendadors depenien de diversos factors condicionants i que les expectatives d'aquests negociants a l'hora d'anar a les subhastes no sempre reflectien únicament les variacions, precedents o esperades, del producte agrari. Són debilitats considerades per Ardit que, tanmateix, tracta d'avaluar la validesa dels seus resultats contrastant les sèries amb l'evolució dels preus del forment. Aquest pas resulta molt arriscat tenint en compte que, d'una banda, la mateixa operació de deflació fa que l'evolució dels preus afecte directament els resultats obtinguts; d'una altra, i sobretot, la mesura de la validesa de les sèries proposada per Ardit - que les seues tendències siguen oposades a les dels preus, una premissa completament certa a curt termini i que sembla produir-se a més llarg termini entre 1650 i 1770 - no

11 Les consideracions metodològiques de l'estudi d'Ardit es troben sintetitzades a «Expulsió dels moriscos i creixement agrari...» (Ardit, 1987: 290-294), i el reconeixement explícit de la necessitat d'una recerca més detallada a la nota 45 (p. 292). 
sempre es compleix en altres conjuntures més llargues — de fet, fins a les darreries del segle Xvi i des de 1770, s'esdevé just el contrari.

En tercer lloc, la recerca d'Ardit presenta una mostra limitada que no inclou ni el sud ni el nord del país. Es tracta d'un problema important atenent que resulta molt difícil controlar el grau de biaix que s'hi introdueix. De fet, Ardit no va assajar cap valoració del percentatge de població que s'incloïa a - o s'excloïa de, tant hi fala seua mostra. Amb tot, la principal debilitat de treballar sols en aquest àmbit és l'exclusió d'entorns agroecològics, l'evolució dels quals probablement no afecte de forma decisiva les tendències, els ritmes i les conjuntures, però sí que podrien fer-ho amb els volums totals o l'estructura de la producció. Hem de prendre en consideració, per exemple, que al territori de la diòcesi d'Oriola l'ordi prevalia sobre el forment com a cereal dominant a finals del segle XVIII i principis del xix. O que, per posar un altre exemple rellevant, és molt probable que se subvalore el pes de la ramaderia excloent-hi àrees com els Ports i l'Alt Maestrat.

Finalment, la presència d'un important i creixent frau en la recaptació, condueix Ardit a no considerar altres factors explicatius en el debilitament del creixement del valor real dels arrendaments des de 1770. D’aquesta manera, a la seua interpretació no considera -o només ho fa d'una manera molt tímida - la probabilitat que el model agrari intensiu tingués cada vegada més dificultats per impulsar el creixement i que l'extensió de la superfície conreada impliqués l'aparició de rendiments decreixents.

\section{LES FONTS PER A L'ESTUDI DELS DELMES: PRIMÍCIES, PARTS BISBALS I TERÇ DELME}

L'existència de fonts documentals diferents per a l'estudi dels delmes s'explica perquè la fiscalitat decimal es repartia entre diferents beneficiaris. Els reis d'Aragó i Catalunya havien estat agraciats amb una sèrie de donacions per part de l'Església, mitjançant diferents butlles, que els van concedir els delmes de les terres conquerides. Tanmateix, en el cas valencià, Jaume I va cedir a la mateixa Església les dues terceres parts d'aquesta exacció. Segons Casey (1982: 330331), el repartiment era el següent: dues novenes parts pertanyien a 
les parròquies - les anomenades primícies - i la resta es dividia al seu torn en tres parts, una de les quals retenia el rei - el terç delmei les altres dues corresponien al bisbe -les parts bisbals. L'autor anglès va suposar que aquesta era una norma general, però el cert és que el més probable és que un estudi de detall ens proporcione una casuística més diversa. Puc adduir l'exemple d'Alcoi (Torró Gil, 1994: 80) on ens trobem amb dos repartiments diferents i simultanis segons els registres del terç delme de finals del XVI i durant el XVII. D'una banda, els cereals tradicionals - tots excepte la dacsa- es partien en les mateixes proporcions: 27 parts, 6 de les quals tocaven a la parròquia, 7 al rei i 14 al bisbe; és a dir, una partició idèntica a la citada per Casey. D’una altra banda, però, la resta de productes -incloent-hi la dacsa- es partien de manera distinta, dividint-se en 28 parts: 7 per a la parròquia, 7 per al rei i 14 per al bisbe. ${ }^{12}$

Aquesta diferència en el repartiment de les recaptacions resulta de poca rellevància. ${ }^{13}$ Tanmateix no es pot dir el mateix quan el que observem és quines collites estaven subjectes a contribució i en quina proporció contribuïen. ${ }^{14}$ D’entrada, les exempcions: junt amb l'exempció completa del pagament del delme de la qual gaudien els privilegiats conreadors de la Valldigna, la Vall de Gallinera i la Vall d'Ebo, cal tenir en compte que també en alguns llocs no contribuïen a les primícies o que aquestes estaven alienades en mans diferents de les mateixes parròquies. Pel que fa a les taxacions, la varietat és senzillament incontrolable. Podríem dir que hi ha una certa homogeneitat pel que fa a les collites d'estiu, entre les quals hi ha els cereals - forment, ordi, avena i mixtures - i els llegums;

12 Es poden contrastar aquestes qüestions amb Llibrer (2011) que ofereix un breu repàs de la configuració de les recaptacions del delme i el seu repartiment al País Valencià. Pel que fa a l'ús de les fonts decimals a l'edat mitjana al conjunt de la Corona d'Aragó cal recórrer a Enric Guinot (Díaz de Durana i Guinot, 2010: 79-88).

13 Tot i que caldria notar que qualsevol variació relativa de les produccions sotmeses a la segona de les particions respecte a la dels cereals tradicionals es veuria distorsionada a les sèries reconstruïdes pel biaix que aquesta doble partició introdueix.

14. La principal font sobre aquesta qüestió prové d'una enquesta de 1758 que va ser objecte d'estudi per part d'Antonio Mestre (1976). La publicació recull una extensa taula amb la informació de les taxes que s'aplicaven a 115 parròquies de la diòcesi de València. 
aquestes collites partien amb poques excepcions a 1/8. En el cas del delme del carnatge tampoc no existeix una gran dispersió, contribuint generalment en proporcions pròximes o lleugerament superiors a 1/10. Les collites de Sant Miquel —fonamentalment oli, dacsa i cànem $-{ }^{15}$ contribuïen majoritàriament entre $1 / 10 \mathrm{i} 1 / 12$, encara que presenten un elevat grau de dispersió.

Ara bé, pel que fa a la resta la dispersió és enorme, sent pràcticament impossible fixar valors mitjans representatius. Això afecta collites tan importants com la fulla de morera i, especialment, les produccions noves. El cas més significatiu i il.lustratiu és el de la garrofa. En una part molt significativa dels casos no hi consta, bé perquè no hi havia producció o bé perquè no s'havia imposat encara cap tipus de partició - cosa que és impossible discernir de la informació presentada per Mestre. Pel que fa a la resta, les proporcions poden oscil.lar entre el màxim d'1/5 - a Xulilla o la Llosa de Ranes- i el mínim d'1/22,5 - a Ondara, Pedreguer, Polop i Callosa d'en Sarrià. Es tracta, de fet, de les quotes més altes i més baixes en termes absoluts. No cal dir que aquesta enorme diversitat dificulta molt la interpretació correcta de les dades i convida a prendre-les amb una enorme precaució.

Pel que fa a l'altra diòcesi estudiada, la d'Oriola, sembla que la norma és la contrària a la que s'observa a València: la uniformitat en les particions. Amb molt poques excepcions, la contribució de les diferents collites se situava en 1/12. Això sí, es tracta de la informació del segle Xvin recollida per Ramos (1980), ja que sembla que tots els autors que empren els delmes d'aquesta diòcesi hagen begut de la mateixa font, amb la notable excepció de Gregorio Canales $(1981,1988)$. No sabem res de períodes anteriors, tret que el terç delme havia estat cedit per Alfons X de Castella el 1281 per a les fàbriques de les esglésies, amb la introducció d'un repartiment força complex. ${ }^{16}$ Descomptant el forment i l'ordi, que eren administrats directament i no ens consta que les seues recaptacions foren dividides en circumscripcions, la resta de les recaptacions eren arrendades per delmaris específics. Oriola, per exemple, tenia sols un delmari per

15 Mestre (1976) inclou l'oli com a collita de Sant Miquel tot i que es tracta d'una classificació dubtosa.

16 V. Alberola-Romà (1984: 250) i alguns exemples de repartiments a Ojeda (1997: 40-41). 
a la fulla de morera, el cànem, la dacsa i l'anomenat extremeny, ${ }^{17}$ però en tenia dos — nord i migdia - per al lli, l'oli i la barrella, i nou de menut - fruita i hortalisses. La recaptació d'alguns delmaris, en canvi, estava cedida als seus senyors temporals; són els casos de Monfort i la seua fillola, Agost, Elda, Petrer, Salines, Asp, Monòver i Novelda; així com Crevillent — del delmari d'Elx. Aquesta cessió s'havia fet el 1449 a través d'un acord entre el bisbe de Cartagena i Alfons el Magnànim a canvi del pagament d'una composició fixa que, per aquesta raó, va esdevenir una renda testimonial (Belando, 1990: 34-38).

Les parts bisbals pertanyents a la diòcesi de València eren arrendades en la seua totalitat. Com ens recorda Ardit (1987: 292), però, aquesta regla té les seues excepcions; sembla que en alguns moments puntuals hom decidia una gestió directa d'algun delmari, fet que ha deixat testimoni escrit als registres catedralicis i que reclama un estudi. De la mateixa manera que a Oriola, el territori es dividia en delmaris en els quals s'arrendaven les recaptacions d'una sèrie de produccions. Així, ens trobem amb el delme de pa $i$ vi, on s'incloïen les principals rebudes de cereals, vi, oli, fruits secs i llegums; el paner de fruites i hortalisses, ${ }^{18} \mathrm{i}$ el carnatge, una càrrega sobre els productes ramaders que es limitava durant l'edat moderna aparentment al ramat oví i cabrum. ${ }^{19} \mathrm{~A}$ més, sols en alguns delmaris i de vegades de forma temporal, apareixen delmes específics com el delme de fulla - una proporció sobre el valor de mercat de la fulla de morera- o el delme del cànem.

Els principals avantatges de les parts bisbals del delme són, evidentment, la seua gran cobertura territorial i temporal, i el fet que es troben plegades en un petit grapat d'arxius. ${ }^{20}$ Tanmateix, tenen

17 Mig delme amb el qual contribuïen els ramats transhumants que hibernaven al terme.

18 En alguns delmaris i en alguns moments es trobava comprès en l'anomenada Sant Miquelada, freqüentment formant part del delme de pa i vi.

19 Es contribuïa en proporció als caps, la llana i els derivats lactis com el formatge.

20 El que comentaré se centra en el cas dels delmes de la diòcesi de València; però, amb alguna petita excepció que indicaré, també val per a la d'Oriola. Atesa la manca d'estudis i coneixements sobre les diòcesis del nord del país, cal entendre que el que diré no es pot aplicar a la seua documentació. 
greus problemes com a font que han de ser presos en consideració per a poder aplicar una metodologia rigorosa i, fins i tot en aquest cas, evitar errors d'interpretació. Per començar, i exceptuant les recaptacions en espècie d'ordi i forment a Oriola, sols coneixem el valor dels arrendaments. Aquest és sens dubte el principal problema i això per diverses raons. La més punyent és la que deriva del deflactor. Caldria disposar de deflactors ponderats ${ }^{21}$ que són impossibles de construir a mitjà i llarg termini $i$, en conseqüència, els valors s'expressen en quantitats de forment equivalent, fent dependre l'evolució global de la del valor d'un sol producte a la ciutat de València. La preferència pels arrendaments quadriennals en el cas de la diòcesi valenciana genera el problema afegit de no poder controlar les fluctuacions anuals. A més, tenim el problema de la manca d'homogeneïtat: en les proporcions de les contribucions - un problema menor si sols pretenem observar les tendències-, en l'aparició de nous conreus i la seua diferent taxació i, finalment, en els mateixos delmaris que s'agreguen i es desagreguen, formant filloles o altres delmaris. Per si tot açò no fora suficient, resta per considerar el problema de l'excusat i del seu increment, particularment, al llarg del segle XVIII. ${ }^{22}$

Una altra part del delme que ha deixat rastre documental és aquella destinada a les primícies que romania en mans de les parròquies. Es tracta sense cap dubte de la porció sobre la qual disposem de menys informació. No coneixem els detalls del procés de la seua recaptació, i la seua gestió local no ha deixat gaires petges documentals, a més de trobar-se extremadament disperses en els arxius parroquials. És dubtós que puga recollir-se suficient informació per a reconstruir sèries, ateses les pèrdues documentals, la freqüència amb la qual sembla estar alienada aquesta renda i els problemes administratius inherents a la majoria de les parròquies. A més, resulta complex en molts casos localitzar la ubicació exacta de la informació sobre les recaptacions de les primícies, freqüentment esparsa en

21 Parle en plural atès que caldria una ponderació per delmari que, a més, anés modificant-se amb el pas del temps per reflectir adequadament les variacions en el pes de les diferents produccions.

22 Sembla evident que la cessió del producte del delme de les principals cases fa perdre representativitat a la font. Caldria controlar quina era la proporció amb la major aproximació possible. O bé trobar els registres d'aquesta recaptació que podrien resultar una nova font d'informació. 
el maremàgnum de llibres de comptes, fàbriques i altres tipus de documents conservats als arxius parroquials. L'única font documental que sembla oferir sistemàticament estimacions sobre el valor de les primícies són les visites pastorals que, ateses les seues característiques, podrien permetre en algun cas l'establiment de tendències a llarg termini. Tanmateix, la marcada inclinació a l'arrodoniment de les xifres i la seva reiteració que presenta aquesta font - vegeu-ne un exemple al gràfic $1-$, ho fan poc probable. En tot cas, deixant de banda el seu ús per a grans prospeccions, particularment aquelles de gran abast geogràfic, podrien resultar útils per a anàlisis locals de caràcter comparatiu i com a font de contrast.

Gràfic 1. Primícies de la parròquia de Santa Maria de Cocentaina (milers de lliures)



Font. Arxiu Parroquial de Santa Maria de Cocetania, 2.2.: Visites pastorals.

A mitjan camí entre les primícies i el terç delme es troba la documentació del terç de fàbriques. Com ja he comentat es tracta d'una part del terç delme reservada per al manteniment de les esglésies que sols sembla haver-se aplicat a la diòcesi d'Oriola. ${ }^{23} \mathrm{Els}$

23 Per als detalls sobre aquesta renda, com s'havia de recaptar i a quines finalitats es dedicava, v. Alberola-Romà (1984: 253-257) i Ojeda (1997). Aquest darrer autor, a més de ser especialment útil per conéixer les despeses de la fàbrica de la catedral d'Oriola (Ojeda, 1997: 71-90), encara ens ofereix detalls d'una 
registres es conserven als arxius municipals, atès que l'ordenament d'aquesta renda indicava que els fabriquers havien de retre compte als municipis dipositant els llibres en mans dels ajuntaments. Malgrat els dubtes que genera la metodologia de recollida de les dades, el treball d'Ojeda ofereix informació sobre les recaptacions susceptible de ser seriada. ${ }^{24}$ Amb elles, i a títol d'exemple, he confegit els gràfics 2 i 3, que presenten, com a qüestions més destacades, el dèbil creixement de la producció de cereals al llarg del segle xvi al terme d'Oriola; la clara caiguda de les recaptacions després dels màxims de finals del XVIII — frau, caiguda de la producció o combinació d’ambdós?_; el clar predomini del forment sobre l'ordi des de molt d'hora, al segle XVI, i com aquesta situació comença a alterar-se des de la segona dècada del segle XviII per acabar amb un clar predomini de l'ordi sobre el forment, ja a les darreries d'aquest mateix segle.

La darrera font documental són els registres del terç delme que, com ja he assenyalat, és la proporció dels delmes reservada a la Monarquia que suposava una mica més d'una quarta part del total del delme i que va estar en mans, generalment, dels titulars de les senyories. De cara a recerques d'àmbits geogràfics extensos suposa un problema ja que els seus registres es troben, per definició, dispersos i, a més, en el cas dels senyors laics o eclesiàstics no sempre es conserven o almenys no en la quantitat i qualitat suficients. Tanmateix, l'administració reial

altra font continguda també als mateixos llibres de fàbrica, l'anomenada quinta casa, que era el producte del delme de la cinquena major casa delmera cedida per Pius II el 1512 a la fàbrica de les esglésies de la diòcesi de Cartagena. Malgrat haver atorgat el títol honorífic de catedral a l'església del Salvador d'Oriola el 1510, aquest cobrament va estar limitat al mateix terme d'Oriola fins a la creació de la diòcesi pròpia el 1564 i la concessió de Gregori XIII de la recaptació de la cinquena major casa contribuent al delme de tots els delmaris de la diòcesi a la catedral el 1578. Aquesta renda suposava un percentatge molt important dels ingressos de la fàbrica de la catedral (Ojeda, 1997: 53-59).

24. El principal dubte metodològic - a banda de la seua pròpia presentació de les dades amb criteris d'agrupació dubtosos i sense deflactar quan es tracta de quantitats en diners - es refereix als preus que ofereix. En efecte, a l'annex III Ojeda (1997: 105-109) ens presenta les quantitats d'ordi i forment recaptades en barcelles i els preus de venda. Atès que esmenta en diverses ocasions que aquestes recaptacions anuals eren objecte de més d'una venda al llarg de l'any, sembla evident que l'arrodoniment de les xifres de preu indica que no són preus ponderats i desconeixem com han estat obtinguts. 
Gràfic 2. Recaptacions en espècie de forment i ordi de la fàbrica de la catedral d'Oriola (1531-1835)

\section{0}

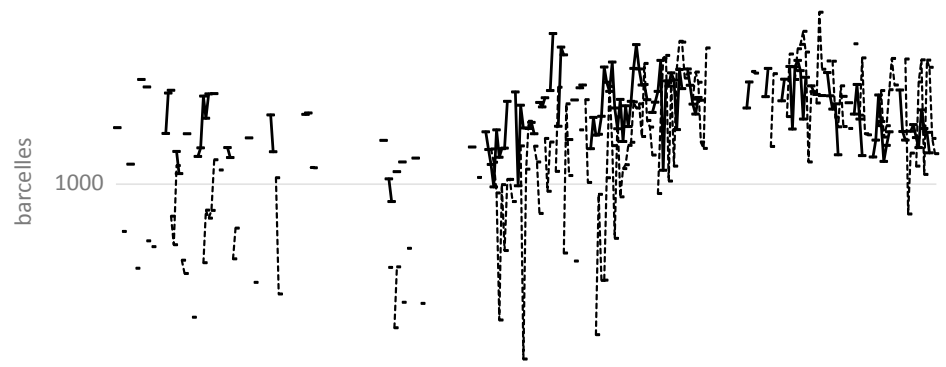

100

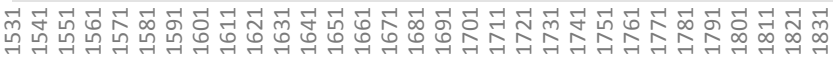
—_Forment Ordi

FonT. Ojeda (1997: 105-108).

Grà fic 3. Recaptacions en espècie de forment i ordi (totals) de la fàbrica de la catedral d'Oriola (1531-1835)

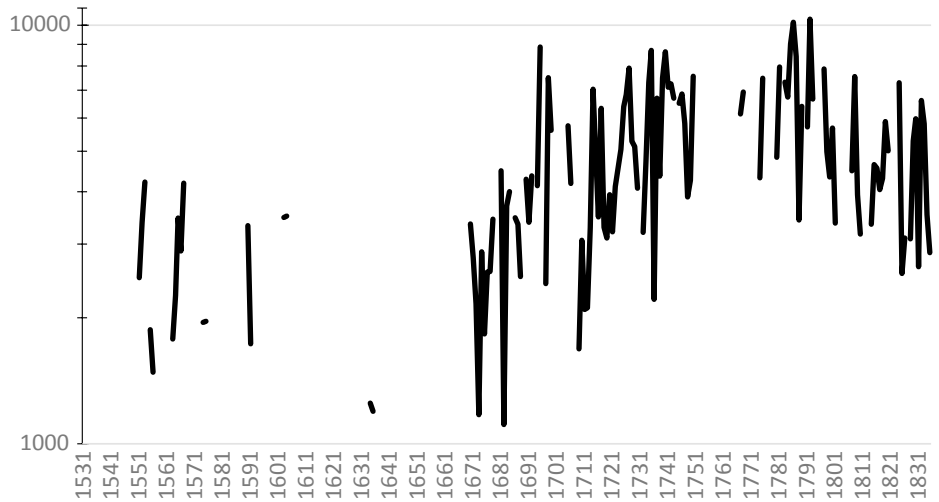

Font. Ojeda (1997: 105-108). 
ens ha llegat una enorme quantitat de documentació. Es tracta de registres que cobreixen un ample marc temporal —com a mínim des de mitjans del segle $\mathrm{xv}$ - i diferents espais geogràfics que comprenen una gran part del territori valencià i una variada mostra de localitats — preferentment urbanes - i sistemes agraris diferents. Els quaderns de l'administració de les diferents batllies conserven registres dels arrendaments del terç delme - i de la resta de drets senyorials del rei-, així com de les gestions directes dels batlles, particularment abundants al llarg del segle XVII. ${ }^{25}$

Aquesta font presenta alguns avantatges importants respecte a l'ús de les parts bisbals. La més important és, sens dubte, poder iniciar les anàlisis molt abans del que permeten els registres catedralicis almenys pel que sabem fins ara, en els casos de València i Oriola- i no presenta les deficiències que s'observen en els de València durant la primera meitat del segle Xvi. A més, l'existència de nombrosos registres anuals de gestió directa per part dels batlles permet aproximar-se a la producció física i a l'estructura de les produccions, encara que de manera prou dispersa. Aquest seria un dels principals inconvenients de l'ús de la font: dona llum a realitats al llarg i ample de tot el país però la seua dispersió territorial fa difícil — tot i que, probablement, no ho faça impossible- agregacions a gran escala. L'altre inconvenient és que, com les parts bisbals, la immensa majoria de la informació prové d'arrendaments, encara que siguen anuals. Finalment, sembla que el 1727 la Corona va vendre al Marqués de Santiago la major part dels seus terços delmes — almenys els de pa i vi, ja que no sembla que vengués els de carnatge-, limitant de forma quasi absoluta l'ús d'aquesta font per al segle XVIII (Romeo, 1986: 35).

25 A més dels treballs que hem anat esmentant, aquesta font ha estat emprada per diferents autors, bé en el marc de l'anàlisi de la Hisenda reial (Correa, 1995) o bé com a estudi local (Vila, 1990; Salvador, 2004). El cas de l'estudi d'Emilia Salvador resulta particularment important en centrar-se en l'Horta de València, però se circumscriu únicament al segle Xvi -Margarita Vila ho fa, per la seua banda, al segle XviI- i, encara que ofereix les dades dels arrendaments en brut i deflactats, la seua anàlisi es troba limitada per partir de gràfics en els quals s'ofereixen a la vegada ambdues sèries sense indexar -la qual cosa obligaria a reelaborar els gràfics i indexar-ne les quantitats. 


\section{Possibilitats i limitacions de les fonts Decimals COM A INDICADORS DE LA PRODUCCIÓ AGRÀRIA}

Constitueixen un indicador adequat del volum i/o del valor de la producció agrària, les fonts decimals? Fins a quin punt? Per tractar de respondre a aquestes preguntes crucials assajaré algunes aproximacions partint de la informació aplegada en les meues investigacions d'un cas local. En aquest exercici empraré de manera creuada diverses fonts, tant d'origen decimal com d'altres. En primer lloc, calcularé la correlació de les fluctuacions conjunturals de les recaptacions decimals amb les variacions dels preus. En segon lloc, mesuraré la representativitat del terç delme en relació amb les parts bisbals. Finalment, tractaré d'avaluar fins a quin punt el valor global de la recaptació decimal és proporcional al del conjunt de la producció agrícola anual i si aquesta proporció s'apropa suficientment a la que hauria de representar el delme segons la seua taxa de recaptació.

Com ja he apuntat, els registres del terç delme conservats a l'ARV - secció Mestre Racional- ens proporcionen informacions de moltes batllies en les quals - per raons generalment desconegudesels batlles reials van haver d'administrar alguns anys les recaptacions en compte d'arrendar-les. Aquests quaderns solen oferir, producte per producte, dades sobre la recaptació total en espècie i sobre la seua divisió entre la parròquia, el bisbe i el rei. A la documentació que jo he pogut estudiar (Torró Gil, 1989; 1994: 80), el batlle venia el producte de les recaptacions i feia constar els preus i els valors obtinguts. Es corresponien les fluctuacions dels preus - ponderats en els casos habituals en què hi havia més d'una venda- amb les del volum recaptat? Doncs la correlació sembla oferir una resposta positiva en el període objecte del test, ${ }^{26}$ tant visualment - v. gràfics 4 i 5-com aritmèticament. En els casos de les dues principals rebudes del camp alcoià, el forment i l'ordi, les anàlisis de correlació mostren $r$ de $-0,79$ per al forment i de $-0,77$ per a l'ordi - amb $r^{2}$ de 0,62 i 0,59 , respectivament. És a dir, correlacions negatives i elevades,

26 La tria del període 1616-1627 respon al fet que es tracta del període més llarg en què el batlle va gestionar directament el terç delme sense arrendar-lo. El que es representa als gràfics 4 i 5 són els percentatges de variació anual respecte a la mitjana total del període. 
Gràfic 4. Variacions de la recaptació i preus del forment, Alcoi (1616-1627)

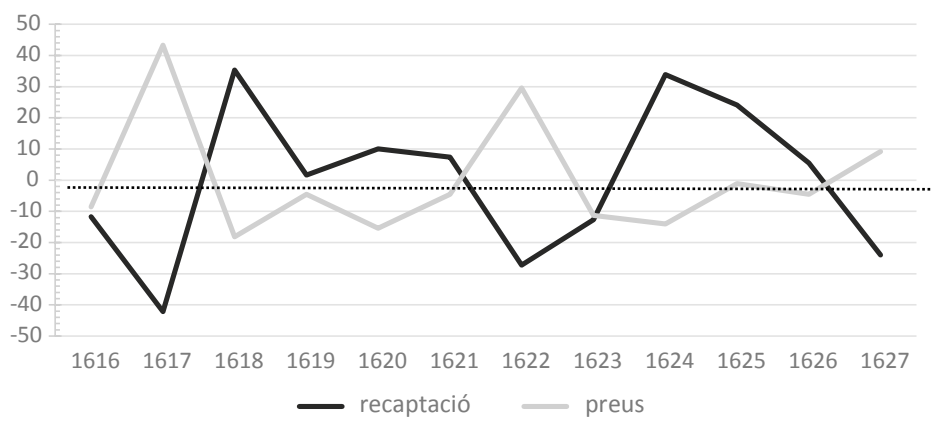

Font. Torró Gil (1989: 52-54).

Gràfic 5. Variacions de la recaptació i preus de l'ordi, Alcoi (1616-1627)

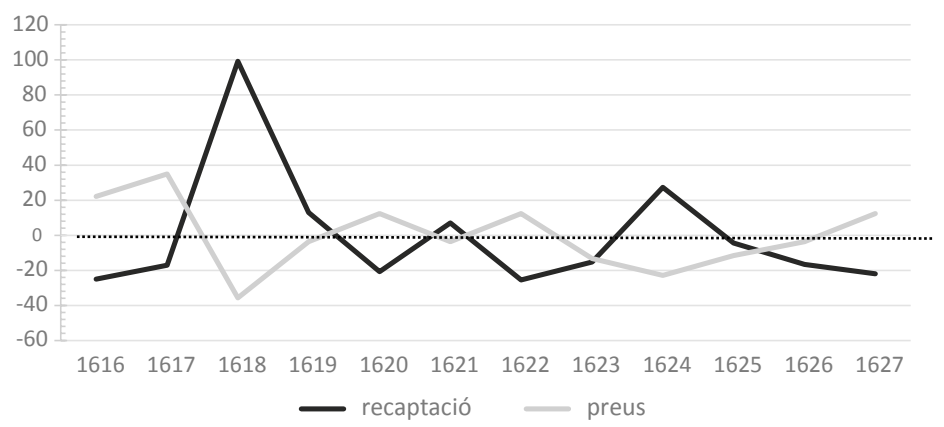

FonT. Torró Gil (1989: 52-54).

que ratifiquen la hipòtesi que, en el curt termini, les fluctuacions dels preus responien de forma inversa a aquelles de les rebudes del delme; çò és, que la recaptació representava efectivament una part proporcional de la producció agrària total de la qual depenien en bona mesura les fluctuacions anuals dels preus.

Una altra mesura de la representativitat d'aquestes fonts pot obtenir-se a partir de la comparació entre el valor del terç delme i el de les parts bisbals. Independentment de la proporció de les primícies - ja hem vist que, segons els productes, podien ser dues novenes parts o una quarta part- la relació entre el terç delme i les parts bisbals era 
Gràfic 6. Valors deflactats dels arrendaments de les parts bisbals i del terç delme (Alcoi, 1568-1596)



FONT. Elaboració pròpia a partir de les dades oferides a Torró Gil (2000: 680-695 i 716-721).

Gràfic 7. Percentatge del valor del terç delme respecte de les parts bisbals (Alcoi, 1568-1596)

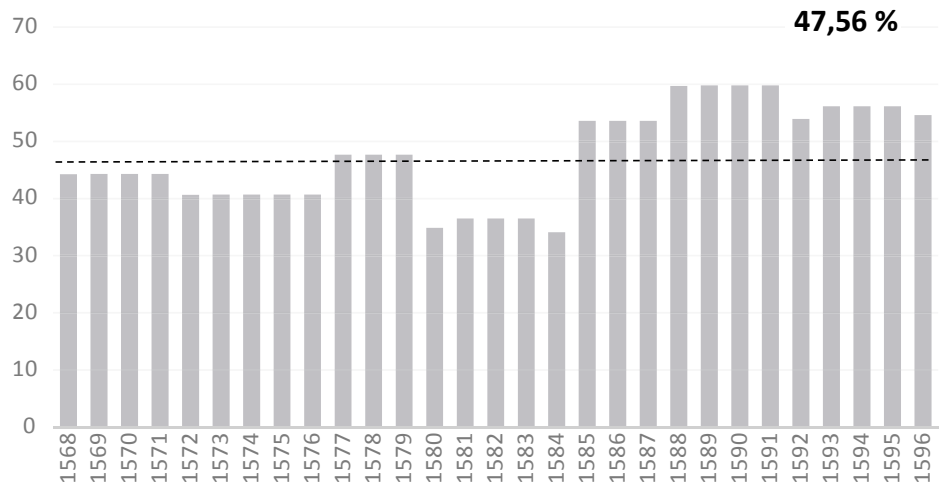

FonT. Elaboració pròpia a partir de les dades oferides a Torró Gil (2000: 680-695 i 716-721). 
Gràfic 8. Percentatge del valor del terç delme respecte de les parts bisbals (Alcoi, 1616-1628)



FonT. Elaboració pròpia a partir de les dades oferides a Torró Gil (2000: 680-695 i 716-721).

Gràfic 9. Percentatge del valor del terç delme respecte de les parts bisbals (Alcoi, 1616-1628)



FonT. Elaboració pròpia a partir de les dades oferides a Torró Gil (2000: 680-695 i 716-721). 
en tots els casos d'una a dues, és a dir, el terç delme havia de suposar un $50 \%$ del valor de les parts bisbals. S'allunyava molt la realitat d'aquesta regla? A la vista de la informació que presente als gràfics 6,7 , 8 i 9, la resposta és clarament negativa, i no sols en els moments en què ambdues rendes eren arrendades, sinó també quan el terç delme era gestionat directament. El que sembla evident, però, és que el sistema d'arrendaments provoca distorsions que li fan perdre representativitat com a indicador a curt termini. Això s'aprecia clarament als gràfics 6 i 7 en què observem l'evolució del valor deflactat de les dues rendes entre 1568 i 1596 - ambdues arrendades, quadriennalment les parts bisbals i anualment el terç delme-, però també als gràfics 8 i 9 en què la comparació es fa entre un terç delme gestionat directament - recaptat en espècie i transformat en diners mitjançant la venda- $\mathrm{i}$ unes parts bisbals arrendades. Una conclusió s'imposa: cal extremar la prudència a l'hora de deduir variacions conjunturals curtes a partir de les fluctuacions dels arrendaments, clarament influits per altres condicionants a més de l'evolució de les collites precedents i l'expectativa de les properes.

Sols resta respondre a la darrera de les qüestions: fins a quin punt el delme representa un indicador fiable del valor global de la producció agrícola? Per al cas d'Alcoi, disposem d'una estimació feta per un testimoni de l'època. ${ }^{27}$ Francesc Pérez Planelles va estimar el valor agrari per a 1807 en $171.772,32 £ \underbrace{28}$ El valor total del delme que es pot deduir a partir de l'arrendament de les parts bisbals suposava per aquelles dates $18.241,91 £ ;{ }^{29}$ és a dir, un $10,62 \%$ del valor estimat

27 Es tracta d'un manuscrit elaborat el 1807 que, sota el títol de Plan estadístico de la villa de Alcoy, va ser premiat per la Real Sociedad Económica de Amigos del País de València (Pérez Planelles, 1807).

28 Per a poder establir comparacions amb el delme, pel que fa al carnatge sols he tingut en compte l'estimació sobre el valor dels caps dels ramats d'ovelles i cabres, així com de la llana produïda. He exclòs la resta de la ramaderia esmentada per Pérez Planelles — cavalls, mules, ases, gallines, coloms i allò relacionat amb l'apicultura - ja que he considerat poc probable que tributaren al delme. En el cas dels productes de la terra, també he exclòs per la mateixa raó la palla, la fusta i el carbó.

29 Atès que no coneixem el valor del terç delme ni de les primícies, he calculat el total a partir de la xifra dels arrendaments de les parts bisbals del delme de pa i vi, i del carnatge. La restitució s'ha fet ponderant la diferent partició entre els cereals - a excepció de la dacsa-i els productes del carnatge (6/7/14, 
per Pérez Planelles. Una estimació del valor del producte agrari a partir de la recaptació del delme ${ }^{30}$ dona un valor de 161.894,62 £. El percentatge de l'estimació a partir del delme representa un 94,25\% de la de Pérez Planelles. Per tant, podríem dir que en vespres de la crisi d'impagament del delme de la Guerra del Francès el marge d'error podria ser inferior al $6 \%$. Ara bé, a Alcoi no hi ha collites noves que se sostraguen del pagament - no hi ha garrofes, per exemple-o que paguen molt poc - no hi ha fulla de morera i poques fruites i hortalisses. Tampoc no prenem en compte el necessari marge de benefici per a l'arrendador.

Tot i que aquesta evidència podria avalar el delme com un indicador suficientment segur, romanen dubtes importants. El primer deriva de la font d'informació que va emprar Pérez Planelles per a la seua estimació. Si aquesta era la mateixa recaptació decimal, hauríem de dubtar de la mateixa estimació i això explicaria l'elevada correspondència que hem constatat. ${ }^{31}$ Així mateix, el contrast de la recaptació del delme del vi de 1627 amb la informació obtinguda de l'anomenat Manifest del $V i^{32}$ del mateix any, ens proporciona una imatge molt allunyada de la que hem vist per a 1807. El 1627 la producció manifestada va ser de 26.719 càntirs, però el delme només en va recaptar 1.400, el que implicaria, segons les particions vigents al segle XVIII, una quantitat 10 vegades superior (Mestre, 1976; Romeo, 1986: 34). I això malgrat tractar-se —el manifest— d'una font de caràcter fiscal susceptible d'haver provocat ocultacions. Entre altres

per a primícies, terç delme i parts bisbals) i la resta —amb la dacsa- (7/7/14, respectivament). La ponderació s'ha fet a partir de l'estimació de Pérez Planelles assignant a la primera partició un $57,15 \%$ i a la segona un $42,85 \%$.

30 Per al càlcul he suposat de nou diferents recaptacions: $1 / 8$ per al delme de pa $\mathrm{i}$ vi, i carnatge - ponderat com en l'estimació precedent amb el 57,15\% del total del valor-i $1 / 10$ per a la resta assignant-li un $42,85 \%$ a la ponderació.

31 De tota manera, una bona part de les estimacions de Pérez Planelles no corresponen a productes gravats pel delme - v. nota 25 .

32 Es tracta d'uns quaderns elaborats a conseqüència de l'aprovació d'un onerós servei per a la Monarquia a les Corts de 1626. Els quaderns, confeccionats localment, recullen el nom de tots els productors i de les quantitats de vi produïdes individualment cada any. A Alcoi s'ha conservat el quadern de 1628 - Arxiu Municipal d'Alcoi (AMA), I.4.4.4.1, Manifest del Vi, 1628-, però la informació de l'any anterior i dels anys següents, fins a 1631, es troba a l'ARV per al conjunt del país (Felipo, 1982; 1984; 1985). Així sabem que la mitjana de càntirs produïts anualment a Alcoi entre 1627 i 1631 va ser de 25.346,5 (Felipo, 1985: 135). 
possibles explicacions podem trobar-nos amb una partició diferent a principis del segle XVII respecte a la constatada per Mestre i Romeo al XVIII o, com també sembla probable, que ens trobem davant un clar indici d'un major control de la producció cerealícola que de la resta. ${ }^{33}$ En definitiva, cal ser molt conscient de les contingències que condicionen els registres de les recaptacions dels delmes com a font informativa.

\section{L'estudi d'un Cas local: Alcoi i la seua comarca (1444-1830)}

Més enllà dels estudis amb perspectiva agregada en els quals, al meu parer, difícilment podrem afegir canvis decisius a les constatacions $i$ interpretacions que ja s'han realitzat, les fonts decimals poden ser determinants a l'hora d'aprofundir en els estudis de casos locals. Tot i que tornaré a incidir en aquestes qüestions a les conclusions, abans presentaré l'estudi de la comarca alcoiana com a exemple dels resultats que poden obtenir-se amb aquestes fonts.

L'estudi del cas alcoià resulta especialment rellevant en el context valencià i espanyol pel seu singular procés d'industrialització. Al llarg del xviII, Alcoi es va convertir en el principal centre espanyol productor de teixits de llana, arribant a fabricar a principis del XIX uns 12.000 draps anuals i configurant-se com el centre d'un autèntic districte protoindustrial (Torró Gil, 2019). L'anàlisi de l'evolució de l'agricultura del seu entorn immediat suposa, per tant, un pas necessari per tal d'entendre les claus d'aquest procés. I aquesta anàlisi ha de contemplar, ineludiblement, l'evolució del producte agrari pel que fa a les seues tendències, al seu volum global i a la tipologia de les produccions i les seues variacions. Per a portar a bon port aquesta

33 El cert és que, segons el quadern del Manifest de 1628 conservat a l'AMA —v. nota anterior - la part corresponent al delme -1.300 càntirs, aquell any - era molt reduïda. El col-lector del delme d'aquell any, Pere Carbonell, va manifestar que la quantitat recollida en espècie era l'esmentada per quant se han concertat los arrendadors ab molts dels vehins ans de la collita y pagaren lo concert en diners y los hereters han manifestat lo vi que havien de donar al delme juntament ab lo demés que han collit AMA, I.4.4.4.1, Manifest del Vi, 1628, p. 15. 
empresa és fonamental la informació que ens proporcionen les fonts decimals.

La recerca que sintetitzaré es va produir en dues fases: una primera de caràcter exclusivament local (Torró Gil, 1989; 1994) limitada als segles XVI i XVII, i una altra en la qual vaig eixamplar la cronologia — des de 1444 fins als inicis del s. XIX — i l'àmbit territorial a tota la comarca - v. figura 1- (Torró Gil, 2000). La informació recollida prové tant dels registres de les parts bisbals conservats a l'ACV com dels del terç delme provinents de l'ARV.

Pel que fa a les dades obtingudes de les parts bisbals, aquestes em van ser molt amablement facilitades pel mateix Manuel Ardit.

Figura 1.




En un primer moment vaig procedir a la selecció de delmaris per a construir una mostra comarcal homogènia. Així, per al carnatge vaig emprar els delmaris d'Alcoi, Bocairent, Castalla, Cocentaina, Penàguila i Perputxent, mentre que per al delme de pa i vi els delmaris seleccionats van ser els d'Agres, Alcoi, Bocairent, Castalla, Vall de Ceta, Cocentaina, Penàguila, Perputxent i Planes. Així mateix, vaig excloure els delmaris de pa i vi de Xixona, que va incloure Ibi i Tibi fins a 1763 , i el d'Ontinyent que va incloure Biar probablement entre 1565 i 1678. La metodologia en el processament de les dades va consistir a omplir els buits de les sèries. Fins a 1650 la restitució es va fer emprant els períodes amb dades de tots els delmaris. A causa de les conseqüències demogràfiques de l'expulsió dels moriscos vaig calcular l'agregació fins a 1615 sobre la base de les dades de 15681602 , mentre que des de 1616 fins a 1650 la base van ser les dades de 1623-1626. Des de 1651 les sèries presenten una notable continuïtat, de manera que vaig cobrir els buits aillats de cadascuna d'elles amb el càlcul del pes del delmari sobre el total en els 8 anys anteriors. Finalment, les dades van ser deflactades amb les mitjanes mòbils (41-4) dels preus del blat de València (Hamilton, 1983: 346-352, 372-375 i 402-407; Palop Ramos, 1977, 1982) atesa la insuficient continuitat de la sèrie de preus d'Alcoi.

Pel que fa al terç delme, la informació prové dels registres de Batllia i Administració de la secció Mestre Racional de l'ARV des de 1444 fins a 1702. Aquesta informació va ser completada amb la que tenim del segle XVIII - molt escadussera - publicada per Romeo (1986: 37). En la pràctica, malgrat trobar-se en un mateix fons documental, la documentació emprada es va obtenir de tres fonts diferents. En primer lloc, la dels arrendaments dels terços delmes de pa i vi i de carnatge consignats en els quaderns de rendes de la batllia. Atès que alguns arrendaments anuals no apareixien en aquests quaderns, els buits van ser coberts amb els valors consignats en l'administració general del mestre racional. Finalment, vaig emprar els quaderns de recaptació del batlle d'Alcoi dels anys en què aquest va administrar la renda directament -1598, 1603-1606, 1611, 1616-1627, 1652, 1657-1658, 1663, 1676 i 1691-1694. La metodologia va resultar més senzilla que amb les parts bisbals, ja que, junt amb els valors dels arrendaments, sols vaig calcular el valor del producte recaptat els anys d'administració directa quan el batlle transformava les espècies 
en diners mitjançant la venda. Posteriorment vaig deflactar seguint el mateix procediment emprat amb les parts bisbals. Com es pot veure al gràfic 10 , la comparació entre les tendències observables en l'evolució dels arrendaments anuals del terç delme i els quadriennals de les parts bisbals — ambdós deflactats amb les mitjanes mòbils dels preus del forment de València- del delmari d'Alcoi no resulten discrepants ni en el llarg ni en el mitjà termini, tret de les dades del segle XVIII. El terç delme ens permet observar la conjuntura llarga de la segona meitat del segle xv com una fase d'estancament o lleugera disminució del valor real d'aquesta renda i, en conseqüència, de la producció agrària de la localitat. A més, el gràfic 11 ens indica que, tendencialment, l'evolució de la recaptació del delme a la comarca presenta uns trets molt semblants als de la mitjana del país observable als treballs esmentats al llarg del text.

Gràfic 10. Parts bisbals del delme i terç delme a Alcoi, 1444-1800

1000



Font. Torró Gil (2000: 186).

Allò més destacable és la clara tendència que presenten els baptismes com a indicadors de l'evolució del volum de la població a créixer a un ritme major que el de la producció agrària representada per les recaptacions decimals. No és, certament, un fenomen especial si no fos per la seua intensitat. Com es pot observar al gràfic 12 les ràtios entre els índexs de les parts bisbals del delme i dels baptismes mostren una clara regressió en el molt llarg termini. Aquesta tendència es 
Gràfic 11. Parts bisbals del delme i baptismes agregats de la comerca d'Alcoi $1785-1799=100$

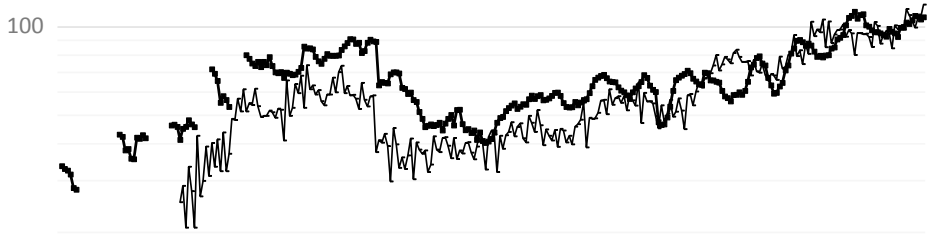

10

8\%

$\longrightarrow$ parts bisbals del delme baptismes

FONT. Torró Gil (2000: 237).

Gràfic 12. Ràtio índex de les parts bisbals del delme / índex de baptismes

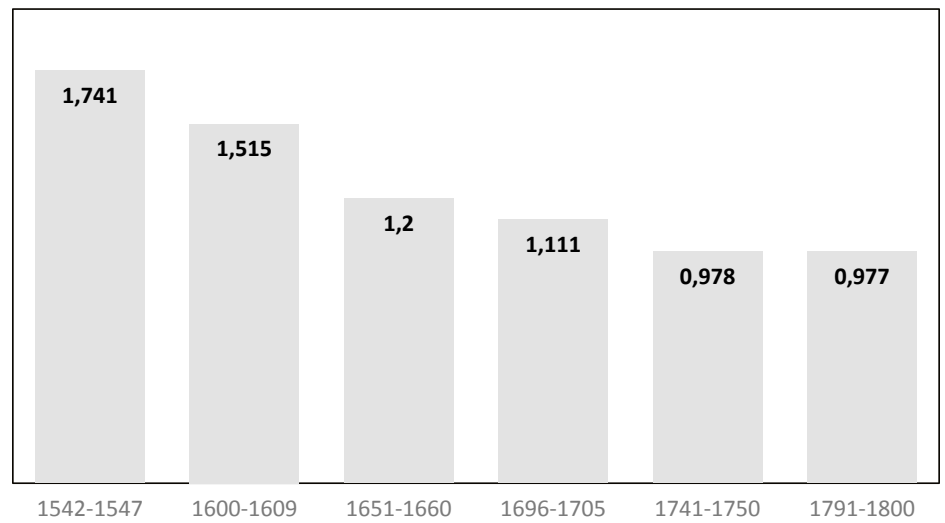

Font. Elaboració pròpia a partir de les dades oferides a Torró Gil (2000: 561-568 i 680-695).

manifesta amb una especial intensitat en el cas de la mateixa vila d'Alcoi -v. gràfic 13. El seu desenvolupament manufacturer és el responsable d'aquesta evolució i condiciona el de tota la comarca en dos sentits: (1) pel pes demogràfic creixent de la vila que coneix els inicis d'un marcat procés d'urbanització, com a mínim des del segon 
Gràfic 13. Parts bisbals del delme, terç delme i població a Alcoi, 1444-1800



FonT. Torró Gil (2000: 716-721).

quart del set-cents, i, (2) per l'extensió de les activitats protoindustrials relacionades amb la draperia al conjunt de la comarca i més enllà. Una vegada constatades aquestes qüestions convé, no obstant això, remarcar que allò a què les fonts decimals permeten apropar-nos en aquest cas no és el volum d'aliments produïts sinó el seu valor de mercat expressat en quantitats equivalents de forment.

Per la seua part, la recaptació en espècie del terç delme de les diferents produccions al llarg del segle xvir permetia observar canvis importants en la composició del producte agrari. I això en dos sentits: (1) dins els cereals comparables directament pel volum de la seua producció, i, (2) en el conjunt de les produccions, a través del seu valor. ${ }^{34}$ Pel que fa als cereals - v. gràfic $14-$, l'evolució al llarg del segle Xvir mostra que les quantitats produïdes de les diferents espècies no variaven en el mateix sentit en tots els casos. Aquesta observació va aconsellar cercar altres fonts per a tractar de descobrir si aquests canvis es limitaven al segle XVII o podien observar-se abans i després. ${ }^{35}$ Així, es pot constatar com, almenys

34 Partint sempre del supòsit que no hi va haver canvis en les particions de les collites al llarg del període cobert per la documentació emprada. 
Gràfic 14. Recaptació de cereals en espècie del terç delme Alcoi, 1598-1694



FonT. ARV-MR, 5.430 a 5.452: Terç delme d'Alcoi.

pel que fa a l'ordi i al forment, sembla que abans de 1500 aquests dos cereals podien equiparar-se quant a la seua producció, com testimonien els arrendaments dels molins reials que van exigir fins a 1536 un pagament en espècie de forment $i$ ordi, meitat per meitat. ${ }^{36}$ De la mateixa manera, la informació presentada per Pérez Planelles (1807) ens indica que aquestes tendències es van perllongar fins a l'alba del segle XIX —v. taula 1. En síntesi, i centrant-nos tan sols en els canvis més importants, al llarg del període estudiat es pot observar com l'ordi va declinar com a cereal panificable; la dacsa es va introduir molt d'hora - a finals del cinc-cents, probablement - i es va convertir en el segon cereal produï; l'oli va perdre terreny enfront de l'espectacular creixement de la producció de vi, i, finalment, el forment es va consolidar com a cereal bàsic al llarg del xvi i ja no va perdre aquesta posició dominant.

36 Pel que sembla, en els moments immediats després de la conquesta cristiana l'ordi superava el forment en una proporció de dos a un (Torró Abad, 1999: 149). El canvi de l'arrendament en espècie dels molins a un altre en moneda fa sospitar que la proporció 50/50 entre ordi i forment ja s'havia alterat a favor del segon fent inviable aquest tipus de recaptació (Torró Gil, 2005: 569). 
Taula 1. Aproximacions a la producció agrària d'Alcoi en espècie (1601-1807)

$\begin{array}{ccccc} & 1601-1603 & 1616-1627 & 1691-1694 & 1807 \\ \text { Forment } & 3.484,66 & 3.562,66 & 3.764,66 & 6.973 \\ \text { Ordi } & 1.274,66 & 1.350,66 & 710 & 480 \\ \text { Dacsa } & 530 & 340,825 & 940 & 4.000 \\ \text { Avena } & 296 & 231,33 & 564 & 14 \\ \text { Sègol } & 0 & 2,66 & 116 & 74,5 \\ \text { Total cereals } & 5.585,32 & 5.488,135 & 6.094,66 & 11.541,5 \\ \text { Oli } & 5.560 & 2.872,5 & 2.070 & 1.000 \\ \text { Vi } & (5.730,625) & 14.720 & 10.500 & 67.500\end{array}$

FonTs. Delme de 1601 a 1694; ARV-MR, 5.430 a 5.452: Terç delme d'Alcoi, 15981694. 1807: Pérez Planelles (1807: 25-26).

Notes:

- El volum dels cereals s'expressa en cafissos, el del vi, en càntirs i el pes de l'oli, en roves.

- El volum de vi de 1601-1603 és una extrapolació del de 1598, ja que en els anys indicats a la taula es recaptava conjuntament amb el paner.

- El volum de la producció s'ha obtingut multiplicant la part del delme per 8 en el cas dels cereals, tret de la dacsa, i per 10 per a la resta.

\section{A MODE DE CONCLUSIÓ: ELS LÍMITS DE LA} DOCUMENTACió DECIMAL I ALGUNES POSSIBLES LÍNIES DE RECERCA

Així doncs, i ateses les característiques de la documentació que s'ha emprat fins a la data, les fonts decimals permeten la reconstrucció d'indicadors amb els quals podem apropar-nos a la realitat de l'evolució de la producció agrària, però amb unes limitacions evidents. En general, crec que estem en condicions d'afirmar que a través del delme podem percebre amb nitidesa les tendències a llarg termini, és a dir, allò que s'ha convingut a denominar com a cicles seculars. Tanmateix, les conclusions sobre la proporció que van assolir aquestes tendències han de ser preses amb una gran prudència atès el caràcter aproximatiu de la font - els arrendaments - i els canvis en les condicions de la seua recaptació - nous conreus, fraus, variacions en les taxes i les formes de recaptació i en les demarcacions dels delmaris, altres canvis com les alienacions o les variacions en l'excusat, etc. Açò ens condueix a afirmar que, de nou amb caràcter general, resulta impossible establir 
ordres de magnitud respecte al valor de la producció agrària ni, menys encara, del producte físic. I, de la mateixa manera, tot i permetre aproximacions molt vagues respecte dels cicles mitjans, no podem, però, reconstituir les variacions anuals a gran escala.

La cosa canvia quan es tracta d'aproximacions a una escala territorial diferent, és a dir, amb un caràcter més local o comarcal. Per exemple, sempre que seleccionem adequadament les mostres, resulta fàcil distingir — de nou, especialment en el llarg terminientre ritmes diferents segons una zonificació prèvia en funció de l'entorn socioeconòmic, de l'agroecològic o de tots dos alhora. A més, en àmbits locals, la disposició de fonts de contrast fa més senzill el control de les variables; fins al punt de permetre reconstruccions més pròximes a la realitat que hom pretén estudiar.

Per aquesta raó, em sembla que una línia de recerca que ha de ser explorada -o reexplorada, segons els casos- és el retorn al marc local. Des del meu punt de vista, les característiques de les fonts aconsellen una multiplicació d'estudis locals que permeten una major profunditat de l'anàlisi per a assajar síntesis de caràcter més general. Això sí, seria necessari el disseny de plans de recerca i la definició de metodologies comunes i compatibles que, d'una banda, permeteren els estudis comparatius, i que, d'una altra, i sempre que fos possible, facilitaren la construcció d'agregats sobre la base d'aquests estudis. Caldria treballar preferentment aquelles àrees amb possibilitats d'emprar fonts diverses, particularment aquelles que continguen informació sobre quantitats físiques - particions de delmes, particions de fruits per al pagament de rendes senyorials, estimacions coetànies... Finalment, i per a millorar la qualitat de les reconstruccions de sèries, atesa la dificultat de recollir informació diversificada sobre els preus dels diferents productes, caldria explorar les possibilitats de reconstruir sèries locals de preus, com a mínim de forment.

Una segona línia de recerca podria consistir en l'eixamplament i l'extensió de la recollida d'informació dels arxius catedralicis. El fons de la catedral de València, per exemple, permet un marge substancial de millora dels coneixements sobre els delmes. Es tracta d'un enorme arxiu amb una probabilitat molt elevada de trobar informacions sobre els mecanismes de cobrament i d'arrendament, sobre les fluctuacions 
de les proporcions cobrades i sobre les administracions territorials —delmaris i filloles. Tan sols amb l'estudi de la documentació que s'hi conserva relacionada amb conflictes sobre el cobrament segurament guanyaríem considerablement en riquesa informativa. És necessari remarcar que, a més, la informació de la qual disposem en l'actualitat resulta especialment insuficient pel que fa al període anterior a 1500 , pel que afecta al frau - particularment abans de 1750_, o pel que toca a la qüestió de l'excusat.

Si aquestes possibilitats s'albiren a l'arxiu més treballat, encara creixen més quan girem la vista envers les altres diòcesis valencianes. Pel que fa a l'Arxiu de la Catedral d'Oriola, no existeixen estudis anteriors al segle XVIII, tret de les recaptacions en espècie del forment $i$ l'ordi. Tampoc no sembla que s'hagen estudiat registres d'aquest àmbit anteriors a la segregació de la diòcesi de Cartagena. Evidentment, les consideracions fetes a dalt sobre l'Arxiu de la Catedral de València resulten igualment vàlides per al de la diòcesi del sud del país. I, encara més, el marge de millora resulta infinit en el cas de la diòcesi de Sogorb i de l'àmbit valencià de la diòcesi de Tortosa, els arxius de les quals encara semblen verges, almenys pel que fa a la qüestió que ens ocupa.

Per acabar, encara resta la consideració del delme com a renda. Sabem molt poc o res de qüestions tan importants com quin era el paper que representaven els delmes en els ingressos de les diferents institucions que gaudien del cobrament. Tampoc no sabem gran cosa sobre quins eren els mecanismes d'arrendament i quines persones se'n beneficiaven. És un terreny amplament inexplorat del qual a penes coneixem algunes generalitats i apunts dispersos ací $i$ allà. A la meua recerca, per exemple, he pogut constatar la importància que van tindre els arrendaments de delmes, rendes feudals i municipals, en els ingressos dels fabricants de draps al llarg del xviII. Ens trobem davant d'un cas aïllat? Finalment, si volem valorar adequadament el paper del frau, cal orientar en aquest sentit la recerca. Ens trobem davant un aspecte clau de l'enfrontament entre els poders feudals i aquells que els sustentaven amb el seu treball. Si volem avançar en el coneixement de la societat feudal i les claus que n'expliquen l'ensorrament, aquesta línia de recerca se'ns presenta com a ineludible. 
๑ :三

$<$

$>$ 


\title{
4. LA RECAPTACIÓ I EL REPARTIMENT DEL DELME A LA CATALUNYA VELLA. EL CAS DEL BISBAT DE GIRONA, SEGLES XIII-XIV ${ }^{1}$
}

\author{
Elvis Mallorquí
}

El delme era la desena part dels fruits i dels altres productes de la terra que es pagava com a tribut a l'Església, al rei i als senyors. Els seus orígens es remunten a mitjan segle viII arran de la mobilització dels tresors de les esglésies franques per Carles Martell, majordom dels reis merovingis, per frenar l'avenç dels musulmans i, després de la batalla de Poitiers, el 732, iniciar la conquesta cristiana de la Gàl.lia. Des de l'any 756 el seu fill, Pipí el Breu, ja esdevingut rei dels francs, va instar els bisbes a imposar el delme. No va ser, però, fins després de les grans fams dels anys 792 i 793, en el Sínode de Frankfurt de l'any 794, que Carlemany va establir que cada fidel pagués el delme a l'església local. Des d'inicis del segle ix cada església havia de tenir un terme format per un conjunt de vil.les i vilars, les unitats

$1 \quad$ El text del present capítol és fruit de la fusió de dues ponències realitzades en poc més d'un mes de diferència a la Universitat de Girona: d'una banda, la que duia el títol «La recaptació del delme a la Catalunya Vella a l'època medieval: un problema historiogràfic per resoldre» que es va presentar el 26 d'octubre de 2018 a la jornada d'estudi «El Delme com a Font per a la Història Rural», organitzada per l'Associació d'Història Rural i el Centre de Recerca d'Història Rural; i, d'altra banda, la que va tractar sobre «El mercat dels delmes al bisbat de Girona, segles XIII-XIV» en el marc del seminari Mercat de la Terra, Crèdit i Crisi a la Baixa Edat Mitjana, celebrat a Girona els dies 24 i 25 de setembre de 2018. 
de poblament rural més freqüents. Havia nascut la parròquia entesa com a demarcació territorial (Mallorquí, 2017a: 18-19).

Aquest delme de Carlemany, però, és el mateix que es va instaurar als comtats de la Marca Hispànica al darrer quart del segle ix per finançar les canòniques fundades a les catedrals dels bisbats d'aquest territori (Puigvert, 1992)? És de quan daten les primeres notícies del delme i de les parròquies al bisbat de Girona: el 888 el bisbe Teuter va concedir els delmes de catorze esglésies a la catedral; i el 889 l'abat de Banyoles va denunciar uns laics per haver-li sostret unes esglésies, anomenades parrochie, i els seus delmes, primícies i oblacions. Poc després, l'any 904 el bisbe Serfdedéu va acudir a Camprodon i a la Bisbal per a consagrar els nous temples que s'hi havien edificat. En el segon cas, el bisbe aparrochiavit atque concessit decimas et primicias de les vil.les de Fontanet, Palatium Maurore i Fonteta, i dels vilars d'Abellars, Perduts i Murell, que van formar la parròquia de Santa Maria de la Bisbal (Mallorquí, 2011a: 79-81).

És el mateix delme que el comte Ramon Berenguer IV de Barcelona va implantar a les terres conquerides de Lleida i Tortosa, i el rei Jaume I, als regnes de Mallorca i València? L'endemà de les conquestes van imposar el delme sobre els productes de l'agricultura, l'oli, el vi, el peix, el bestiar, la cacera, els molins, els forns i, a València, el que es rebia dels sarraïns. A més, a la península Ibèrica era costum que els monarques sol-licitessin al papa convertir en croada cada conquesta d'un territori musulmà i, així, apropiar-se del terç del delme per cedir-lo en porcions a nobles i cavallers que reconeixien com a feus dels bisbes respectius (Burns, 1962: 249-250, i 1966: 440-451; López Bonet, 1989: 353-356; Barton, 2009: 10-31). A Menorca, però, el rei Jaume II es va reservar tots els delmes i totes les primícies amb els quals proporcionava les rendes als clergues parroquials de l'illa (Sastre, 1981-1984: 152; Sastre, 1997-1998: 46-47).

El delme de Carlemany és el mateix delme que va ser confirmat pel rei Ferran II el Catòlic en la Sentència arbitral de Guadalupe de 1486? El text del capítol 15 deixa clar que:

los dichos pageses [de remença] sean tenidos d.aquí adelante integramente sin frau alguno, bien y lealmente a su senior o senyores a quien pertenescen pagar diezmos, promicias, 
censos, tascas, quintos, quartos e otros drechos reales que sean acostumbrados pagar por razón y causa de los mases, tierras y possessiones que posseen e possehiran. (Vicens, 1978: 344-345)

És el mateix delme que apareix contínuament en la legislació de les Corts catalanes del segle xvi (Fontana, 1966; Serra, 1988: 5157)? Aquesta qüestió va generar un munt de plets entre els senyors delmadors i les comunitats subjectes al delme durant tota l'època moderna. El resultat va ser una gran varietat de pràctiques de delmar, cosa que reflecteixen les consuetes escrites pels rectors parroquials a l'hora de fixar la quota a pagar, la part corresponent a la primícia, els productes subjectes a la prestació, si es feia en gra a l'era o en garba al camp, l'exclusió o no de la llavor per a la sembra següent i dels baleigs, rebaleigs i solatges (Gifre, 2011: 174-180 i 216-246).

¿I és el mateix delme que s’abolí a França durant l'agost de 1789, a l'inici de la Revolució francesa? Després d'una proposta inicial el 4 d'agost, al cap d'una setmana es va debatre sobre la seva abolició i es van posar de manifest les posicions dels diversos grups socials a l'entorn del delme: l'alt clergat n'acceptava la supressió; els rectors parroquials no ho volien perquè servia per finançar l'assistència als pobres i l'ensenyament i perquè els pagesos no se n'havien queixat als cahiers de doléances; mentrestant, Mirabeau considerava el delme com un robatori als propietaris i demanava noves formes de finançament del culte cristià (Arnoux, 2012a: 226-232).

És el mateix delme que, tot $\mathrm{i}$ haver estat reduit a la meitat durant el Trienni Liberal a Espanya, va ser recuperat per Ferran VII durant la Dècada Ominosa, de 1823 a 1833, i els rectors parroquials predicaven als fidels que calia pagar perquè era el cinquè manament de l'Església (Canales, 1982: 142-168)? Un delme que, des de l'entronització d'Isabel II, els propietaris sabien que desapareixeria aviat i ja preveien que, quan succeís, els masovers els l'haurien de pagar (Congost, 1986: 274-277). Un delme que, tot i que va ser abolit el 1837 a Espanya, encara va sobreviure uns anys fins a 1845 en què es va implantar la contribució agrària proposada pel ministre Pascual Madoz (Canales, 1985: 260-273).

En el present estudi hem seguit la hipòtesi que sí, que tots aquests delmes són, en essència, la mateixa renda que pagaven els habitants de la parròquia a uns senyors particulars, laics i/o eclesiàstics, que, 
en un principi, havien tingut la responsabilitat d'assegurar el culte a l'església parroquial. Aquesta definició àmplia de delme pot incloure totes les transformacions de la renda al llarg dels prop de mil anys que va durar, entre l'any 888 i el 1837 a les terres de Girona, juntament amb els canvis en l'ordenació de la societat, l'organització del territori rural, urbà i fins i tot marítim, l'estructuració política dels regnes feudals i, és clar, les activitats econòmiques.

Després d'un breu balanç historiogràfic sobre el delme dels segles de l'edat mitjana, volem presentar, a partir del cas concret del bisbat de Girona durant els segles IX-XIV, tota la complexitat que comporta l'anàlisi del delme. Per això, exposem, en primer lloc, les possibilitats i les mancances de les fonts documentals que permeten aproximar-s'hi. A continuació, descrivim totes les accions que resten amagades rere el verb delmar i analitzem el paper de totes les persones que hi són implicades. Finalment, assagem de descobrir les evolucions dintre dels grups dirigents de la societat que tradicionalment qualifiquem com a feudals entre els segles x i xiv. Unes evolucions que, si bé poden haver-se donat a la resta de la Catalunya Vella i a altres territoris de l'antic Imperi carolingi, difereixen enormement de les de la resta de la Hispània conquerida als musulmans a partir de la fi del segle XI.

\section{BALANÇ HISTORIOGRÀFIC DEL DELME A L'EDAT MITJANA}

El delme, inicialment considerat com una renda de natura eclesiàstica, va ser primerament estudiat pels historiadors de l'Església. Paul Viard (1909 i 1912) va establir la diferenciació entre el delme jueu pagat a levites i sacerdots fins al segle i dC i el costum cristià de pagar-ne de manera voluntària des de la fi del segle IV dC; a més, considerava com a anomalia l'apropiació del delme pels senyors laics produïda en el context de la fragmentació política de la fi de l'Imperi carolingi, situació que va ser corregida a partir de la reforma gregoriana amb la restitució de delmes a clergues i monjos. Els seus punts de vista, enriquits amb les aportacions de Catherine E. Boyd (1952) i Giles Constable (1964), perviuen encara en la tesi de Pierre Bonnassie (1979-1981), el qual, si bé documenta nombrosos delmes que eren cedits entre laics com a feus, no els integra en les seves argumentacions sobre la formació de la societat feudal catalana. Des 
d'aleshores, diverses contribucions puntuals, recollides en la completa síntesi de José Ramón Díaz de Durana i Enric Guinot (2010) sobre el delme en els regnes peninsulars durant l'edat mitjana, han permès situar-lo al cor de l'organització de la societat i del territori rurals.

\subsection{Un cert oblit}

Arran de les grans trobades d'historiadors modernistes que plantejaven utilitzar les sèries i els registres del delme per seguir les fluctuacions de la producció agrària (Goy i Le Roy Ladurie, 1972 i 1982), a Catalunya també es van començar a prendre les sèries d'arrendaments de delmes dels segles XVI, XVII i XVIII per a l'estudi de la renda senyorial i, en certs casos, de la producció agrària. Pierre Vilar, Jaume Dantí, Eva Serra i molts d'altres tenien clar que el delme i la primícia eren elements clau de l'organització feudal a partir de la Sentència arbitral de Guadalupe (Mallorquí, 2011b: 24-26). En canvi, el delme a la Catalunya medieval continuava essent un gran desconegut en comparació amb la senyoria sobre els homes i les terres, de la qual s'ha estudiat a fons la imposició de la servitud i el control de les transaccions de les parcelles que constituïen els masos (Bonnassie, 1979-1981: II, 260-267; Freedman, 1993; To, 1993 i 2005; Lluch, 2005). Però aquesta és tan sols una de les realitats que definien la pagesia medieval catalana (figura 1).

Els historiadors de la societat i l'economia medievals, en les darreres dècades, han dirigit les seves recerques a dues qüestions que van, en paraules de Pau Viciano (2017), més enllà de la senyoria: el mercat i els impostos. D'una banda, el naixement de la fiscalitat d'estat a partir de la fi del segle xir i la seva extensió a tots els territoris del Principat des de mitjan segle xiv, a causa de les necessitats financeres de la Monarquia per fer front a les successives guerres, va comportar l'establiment d'impostos directes que eren repartits a través dels fogatges (Sánchez Martínez, 1995; Ortí, 1999). D’altra banda, l'estudi de les implicacions del desenvolupament de les xarxes comercials que connectaven els habitants dels masos servils amb les petites viles amb mercat i notaria, on acudien els mercaders de les ciutats properes per vendre - generalment a crèdit- els productes de l'artesania local o matèries importades de més lluny (Farías, 
Figura 1. Drets, rendes i impostos sobre els pagesos de mas del bisbat de Girona, segle XIV


2009). Pel que fa a l'estudi de la jurisdicció, als tradicionals estudis sobre les implicacions de la senyoria sobre els habitants d'un castell termenat -monopolis senyorials sobre la ferreria, el forn o el molí, drets d'accés a les pastures i boscos comunals, obligacions de treball a les fortificacions, serveis militars-, cal afegir-hi recerques més recents que han permès detectar els mecanismes jurisdiccionals que permetien als comerciants que venien productes manufacturats als 
pagesos emparar-los les collites per cobrar els deutes pendents, si és que en tenien (Sales, 2014: 52-54; 2018: 656-657, i 2019: 45-49).

Encara queda, però, la realitat de la parròquia, una altra forma de subjecció de la pagesia rural, no només en l'àmbit espiritual, sinó també en les qüestions materials, pels diversos drets que demanaven els clergues de l'Església i, sobretot, pel delme i la primícia. Pel fet de no anar lligats a una terra individualitzada, la documentació generada no és tan precisa com la relativa a la senyoria directa. Delmes i primícies afectaven, de manera universal, a totes les terres d'una parròquia i a totes les - principals - activitats econòmiques que s'hi donaven. En paraules de Mathieu Arnoux (2012a: 221), durant près d'un millénaire, la dîme ecclésiastique fut probablement le phénomène le plus massif de l'économie européene.

\subsection{El delme com a índex de la producció agrària}

Per als primers segles medievals, les dades concretes per avaluar la producció agrària i l'ingrés dels senyors a partir del delme són escasses. Jean-Pierre Devroey (2010: 49-54) prova d'estimar-ne el valor per a les comunitats pageses descrites en els políptics carolingis. Per això, cal destacar l'excepcional inventari dels ingressos de la parròquia, plebe, de San Pietro di Tillida a mitjan segle $\mathrm{x}$ conservat a la seu episcopal de Verona: 700 modis de gra, 80 àmfores de vi, 350 anyells i porcells, i 300 mesures de lli. Els productes procedien de dotze nuclis de població rural, els vici, integrats en el terme parroquial de Tillida, i una part del forment, el sègol, les faves, el mill, el panís i la melca era per a l'arxiprevere de Verona (Castagnetti, 1976: 157-165).

Per a la baixa edat mitjana, els llibres de comptes del Reial Patrimoni de Mallorca permeten resseguir els preus pels quals els procuradors reials venien - és a dir, arrendaven - les rendes, entre les quals hi ha el delme del bestiar, el vi, les hortalisses, l'oli i el blat (López Bonet, 1983; Sastre, 1989-1990, 2009 i 2012; De Juan, 1996). En el cas del bisbat de Girona, cal esperar fins al segle xv per a tenir dades seriades per avaluar l'evolució del delme i les altres rendes feudals. Els pabordes de l'Almoina del Pa de la seu de Girona van comprar totes les porcions del delme de Santa Cristina d'Aro - excepte un sisè que era de la catedral- entre els anys 1417 i 1430. Els llibres de comptes de la 
institució enregistren els preus dels arrendaments durant bona part del segle $\mathrm{xv}$, excepte per a sis anys en què els pabordes no el van poder vendre i van gestionar directament la recol-lecta, l'emmagatzemament i la venda dels productes delmats: forment, mestall, ordi, mill, civada, raïms, vi, polls, anyells, porcells, lli, cànem, llobins, faves, cebes, veces, cigrons i safrà (Marcó, 2008: 118-131; Mallorquí, 2017a: 69). El valor del delme es va anar depreciant, com la resta de rendes agràries, fins al punt més baix que va ser el 1471, en plena Guerra Civil catalana.

\subsection{El delme com a element estructurador de la societat}

Les notícies sobre el delme medieval permeten aproximar-se a l'estructura interna de la societat medieval. Dues publicacions colllectives, coordinades per Roland Viader (2010a) i Michel Lauwers (2012a), contribueixen enormement a modificar la mirada dels medievalistes sobre el delme. El títol d'un article de divulgació, «Comment l'Église a confisqué la dîme» (Lauwers i Mazel, 2014), resumeix el canvi de paradigma en relació amb el model establert pels primers historiadors de l'Església que defensaven el delme com una renda eclesiàstica ja en origen, que hauria estat usurpada pels senyors feudals i que, a instàncies dels dirigents de la reforma gregoriana del segle XI, hauria anat essent restitü̈da a institucions eclesiàstiques. Aquests mots, i d'altres de sinònims, són els que apareixen en els documents que, curosament, han conservat monestirs, catedrals i esglésies en els seus arxius per demostrar quan calia els seus drets sobre els delmes. L’any 1089 Guillem Guillem va definir l'església de Vilatenim a Santa Maria de Vilabertran perquè el prelat del monestir va demostrar judicialment que cent vint anys abans Bonadona havia donat els delmes per a la illuminació i el culte de l'església monàstica; tanmateix, el laic defensava que durant aquest període de temps els delmes havien estat en mans de la seva família i, al final, va aconseguir 60 sous a canvi de la definició (Marquès, 1995: n. 161). Aquest tipus de disputes encara es produien al segle xviII: l'any 1786, per exemple, mentre que els pescadors de Lloret defensaven en un plet que el delme del mar de la catedral de Girona, titular del castell del lloc, derivava d'un dret feudal vinculat al castell segons constava en documents dels anys 1217 i 1372, la catedral mantenia que el delme li pertocava gràcies a una butlla de l'any 1002, l'única còpia de la qual, al Cartoral 
de Carlemany escrit a inicis del segle XIII, conté algunes interpolacions que atribueixen al bisbe i a l'Església una autoritat sobre tots els delmes del bisbat. Ja ho sospitaven els procuradors dels pescadors, que afirmaven que no se han sacado de los originales ni matrices y que estos no existen como se creía ni en el archivo del Cabildo ni en oficio ninguno (Mas, 1988; Marquès, 1993: n. 70; Mallorquí, 2017a: 80-81 i 2018a: 21-23).

En el conjunt de treballs aplegats en els volums coordinats per Roland Viader i per Michel Lauwers s'hi destaquen tres idees essencials: en primer lloc, el pes important del delme en la construcció de les senyories i en l'organització de la jerarquia feudal, atès que era un element essencial dels feus; en segon lloc, el seu rol com a motor de la formació de les comunitats rurals perquè era un mecanisme de redistribució de les riqueses a través, per exemple, de l’almoina local; i, en tercer lloc, la dimensió eclesiàstica del delme, que sobretot a partir del IV Concili del Laterà va esdevenir el símbol i l'instrument de la dominació universal de l'Església (Viader, 2010b; Lauwers, 2012b). Tot això, però, sense oblidar que el delme suposava una sostracció del $10 \%$ de la producció i que, per tant, separava la minoria de senyors que en rebien de la majoria de la població, els pagesos, que en pagaven. Era un element constitutiu de la identitat social pagesa fins al punt que, a molts indrets d'Europa, va esdevenir una institució de la vida comunitària (Arnoux, 2012a: 235-237). La qüestió que ens plantegem en aquest estudi és fins a quin punt també ho va ser a la Catalunya Vella i, en concret, a les terres del bisbat de Girona.

\section{FonTS DOCUMENTALS SOBRE EL DELME AL BISBAT DE GIRONA}

A partir d'un llibre episcopal de característiques prou excepcionals, el Llibre verd dels feus, dels anys $1362-1371,{ }^{2}$ hem pogut entendre que el delme era un component essencial en la societat medieval gironina,

2 Bona part de les informacions recollides en les pàgines que segueixen procedeix de l'edició completa del Llibre verd i del seu estudi introductori, així com d'una publicació divulgativa sobre el delme (Mallorquí, 2011b i 2017a). Hi fan referència totes les notícies sense una cita específica. 
especialment en el món rural. A través de la seva comparació amb fonts documentals anteriors i contemporànies s'illuminen tènuament els processos complets amb els quals una part de la producció del món rural acabava als graners i cellers d'un grup molt divers de senyors delmadors. Presentem, tot seguit, els diversos tipus de documents que aporten, des de múltiples perspectives, detalls reveladors sobre la pràctica del delmar al bisbat gironí.

\subsection{La legislació eclesiàstica}

Tot i que entre els segles XI i XII ja hi ha disposicions canòniques que tracten el delme, no és fins a les del IV Concili del Laterà, de l'any 1215 , que tenen validesa sobre tota la cristiandat occidental. Es tracta dels cànons $53,54,55,56$ i 61 , que estableixen la precedència del delme per davant d'altres tributs - censos i agrers- i la vinculació definitiva dels feligresos a la seva parròquia a través de l'obligatorietat del seu pagament. En el Concili Provincial de Lleida de 1229 es va conferir una autoritat als bisbes de la Tarraconense sobre els delmes que monestirs i clergues de les esglésies rebien de part dels laics (Bueno, 2000: 335-336). Dels sínodes diocesans de Girona, celebrats regularment des de la meitat del segle XIII, en conservem algunes constitucions relatives al delme. Cal subratllar la reiteració, els anys 1256, 1335 i 1367, de manaments als rectors parroquials per tal que preguntin diligenter quis percipit decimam parrochiarum suarum, et pro ipsa decima teneatur, et quot domini sint in ea. I, fins i tot, va comunicar al bisbe omnes venditiones, permutationes, obligationes et alias quascumque alienationes actenus de decimis infra suam parrochiam (Noguer i Pons Guri, 1966-1967: 112 i 121; Bueno, 2000: 347-350).

\subsection{Els textos consuetudinaris}

En el cas del bisbat de Girona, la universalitat del pagament del delme no es tradueix en un alt nombre de regulacions consuetudinàries vàlides a tot arreu. Dels 198 articles que formen la versió més difosa dels Costums de Girona, la de Tomàs Mieres de mitjan segle XV, només n'hi ha 2 -articles XXXVII.1 i XXXVII.3-i 
unes glosses que s'hi refereixen directament i 2 més que fan referència a la situació dels alous fiscals i dels alous francs - articles XIX.16 i XXXVIII- que, com veurem tot seguit, tenen a veure amb el delme (Mieres, 2001: 152-155 i 259-260). El primer article és el més citat:

Quando decima et tascha et premitia et calcatura praestantur, sic solvuntur: primo solvitur decima quae est decima mensura; secundo solvitur tascha quae est undecima mensura; tertio solvitur premitia quae est medietas decimae, et sic est $\mathrm{XV}$ mensura; quarto solvitur calcatura; et mensura calcaturae debet esse eiusdem valoris mensurae que est tascha. Idem est in braciaticho, quod est similis mensurae taschae [...].

En realitat, de costums sobre la manera de recaptar i repartir el delme i les altres rendes a parts de fruits, n'existien a cada localitat. A Castelló d'Empúries es va dictaminar, el 1224, que un camp havia de pagar el quart dels esplets secundum consuetudinem parrochie Castilionis de terris quarteriis (Marquès, 1986: n. 101). A Lladó, l'any 1319, dos àrbitres van dictar, seguint la consuetudinem antiquam dicti loci, un centenar d'ordinacions per resoldre les qüestions que enfrontaven els parroquians i membres de la Universitat local amb els rectors de la parròquia de Sant Feliu i els canonges de Santa Maria de Lladó. Només 7 resolucions tracten els delmes i les primícies, els productes que en pagaven, les formes de prestació i qui n’obtenia (Mallorquí, 2012: 99-101). De situacions similars, se'n donaven a moltes localitats, tal com demostren les sentències, concòrdies i acords sobre delmes o primícies en què es detallen formes de recaptació o de divisió dels delmes; i també els establiments, les promeses o autoritzacions efectuades pels senyors envers els seus batlles (figura 2).

\subsection{Els arxius senyorials}

El delme apareix poc entre la documentació generada per senyors laics i institucions eclesiàstiques. Els capbreus senyorials reflectien els drets concrets que tenien els senyors en un o diversos indrets en el moment en què van decidir encarregar-ne la redacció. Per tant, si el senyor no tenia delmes, cosa que era molt corrent a la Catalunya Vella pel gran nombre de senyors existents a cada parròquia, en 
Figura 2. Localitats gironines amb notícies sobre pràctiques consuetudinàries en relació amb delmes i primícies

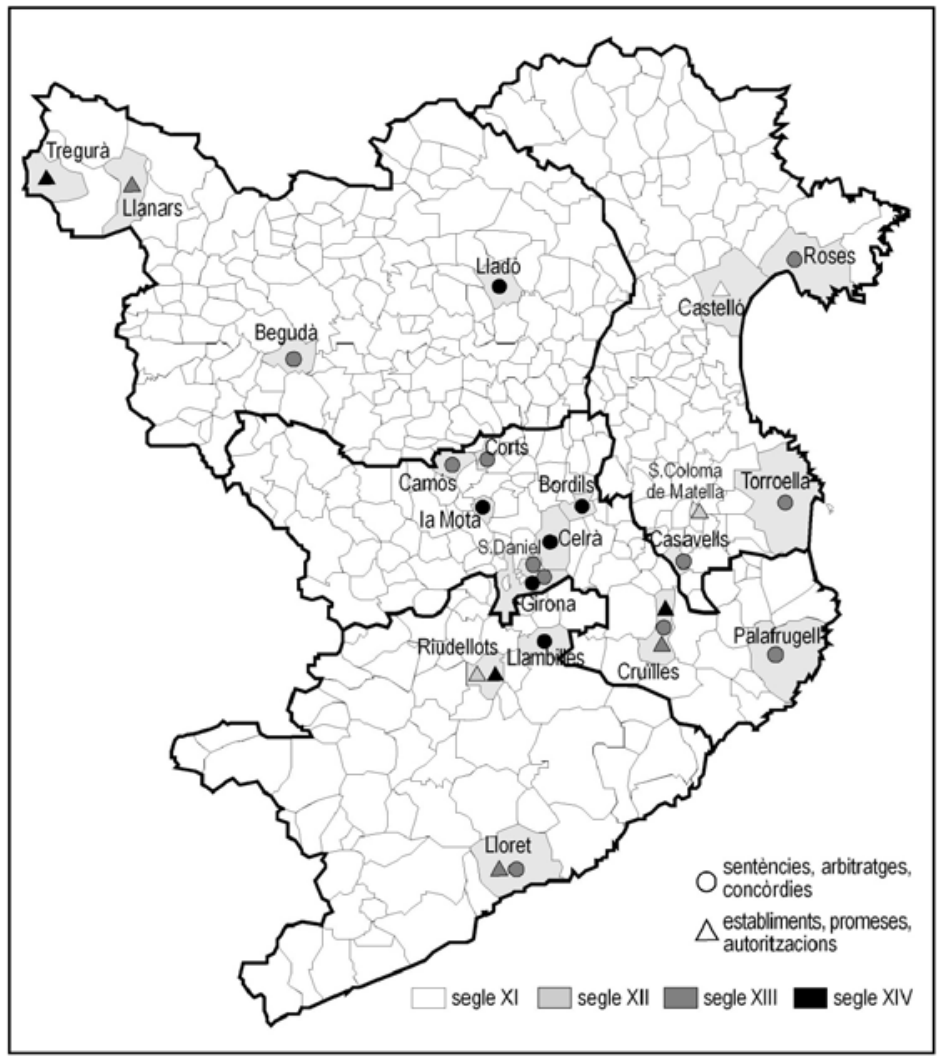

els seus capbreus no hi sortia cap menció o només alguna de molt circumstancial: en el capbreu de Palau-sator de 1410 la casa de la ferreria, dintre la vil.la, afrontava a migdia amb l'hospicio decime, amb la casa del delme, situada a prop del castell de Palau-sator i que devia ser on el senyor del lloc, Francesc de Sant Feliu, abans de 1362 hi feia recollir la meitat del delme del terme. ${ }^{3}$

3 Arxiu Nacional de Catalunya (ANC), fons ANC1/1141, Llinatge Riquer, marquesos de Benavent i comtes de Casa Dávalos, vol. 60, f. 53v (1406-1408); Torres, 2018: 49 i 54; Mallorquí, 2011b: n. 80. 
En canvi, quan el senyor que ordenava el capbreu també cobrava el delme, pot ser que se'l mencioni si les prestacions d'alguna terra escapaven del règim comú. Per exemple, l'any 1317 els habitants de Ravós del Terri pagaven censos i tasques a l'ardiaca de Ravós o de Girona. Un d'ells, Ramon Gassèn, tenia un camp al lloc dit Trial pel qual pagava un cens i la tasca a l'ardiaca, i el braçatge al batlle; d'una quarta part del camp, però, se'n reservava els esplets per a ell. Aleshores especifica que del camp havia de pagar al domino archidiacono decimam i a l'ecclesie primiciam. ${ }^{4}$ El 1319 l'abat de Sant Feliu de Guíxols obtenia la tascham et decimam de les terres dels masos del veïnat de Panedes, a Llagostera (Mallorquí, 2014b: 72). Del mateix any daten la majoria de les declaracions del capbreu de Cruïlles que el senyor del castell, Bernat de Cruïlles, i el prior del monestir de Sant Miquel van pactar realitzar conjuntament. De les prop de 1.000 parcel.les declarades, n'hi havia 26 que no pagaven els agrers acostumats, però sí el delme, al cavaller Ramon de Sant Miquel, al prior de Sant Miquel o bé al senyor del castell: es tracta de terres tingudes sota el règim d'alou fiscal, que implicava pagar delme i alguns drets de senyoria — terços i lluïsmes, però no la tasca-, o d'alou franc, que només implicava pagar el delme (Mallorquí, 1999: 68-69). La primícia també, que sempre anava associada al delme.

A través dels manuals de comptes dels senyors o d'institucions eclesiàstiques, com els dels pabordes de l'Almoina del $\mathrm{Pa}$, es coneixen els ingressos de la institució de conceptes de mals usos durant els segles XIV i Xv (Lluch, 2005 i 2008). Queda pendent, però, l'estudi exhaustiu dels delmes rebuts per l'Almoina. Els llibres de les dècades de 1330 i 1340 enregistren les quantitats de cada producte ingressades pel delme a cada localitat: a Riudellots de la Selva, per exemple, l'Almoina obtenia el delme, la tasca i el lloçol en espècie. Els productes eren majoritàriament cereals — forment, blat, civada, ordi, espelta i mill—, però també farratges - melca- i llegums - faves-; però la variabilitat de les collites era molt important: el 1337 es va recollir més del doble d'aquests productes que el 1334 (taula 3, infra). Els anys 1347-1348 les porcions de delmes de 13 parròquies suposaven la tercera part dels ingressos de l'Almoina (Guilleré, 1985-1986: 466).

4 Arxiu de la Corona d'Aragó (ACA), Monacals d'Hisenda, vol. 381, f. 9rv (8-8-1317). 


\subsection{Els arxius episcopals}

Lautoritat dels bisbes sobre els delmes, establerta en el IV Concili del Laterà, es va materialitzar a través d'un mecanisme legal bàsic en les relacions feudovassallàtiques des del segle xI, el feu de represa, pel qual els nobles cedien al bisbe els delmes, li prestaven homenatge i li juraven fidelitat $i$, acte seguit, els recuperaven com a feu tot esdevenint vassalls episcopals. Així es documenta al bisbat d'Elna als segles XIII i XIV, on el bisbe ja tenia uns quants feus cedits a laics segons un inventari de la fi del segle XII (Catafau, 1999 i 2003: 142-149). Al bisbat de Girona, aquesta situació es dona, de manera especial, a partir de 1226 en què, davant l'amenaça d'invasió d'un nou exèrcit croat encapçalat pel rei francès Lluís VIII, el comte d'Empúries va prestar homenatge i va jurar fidelitat al bisbe gironí Alemany d'Aiguaviva (Benito, 2005). Tots els vassalls del comte van seguir el seu exemple, de manera que el bisbe es va convertir en el senyor eminent dels senyors laics que obtenien delmes. Així ho demostren els pergamins dels calaixos 1, 2, 3 i 4 de l'armari de la Mitra episcopal, dos registres amb escriptures de delmes que el bisbe Bernat de Vilamarí va fer copiar el 1301, la part final del Cartoral de Carlemany, bona part del Cartoral de rúbriques vermelles i el protocol del notari Pere de Capmany. ${ }^{5} \mathrm{La}$ cronologia d'aquesta documentació epsicopal relacionada amb els delmes permet comprovar l'impuls decisiu donat pel bisbe Pere de Rocabertí (1318-1324) a la seva recopilació (figura 3).

La consolidació de l'administració o cúria diocesana, entre la fi del segle XIII i l'inici del xIV, coincideix amb l'inici, en aquest període, de les sèries de registres episcopals de Lletres, Notaria, Processos, Dotalies i Visites pastorals (Marquès, Puig i Serrat, 2009b: 269-276; Mallorquí, 2011a: 47-51). Segons el qüestionari de la visita de 1329, els visitadors havien de preguntar als clergues qui eren els delmadors laics i els seus batlles naturals, quina part del delme rebien, quin valor econòmic tenia i si utilitzaven el delme per garantir dots. ${ }^{6}$ Notícies similars es troben en altres registres episcopals: el 1326 els clergues

5 Tots aquests documents han estat inventariats i/o publicats íntegrament: Marquès, 1984 i 1993; Marquès, Puig i Serrat, 2009a i 2009b; Mallorquí, 2011b. L'única excepció són els registres de delmes encetats el 1301: Arxiu Diocesà de Girona (ADG), Mitra, calaix 5, vol. 24 i calaix 11, vol. 6 b.

6 ADG, visites pastorals, vol. P-4 (1329); Monjas, 2008: 125-133. 
Figura 3. El control dels delmes laics del bisbat de Girona, 1220-1360



Reconeixements i homenatges de laics amb delmes al bisbe

Firmes i establiments de delmes esglésies


pel bisbe a laics 
de Cantallops informaven el bisbe del valor de la part de delme adquirida per un laic i el 1347 el bisbe va obligar tots els rectors de la diòcesi a informar-lo de qualsevol canvi de titular dels delmes. ${ }^{7}$

A banda del control dels delmes laics, els bisbes procuraven mantenir els drets - foriscapia, les taxes de mutació- sobre els delmes cedits a persones eclesiàstiques. Segons una lletra de l'arquebisbe de Tarragona de 1319, el bisbe gironí rebia la quarta part d'aquestes porcions de delmes in recompensacionem terciorum et laudismiorum, és a dir, en recompensa de les taxes de mutació que l'església gironina perdria en el futur. Fins i tot, tal com es va donar a Aiguaviva aquest any, la seu i el bisbe gironins podien fer recollir i llevar -colligi, recipi et levari-, si volien, per nostrum baiulum vel nuncium l'esmentada quarta part dels fruits del delme (Marquès, 1984: n. 812; Marquès, Puig i Serrat, 2009a: n. 152).

\subsection{El Llibre verd dels feus (1362-1371)}

L’any 1362 el bisbe gironí Berenguer de Cruilles va conferir poders al seu majordom, Guillem Bernat de Perles, ad [...] petendum et levandum omnia jura decimarum et aliorum feudorum corresponents a la dignitat episcopal sobre tot el bisbat i també ad requirendum tenetores et possidentes dicta feuda ut ipsa feuda et decimas deberent dicto domino episcopo recognoscere et capudbreviare. A la vegada, va manar als clergues de la diòcesi d'informar el procurador dels feus episcopals super negociis tangentibus ipsa feuda. El seu successor, el bisbe Ėnnec de Vallterra, li va permetre rebre en nom seu reconeixements de tenir delmes en feu, percebre'n els lluïsmes corresponents i, si no era així, emparar-los. D’aquesta tasca, en donen fe dos capbreus de delmes amortitzats de l'any 1363. Mentrestant, Guillem Bernat de Perles va acudir a totes les parròquies del bisbat per preguntar als clergues, batlles i llevadors quin era el valor dels delmes, qui n'eren els posseïdors, si eren clergues o laics, i si hi havia feus pertinents a la dignitat episcopal; a més, va utilitzar un munt de documents relatius als delmes conservats a l'arxiu episcopal. El fruit de tot plegat és el Llibre verd dels feus, un llibre ordenat per capitula 
et per parrochias et loca clare et distincte, que es degué cloure cap a l'estiu de 1371, en temps del bisbe Jaume de Trilla. ${ }^{8}$

El llibre va ser escrit ad memoriam huiusmodi in futurum de predictis habendam, és a dir, per a memòria de la informació bàsica per cobrar els lluïsmes corresponents a les transaccions dels delmes laics. La paraula laudemium apareix en una sola anotació marginal: a la parròquia de la Garriga, Francesc de Fortià tenia un terç del delme en feu pro monasterio de Vilanera i el monestir, al seu torn, pro domino episcopo et ecclesia Gerundensi, de manera que el monestir era dominus medius totius dicte decime i el bisbe, el dominus major. Aleshores, els lluïsmes i foriscapis es partien, per meitats, entre el senyor mitjà i el major. Quina taxa era exactament? Segons la declaració del vicari general de la diòcesi de Girona el 1369, era costum arreu del bisbat que, per les coses immobles que es tenien en feu i que eren traspassades, es pagués al senyor directe, sobre 100 sous, 25 sous pel mig terç i 5 sous més pel mig lluïsme, la qual cosa equivalia al $30 \%$ del preu de la venda o del traspàs. ${ }^{9}$

Per a l'economia dels bisbes de Girona, davant la davallada d'ingressos senyorials des de la pesta negra de 1348, l'obtenció de les taxes de mutació dels delmes laics era tan essencial que en el Llibre verd dels feus també s'enregistraven els censos anuals que els clergues beneficiats d'una església o altar, després d'adquirir per donació o compra una porció de delme laic, pagaven al bisbe in recompensacionem foriscapiorum, terciorum vel laudismiorum o bé in novitate clerici - a l'entrada d'un nou titular en el càrrec. Per exemple, na Blanca de Maura obtenia un terç del delme major de la parròquia de Foixà, valorat en 15 lliures barceloneses anuals, però entre 1362 i 1371 el va vendre al prior de la capella de Foixà, el qual havia de pagar 55 sous com a censu in recompensacione foriscapiorum domino episcopo quolibet anno in festo Natalis Domini. El 1366 el bisbe Ėnnec de Vallterra va encetar un altre

8 ADG, Lletres, vol. U-43, f. 164r (2-9-1362) i Notularum, vol. G-45, f. 51v-52r (20-6-1363); ADG, Mitra, calaix 5, Llibre verd dels feus, f. 1r (1362-1371); Mallorquí, 2011b: n. 1. 
registre només amb els reconeixements de clergues que li pagaven censos en recompensa dels lluïsmes. ${ }^{10}$

El Llibre verd dibuixa prou bé la piràmide de dependències de la noblesa laica envers el bisbe i en relació amb uns feus molt específics: els delmes. Amb la seva representació gràfica (figura 4), podem comprovar com la gran majoria de porcions infeudades de delmes, 337 de 367, eren en mans de cavallers i altres laics; al voltant de la meitat eren feus de senyors de castells, nobles, vescomtes i comtes. Tanmateix, era el bisbe qui, directament o mitjançant senyors que feien d'intermediaris, acabava essent senyor de pràcticament tots els delmes infeudats existents a la diòcesi gironina. Aquests vincles, doncs, implicaven estretament el bisbe de Girona amb la feudalitat laica del bisbat $i$, en conseqüència, l'erigien com el principal poder en aquestes terres: com a cap de l'Església tenia autoritat sobre tots els eclesiàstics i monestirs i com a senyor eminent dels delmes laics podia imposar la seva senyoria sobre els senyors dels castells i els cavallers del bisbat (Guilleré, 1985-1986: 449).

Figura 4. L'estructura feudal del bisbat de Girona, 1362-1371

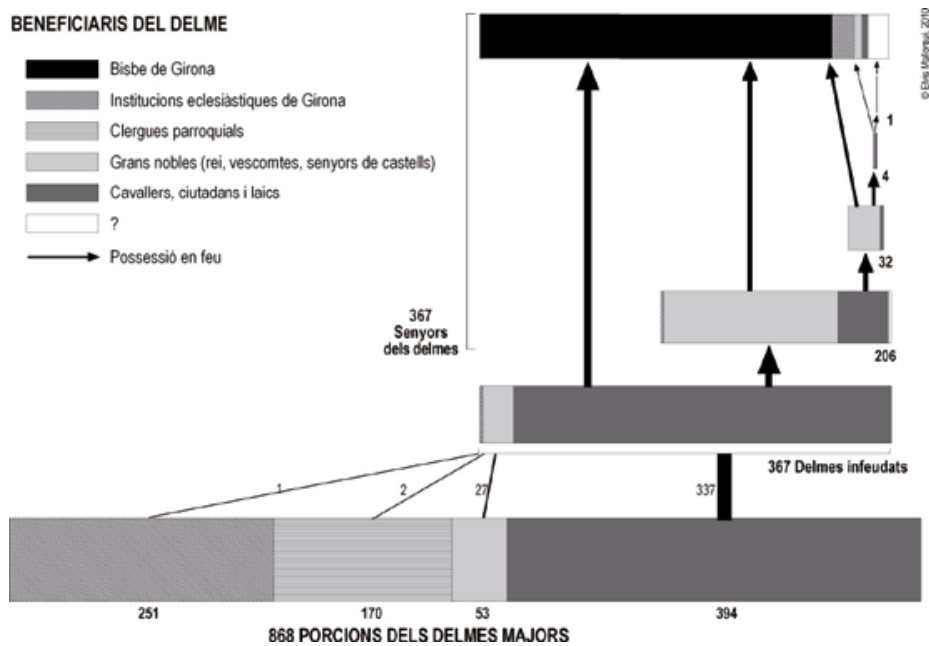

10 ADG, Mitra, calaix 12, vol. 13 (1366-1369), 39 f. 


\section{Delme en Singular... O DELMES EN PLURAL?}

En el Llibre verd, al final de gairebé cada declaració trobem un breu llistat dels productes que hi eren delmats. A Sant Cebrià dels Alls, per exemple, prestatur autem decima in dicta parrochia de omni grano, racemis, lino, canabo, lana, carnatico et de ortalicia et etiam de olivis. Rere la frase s'amaga una gran complexitat: per obtenir el delme de cada producte, calia adaptar-se als temps i a les condicions que cada activitat econòmica necessitava per a produir-los. El juliol era, segurament, la millor època per delmar el blat, just després de la sega i de la batuda, mentre que el delme dels raïms no es podia obtenir fins als temps de la verema, ja entrat el setembre.

En efecte, l'obtenció del delme dels raïms anava estretament lligada amb l'elaboració del vi, un producte que podia ser conservat i venut amb posterioritat. El 1319 l'abat de Sant Feliu de Guíxols obligava els pagesos del veïnat de Panedes, a Llagostera, a portare et mitere els raïms de la tasca i del delme in ipsa tina, que havien de tenir condirectam et circulatam i, a canvi d'un berenar, seca, rentada i encerclada (Mallorquí, 2014b: 73). Era responsabilitat dels senyors tenir tota la infraestructura necessària als seus cellers: el sagristà major de la seu de Girona, l'any 1334, tenia a Llambilles un celler i un pati amb tinas et vasa vinaria pro dicto vino suo faciendo, recolligendo et reservando i les havia de tenir condirectas et condirecta de dogues et de cimentar quociens opus fuerit. ${ }^{11}$ Aleshores, els batlles podien fer-hi totum vino primo [...] sine mixtione aque. El dia de trascolar el vi, el batlle havia d'avisar el senyor per si hi volia ser present. De manera semblant, els arrendataris del delme de l'Almoina del Pa de la seu de Girona, els anys 1354 i 1355, van pagar una part del preu de l'arrendament en espècie, en concret amb uns cercles [...] qui fuerunt positi in vexellis et tinis cellarii Elemosine dicti loci de Sancta Leochadia. ${ }^{12}$

Dels delmes de lli i cànem, no hi ha constància documental de com eren delmats. En canvi, les hortalisses i els llegums no eren delmats arreu, potser només allà on la producció era prou important com per anar al mercat $i$, aleshores, atreure l'interès dels senyors i dels clergues. A més, cal assenyalar la introducció d'alguns productes agraris que

11 ADG, Monacals, Seu de Girona, Sagristà major, pergamí n. 102 (2-7-1334).

12 AHG, Hospici, vol. 20, f. 25r (1354-1355...). 
van començar a ser delmats entre els segles XIII i XIV: d'una banda, un cereal que les classes populars consumien en forma de sèmola, el gruanum - nom similar al gruau francès-; i, de l'altra, plantes útils per a la manufactura de la pell, com el roldor, o per a tenyir els teixits, com la roja, el safrà o el pastell (Mallorquí, 2016: 75-80).

Pel que fa als productes derivats de la ramaderia, és destacable el cas de la llana. En principi, com a Sant Joan Sescloses, es pagava de quilibet manso $\cdot I$. velor lane, és a dir, un velló de llana - el conjunt de llana tosa d'una ovella o xai- per mas (Mallorquí, 2014c: 114). Ara bé, amb el Llibre verd s'observa una doble particularitat: mentre que moltes poblacions de les planes de l'Empordà i la Selva estaven exemptes de pagar el delme de la llana, els delmes de les parròquies de la vall de Camprodon tenien un valor molt elevat. Els de Vilallonga i Molló valien més que no pas els d'una vila amb un extens territori, un mercat setmanal i un port de mar com Torroella de Montgrí. Aquesta situació es pot relacionar amb la transhumància entre el massís del Montgrí i la capçalera del Ter (Soldevila, 2002; Mallorquí, 2010a: 181-184) i amb el fet que es delmava a l'inici de l'estiu, just abans que el bestiar pugés als cimals del Pirineu.

El carnaticum corresponia al delme sobre els animals nascuts al llarg de l'any en un mas. Potser en origen era un de cada deu animals, que el 1221 a Roses es pagava entre Pasqua i Pentecosta: l'abat del monestir demanava el delme dels anyells en el primer termini i el dels xais, en el segon; en canvi, pels pollins, vedells i ases es pagava un diner (Marquès, 1986: $\mathrm{n}$. 121). Al segle xIv, les prestacions havien estat monetitzades a altres indrets: a Lladó, el 1319, es pagaven 2 diners per cada pollí o vedell nascut al llarg de l'any; pel que fa als anyells, cabrits i porcells, si el ramat tenia més de nou animals, es donava el setè com a delme, i si el ramat era més petit, es pagava 1 diner i mig per cada animal nascut; de polls, només alguns masos i bordes en prestaven tres com a delme a l'any, mentre que la majoria de pagesos i borders en pagaven dos i els homes joves i masovers, només un. ${ }^{13}$ Finalment, queden els formatges: al maig, els pagesos $\mathrm{i}$

13 Els homes joves són fills segons de pagesos de mas que no han heretat l'explotació i que sovint viuen a les celleres o als nuclis concentrats del terme, i que conserven l'estatus servil, però amb menys obligacions que els homes propis de mas, sovint anomenats rustici en els documents; Mallorquí, 2011a: 381-384. 
els borders en pagaven quatre que havien de ser fets amb la llet d'un sol dia (Mallorquí, 2012: 99-101).

A les parròquies del litoral, el delme del peix era present a tot arreu on es pescava i es duia el peix a la platja amb xàvegues, boligs i barques. Allà era on els batlles senyorials recollien les porcions que es corresponien del peix de tall i la part del que s'havia pescat que s'acostumava a pagar: a Tossa la proporció, el 1587, era del $8 \%$ del peix pescat per a l'abat de Ripoll, del qual s'extreia el redelme - un peix de cada onze- per al batlle (Zucchitello, 2013: 103; Pujol, 2005: 34-37). Al cap de Creus i al cap de Begur també es delmava el corall.

L'any 1221 l'abat de Roses reclamava la prestació del delme dels molins, els colomers, la mel i la cera - decimam [...] molendinorum, columbariorum et mellis et cere- (Marquès, 1986: n. 121). D'aquests, l'únic que és esmentat amb certa freqüència és el delme del benefici dels molins, una desena part dels beneficis generats pel dret de moltura: des de 1209 fins al segle Xvir el sagristà segon de la seu gironina el va obtenir als molins del Monar Reial (Canal, Canal, Nolla i Sagrera, 1995: 58-64; Reixach, 2019: 74). Pel que fa als productes de l'artesania, es pagava el delme de les olles de terra a Masarac i Vilarnadal: de qualibet fornata, una olla.

Finalment, queda el delme dels productes venuts al mercat, pels quals es pagava la lleuda. En el mateix moment, se'n separava la part corresponent al delme. És el que es dedueix de les ordinacions sobre la divisió de la col-lecta de la lleuda menuda de Girona, l'any 1312, que afectava les verdures, les fruites, el bestiar, les olles de Quart i tota mena de productes agraris, forestals i artesanals, i de la qual se salva el delme per a la seu de Girona, salva decima Sancte Marie (Madurell, 1968).

\section{LA RECAPTACIÓ DEL DELME MAJOR AL BISBAT DE GironA}

A partir del conjunt de documentació procedent del bisbat gironí, intentarem distingir els moments i les accions relatives al procés de delmar el gra, els cereals, la principal producció agrària. El punt de partida és, naturalment, el marc territorial sobre el qual es recaptava el delme. 


\section{1. El terme delmer: la parròquia}

El Llibre verd dels anys 1362-1371 recull el nom de 419 parròquies, agrupades en els ardiaconats de Girona, Empúries, la Selva i Besalú, però hi ha 401 declaracions equivalents al mateix nombre d'unitats de recaptació del delme, 17 de les quals eren grups de dues o més parròquies. La segregació d'una parròquia, per tant, no sempre comportava la separació del decimarium, del territori subjecte a delme. En canvi, l'existència prèvia del decimarium castri de Blanis, un territori que pagava el delme al senyor del castell, va facilitar la separació de la parròquia de Blanes respecte de la de Tordera l'any 1319 (Mallorquí, 2020b).

De la resta d'unitats delmeres, n'hi havia 349, el $87 \%$, que eren parròquies (figura 5). En el cas de Girona, la xarxa parroquial es va completar gairebé del tot entre els segles X i XI. A partir del segle XII les úniques modificacions són trasllats de seus parroquials i creacions de noves parròquies a viles monàstiques i a l'entorn immediat de la ciutat de Girona (Mallorquí, 2011a: 80-84 i 137-142). A la majoria de parròquies gironines, doncs, de tota la producció cerealícola del terme delmer, se'n feia una pila comuna a partir de la qual els delmadors obtenien la seva part, com veurem més endavant. Però les excepcions eren molt freqüents: en almenys 215 parròquies, hi havia terres que escapaven del règim general de la parròquia en pagar el delme de manera separada de la resta; en 95 parròquies era algun mas el que delmava de manera diferent de la resta; en 40 parròquies hi havia un veïnat o més d'un que, en relació amb el delme, es distingia de la resta del terme, igual com passava amb els espais de la cellera i els horts que l'envoltaven en 5 altres parròquies.

En general, el terme delmer coincideix amb el primiciarium, el territori subjecte a la primícia. L'any 1237 el sagristà segon de la seu de Girona i el capellà de Sant Feliu compartien la primícia de les vinyes d'un territori limitat pel camí de Sant Daniel a Palol pel coll de Déu-gràcies i que arribava fins al decimarium de Palol. ${ }^{14}$ De manera semblant, l'any 1312 es van fixar amb vuit fites de pedra -terminis lapideis - els límits del primiciale et decimale de Lambillis versus Sanctam Pelagiam i el primiciale et decimale Sancte Pelagie versus

14 ADG, Sant Feliu de Girona, pergamí n. 73 (3-8-1237). 
Figura 5. Les unitats delmeres principals del bisbat de Girona, 1362-1371

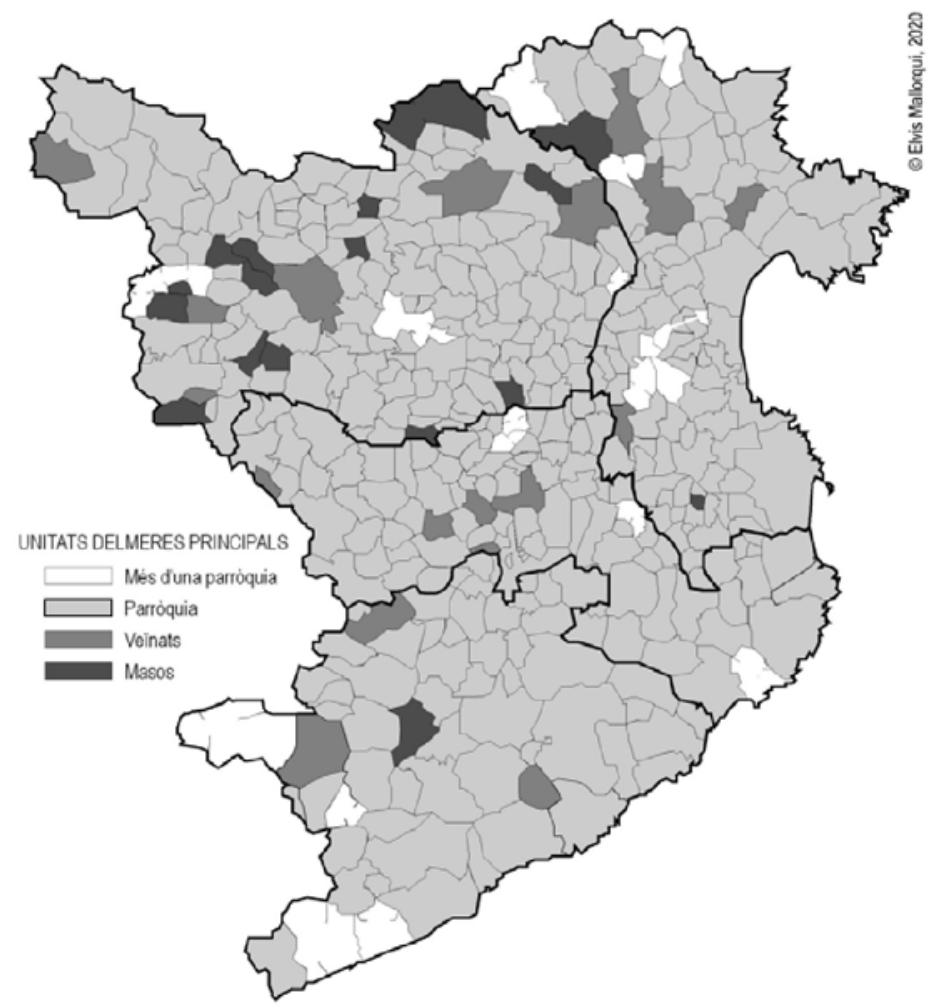

Lambillas, per delimitar a quins senyors pertanyien els drets sobre unes terres segurament desboscades feia poc (Mallorquí, 2011a: n. 11).

La percepció del delme s'adaptava a les estructures de poblament existents. En 18 parròquies el delme es recaptava per vicinati, territoria o loci, unes entitats menors de poblament que eren la base de la percepció del delme i, segurament també, de l'organització de la societat rural perquè provenen de les vil.les i vilars de l'alta edat mitjana (Mallorquí, 2008: 365-368 i 375-376). A Peralada, per a cada sector del terme - Peralada, Costes, Garriga, Vallgornera, Puig Barutell, les Olives, Viladequirc i Morassac - s'especifica qui obtenia el delme i quin n'era el valor. En unes altres 17 parròquies, 
eren els tinents de cada mas els responsables de pagar directament el delme de les seves explotacions.

\section{2. Delmes majors i menors}

En les declaracions del Llibre verd els delmes menors s'esmenten abans de la descripció del repartiment del delme major. A Vilobí d'Onyar, després d'anomenar els delmes de l'ardiaca de la Selva, la sagristana del monestir de Sant Daniel de Girona i el sagristà i domer de l'església de Vilobí sobre les coromines del castell de Vilobí i d'en Pere Serradavall, els masos i les terres d'en Serradavall, d'en Comaneta i d'en Pere Serra, i els polls dels habitants de la cellera de Vilobí, es diu el següent: de tota vero alia decima dicte parrochie et decimalis eiusdem, scilicet expletorum panis et vini et omnium aliorum de quibus decima est ibi prestari assueta, fiunt $\cdot X X X I I$. partes equales, et vocatur decima major.

El delme major, doncs, correspon a la part del delme que generava més ingressos i que afectava més terres del terme. En general, coincidia amb el delme sobre els dos principals productes, els cereals i la vinya, però en la majoria de parròquies s'hi incorporaven les altres produccions. En canvi, els delmes menors afectaven només una petita part de la parròquia - unes terres, uns masos, uns veïnats - o corresponien a un sol dels productes delmats. A Paret Rufí, per exemple, es distingia la decima tocius grani grossi del delme dels expletorum minutorum et racemorum ac tocius lini, canapi, lane, carnatici et ortalicie; a Peralada, el delmaton o delme menor corresponia al delme d'unes quantes possessions disperses pel terme parroquial. També eren menors els dels novals, les terres posades en conreu encara no feia quaranta anys (Mallorquí, 2016: 67-73). En total, per al bisbat de Girona hem arribat a comptar 832 porcions de delmes menors, enfront de 868 de delmes majors.

\section{3. Informants i recaptadors}

A banda de la recerca realitzada en els arxius episcopals, Guillem Bernat de Perles va recollir les informacions sobre els delmes i els titulars. Qui les hi va proporcionar? Ell mateix explica en el primer 
foli del Llibre verd que cum clericis, bajulis et levatoribus decimarum singularum parrochiarum diligenter inquisivit veritate de predictis decimis, de quibus habuit totam certitudinem ut melius potuit. Dels més de 500 informants, la gran majoria eren rectors, domers, sagristans i capellans curats que servien a la parròquia d'on es descriu el delme o a les veïnes (taula 1). Menys sovint, els clergues sense cura d'ànimes - diaques, clergues beneficiats, clavers i vicariso els monjos amb càrrec - abats, priors, cambrers, almoinersinformaven Guillem Bernat de Perles sobre els titulars i les porcions dels delmes. Si els clergues parroquials coneixien bé com es recaptava el delme és perquè hi eren ben presents, en la seva recol-lecció, no pas per controlar que ningú escapés a aquesta obligació cristiana, sinó perquè, per damunt de tot, els interessava recaptar la primícia, que normalment els pertanyia en exclusiva. Per tant, els clergues eren una part tant o més interessada que el bisbe en el negoci del delme.

Mentre que els rectors parroquials recollien la primícia, els batlles ho feien en nom dels seus senyors. La batllia del delme, com la de qualsevol altre conjunt de rendes senyorials, era concedida en un acte d'establiment. L'any 1266 Bernat d'Arenys va prometre que el seu germà Arnau signaria l'establiment de baiulia tocius illius

Taula 1. Els informants del Llibre verd dels feus, 1362-1371

\begin{tabular}{lc}
\multicolumn{1}{c}{ INFORMANTS } & TOTAL \\
\hline A. Eclesiàstics & 341 \\
\hline Clergues amb cura d'ànimes (i antics rectors) & 56 \\
\hline Clergues sense cura d'ànimes (i vicaris) & 10 \\
\hline Capellans (i càrrecs monàstics) & 407 \\
\hline \multicolumn{1}{c}{ TOTAL } & 6 \\
\hline B. Laics & 19 \\
\hline Col-lectors, llevadors i compradors de delmes i rendes & 10 \\
\hline Agents senyorials (batlles, saigs, notaris) & 1 \\
\hline Artesans i pagesos & 61 \\
\hline Cavallers & 97
\end{tabular}


nostre partis decime de Laureto, ut in carta stabilimenti inde confacta lacius noscitur contineri, al nou batlle, Barceló Ioga. ${ }^{15}$ Mentrestant, a Riudellots de la Selva el paborde de l'Almoina del Pa de la seu de Girona autoritzava el 1336 el seu batlle, Bernat Gombau, a reconèixer el principal obtentor del delme de la localitat, el cabiscol major de la seu, que tenia en feu per ell la bajuliam quam habeo in parte seu partibus quas dicta Elemosina habet et percipit in decima parrochie de Rivolutorum de Cilva et in aliis locis in quibus decimale ipsus parrochie extenditur. ${ }^{16}$ A canvi de la batllia, havia de llevar el delme, congregarlo i transportar a Girona les parts corresponents a l'Almoina.

$\mathrm{Al}$ segle XIV els batlles encara no són mai designats com a batlles de sac, expressió característica dels segles moderns; en canvi, molts dels que apareixen en el Llibre verd són baiuli naturales, és a dir, que el càrrec de la batllia requeia de manera perpètua sobre la mateixa família. Un bon exemple és el de la família Roca, que entre els segles XIII i XIV recaptava el delme de la parròquia de Fontajau en nom de l'abat de Sant Pere de Galligants (Francesch i Aparicio, 2017: 237). Aquest detall interessa molt al bisbe de Girona, perquè el canvi d'hereu de la batllia era un motiu per demanar el pagament del lluïsme. A més, si sabem que el redelme equivalia a una desena part de tot el que s'havia recaptat en concepte de delme, podem arribar a estimar els ingressos dels batlles gironins (taula 2). Tot i que existia una enorme diversitat, el valor mitjà dels redelmes dels batlles era d'unes 3 lliures anuals, si bé molts disposaven d'ingressos suplementaris.

Entre els informants del Llibre verd també s'esmenten arrendadors - o llevadors- del delme, col-lectors o compradors de les rendes. Es tractava de persones que, a canvi d'una quantitat de diner pagada als senyors delmadors, recollien els delmes d'un o de diversos anys. Aquesta pràctica d'arrendament sembla generalitzar-se al llarg del segle xiv. Els pabordes de l'Almoina del $\mathrm{Pa}$, a partir de 1347, es van veure obligats pels nous estatuts aprovats a arrendar cada any els delmes i les altres rendes senyorials (Lluch, 2005: 35-36, i 2008: 89-92).

15 ANC, fons patrimonial Cruïlles Peratallada, pergamí n. 893 (18-1-1266).

16 Arxiu Diocesà de Girona (ADG), Almoina, Riudellots de la Selva, pergamí n. 39 i Seu de Girona, Cabiscol major, pergamí n. 5 (13-9-1336). 
Taula 2. Els batlles i el valor dels seus redelmes

\begin{tabular}{|c|c|}
\hline BATLLES & \\
\hline \multicolumn{2}{|l|}{ NOMBRE DELS BATLLES } \\
\hline Batlles naturals & 103 \\
\hline Altres batlles & 29 \\
\hline Lloctinents dels batlles & 1 \\
\hline (batlles informants) & (16) \\
\hline TOTAL & 133 \\
\hline \multicolumn{2}{|l|}{ VALOR DELS REDELMES } \\
\hline Valor dels delmes recaptats (en $\mathfrak{E}$ ) & $3.076,50$ \\
\hline Nombre de batllies amb el valor del delme especificat & 97 \\
\hline Estimació del valor mitjà del redelme (en $\mathfrak{E}$ ) & 3,17 \\
\hline
\end{tabular}

\subsection{El districte: qui obliga a delmar?}

En el Llibre verd del bisbe de Girona, a mitjan segle xiv, hi ha una supervivència dels temps carolingis: el districtum. A Pals, el batlle del castell havia de fer districtum ad prestacionem decime carnatici; a Paret Rufí també era el batlle del castell qui havia de convocare congregaciones dicte decime et distringere prestantes dictam decimam ad solvendum eam quibus pertinet; en una part de la parròquia de Sant Sadurní pertanyent al terme del castell de Cruilles, el senyor d'aquest darrer lloc i el prior de Sant Miquel de Cruilles obtenien unes oques de cens de les possessions que eren sub eorum districtu per tal que el senyor i el prior faciunt melius dictam decimam prestari; a Verges i Siurana era el comte d'Empúries qui obtenia censos d'oques, ordi i raïms per compelli et distringi [...] omnes illos qui tenentur ad prestacionem dicte decime ad solvendum ipsam predictis parceriis; en contrast, al Far d'Empordà era un eclesiàstic, el paborde de Fortià del monestir de Sant Pere de Rodes, qui, faciendo inde omnem districtum ibi necessarium, obligava tothom a pagar el delme; a Lladó, qui feia aquesta feina era un dels perceptors del delme, el cavaller Simó de Biure; i a Palau-saverdera, la tasca se la repartien el senyor del castell de Palau, el cambrer de Sant Pere de Rodes, Pere Guillem d'Estany Bovós, i Pere Paner de Castelló. 
L'ús del mot districtum, sinònim de ban, ens remet al temps en què comtes i vescomtes exercien el seu poder com a representants de l'autoritat pública carolíngia i tenien la facultat d'obligar la població i castigar qualsevol infracció de l'ordre públic. A partir del segle $\mathrm{x}$, comtes, vescomtes i veguers es van apropiar d'aquesta facultat del poder que, al segle xI, es va disseminar entre tots els nobles i senyors que posseïen castells, des d'on exercien la seva autoritat banal i, més tard, entre els agents inferiors de la senyoria (Bonnassie, 19791981: II, 48-49; Farías, 1998: 33-34). Els batlles eren els encarregats de fer efectives totes les exigències que recaptaven els senyors en virtut de la seva facultat de mandare i distringere els habitants d'un terme: quèsties, toltes, forces, lloçol, administració de la justícia i bans per assegurar la convivència pacífica dels vassalls del senyor (Farías, 2000: 893-894). Assegurar la recaptació del delme encaixa, naturalment, entre aquestes facultats cedides als batlles, els quals ja eren els encarregats de supervisar els treballs pagesos durant les collites (To, 1993: 164-165).

\subsection{En garbes als camps?}

El Llibre verd, desafortunadament, no aclareix gaire en quin moment ni de quina manera es recollia el delme: si es feia al camp, quan el cereal encara era en garbes, o bé si es feia a l'era, després de batre. Tampoc no ho fa la documentació del segle xiv: les notícies sobre les prestacions en garba a les terres del bisbat de Girona tenen a veure, d'una banda, amb els serveis en treball que els homes propis realitzaven a les terres dels senyors gestionades directament per tal de transportar les garbes: els de Ravós del Terri, per exemple, rebien de l'ardiaca de Ravós dinar, berenar i sopar quando faciunt tiratam garbarum frumenti, que era un dia l'any. ${ }^{17}$ D'altra banda, la prestació de part de la collita en garbes sol anar associada a la tasca: només 2 dels 71 declarants d'un capbreu de 1294 que va fer redactar la muller de Ramon de Juià, a Llambilles, i només per una peça de terra cadascun, pagaven la tascam in garbis. ${ }^{18} \mathrm{El}$ mateix any,

17 ACA, Monacals d'Hisenda, vol. 381, f. 66v-67v (1317).

18 ADG, Almoina, Llambilles, pergamí n. 95 (1294). 
a Vilobí d'Onyar, el senyor del castell i ciutadà de Girona, Berenguer de Gornal, va enfranquir els seus homes propis de pagar la tasca en garbes, prestació que va quedar fixada el $1297 .{ }^{19}$ Mentrestant, Arnau Rovirola, habitant d'un mas de Riudellots de la Selva, va comprar tres peces de terra entre 1336 i 1345, per les quals havia de pagar a la pabordia de Cassà de la seu de Girona unam tascham in garbis. ${ }^{20}$

En contrast, a les terres del Ripollès, ja en el bisbat d'Osona, es documenta la prestació del delme en garbes. L’any $1220 \mathrm{Hug}$ de Mataplana va intercanviar amb l'abat del monestir de Sant Joan de les Abadesses els censos que obtenien a la parròquia de Sant Pere de Mogrony, un sobre el delme del vi i l'altre sobre el delme del blat en garbes, decimam nostram tocius parrochie Sancti Petri de Mogroin in garbis (Ferrer, 2009: n. 236). I a Sant Joan de les Abadesses, l'abat va establir, al teixidor Jaume Roca, una peça de terra a les coromines del Bac, l'any 1305, amb les condicions de plantar-hi vinya abans de tres anys, de donar al monestir decimam et primiciam de omnibus expletis de blado in garba et de vindemia i de portar-ho al portal de la vila de Sant Joan. ${ }^{21}$

\section{6. [...] in areis rusticorum [...]}

La manca de notícies sobre el fet de delmar en garba és un argument per pensar que, almenys al segle XIV, el procediment general a l'hora de pagar el delme era en gra. Però en el Llibre verd només s'esmenta un sol cop: a Pals, el batlle del castell, els batlles de les parts del delme pertanyents a Bernat de Torroella, un clergue beneficiat de Sant Feliu de Boada, i el laic Pere de Castell obtenien un cens d'una

19 Coneixem el privilegi de 1294, no conservat, gràcies a la confirmació de privilegis efectuada el 1365 per Gastó de Montcada: AHG, Notarial, CaldesLlagostera, vol. 71, quadern sense numerar, f. 1r-8r (27-8-1365); Sales, 2018: 662-663; Marquès i Mallorquí, 2019: 18-19. Agraeixo aquesta informació a Lluís Sales i Favà.

20 Arxiu Comarcal de la Selva, Santa Coloma de Farners (ACSE), fons patrimonial Rovirola-Batlle, capsa 1, pergamins n. 4 (10-1-1336), n. 7 (14-9-1344) i n. 8 (29-3-1345).

21 Arxiu del Monestir de Sant Joan de les Abadesses (AMSJA), Llibre d'administració de l'abat Guillem de Sant Joan de Pladecorts, 1305-1313, f. 72v (13-12-1305). Agraeixo aquesta notícia a Joan Ferrer i Godoy. 
mitgera d'ordi tant del delme com de la primícia, abans que fossin dividides. La prestació es feia per tal que ipsi bajuli convocent et convocare teneantur levatores seu congregatores dictarum decime et primicie quando vadunt ad dividendum expleta in areis rusticorum, a les eres dels pagesos dels masos. Així doncs, batlles i llevadors dels delmes passaven casa per casa per recollir les parts corresponents al delme i la primícia en gra, no pas en garba.

\section{7. [...] ire ad levandum [...]}

Batlles i clergues parroquials, juntament amb recaptadors i llevadors, anaven a cada mas per recollir el delme, la primícia i els drets derivats de la senyoria directa. En general, els batlles recollien per separat el delme i la tasca, perquè els senyors que els cobraven eren diferents. A Cruilles, l'any 1264, es va donar una situació particular: després d'una llarga disputa entre el senyor Gilabert de Cruilles i el prior del monestir de Sant Miquel, es va arribar a molts compromisos, un dels quals era que quan el bajulus predicti monasterii seu prioris iret ad levandum agraria - els agrers, entre els quals, la tasca-, calia que el bajulus castri ibit ad levandum decimam pro ipso castro, ita quod ambo bajuli simul vadant (Mallorquí, 2000: n. 85).

\section{8. [...] decima mensura [...]}

En quin moment s'aplicava la proporció del delme descrita als Costums de Girona? Potser quan els batlles i els altres recaptadors de rendes arribaven a les eres dels pagesos? Si fos així, ¿ens hem d'imaginar els batlles amb una mesura concreta - de fusta, potserper anar comptant fins que, en arribar a la decima mensura, la separaven pel delme? I que, amb la undecima mensura, feien el mateix per a la tasca? I seguien comptant fins a arribar a la $X V \cdot$ mensura, que separaven per la primícia? Aquesta és la lectura que fem de l'article esmentat dels Costums de Girona: entra tasca, delme i primícia, tres de cada quinze parts de la collita, el $20 \%$, eren sostretes als pagesos (figura 6). Algunes notícies podrien confirmar-ho: a Caldes de Malavella l'any 1336 tascha et decima elevantur insimul, és a dir, se separen al mateix temps, segurament, de les piles de gra situades 
Figura 6. Porcions de delme, tasca i primícia segons els Costums de Girona

\begin{tabular}{|c|c|c|c|c|}
\hline 1 & 2 & 3 & 4 & 5 \\
\hline 6 & 7 & 8 & 9 & 10 \\
\hline 11 & 12 & 13 & 14 & 15 \\
\hline
\end{tabular}

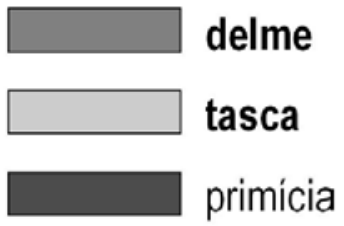

a les eres dels pagesos. Al final, tasca i delme havien de sumar el mateix: est tantum bladum et frumentum [...] de decima sicut de tascha. ${ }^{22}$ Tanmateix, no ho sabem del cert: les formes i les possibilitats del frau pagès a l'hora de delmar eren moltes (Feliu, 2011: 244-245).

\section{8. [...] congregata tota decima et primicia [...]}

En tot el text del Llibre verd dels anys 1362-1371, el mot grani apareix fins a 29 vegades, normalment en expressions com congregata tota decima et primicia dicti grani. A Llambilles, segons l'arbitratge de l'any 1334 entre la vídua del batlle i el sagristà major de la seu de Girona, calia que els titulars de la batllia elevent et congregent sense despeses de la sagristia omnes census, decimas, taschas, agraria et quecumque alia jura que dicta sacristia habet [...] in dictis parrochiis et locis. ${ }^{23}$ De manera semblant, el batlle que l'Almoina del Pa tenia a Riudellots reconeixia que, ell i els seus successors, levabimus et congregabimus bene et fideliter dictas partes quas ipsa Elemosina habet in dicta decima et eas vobis [...] trademus fideliter atque bene, és a dir, que havien de llevar i reunir les parts del delme de l'Almoina i

22 Arxiu General de la Diputació de Girona (AGDG), Manuals de comptes dels pabordes de l'Almoina, vol. 4, f. 119v-120v (1336-1337).

23 ADG, Seu de Girona, Sagristà major, pergamí n. 102 (2-7-1334). 
transportar-les fins allà on calgués. ${ }^{24}$ Però, on exactament s'apilonaven els drets senyorials per després fer-ne les partions oportunes? Aquest és el principal dubte relatiu a aquesta acció dels batlles. Als llocs on hi havia un castell, com és el cas de Cruïlles i de Llagostera, les parts de les collites recollides als pagesos podien acabar a l'era del Castell. És on s'hi batia el gra procedent de les terres o coromines dels mateixos senyors, però potser també era l'espai més adequat per a recollir el blat dels pagesos i repartir-lo després (Mallorquí, 1999: 69; Llinàs, 2010: 184).

\section{9. [...] de comuni acervo [...]}

Desconeixem si es tractava d'una cerimònia regulada o no, però tot apunta que l'extracció de les porcions corresponents a cada senyor a partir de la pila comuna del delme i dels altres drets senyorials es duia a terme en presència de tota o part de la comunitat local. El que sí que sabem, gràcies al Llibre verd i a altres documents, és que hi havia censos extrets de comuni acervo, de la pila comuna, abans de repartir el delme. El 1211 l'ardiaca de Besalú va concedir unes cases i un camp, situats a Santa Maria Sasserra, a Dalmau de Creixell, que hauria de prestar, al paborde de Gener de la seu de Girona, un cens d'una emina d'ordi i una de civada antea quam mensuretur pars mea decime (Marquès, 1993: n. 400a). El mateix any l'arquebisbe de Tarragona va dictar una sentència sobre la prestació de delmes per part d'uns laics al monestir de Roses, segons la qual, antequam decimetur acervus, calia avisar l'abat o el seu nunci per si hi volia ser present. En el cas que no vingués, calia separar primer el delme de l'abat fideliter et sine fraude, si no és que hi hagués una gran necessitat per culpa de la guerra o per una sobtada pujada de les aigües (Marquès, 1986: n. 121).

Molt sovint, el capellà de la parròquia tenia el dret d'extreure primer de tot la sisena part del delme. A Vilobí d'Onyar, de comuni acervo antequam dividatur, s'extreien uns censos de forment per al senyor del castell de Vilobí i per al paborde de l'Almoina i, acte seguit,

24 ADG, Almoina, Riudellots de la Selva, pergamí n. 39 i Seu de Girona, Cabiscol major, pergamí n. 5 (13-9-1336). 
la sextam partem tocius decime majoris [...] et ista $\cdot \mathrm{VI}^{\mathrm{a}} \cdot$ pars vocatur Siston. A Palafrugell, el 1234, en el plet entre l'abat de Sant Pere de Galligants, capellà de la parròquia, i el prior del Sant Sepulcre, titular del castell, no va quedar clar qui treia la primera part de la pila del delme, però sí que el mateix batlle del castell havia de recaptar el sisè del delme per al monestir gironí, a canvi del redelme corresponent (Mallorquí, 2013: n. 229).

Gràcies a una descripció en el manual de comptes dels pabordes de l'Almoina de 1336, sabem que al terme de Caldes la tascha est tota domini de Calidis, mentre que, del delme, se'n feien quatre parts: una per al senyor del lloc, Ot de Montcada, i una per a cadascun dels altres tres obtentors del delme -l'Almoina, el monestir de Sant Daniel i el senyor de la casa de Perella. L'extracció de cada porció es feia seguint unes operacions molt precises que donaven aquell resultat (figura 7):

Primo eleuantur de toto acerbo decime, pro sinodo quatuor squillate et quarteria frumenti et tot idem de blado. Residuum diuiditur isto modo:

- quod dominus Hoto accepit $\cdot V \cdot$ mensuras primo;

- postea Elemosina unam mensuram;

- et Sanctus Daniel Gerunde aliam mensuram;

- et dominus de Perela qui moratur in loco de Calidis alteram mensuram.

Et sic diuiditur tota decima. Et cum dicte mensure ascendunt ad centum mensuras dominus Hoto accipit $\cdot$ VIII ${ }^{\text {to }}$. mensuras pro honramento de toto acerbo, et sic pro quolibet centenario.

[...] Tascha est tota domini de Calidis, et sic accipit dictus dominus de toto acerbo IIIIor. mensuras pro tascha, et unam mensuram pro decima, et sic alii qui partem habent ut iam dicitum in dicta decima quilibet aliam mensuram de dicta decima. ${ }^{25}$

25 AGDG, Manuals de comptes dels pabordes de l'Almoina, vol. 4, f. 119v-120v (1336-1337). A la parròquia veïna de Franciac, Ot de Montcada també extreia un cens en espècie - dues mitgeres de forment, tres d'ordi, tres de civada, un anyell i un poll- pro hunramento de la pila comuna i abans que ningú; AGDG, Manuals de comptes dels pabordes de l'Almoina, vol. 4, f. 118rv (1336-1337). 
Figura 7. Extracció del delme i altres drets de la pila comuna de Caldes, 1336



\subsection{0. [...] excepta tamen retrodecima [...]}

Un cop extretes les parts del delme dels senyors feudals, els batlles no s'oblidaven de la seva recompensa: la retrodecima, el redelme, una desena part sobre la porció del delme - o dels altres drets senyorialsdels seus respectius senyors (Benito, 2003: 273-274). A Riudellots, l'any 1336, queda clar que, després de complir totes les obligacions del càrrec, el batlle es quedava el redelme per la feina realitzada: retenta michi et meis retrodecima tamen pro labore meo. ${ }^{26}$ En el cas de Llambilles, l'any 1334, els hereus de Francesc de Santa Cecília, batlle, havien de rebre el redelme per dret de batlliu, jure baiulivi de tot el frumentum, ordeum, siligo, avena, spelta, civada et omne mastallum, linum, canabum et carnaticum. Sobre el mestall, s'aclareix que pot ser la barreja de dos dels anteriors productes o un d'ells amb llegums, mentre que de cinc parts n'hi hagi almenys una de cereals. En el cas

26 ADG, Almoina, Riudellots de la Selva, pergamí n. 39 i Seu de Girona, Cabiscol major, pergamí n. 5 (13-9-1336). 
de les fabe, lentie, cicera, guixes, veçes, garrofes et quecumque alia genera legumine, el batlle no obtenia redelme, però es quedava amb la meitat del delme. Finalment, el mill, el panís i la melca recollits pel delme anava tot per al batlle, sempre que no fossin barrejats i se'n pogués dir mestall (figura 8). ${ }^{27}$

Figura 8. Delmes i redelmes dels cereals i llegums de Llambilles, 1334

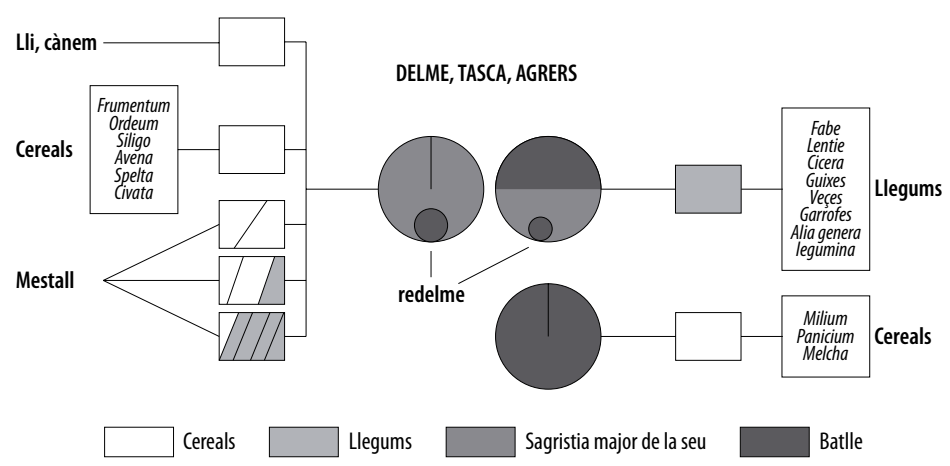

\subsection{Baleig i solatge}

Un cop esgotada la pila comuna, és possible que encara quedés gra a terra. A Vilobí d'Onyar el senyor Berenguer de Gornal, l'any 1297, va establir el procediment de pagament dels drets senyorials per part dels seus homes propis: de cada 19 mesures, el senyor rebia pro tasca et media tres mensures i després es donaven due mensure pro decima et etiam datur primicia ut consueta est dari (figura 9). Del que quedava a l'era, els senyors es reservaven duas mensuras de balegio - baleig, derivat d'escombrar-, mentre que els grans que eren a terra, el solagium o solatge, se'l quedaven els pagesos: remaneat solagium sive consuevit remanere predictis hominibus (Marquès i Mallorquí, 2019: 103). A l'època moderna, els rectors parroquials descrivien amb molta precisió, a les consuetes, a qui corresponien els baleigs, els rebaleigs i els solatges, que identifiquen amb aquell

27 ADG, Seu de Girona, Sagristà major, pergamí n. 102 (2-7-1334). 
Figura 9. El repartiment dels drets senyorials a Vilobí d’Onyar, 1297

\begin{tabular}{|c|c|c|c|c|}
\hline 1 & 5 & 9 & 13 & 17 \\
\hline 2 & 6 & 10 & 14 & 18 \\
\hline 3 & 7 & 11 & 15 & 19 \\
\hline 4 & 8 & 12 & 16 & 20 \\
\hline
\end{tabular}



blat que no.s pot aprofitar ab la rassadora (Gifre, 2011: 176). És una evidència que, tot $i$ la seva migradesa, eren recursos importants per a les famílies pageses o, potser, per a les més pobres que s'esperaven fins a la fi de la cerimònia de repartiment de la pila comuna per a escurar-ne les engrunes que havien quedat a terra.

\subsection{2. [...] domus ubi congregatur decima [...]}

Un cop enllestit el repartiment del delme, els batlles o els arrendadors del delme feien transportar el gra cap als graners senyorials. Aquest és l'origen de les diverses cases del delme que es conserven a Fortià, Salitja, Santa Pau, Ventalló o Viladamat (Mallorquí, 2018b: 147). En realitat, n’hi hagué moltes més: a la parròquia de Sant Martí de Llaneres, el senyor de Castell d'Empordà obtenia un cens dels senyors delmadors racione domus ubi congregatur dicta decima; a Vilavenut, l'hereu de Ramon de Canet havia de pagar censos de forment, ordi i civada pro servicio domus in qua reservatur et congregatur dicta decima. A llocs en què no hi havia castell, un dels senyors delmadors podia disposar d'una casa per guardar el delme: a Riudellots de la Selva, l'Almoina del Pa de Girona tenia, in cellaria dicti loci, justa ecclesiam, quandam domum qua est granarium, quam tenet ad suam propietatem i pagava al cabiscol de la seu, el principal delmador de la parròquia, el cens d'un capó i 4 diners anuals pro 
dicta domo seu granerio. ${ }^{28}$ En molts casos, el mateix graner servia com a celler per a guardar i produir el vi amb els raïms obtinguts del delme: a Arbúcies, els senyors de Dosrius tenien quasdam domos que dicuntur Celer in quibus reconduntur sive recolliguntur fructus decimi, que eren, l'any 1315, 12 quarteres de mill, 3 quarteres i mitja de civada, 15 quarteres de llenties, 14 quarteres d'ordi, 11 quarteres de sègol a la mesura d'Hostalric i un cafís de vi (Mallorquí, 2017c: 31-32).

\subsection{3. [...] venire ad compotum [...]}

L'última operació era la de passar els comptes. Els manuals dels pabordes de l'Almoina donen fe del que ells, com a responsables de la institució, trobaven als diferents graners un cop s'havien conclòs les operacions de recollida del delme i altres drets senyorials que eren en espècie a cadascuna de les parròquies on en tenien. La comparació d'una anyada amb d'altres de properes, però, ens il-lustra la gran variabilitat de les rendes recollides i de les collites d'un any en relació amb el següent (taula 3).

\section{El VAlor Del Delme}

La complexitat inherent a la recaptació dels delmes i de les primícies dels diversos productes generats per les activitats econòmiques del món rural no interessava gaire als senyors. Almenys als que, des del segle xiv, van optar per l'opció d'arrendar delmes i altres rendes derivades de la terra a canvi d'uns preus anuals. El valor de les porcions dels delmes en mans de laics recollides al Llibre verd dels anys 1362-1371, corresponia, probablement, al preu del seu arrendament anual que, per als oficials del bisbe de Girona, era la base per a calcular el valor dels lluïsmes que li pertocaven en cas de traspàs a un nou titular del delme.

28 AGDG, Hospici, Manuals de comptes dels pabordes de l'Almoina, vol. 4, f. 115r-117r (1336-1337). 
Taula 3. Les rendes de l'Almoina del Pa a Riudellots de la Selva, 1334-1338

\begin{tabular}{|c|c|c|c|c|c|c|c|c|c|c|c|c|c|}
\hline $\begin{array}{l}\text { PRODUCTES } \\
\text { (en mitgeres) }\end{array}$ &  & $\ddot{z}$ & $\overbrace{\overparen{Z}}^{\widetilde{T}}$ & & $\begin{array}{l}\vec{\circ} \\
\stackrel{4}{\infty} \\
\dot{\infty}\end{array}$ & $\bar{\Xi}$ & $\frac{\tilde{\Xi}}{\Xi}$ &  & $\begin{array}{l}\stackrel{\mathscr{\Xi}}{\Xi} \\
\stackrel{0}{=}\end{array}$ & : & 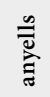 & $\stackrel{\infty}{\overline{\check{\partial}}}$ & $\frac{\mathscr{g}}{\Xi}$ \\
\hline \multicolumn{14}{|l|}{$1334-1335$} \\
\hline Tasca & $51 / 2$ & $71 / 2$ & & 4 & & 2 & 2 & & & & & & \\
\hline Lloçol & 7 & 3 & & & & & & & & & & & \\
\hline Delme & 16 & 16 & 7 & & & $10^{1 / 2}$ & 6 & $1 / 2$ & & & & & \\
\hline \multicolumn{14}{|l|}{$1337-1338$} \\
\hline Tasca & 10 & 14 & 6 & & & $\begin{array}{c}31 / 2 \\
1 \\
\text { modi }\end{array}$ & & & & & & & \\
\hline Lloçol & $10^{1 / 2}$ & & & & & & & & & & & & \\
\hline Delme & 40 & 55 & $27^{1 / 2}$ & & 1 & $11^{1 / 2}$ & $31 / 2$ & 2 & 1 & $31^{*}$ & $40^{*}$ & $6^{* *}$ & $8^{* *}$ \\
\hline
\end{tabular}

Nota. Les quantitats són en mitgeres, excepte ${ }^{\star}$ (sous) $i^{* *}$ (animals).

FonT. AGDG, Hospici, vol. 1889, f. 20r-21r (1334-1335) i vol. 5, f. 21rv (1337-1338).

\subsection{Una visió general sobre el bisbat}

La distinció entre delmes majors i delmes menors tenia una evident traducció econòmica. De les 832 porcions de delmes menors, només disposem de 90 indicacions monetàries que coincideixen en el fet que eren de poc valor: gairebé el $90 \%$ eren per sota de les 10 lliures anuals i més de la meitat per sota de les 5 lliures anuals. Només el delme dels peixos del mar i de l'estany de Castelló arribava a les 100 lliures anuals.

En relació amb els delmes majors, en coneixem la valoració econòmica de les fraccions que estaven en mans de laics $i$, així, podem calcular el valor total dels delmes majors o principals i les porcions dels delmadors eclesiàstics per a 280 parròquies, uns dos terços de les de tot el bisbat de Girona (taula 4). Sumant el valor d'aquests delmes, se superen les 14.000 lliures anuals del delme, la qual cosa significa una mitjana de 50,98 lliures per parròquia. Probablement, la mitjana seria més alta perquè si el delme de Peralada era de 619 lliures anuals, el de les viles monàstiques - Sant Feliu de Guíxols, Camprodon, 
Taula 4. El valor dels delmes majors del bisbat de Girona, 1362-1371

\begin{tabular}{lc} 
PARRÒQUIES & TOTAL \\
\hline Nombre de parròquies: & 419 \\
\hline \multicolumn{1}{c}{ - sense dades } & 139 \\
\hline \multicolumn{1}{c}{ amb dades } & 280 \\
\hline Valor total delme major & $14.274,20 £$ \\
\hline Valor mitjà per parròquia & $50,98 £$ \\
\hline Extrapolació del valor total del delme major & $21.360,32 £$ \\
\hline Extrapolació del valor total de la primícia & $10.680,16 £$
\end{tabular}

Amer i Banyoles - i el de la ciutat de Girona, per a les quals no tenim dades, serien similars o superiors. De totes maneres, extrapolant el valor mitjà del delme per parròquia al conjunt del bisbat, arribem a la xifra de 21.360,32 lliures anuals que, amb la primícia, podrien pujar un mínim de 32.040,48 lliures, sense comptar els delmes menors i els dels novals el valor econòmic dels quals desconeixem. Això era gaire? Per tenir uns punts de comparació: els ingressos de l'Almoina del Pa els anys 1375-1376 voltaven les 1.000 lliures anuals i els del municipi de Girona els anys 1376-1377 sumaven poc més de 10.000 lliures anuals (Guilleré, 1990: 90, i 1993-1994: I, 346-347). Mentrestant, els braços de les Corts de Cervera de 1359 van concedir, per al conjunt del Principat de Catalunya, un donatiu de 144.000 lliures per any a raó de 50 sous per a cada foc de jurisdicció reial i 20 sous per a cada foc de jurisdicció eclesiàstica o militar (Sánchez Martínez, 1995: 133; Ortí, 1999: 763-766).

\subsection{Abans de les mortaldats del segle XIV}

El pes del delme havia estat encara més elevat abans de la pesta negra? En el Llibre verd només es recorda, per a 8 parròquies, el bono tempore que havia existit ante mortalitates (taula 5). A Beget, Sant Llorenç de la Muga i Santa Margarida de Bianya el valor del delme havia disminuït a la meitat i a Sils, Vidreres i Tapis, la reducció encara havia estat major. Sorprenentment, el delme dels peixos que el comte d'Empúries obtenia entre Castelló i Cadaqués, i de l'estany de Castelló 
d'Empúries, en lloc de disminuir, havia augmentat de 80 lliures abans de les mortaldats a 100 lliures. Després d'una sobreexplotació dels recursos pesquers del mar i de l'estany abans de 1348, la davallada demogràfica posterior els hauria permès recuperar-se ràpidament.

Taula 5. Delmes dels bons temps abans de les mortaldats, 1362-1371

\begin{tabular}{|c|c|c|}
\hline PARRÒQUIA & DELME (DELMADOR) & VALORACIÓ \\
\hline $\begin{array}{l}\text { Castelló } \\
\text { d’Empúries }\end{array}$ & $\begin{array}{l}\text { Delme dels peixos del mar de Castelló, del } \\
\text { mar de Roses, del mar de Cadaqués i de } \\
\text { l'estany de Castelló (comte d'Empúries) }\end{array}$ & $\begin{array}{l}\text { Ante mortalitates: } 80 £- \\
\text { Modo (1362): } 100 £\end{array}$ \\
\hline Sils i Vidreres & $\begin{array}{l}\text { 1/4 delme de Vidreres i } 2 / 3 \text { delme de Sils } \\
\text { (5 clergues establerts per Ermessenda de } \\
\text { Cartellà) }\end{array}$ & $\begin{array}{l}\text { Ante mortalitates: } 10 £- \\
\text { Modo (1362): quasi nichil }\end{array}$ \\
\hline Beget & $\begin{array}{l}\text { 1/4 delme major (Guillem de Montagut, } \\
\text { senyor de Fornells d'Avall) }\end{array}$ & $\begin{array}{c}\text { Ante mortalitates: } 30 £- \\
(1362): 15 £\end{array}$ \\
\hline Tapis & $\begin{array}{l}\text { Delme del mas de Broça (clergue de l'altar } \\
\text { de Sant Joan de l'església de Costoja) }\end{array}$ & $\begin{array}{l}\text { In bono tempore: } 10 \mathrm{~m} . \mathrm{de} \\
\text { blat a mesura de Peralada - } \\
\text { (1362): } 3 \mathrm{~m} \text {. de blat }\end{array}$ \\
\hline $\begin{array}{l}\text { Muga, Sant } \\
\text { Llorenç de la }\end{array}$ & $\begin{array}{l}\text { Delme del vilar o veïnat de Ferrerós } \\
\text { (Jaume de Palou, de Terrades) }\end{array}$ & $\begin{array}{c}\text { Bono tempore: } 10 £-\text { Modo } \\
\text { (1362): } 5 £\end{array}$ \\
\hline Biure & $\begin{array}{l}1 / 2 \text { delme del lloc de Capell (Bernat de } \\
\text { Clusa, de Capmany) }\end{array}$ & In bono tempore: $25 \mathrm{~s}$. \\
\hline $\begin{array}{l}\text { Bianya, Santa } \\
\text { Margarida de }\end{array}$ & $\begin{array}{c}\text { Delme de les possessions del torrent } \\
\text { del Forn avall, excepte els masos d'en } \\
\text { Gravalosa (Pere de Collell) }\end{array}$ & $\begin{array}{c}\text { Bono tempore: } 30 £-\text { Modo } \\
(1362): 15 £\end{array}$ \\
\hline
\end{tabular}

Nota. Abreviatures: $£$ : lliures / m.: mitgeres / s.: sous.

\subsection{Delme per masos}

El mas de Broça, de la parròquia de Tapis, va passar de proporcionar 10 mitgeres de blat abans de la pesta a només 3 després. Aquest detall confirma que als sectors de poblament dispers els senyors havien adaptat l'estructura de les seves senyories i l'obtenció de les seves rendes als masos. Per això, per a algunes de les 17 parròquies en què la percepció del delme es feia de forma individualitzada per masos i no sobre tot el districte parroquial, podem conèixer el valor del delme d'un mas. A Tapis i Maçanet de Cabrenys, Guillem Galzeran de Rocabertí obtenia 30 lliures anuals pel delme de 55 masos, la qual cosa feia que, de mitjana, cada mas pagués 10,9 sous anuals, més de mitja lliura; en canvi, la senyora de Mollet obtenia més d'una lliura 
per mas: 20 lliures anuals de 19 masos; i Gaufred d'Avinyó encara més: 20 lliures per 14 masos, de manera que cada mas proporcionava 28,6 sous per mas, gairebé una lliura i mitja. Al terme de Capmany, coneixem el valor del delme d'alguns masos que rebien senyors laics: el vescomte de Rocabertí obtenia 1 lliura de 2 masos; en Ferrús de Llers rebia 1 lliura del mas Famada; i Pere de Casandal rebia 5 lliures del mas Pellicer.

Aquestes equivalències es podrien extrapolar a altres localitats de les quals coneixem tots els masos: a Vilobí hi havia 74 masos els anys 1337-1338 i uns 21 habitants a la cellera, i el delme major proporcionava 124 lliures; a Riudellots, on el delme superava de poc les 100 lliures anuals, hem comptat 98 masos anteriors a la pesta negra i unes 10 famílies a la cellera; i a Cruilles, amb un delme també de 100 lliures, hi havia 81 masos i 83 habitants en els nuclis concentrats del castell, del monestir de Sant Miquel i de la salvetat de Rabioses (Mallorquí, 2010b: 153-154; Marquès i Mallorquí, 2019: 53-54, 73-74 i 100-101).

\section{EL REPARTIMENT DEL DELME}

Al segle XVIII la proporció de delmes en mans de laics al bisbat de Girona continuava essent molt alta. Així consta en les relacions episcopals de 1769 , en les quals el delme cobrat per eclesiàstics representava el 59,72 \% del valor total (Congost, 1990: 57). Entre el panorama que s'observa per al segle XIV a través del Llibre verd i el del segle XVIII, la tendència hauria estat una lenta cessió de delmes laics a monestirs i institucions eclesiàstiques els segles XIV i XVIII (figura 10). Amb la documentació conservada en fons episcopals, juntament amb la de diversos arxius monàstics, com el de Santa Maria de Vilabertran, es pot remuntar l'evolució dels obtentors de delmes fins a inicis del segle XıII $i$, de manera més puntual, fins als segles de l'alta edat mitjana.

\subsection{Els senyors obtentors de delmes al segle XIV}

Partint dels primers treballs de Christian Guilleré (1990: 88-92, i 1993-1994: I, 346-347) sobre la pertinença social dels titulars de delmes dels ardiaconats de la Selva i de Girona, l'estudi complet del 
Figura 10. L'evolució dels titulars dels delmes del bisbat de Girona, segles XI-XVIII

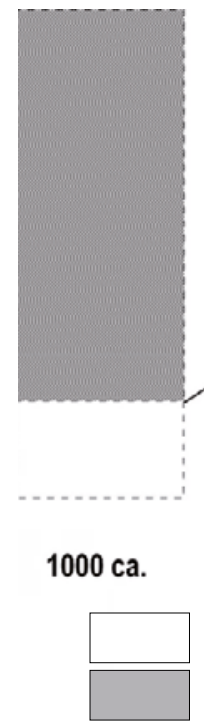

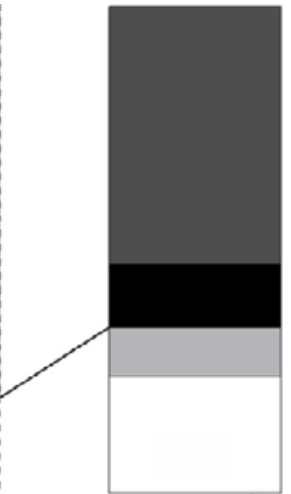

VALOR

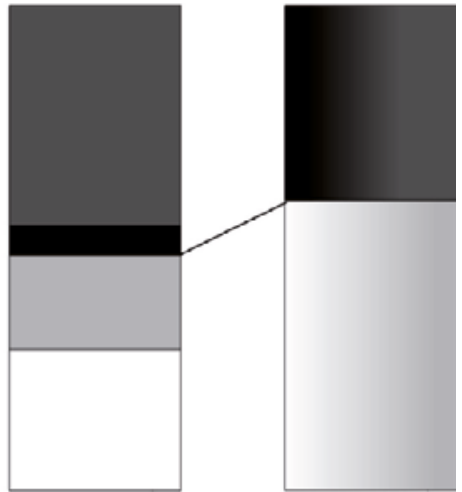

N. PORCIONS

1362-1371

1769

Monestirs i institucions eclesiàstiques de Girona

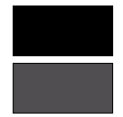

Reis, nobles i senyors

de castells

Clergues parroquials

Cavallers, ciutadans

i altres laics

Llibre verd permet aprofundir en aquesta qüestió per al conjunt de la diòcesi a partir de la classificació dels delmadors o obtentors de delmes en quatre grans grups (figura 11).

El primer correspon a les persones i institucions eclesiàstiques extraparroquials, amb seu o residència fora de la parròquia d'on obtenen el delme i, sovint, sense relació directa amb la institució parroquial: d'una banda, els càrrecs i les institucions establerts a la ciutat de Girona - bisbe, canonges, pabordes, ardiaques i clergues de la seu, hospitals, almoines, etc.- controlaven molts delmes als ardiaconats més propers a la capital, els de Girona i la Selva; de l'altra, abadies i priorats benedictins, i canòniques agustinianes tenien els delmes de les parròquies veïnes.

El segon grup és el dels clergues vinculats directament amb les parròquies rurals, que obtenien aproximadament el $10 \%$ dels delmes. En contrast, els delmes menors i els dels novals anaven majoritàriament —prop de la meitat, el $46 \%$ - a rectors, sagristans, domers, diaques 
Figura 11. Porcions dels delmes majors i menors al bisbat de Girona, 1362-1371

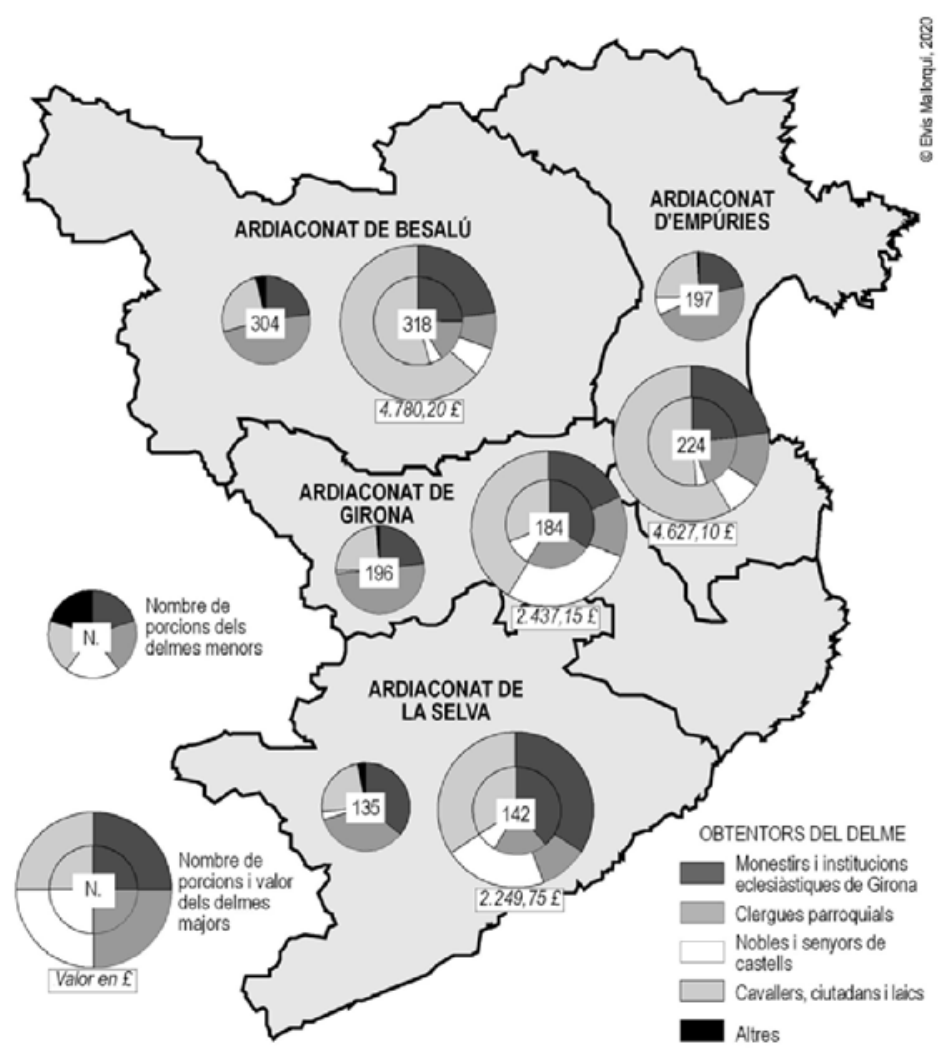

i clergues beneficiats. Tanmateix, cal deixar constància que també hi tenien dret els capellans o titulars d'una capellania de parròquia rural que, molt sovint, eren membres d'un monestir benedictí, d'una canònica agustiniana o de la catedral de Girona. Els seus drets sobre els delmes derivaven de la seva antiga preeminència sobre els encarregats de la cura d'ànimes a qui, pel dret de patronat, escollien i presentaven als bisbes. Sovint es produien conflictes entre rectors i capellans per aquests delmes locals. La migradesa de la participació del clergat parroquial en el delme quedava compensada amb les primícies, que rebien gairebé en exclusiva. 
En tercer lloc, hem agrupat els grans senyors de les terres de Girona, que fonamentaven el seu poder en la possessió d'un o de més d'un castell feudal i que estaven encapçalats pels reis d'Aragó, els comtes d'Empúries i els vescomtes de Cabrera i Rocabertí. En nombre, eren relativament pocs, però les porcions que obtenien eren les més valuoses de cada ardiaconat.

Finalment, el quart grup correspon a la resta de laics, entre els quals destaquen els cavallers i petits nobles rurals per sobre dels ciutadans de Girona, dels habitants de viles rellevants i de simples pagesos de mas o artesans. Cal assenyalar que, als ardiaconats de Besalú i d'Empúries, aquest grup de delmadors laics controlava el $60 \%$ dels delmes. D’aquesta manera, la situació al bisbat de Girona s’assemblava a la de les terres de Barcelona i Osona on el delme era una renda dels castells feudals infeudada als castlans, tal com apareix en l'enquesta encarregada el 1328 pel rei Alfons III per recuperar els lluïsmes sobre les transaccions dels drets i delmes que se li havien escapat per la mala gestió dels castlans (Sabaté, 1993: 191-194 i 206-207).

\subsection{Una prosopografia dels delmadors gironins, segles X-XIV}

L'anàlisi dels orígens dels grups de senyors obtentors de delmes al segle XIV, que hem encetat per als antics comtats de Girona i Besalú (Mallorquí, 2009a), permet detectar algunes continuïtats i moltes evolucions. Entre les primeres, destaquen els casos dels monestirs de Santa Maria d'Amer i Sant Esteve de Banyoles que, després d'obtenir els drets sobre algunes localitats properes a través de preceptes dels reis carolingis dels segles IX i $\mathrm{x}$, al segle XIV encara conservaven el dret de rebre-hi tot el delme major (Mallorquí, 2017b i 2018a: 15-21 i 31-34). Es tracta de l'evidència més clara que tenim d'uns delmes establerts ja en temps carolingis.

Al segle $\mathrm{x}$ la major part dels delmes, tanmateix, estaven controlats pels diversos comtes, que els concedien als monestirs que fundaven per convertir-los en mausoleus familiars. A la vegada, retribuïen els serveis dels seus vassalls fidels amb uns feus que, tal com s'evidencià en el cas de la revolta de part dels nobles del comtat de Besalú el 957, podien confiscar-los-els (Mallorquí, 2014d: 168-169). Aquesta realitat, 
coneguda per moltes donacions i compravendes, xoca amb la de les actes de consagració, en les quals el protagonista és el bisbe que arriba a una església per a consagrar-ne l'altar i per a establir el terme delmer, el territori assignat al temple els habitants del qual hauran de pagar delmes, primícies i oblacions als clergues que hi serveixen. Aquesta doble realitat es pot entendre, creiem, si considerem l'existència de dos nivells superposats: el dels pagesos de les vil.les i vilars que pagaven el delme a l'església parroquial, fet que s'establia en l'acta de consagració pel bisbe, i el dels comtes que assignaven esglésies i delmes a monestirs i vassalls seus a canvi que garantissin el servei religiós al temple a càrrec d'uns clergues.

$\mathrm{Al}$ segle XI, segons la visió més tradicional, la pèrdua d'autoritat dels comtes es tradueix en l'apropiació dels delmes i d'altres rendes per part dels senyors feudals. En realitat, però, moltes nissagues senyorials ja disposaven de delmes des de feia molt de temps, tant que quan van arribar els llegats papals a Girona els anys 1068 i 1078 no van aconseguir que els retornessin a institucions eclesiàstiques, sinó tan sols assegurar les primícies per al manteniment dels rectors de les parròquies. A canvi, els senyors laics van rebre una compensació: el pagament de la tasca sobre les terres dels seus dominis. Al Llenguadoc l'evolució és similar, però la competició entre les elits laiques i les eclesiàstiques pel delme va conduir, ja al segle XII, a la difusió de l'heretgia càtara a moltes llars de la noblesa que no volien perdre el control sobre els delmes parroquials (Panfili, 2012). També van provar altres vies per evitar ser excomunicats per la jerarquia eclesiàstica: cedir petites porcions a filles que es feien monges, infeudar delmes als cavallers, utilitzar delmes per garantir dots de les filles que es casaven i cedir delmes a institucions eclesiàstiques $\mathrm{o}$ al bisbe que els els retornaven com a feu.

Amb aquests mecanismes, que també es van donar al bisbat de Girona, arribem al segle xıII. A partir de la dècada de 1220 molts nobles van optar per reconèixer la senyoria eminent dels bisbes de Girona sobre els seus delmes i recuperar-los com a vassalls episcopals a continuació. I, tot seguit, els van anar infeudant a famílies de cavallers si no era que ja ho havien fet abans. Per això, al llarg de la centúria es dona una baixa progressiva de la titularitat de delmes de l'alta noblesa i, en canvi, un clar predomini dels delmes en mans de cavallers. En els sectors més rurals i muntanyencs dels ardiaconats 
de Besalú, Girona i Empúries, la permanència dels cavallers com a titulars de delmes infeudats per nobles i pels bisbes es manté fins al segle XIV, com és ben clar a la vall d'Hostoles. Fins i tot, més enllà: el delme de Navata al segle XviII es dividia en tres terçons tinguts per laics, una partició ja existent el 1226 quan el senyor Arnau de Navata, hereu de Bernat Adalbert que el 1099 ja tenia els delmes de l'església, reconeix al bisbe de Girona que el té cedit a tres cavallers: Ramon de Galliners, Bernat de Palol i Pere de Vilafreser (Congost, 1990: 57; Marquès, 1993: 179 i 414).

En canvi, en alguns sectors del bisbat es donen evolucions ja al llarg del segle XIII. D'una banda, a l'entorn proper de la ciutat de Girona s'incrementen les donacions de petites porcions de delmes a les noves institucions eclesiàstiques de beneficència nascudes al segle XIII: les almoines del $\mathrm{Pa}$ i del Vestuari de la seu de Girona i els hospitals, en l'Hospital Nou de Santa Caterina de Girona. De l'altra, tant als volts de la ciutat gironina com a l'entorn de viles actives econòmicament, amb mercats, fires i grups d'artesans especialitzats, es produeix un transvasament de delmes de les mans de cavallers a les dels mercaders, ciutadans i vilatans locals. Potser el cas més rellevant és el de la vila de Camprodon, on els mercaders es degueren enriquir per la seva participació en el negoci del bestiar transhumant entre el litoral empordanès i les valls del Ripollès. Així, a banda d'invertir en el negoci del teixit de la ciutat, van poder assegurar l'aprovisionament de llana per a la indústria local comprant moltes petites porcions de delmes a les parròquies de la contrada (Mallorquí, 2014c: 117-122).

\section{Conclusions: EL DElme, COBEJAT PELS GRUPS DE LA SOCIETAT RURAL}

Reis, nobles, canonges de la catedral, abats, priors, rectors, beneficiats, cavallers, ciutadans, vilatans i, fins i tot, alguns pagesos. De perceptors de delmes, al segle XIV, n'hi havia de tots aquests grups. El bisbe també en rebia; però, a més, controlava pràcticament tots els delmadors: els eclesiàstics, perquè era el seu superior jeràrquic en les terres del bisbat de Girona, i els laics, perquè, en la majoria de casos, era el seu senyor eminent en la jerarquia feudovassallàtica. En tota la documentació existent sobre el delme a les terres de Girona, el 
grup social que majoritàriament el pagava, els pagesos, n'és gairebé absent en el poc que sabem de les pràctiques concretes de les formes de delmar el producte majoritari, els cereals.

En contrast, al nord d'Europa la situació és ben diferent: el delme era llevat al camp, en garbes, en el moment de la collita, i era dut a les granges aux dìmes, la peça essencial en el sistema de recaptació decimal fins al punt que, per molt que hi hagués un propietari de la granja - un senyor, un monestir-, hi havia tres claus per obrir-ne la porta. La comunitat local exercia una autoritat sobre la recaptació i l'ús dels delmes: probablement, no eren completament apropiats pels senyors laics o eclesiàstics, sinó que una part servia per a la construcció i el manteniment de l'església, per a la subsistència del clergat i per a l'assistència dels pobres (Arnoux, 2012b: 593-597).

Dues comparacions poden ajudar a entendre el lloc del delme al bisbat de Girona i, en bona mesura, a la Catalunya Vella. Per al regne de Lleó medieval, Isabel Alfonso (2010) ressalta la capacitat col-lectiva dels pagesos per actuar col-lectivament dintre dels marcs acceptats per limitar o oposar-se a les imposicions exteriors - dels monestirs, per exemple-i per provar d'instrumentalitzar a favor seu el delme de les esglésies locals. En molts conflictes relatius al monestir de Sahagún, els pagesos actuaven sovint d'acord amb els clergues locals per defensar la seva església i, justament, aquestes accions contribuien a enfortir el sentiment comunitari. Aquesta col-laboració, malgrat la distància en el temps i l'espai, també es donava a la Cerdanya del segle xvirI: gràcies als 47 quaderns de comptabilitat de la parròquia d'Ur, es coneix el valor de la producció i la part del delme de cada delmador d'unes 300 parcel-les d'un total de 25 anyades entre 1733 i 1787 (Conesa, 2010). De l'anàlisi de les dades, se'n dedueix, d'una banda, que existia encara una agricultura itinerant al peu de la muntanya i, de l'altra, que tant als pagesos i ramaders com als rectors de la parròquia els interessava declarar que aquestes terres eren novals perquè la taxa era del $10 \%$, per sota de la de les parcel-les conreades permanentment, i perquè anava tota per al rector.

Aquesta precisió dels textos del segle xvin — tot i les seves llacunes- posa en evidència les mancances que tenim per als temps medievals, fins i tot per a una diòcesi ben documentada, en 
relació amb el delme, com la gironina. Quina era la posició de les comunitats parroquials del bisbat enfront dels senyors delmadors? Les actuacions en què apareixen, sempre puntuals, ens indiquen que es tracta d'una qüestió que els era ben propera i coneguda: els àrbitres de la disputa pel delme i la primícia d'unes parcel-les entre Santa Pellaia i Llambilles, el 1312, eren dos pagesos de mas, un de cada parròquia, i la força negociadora de la Universitat de Lladó, el 1319, va forçar l'escriptura d'un centenar de costums locals, entre els quals n'hi havia set sobre el delme i la primícia (Mallorquí, 2011a: n. 11, i 2012). Tot i el cas d'un habitant de Santa Àgata de Montnegre, que el 1332 va pagar 202 sous al rector parroquial racione cuiusdam porcelli decime i 50 sous més per les despeses del plet, no tenim evidències de frau dels pagesos gironins a l'hora de pagar el delme al segle XIV: els únics excomunicats en relació amb el delme eren senyors laics que no n'havien reconegut les porcions al bisbe (Mallorquí, 2011a: 226 i 344). Ara bé, les possibilitats de no pagar la desena part de la collita eren moltes atès que el blat es delmava a l'era dels pagesos $i$, en un territori de poblament dispers en masos, això era pràcticament impossible de controlar.

Davant d'aquesta situació, potser cal posar en relleu les persones, pertanyents a grups socials diversos, que feien d'intermediàries entre els pagesos i els senyors a l'hora de recaptar el delme. Per un costat, els batlles, molts dels quals eren pagesos de mas, i els arrendataris, sovint comerciants i negociants de les viles properes. Però, per l'altre, també els clergues parroquials que rebien la primícia i que, per al bisbe, eren uns agents clau a l'hora de conèixer els canvis dels titulars laics dels delmes. Quina relació tenien uns i altres amb la resta de la comunitat pagesa? Actuaven els primers només en benefici dels senyors delmadors i en el seu propi? O bé, a banda de donar feina a traginers i de permetre als més pobres recollir el gra que s'escombrava d'allà on hi havia hagut la pila comuna del delme, feien de portaveus de la resta de convilatans i posaven condicions als perceptors dels delmes? Per exemple, potser la major part del producte del delme sortia fora de la parròquia on s'havia recaptat, però la primícia dels rectors s'hi quedava emmagatzemada per tal que, arribat el cas d'una carestia o d'una guerra, pogués satisfer les necessitats urgents dels parroquians? Els nombrosos conflictes a l'entorn dels novals dels segles XIII i XIV amaguen el que es documenta a la Cerdanya del 
segle XViII? I com van afectar la reducció de la població arran de les mortaldats des de mitjan segle XIV i l'increment de la fiscalitat d'estat i de la municipal en la percepció del delme?

Les qüestions per resoldre encara són moltes, però és ben evident que cal integrar delmes i primícies $i$, en conseqüència, la parròquia en el cor del funcionament del sistema feudal de la Catalunya Vella. La cessió de delmes per part dels senyors dels castells als cavallers, abans del segle XIII, no només és coetània del mateix procés a Occitània i a altres regions europees, sinó que també coincideix amb l'erecció de les cases fortes per part d'aquestes famílies de la baixa noblesa: és el cas de la Torre Ferrana de Montfullà, llar dels Perafort (Mallorquí, Prat i Sagrera, 2020). No només això: rere la construcció, la decoració i les reformes d'esglésies, monestirs i castells romànics i, potser en menor mesura, de palaus i temples gòtics, sempre hi sol haver un delme. La mateixa catedral de Girona no se n'escapa, de la relació amb el delme: des de la primera notícia sobre aquesta prestació al bisbat gironí, l'any 888 , i les sitges que es troben actualment als soterranis de la seu, fins a l'assignació, al segle XII, de les rendes del delme de Sant Feliu de Boada a l'obra de la catedral, i a la percepció, al segle XIV, d'un delme sobre els productes venuts al mercat, a banda dels que rebien directament moltes persones eclesiàstiques de la seu.

Però també cal tenir present que el delme va ajudar a configurar una fesomia pròpia de les comunitats rurals gironines, on el sentiment comunitari potser no era tan accentuat com al nord d'Europa o potser quedava soterrat rere el protagonisme d'alguns pagesos que, pel fet de participar activament en la percepció del delme i d'altres rendes senyorials com a batlles, van enriquir-se i, com és evident en la casa del Sobirà de Santa Creu d'Horta i en altres (Mallorquí, 2005: 87-88), a partir del segle $\mathrm{xv}$, van poder mostrar-ho públicament amb la construcció d'unes cases amb torre que, gràcies al morter de calç emprat, han arribat fins als nostres temps. 
๑ :三

$<$

$>$ 


\section{ELS ARRENDAMENTS DE LES CAPELLANIES DE LA SEU DE GIRONA (1503-1705). UN INDICADOR DE LA RENDA AGRÀRIA DELS SEGLES XVI I XVII?}

Pere Gifre Ribas

\section{INTRODUCCIÓ}

Ja fa temps que els historiadors del món agrari han vist la necessitat de quantificar l'evolució de la producció agrícola, la conjuntura i la renda per l'època preindustrial i preestadística. La proposta d'utilitzar el delme com a reflex de la producció agrària va ser engegada per historiadors francesos, amb uns primers resultats (Goy i Le Roy Ladurie, 1972), fins que l'enquesta s'internacionalitzà en el VII Congrés Internacional d'Història Econòmica. Els debats a què va donar lloc i la publicació posterior de les actes (Goy i Le Roy-Ladurie, 1982) van suposar un punt d'arribada per aquest tipus d'estudis. A Catalunya, com veurem, sense que hi hagués una participació directa en aquest congrés, també ha interessat aquesta temàtica. A hores d'ara, però, per als segles XVI i XVII són pocs els treballs en aquesta línia: Eva Serra $(1978,1986,1988)$ i Montserrat Duran $(1984,1985,1986)$, sobretot, i Jaume Dantí pel Vallès Oriental (1988). Dels anys noranta ençà, la historiografia catalana ha traçat altres línies de recerca, sobretot s'ha avançat en la identificació de la diversitat estructural 
al si de Catalunya, seguint les petjades de les Catalunyes de Vilar (Serra, 2014: 308). No obstant això, els aspectes que Serra i Duran han apuntat són lluny de resoldre els problemes que es plantegen, tant pel que fa a l'evolució de la renda, com a les diferents geografies.

Per al segle Xvi, amb un país buit o per omplir —en això no hi ha conclusions fermes en l'anàlisi, en revisió, de l'evolució entre els fogatges de 1497, 1515 i 1553 i els recomptes de començament del segle XVIII (Ferrer, 2016) -, quin és l'abast del redreçament del camp català després de la Sentència arbitral de Guadalupe (1486)?, hi va haver canvis en l'estructura de conreus? Aquest redreçament, que hauria de tenir en compte la situació del segle Xv com a punt de partida, i aquí caldrà analitzar amb detall si després de la pesta negra hi ha una edat d'or de la pagesia (Feliu, 2006: 65-66), ¿és un veritable creixement, o sols és una recuperació dels nivells anteriors a 1450 (si no d'abans)? Encara que la problemàtica pagesa i remença no hauria afectat directament l'economia catalana fins a la segona meitat del segle $\mathrm{xv}$, segons les revisions que s'estan fent de la cronologia de la crisi de la baixa edat mitjana catalana (Feliu, 2004: 455).

Per altra banda, s'ha plantejat que el creixement de la renda agrària del cinc-cents entraria en una fase d'alentiment entorn de la dècada de 1580-1590, per desembocar en una atonia que enllaçaria amb la crisi del segle XVII anterior a la Guerra dels Segadors. ${ }^{1}$ Les sèries del Patrimoni reial a Catalunya de Montserrat Duran han estat recalculades per Eva Serra (1986) i en resulta una interpretació diferent de les que donava la primera autora. I la comparació amb València, amb l'expulsió dels moriscos el 1609, no sembla possible. La guerra i la fiscalitat de guerra, un factor extern, venen a trencar les dinàmiques internes de la societat pagesa durant el llarg període

1 L'evolució del valor real de l'ingrés senyorial, a partir dels arrendaments del Reial Patrimoni a Catalunya, la sintetitza Montserrat Duran en dues etapes per al segle XVI i començament del XVII: Una etapa de creixement general de l'ingrés al llarg del segle xvi que ateny el punt màxim entre els anys 1545-50 i 1580-85, bé que en alguns arrendaments aquesta fase s'allarga fins als darrers anys del segle. Frenada, o decreixement en alguns casos, de l'ingrés real, que, més o menys marcadament, es manté del 1580-1585 fins als anys 1640-1645 (Duran, 1985: 8). La tendència al creixement que troba pel segle Xvi coincideix amb la tendència general a Europa, tant pel que fa a la producció agrària, com a la població. 
de 1640 a 1719. Unes dinàmiques que portaren a l'extensió de la vinya, tal com s'ha apuntat en el cas del litoral i del Vallès Occidental (i també de la Catalunya central, ja des de començament del segle XVII (Ferrer, 2013), mentre que a les comarques properes a Barcelona, especialment el Vallès Occidental, condü̈ren a una substitució dels blats pels mestalls i cereals per a pinso, cosa que fa pensar en un augment de la cabana ramadera i, per tant, una major disponibilitat de fems per adobar la terra i, amb això, poder incrementar la productivitat. L'augment de la cabana ramadera també obeeix a una demanda de carn dels carnissers de Barcelona que no satisfeia prou l'oferta ramadera catalana. Aquestes dinàmiques, segons diferents indicis, s'haurien consolidat en la dècada de 1680, que prepararia la recuperació definitiva, aquest cop sí, el veritable creixement del segle XviII, una vegada superats els efectes de la Guerra de Successió, que s'hauria reprès a partir de 1725-1730.

Aquest és el punt de partida historiogràfic que posarem en relació amb la imatge que ens proporcionaran els arrendaments de les capellanies de la seu de Girona entre 1503 i 1705.

\section{ESTUdis DELS INGRESSOS SENYORIALS A CATALUNya}

Com en tantes altres coses, Pierre Vilar és el primer que, d'una manera sistemàtica, utilitza les sèries dels arrendaments del domini reial a Catalunya (1715-1808), posats a subhasta cada tres o cinc anys, per estudiar, geogràficament $i$ tècnicament, els fenòmens conjugats de l'extensió, de la intensificació agrícoles i de l'alça dels preus (Vilar, 1966: III, 483, 486, 492). Ho feia amb el propòsit d'observar els ingressos constituïbles en sèries llargues i contínues. Prèviament, havia constatat que els arrendaments estan configurats per una varietat de drets: És la quantitat efectiva que cobra el rei en tant que senyor, és a dir, el moviment d'una renda senyorial. L'anàlisi dels arrendaments que feia Vilar entroncava amb l'estudi de la conjuntura i la llarga durada dels preus i dels ingressos del segle XVIII francès del seu mestre Ernest Labrousse, que es publica el 1933. Amb tot, però, és la conjugació de la informació general i de l'anàlisi concreta, el moviment general, macroeconòmic (els preus, però també els ingressos i els salaris), i el particular, microeconòmic (els arrendaments de les heretats de 
l'Hospital o, més tard, els comptes de la petita explotació a l'horta de Tàrrega), el que permet a Vilar bastir la seva interpretació. ${ }^{2} \mathrm{La}$ iniciativa de Vilar ha tingut continuadors a Catalunya: per als segles anteriors i per al període final de la renda feudal. Per a això, però, hauran de passar alguns anys.

Eva Serra $(1976,1986,1988)$ utilitza el delme percebut en espècie, de Sentmenat i del Baix Llobregat, però també d'algunes dignitats de la catedral de Barcelona - tot i que no són sèries continuades, en alguns casos només uns pocs anys- per estudiar la producció agrària del segle Xvir, al costat de comptes de collites i de parts de collita. Aquesta opció la pren després de referir-se al debat historiogràfic dels anys setanta sobre el delme com a indicador de la renda i la producció, i considerar la possibilitat de no usar aquesta tipologia de font. ${ }^{3}$ En canvi, els arrendaments de drets senyorials, en els quals hi ha el delme, els usa per estudiar la renda feudal. Conscient, però, que hi ha altres ingressos que queden al marge de la renda percebuda (com els càrrecs i oficis), fet que la porta a matisar: tot això fa que hom no pugui pas assimilar el concepte de renda total els ingressos senyorials que estudiaré. Aquests, però, en són part substancial (Serra, 1988: 281). És a dir, l'índex que en resulta és indicatiu de la renda feudal i aquesta fonamentalment té origen agrari.

Montserrat Duran (1984) desqualifica, sense més, les comptabilitats pageses, ${ }^{4}$ que seria la forma adient d'acostar-se a l'estudi de la

2 Només la combinació raonada d'aquests dos tipus de fonts permet de completar un per l'altre i de controlar recíprocament les diverses formes d'observació, microobservació, macroobservació, observació en el temps, observació en l'espai (Vilar, 1966: I, 36).

3 Davant d'aquesta polèmica em vaig sentir temptada a abdicar de la meva documentació, però els esforços per localitzar unes fonts indicatives de la producció havien estat tan poc fructífers que em va semblar que, tot i les reserves que mereixen les fonts decimals, calia provar quines deduccions hom podia extreure del seu ús com a font indicadora de la producció, sempre, però, mantenint la consciència del marge d'incerteses que apunta Frêche $i$ indicant sobre la marxa el grau de garanties real de la documentació (Serra, 1988: 165).

4 La font documental òptima per a l'estudi del moviment de la producció són les comptabilitats agricoles, especialment les dels grans dominis senyorials -laics o eclesiàstics-, però aquest tipus de documentació comptable és escassa, per no dir inexistent, a Catalunya. Els llibres de comptes que es conserven en els nostres arxius, bé que nombrosos, aporten molt poca informació referent a 
producció i la productivitat. ${ }^{5}$ Amb aquesta situació de partida, l'opció serà estudiar el delme, que a Catalunya és arrendat juntament amb altres drets jurisdiccionals, senyorials, etc. Ateses aquestes característiques de les fonts, opta pels arrendaments de rendes i drets senyorials, la millor font per a l'estudi de les fluctuacions i de la tendència dels ingressos senyorials. Amb aquesta finalitat, Montserrat Duran utilitza els arrendaments del domini reial a Catalunya, en la línia de Pierre Vilar, de quatre comarques: l’Alt Urgell, el Tarragonès, la Conca de Barberà i el Baix Empordà, entre 1500 i 1800.

Gaspar Feliu considera que [e]ls arrendaments constitueixen la millor documentació disponible per a estudiar l'evolució dels ingressos senyorials i àdhuc l'evolució general de la conjuntura (Feliu, 1990: 95). No obstant això, té en compte les crítiques que ha rebut aquesta font indirecta, però conclou que a pesar de tots aquests entrebancs, el valor dels arrendaments continua essent un indicador útil, per més que barroer, de l'evolució, tant dels ingressos senyorials, com de la conjuntura econòmica general (Feliu, 1990: 102). Amb aquesta prevenció pot estudiar els beneficis senyorials i, d'una forma indirecta, el valor de la producció pagesa. En el seu cas, les fonts utilitzades provenen del Gran Priorat de Catalunya, les comandes de l'Espluga Calba i Barbens. I també, encara que d'una altra naturalesa, l'onzè de Sidamon. De l'anàlisi de la comptabilitat d'una companyia d'arrendataris dedueix que els guanys pel segle XviII, entre 1764 i 1773 , oscil.len entre un $18,27 \%$ i un $55,40 \%$ de benefici anual (Feliu, 1990: 100): percentatge lucratiu, sens dubte, que hauria de ser contrastat. Pels mateixos anys, les terres de Lleida rebran l'atenció

l'organització i funcionament del camp català (quantitat de llavor emprada, extensió real de terra sembrada, valor total de la collita...), atès que es limiten a consignar xifres globals, unes vegades, $i$ dades molt parcials, en d'altres (Duran, 1984: 83).

5 Que les comptabilitats agrícoles són escasses no s'ajusta prou a la realitat de la recerca actual. Que són locals i, per tant, difícils de generalitzar, i que no solen donar dades de llavor sembrada, són dificultats a tenir en compte; però quan s'estudia amb la finalitat de datar i concretar canvis, transformacions i continuïtats de moviments agrícoles i de la producció agrària d'abast general, són una bona font, com hem mostrat en una síntesi de treballs efectuats amb documentació comptable d'origen patrimonial (Gifre, 2017: 211-216). El que segueix sent cert és que pel segle XVI no tenim aquests comptes. 
d'Enric Vicedo a través de l'estudi dels arrendaments del capítol de la seu (Vicedo, 1991: 179-215; Vicedo, 2015a i b).

Montserrat Caminal, Esteban Canales, Àngels Solà i Jaume Torras (1978) usen la sèrie dels arrendaments dels Medinaceli a Catalunya entre 1770-1835 arrendats per estats - la forma en què estava dividit el patrimoni de la casa senyorial a Catalunya-, que procedien, bàsicament, de delmes o parts de delmes, juntament amb drets, la renda dels quals era proporcional a la collita, i censos emfitèutics; la resta de drets tenien poca importància econòmica. Enric Tello (1992) hi afegeix altres sèries fins a arribar a 62 rendes senyorials, entre 1732-1800, per estudiar la crisi de l'antic règim. ${ }^{6}$

A Catalunya, els historiadors han estudiat els ingressos senyorials de 1500 a 1835 a partir dels arrendaments de drets. Una barreja de drets emfitèutics i feudals, en què el delme - o les parts de delmeacostuma a ser el principal d'aquests ingressos. S'han fet moltes crítiques a la font, però no n'hi ha, ara per ara, una altra d'alternativa. Indirectament, l'índex que podem extreure de l'agregació de sèries d'arrendaments, que habitualment tenien una durada de tres anys, serà un indicador, sovint, de les expectatives que consideraven els arrendataris que podien pagar per la recol-lecció d'aquella renda; ${ }^{7}$ indicador, al cap i a la fi, en haver-hi competència entre arrendataris, del que eren els ingressos senyorials i, per tant, de la renda senyorial

6 El método empleado para el tratamiento ha sido el aplicado por Jaume Torras, Montserrat Caminal, Esteban Canales y Àngels Solá a las series de rentas del ducado de Cardona percibidas por los Medinaceli a finales del Antiguo Régimen: agregar los distintos valores nominales hasta obtener un índice compuesto del que pueda obtenerse un equivalente «real» usando como deflactor los precios del trigo (Tello, 1992: 287).

7 Manuel Ardit ha vist en els arrendaments de l'arquebisbat de València una superposició de cicles agraris i de cicle de negocis: Personalment tinc la impressió que als cicles pròpiament agraris se superposa un cicle que podriem anomenar «de negocis». Els increments $i$ decrements que sovint experimenten els preus d'arrendament, en desenes de lliures exactes, o en quantitats simbòliques de 10 sous, fan sospitar que darrere de les subhastes es negociaven pactes i compromisos. A més, el seu caràcter quadriennal introdueix un lapsus temporal entre el fenomen agrari i el seu reflex decimal: en algunes sèries, l'expulsió dels moriscos s'hi manifesta quatre anys més tard. Així i tot, opine que aquests factors poden revestir alguna importància en les sèries individuals, però no en les agregades, on tendeixen a contrarestar-se (Ardit, 1987: 293). 
i feudal. ${ }^{8}$ Indicador també de la producció agrària? Sí, quan entre els productes que han de ser recol-lectats hi ha un predomini elevat de les prestacions proporcionals a la collita, bàsicament delmes i tasques; allà on les prestacions s'hagin convertit en censos fixos, en diner o en espècie, no reflecteixen tant la conjuntura agrària. A fi de tenir en compte què es mesura, cal combinar l'anàlisi dels llibres de comptes dels perceptors de la renda, les tabes dels contractes d'arrendament i l'evolució de les relacions entre els senyors perceptors de rendes i la pagesia subjecte als pagaments, en forma de capbrevacions, d'una banda, però també de plets, concòrdies i sentències per si poden canviar les taxes i els productes a delmar. Quan es disposa de tota aquesta documentació, que no sempre passa, podem considerar que la sèrie resultant reflectirà la renda senyorial/feudal i, en la mesura que sigui un reflex, ni que sigui indirecte, de la collita, la tendència de la producció agrària. ${ }^{9}$

\section{Prevencions metodològiques}

Hi ha un primer element a tenir en compte abans de treballar les sèries d'arrendaments de rendes (emfitèutiques, feudals, delmes...), a la Catalunya Vella, la Catalunya dels masos, i al bisbat de Girona en concret: sovint el delme no és arrendat de manera exclusiva. Els diferents partícips del delme, terçons i altres parts, els recullen conjuntament amb altres pagaments en concepte de senyors directes. La renda dels senyors directes, sovint, és la suma de diferents pagaments emfitèutics i feudals, entre els quals hi ha el delme que, com a pagament universal, sol ser el més important, però no pas l'únic.

8 Aquest joc entre oferta i demanda, i d'expectatives dels arrendataris fa que Jean Jacquart consideri que els arrendaments de delmes acaben sent un indicador social, més que no pas de la conjuntura agrícola (Jacquart, 1975: 355-376).

9 En la nota introductòria, els responsables de l'enquesta francesa mostraven la seva precaució en parlar de presumpció: présomptions capitales sur la marche de la production agricole, présomptions qui se transforment en certitudes au fur et à mésure que le nombre de séries mises en oeuvre, et concordantes entre elles augmente [...] (Goy i Le Roy Ladurie, 1972: 14). 
Abans d'analitzar els arrendaments dels drets i rendes feudals, entre els quals hi ha el delme, cal tenir present quins són els productes dels quals es paga delme, o tasca, i censos, si és el cas, en cada localitat o parròquia i la taxa a què s'ha de pagar. Aquesta és una dada que no pot ser negligida. L'arrendador sol fer constar a la taba, quan posa a subhasta l'arrendament, tots els productes pels quals s'ha de delmar. Però la dinàmica de cada delmar sol ser diferent, malgrat ser el delme un pagament universal en el conjunt d'una parròquia. La dificultat augmenta en el cas de les tasques i els censos, ja que el domini directe dels llocs està molt repartit i són moltes les situacions possibles. Encara que en les tabes dels arrendaments s'hi inclogui l'afegitó $i$ tots els altres productes, en el que vol ser una fórmula dels arrendadors i dels arrendataris per poder percebre delme de nous conreus (o de l'aprofitament de les herbes i pastures en el cas de percebre el delme de carnalatge), els productors solen delmar només aquells que figuren explicitats en la taba, i que són els que han convingut, tradicionalment, de delmar. Les diferències entre delmadors i productors apareixen sovint, sobretot, en moments de creixement agrari, d'arrencada de terres, amb tota la casuística derivada dels novals, d'introducció de nous conreus o de substitució. Pel que fa a la taxa a què es paga, pot variar en el temps, raó per la qual cal estar atent als canvis que es puguin produir, sobretot per produccions noves, o de les quals no s'havia pagat en concepte de delme.

Cal tenir en compte també que s'ha documentat una aturada en la producció de cereals els darrers anys del segle Xvi, quan es produeix un procés de plantada d'oliveres, almenys en terres de l'Empordà i les garrotxes d'Empordà: en primera instància en terres marginals, per anar estenent-se, a poc a poc, vers les terres campes; o des de les darreries del segle XVII, sense tenir en compte que és el moment en què, en algunes zones del litoral i de la Catalunya central, el pla del Bages pròpiament, una part de la terra campa és dedicada a la plantació de vinya. És clar que el delme baixa en els primers anys, però també ho és que al cap de vuit o deu anys la producció de vinya comença a assolir cotes importants. Si els delmadors no han estat al corrent del canvi de producció, o si hi han estat, però no figurava en els capbreus i llevadors de rendes, o en les concòrdies que havien dirimit les diferències entre pagesos i delmadors, la caiguda de la 
renda no pot ser interpretada com una caiguda de la producció, sinó com un canvi de producció que encara no ha quedat reflectit en el delme.

Si aquesta aproximació és bàsica per entendre les dinàmiques precises i concretes, més ho és encara quan es disposa d'unes poques corbes que són representatives exclusivament d'un delmar o parròquia. Voler fer representatiu d'una comarca l'arrendament del delme de Pals en el segle XVI, sense tenir en compte l'expansió del conreu de l'arròs, suposa agafar una situació excepcional, limitada a una geografia concreta i a un conreu específic i determinat; és a dir, voler convertir l'excepcionalitat en norma (Duran, 1984; 1985). Hi tornarem.

La lluita d'interessos entre productors agraris i delmadors per les produccions a delmar, o per les quotes a què s'han de pagar, amb variacions significatives per parròquies i delmars, sol acabar en forma de plet. I mentre hi ha plet, sol no pagar-se, ${ }^{10}$ amb la qual cosa hi ha una prova de resistència entre delmadors i productors que pot

10 A Pelacalç i Montiró, el 1686, no es paga res de dret de capellania perquè hi ha plet a la cort de Calonge. No es recupera el nivell dels arrendaments de 1679-1683 fins al període 1694-1697, durant la Guerra dels Nou Anys (Arxiu de la Catedral de Girona (ACG), Llibre de comptes de capellanies de la seu de Girona, 1675-1705, f. 105r). Per altra banda, Ventalló i Valveralla dilaten un plet pel delme de l'oli durant un segle, 1603-1702, quan s'arriba a una concòrdia amb el delmador del lloc, pagant els endarreriatges per 650 lliures, pels quals s'imposa un censal a la parròquia. Cent anys de no pagar, 650 lliures. S'imposa un redelme sobre l'oli de 10/1 per poder fer front a les 650 lliures (Arxiu Històric de Girona (AHG), P. Rosselló, Notarials, Girona-8, 533 (1702): 26 de novembre de 1702). 
acabar en sentència, ${ }^{11}$ que sol ser recorreguda, o en concòrdia, ${ }^{12}$ amb una rebaixa de la quota o dels productes per delmar. La negociació sol ser la sortida habitual per no allargar els plets. S'ha de tenir present a l'hora d'interpretar canvis sobtats en el preu al qual es pacta l'arrendament. Per tot plegat, a banda dels llibres de comptes de rendes, si es vol entendre en la seva justa mesura la corba que en resulta, cal estudiar la documentació generada per les parts: la de les parròquies, fet no sempre possible, i la dels perceptors de rendes. ${ }^{13}$

Les casuístiques són moltes i diverses, i s'han de tenir molt presents quan es vol analitzar una sola corba, per saber el grau de representativitat de la producció del terme o delmar, ja que, en alguns casos, la parròquia o universitat d'un lloc acaba per comprar el delme d'un determinat conreu; aquest és el cas del delme d'olives,

11 El 1585 la parròquia d'Ordis va ser sentenciada a pagar delme d'olives, quan fins llavors no se'n pagava, ratificada encara el 1591, i amb obligació de pagar endarreriatges (ACG, Repertori general de capellanies II, f. 672v; AHG, Notarials, Girona-6, 565: 5 de juny de 1592). Quan analitzem el valor dels arrendaments ens adonem de la pujada substancial: de 1591 a 1593 es pagaven 176 lliures anuals, el 1594-1596 es passa a pagar 238 lliures; el 1597-1599: 255 lliures i el 1600-1602: 269 lliures. L'augment del valor dels arrendaments obeeix, doncs, a la sentència. En canvi, la sentència de 1599 que condemnava Albons a pagar delme de tot gra d'aresta (blat, sègol, espelta, ordi, civada, mill, arròs) i de llegums (faves, cuinats i llobins) i també alls, de 13/1 de les terres no tascals i de 12/3 de les terres tascals (AHG, Notarials, Girona-6, 591, de 8 de juliol de 1599), no sembla haver modificat substancialment el valor dels arrendaments, ja que en el període 1598-1600 es pagaven 101 lliures, i amb posterioritat a la sentència: 91,50 (1601-1603), 86 (1604-1606), 102 (1607-1609), 85 (1610-1612). A Sant Gregori, que la sentència de 1595 obliga a pagar delme d'11/1 de faves, llobins i fesols, sembla que experimenta un lleuger augment: es pagaven 96 lliures en el període 1592-1594, i es passa a pagar 81 (1595-1597), 101 (1598-1600), 100,5 (1601-1603) i 100 (1604-1606). Potser perquè es tractava de conreus menors, la presència dels quals se sabia, i els delmadors van voler tenir constància que es pagaria si n'hi havia una major collita (AHG, Notarials, Girona-6, 583: 8 d'octubre de 1596; Gifre, 2011: 233-236).

12 En alguns casos, la concòrdia implica la compra del delme d'olives: així a Esponellà el 1606; o a Figueres el 1636 amb la imposició d'un tretzè sobre l'oli durant 25 anys; a Vilanant el 1640, a Lladó el 1646 o a Beuda el 1695 (Gifre, 2011: 239).

13 En el cas de la catedral de Girona, les diferents institucions de la seu han preservat bona part de la documentació relacionada amb el cobrament de la renda i en el segle Xvin van procedir a elaborar llibres índexs de les rendes, en què queden recollides les sentències i concòrdies que afecten les diferents parròquies del bisbat (Portella i Sanz: 1985). 
fet que provocarà des d'aquell moment una extensió de la seva plantada en el lloc. ${ }^{14}$ En aquest cas, l'arrendament pagat a aquell delmador no és representatiu de la producció del lloc. Pel que fa a la representativitat de la renda, aquesta hauria de considerar tant el valor de l'arrendament, com la pensió del censal que s'encarreguen els propietaris del lloc.

Disposar del valor de l'arrendament, fins i tot del contracte notarial pel qual s'adjudica l'arrendament, no sempre és suficient. Cal seguir-lo, ja que hi ha clàusules del contracte que en possibiliten la rescissió. És el cas, per exemple, de la declaració de guerra (causa belli, ratione belli). Davant de situacions com aquesta, cal acudir als llibres de comptes dels perceptors finals de la renda per saber quin va ser l'ingrés real, ja que en rescindir-se el contracte, el delmador podia fer recol-lectar el delme i els altres drets, com passarà en més d'una ocasió en les parròquies que eren objecte d'arrendament de les capellanies de la seu de Girona durant la segona meitat del segle XVII i els primers anys del segle XVIII.

14 Aquest és el cas del lloc de Vilademires, que el 1681 arriba a una concòrdia amb els delmadors, el capítol de Vilabertran i el benefici del Soler de Vilanant, pel qual els propietaris del lloc els indemnitzaven amb un censal de 660 lliures a canvi de no pagar el delme d'olives. Anys més tard, davant l'extensió de les oliveres en el lloc, entre final del segle XVII i primers anys del segle xviı —es diu que van multiplicar-se per cinc-, els delmadors van instar causa a l'Audiència per revocar aquesta concòrdia en considerar que havia estat lesiva als seus interessos, ja que l'exempció del pagament del delme d'olives afectava només les oliveres plantades en els marges i en terres ermes; en canvi des de 1681 s'havien plantat en terra campa i en terra plantada de vinya i havia perjudicat els delmadors. No obstant la concòrdia de 1681, ratificada amb una altra de 1742, el 1772 hi ha sentència favorable als propietaris; però el 1801 de nou es mou plet, que encara continua els anys 1818 i 1819. Arxiu Comarcal de l'Alt Empordà (ACAE), Fages, 38, 40, 41. Al-legacions impreses de les parts. Pels mateixos anys, també hi ha concòrdia pel delme d'olives a Queixàs, entre tres particulars i Guerau Alemany, amb un plet iniciat el 1643 i una concòrdia de 1673 (Gifre, 2009: I, 148-149), fet que denota un procés generalitzat de plantada d'oliveres en aquesta zona de les garrotxes d'Empordà. 


\section{FONTS PER L'ESTUdI DE LA RENDA SENYORIAL AL BISBAT DE GironA}

Amb el propòsit d'estudiar l'evolució de la renda en els segles XVI i XVII, vam començar una cerca de fonts comptables que ens permetessin analitzar l'evolució de la renda feudal amb posterioritat a la Sentència arbitral de Guadalupe i poder establir les etapes de la recuperació i el creixement del segle xvi; per altra banda, també volíem situar la crisi de la renda durant el segle XvII, per saber si havia precedit els fets de 1640 o els havia intensificat; finalment, es tractava de situar la conjuntura de recuperació de 1680, i el retard que hauria significat la continuïtat de les guerres amb França. És a dir, una corba representativa del moviment de llarga durada. Amb aquesta finalitat, disposàvem de tres fonts diferents: les rendes de l'Almoina del Pa de la seu de Girona, les de les pabordies de la seu i, finalment, les de les capellanies de la seu. Les diferents institucions de la catedral de Girona, com a delmador universal de parròquies, com a partícips en el cobrament dels delmes, en forma de terços, o com a perceptors de censos emfitèutics, ens han llegat un volum comptable significatiu per l'època moderna, tot i que en aquests moments no estigui a l'abast dels investigadors. Amb l'excepció del treball de Montserrat Duran (1984), no disposàvem de cap sèrie relativa al bisbat de Girona per als segles XVI i XVII. I, encara, les seves dades quedaven limitades a Bellcaire, Torroella de Montgrí i Pals: una geografia molt concreta, marcada en bona mesura pel conreu de l'arròs, almenys en el segle XVII, que diferia de bona part de la geografia del bisbat.

El llibre de pabordies o Llibre gros de l'Arxiu de la Catedral de Girona recull els ingressos i les despeses de les nou pabordies de la seu de Girona: de Juny o de Celrà (1661-1699); de Juliol o de la Vall d'Aro (1661-1699); d'Agost (1661-1695); de Setembre i Octubre, dita de Cassà (1661-1700); de Lloret o de Novembre (1661-1700); de Desembre (1662-1698), amb la particularitat que la parròquia de Vilablareix es percep delme en espècie; de Gener (1661-1700); de Febrer, Març i Abril, dita de Castelló (1661-1700), i de Maig (16611697), amb Sant Julià de Ramis que sovint es col-lecta directament. Narcís de Puig (2003) ha estudiat el Llibre gros i, tot estirant per dalt i per baix, ha proposat una sèrie de 1631 a 1839, amb alguns anys del segle XVIII en què no disposa de dades. Finalment, acaba per estudiar, 
sobretot durant el període 1661-1700, la identitat dels arrendataris i fermancers. Aquesta comptabilitat ens deixava de banda tot el segle XVI i els primers trenta anys del segle XVII, fet que no permetia el que ens proposàvem estudiar.

La renda percebuda per l'Almoina del Pa de la seu de Girona, l'arxiu de la qual es troba dipositat a l'Arxiu Històric de Girona, permet, a partir dels llibres de comptes del paborde dels segles Xvi i XVII, acostar-se a la renda realment percebuda per aquesta institució. Amb la dificultat, però, de la discontinuïtat de la sèrie que en resulta, ja que els volums comptables no s'han conservat en la seva totalitat:

SEGLE XVI: 339 (1506-1507), 340 (1508), 341 (1513), 342 (1516), 350 (1519), 351 (1520), 352 (1525-1526), 353 (1528), 345 (1531-1532), 343 (1538-1539), 344 (1553-1554), 347 (1564-1565), 346 (1570-1571), 348 (1577-1578), 349 (1586).

SEGLE XVII: 354 (1604), 355 (1612-1613), 356 (1613-1614), 357 (16211622), 358 (1623-1624), 359 (1628-1629), 365 (1639-1640), 360 (16431644), 361 (1644-1645), 362 (1651-1652), 366 (1655-1656), 363 (16571658: sense arrendament de censos), 364 (1680-1682), 368 (1700-1701), 369 (1701-1702), 370 (1703-1704).

Hi ha encara una dificultat afegida: no sempre s'anoten els arrendaments de censos de tots els llocs (23 sèries), ni es poden agregar totes les sèries. En total, l'agregat de les 23 sèries només és possible en 11 anys. Es pot completar seguint els contractes notarials dels arrendaments, si s'han conservat, però no sabrem mai si va ser la renda final realment percebuda per l'Almoina. En tot cas, seria una renda prevista en el moment de l'adjudicació de l'arrendament.

Des del segle xiv, les rendes de les capellanies de la seu de Girona foren agregades a la mensa capitular de la seu. La mesura del bisbe de Girona, de 1313, va establir que cap renda superior a 150 sous de tern anual no pogués ser conferida a ningú, sinó que havien de quedar unides a la mensa episcopal en benefici dels clergues i canonges de la seu de Girona després de la mort o renúncia d'aquells que les obtenien. El 1315, es va nomenar una comissió per verificar quines eren les capellanies que superaven la renda de 150 sous. No obstant que l'arquebisbe de Tarragona va anul-lar aquesta disposició el mateix any 1315, el bisbe i el capítol de la seu van aconseguir, definitivament, l'agregació de les rendes de capellanies a la seu pel papa d'Avinyó 
Gregori XI el 1372. ${ }^{15}$ D'aquesta manera, definitivament, les rendes de les capellanies quedaven unides a la seu. I s'establia que les rendes havien de quedar distribuïdes, per això reben el nom de distribucions, en les següents parts:

a) La meitat per al bisbe, canonges i persones del capítol, segons l'assistència als oficis; al bisbe se li'n donarà el doble.

b) L'altra meitat quedava per als altres beneficiats de la catedral, i per al ferial i la fàbrica de l'església, a raó de tres parts iguals.

D'aquesta manera, des del segle xIv, la catedral de Girona havia unit les capellanies superiors a 150 sous de renda anual que quedaven distribuïdes entre el bisbe, el capítol i altres institucions de la seu. És de les rendes d'aquesta institució que han arribat diferents llibres de comptes ${ }^{16}$ que han permès elaborar una sèrie continuada dels segles XVI i XVII, excepció feta del tall dels anys centrals, de 1652 a 1661, en què no hi ha dades. Presenta l'inconvenient que són rendes poc significatives pel valor i que hi ha una barreja de pagaments: censos, delmes, tasques... En la majoria de parròquies, la renda de la capellania correspon a censos sobre unes quantes parcel-les. Quan són censos fixos en diner, poden ser susceptibles de perdre valor (Duran, 1999), no pas, però, quan són en espècie, que segueixen els preus. A fi d'analitzar la validesa de la suma agregada de les sèries, hem procedit a efectuar una simple prova: hem distribuït les rendes per parròquies i per ardiaconats, i hem representat gràficament l'evolució de les rendes superiors a cent lliures en començar el segle XVII, les quals, a banda de reflectir el cobrament de censos, també recollien parts de delmes, i les hem diferenciat de les inferiors a aquesta quantitat. La mostra és prou evident de la gairebé superposició de les corbes, amb l'excepció de les parròquies de l'ardiaconat de la Selva a partir

15 Encara ben entrada la segona meitat del segle XVIII, s'anota la transcendència d'aquesta butlla. En una nota marginal llegim: Esta butlla per obviar que essent com és original en lo arxiu no patesca extravio poden-se necessitar, que se produesca en causas molt freqüentment, se ha exemplat ab las degudas solemnitats en poder del doctor Bonaventura Bou y Guinart, notari de Gerona, als 31 de agost 1782, de ahont deurà tréurer-se còpia autèntica sempre que convínguia y lo original se trobarà al arxiu de baix, en lo armari de privilegis apostòlics, ACG, Repertori general de capellanies, s.f.

16 ACG, Llibres de comptes de capellanies de la seu de Girona, 1503-1556; $1556-1615 ; 1615-1675$. 
de 1581, quan hi ha una forta diferència, atribuïble, suposem, al fet de disposar de molt poques sèries.

\section{Gràfic 1. Ardiaconat de Besalú}

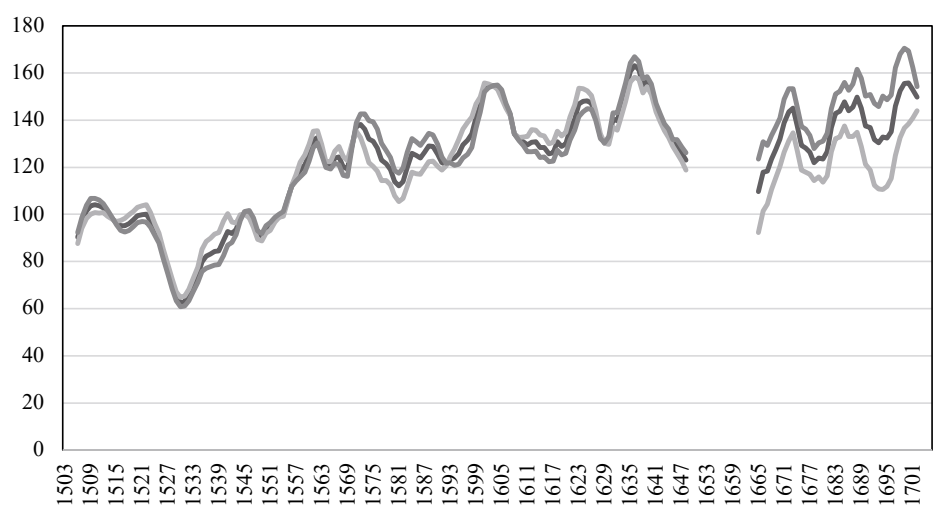

- Renda deflactada per ardiaconats $(1510-1519=100)$ Mitjana mòbil 7 anys Besalú total

Font. ACG, Llibres de comptes de capellanies de la seu, 1503-1556; 1556-1615; 1615-1675.

\section{Gràfic 2. Ardiaconat d'Empúries}

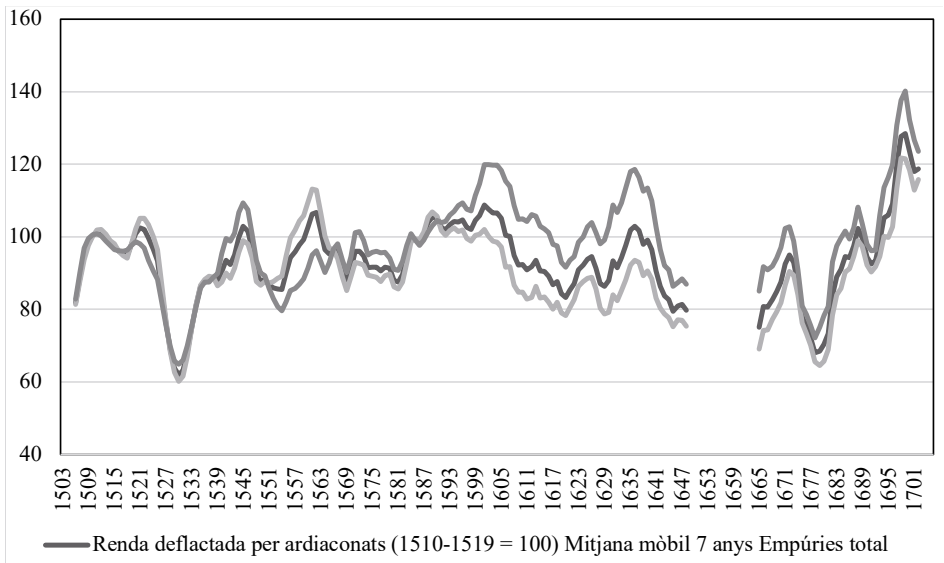

Font. ACG, Llibres de comptes de capellanies de la seu, 1503-1556; 1556-1615; 1615-1675. 


\section{Gràfic 3. Ardiaconat major}



Font. ACG, Llibres de comptes de capellanies de la seu, 1503-1556; 1556-1615; 1615-1675.

\section{Gràfic 4. Ardiaconat de la Selva}

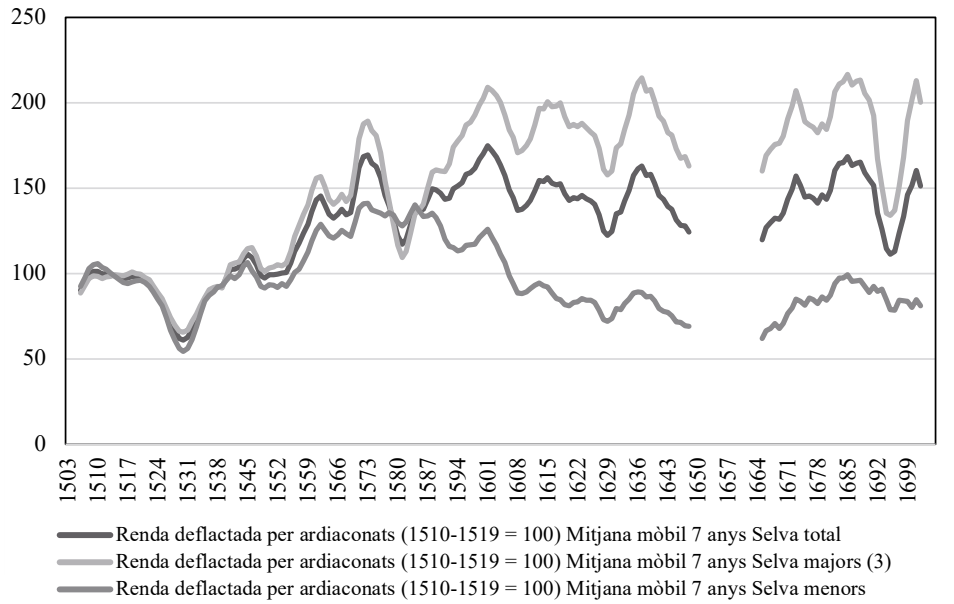

Font. ACG, Llibres de comptes de capellanies de la seu, 1503-1556; 1556-1615; $1615-1675$. 
La renda de les capellanies de la seu de Girona també presenta avantatges significatius. És la renda efectivament percebuda: en cas de renúncia es fa la colllecta directa; els arrendaments, ho són per períodes curts de temps, sovint tres anyades, algunes vegades dues; ${ }^{17}$ i els pagaments són anotats per terces. Finalment, permet l'agregació de les rendes procedents de les parròquies que hem procedit a agregar per ardiaconats: Besalú (29), Empúries (21), Major (22), Selva (7). En total, s'han utilitzat 79 sèries, amb continuitat pels segles XVI i XVII. I, excepte la zona selvatana, que queda poc representada, reflecteix la geografia del bisbat de Girona. És així com hem optat per agregar les 79 sèries i treballar-les amb l'objectiu de presentar-les com una dada indicativa de l'evolució de la renda percebuda per les capellanies de la seu durant el període 1503-1705, una renda que és el resultat de la barreja de rendes emfitèutiques i feudals, el delme inclòs. És la renda percebuda anualment per la catedral en concepte de capellanies. Hem optat per acabar la sèrie el 1705, pel fet que amb la Guerra de Successió hi ha una enorme dificultat per part de la seu de Girona de cobrar les rendes. Valgui d'exemple l'anotació que figura en acabar la guerra:

Se nota que lo die 17 abril 1716 dos expedients se discorregueren per haver experimentat en los anys antecedents molt enganyo en los arrendaments, pues los arrendadors simulavan ser homes de convenièncias y después se encontrava no tenian res, $y$ si bé per los dos primers anys de l'arrendament encara no se descobria la poca seguretat dels arrendadors, però a las últimas terças después que havien col-lectats los fruits, aleshores se trobava la impossibilitat dels arrendadors quant ja no y havia medi algun per recobrar los fruits, ni embargar aquells. Posat pues lo temps ja ab aquella tranquilitat que públicament se desitjava en dit any 1716, foren dos los medis se resolgué péndrer lo molt il.lustre capitol: de allí en havant, lo molt il.lustre capitol, lo primer, que ningú fos admès als arrendaments que no fos conegut o aprovat per los dos senyors comissaris que alli en havant se

17 A l'arquebisbat de València els arrendaments són a quatre anys (Ardit, 1987: 290). Pel Vallès Oriental, els arrendaments també són cada dos o tres anys (Dantí, 1988: 208). 
destinarian; lo segon, que vehent los administradors que no pagan los arrendadors, procuressin fer-los embargar los fruits. ${ }^{18}$

Les dificultats pel cobrament de la renda no sols venien de l'ocupació militar del territori. Els adjudicataris de l'arrendament també jugaven les seves cartes. Això passava en moments convulsos. Hem trobat casos, i ocasions, en què els arrendataris no sempre eren de fiar. No només hi ha frau en el pagament de les rendes, també n'hi pot haver entre els arrendataris de les capellanies.

\section{Proposta de Periodització}

La corba de la renda de les capellanies de la seu de Girona pel període 1503-1705, deflactada segons els preus del blat ${ }^{19}$ de Barcelona, ${ }^{20}$ presenta una evolució amb pocs canvis: no hi ha creixements espectaculars, ni daltabaixos significatius. Quan partim d'una base 100 en els anys que van de 1510 a 1519, a fi de poder percebre el creixement de la renda en l'inici del període, ${ }^{21}$ trobem el punt més baix de la sèrie el 1530, quan és de 52,54, i el punt més alt s'assoleix el 1700, amb 170,46. Podem pensar en una renda que no varia excessivament, i que en bona mesura segueix l'alça dels preus,

18 ACG, Llibre de comptes de capellanies de la seu de Girona, 1707-1715.

19 La deflactació pels preus del blat va ser objecte de controvèrsia i debat, i potser hauria estat millor fer-ho pels preus d'altres productes agraris, l'oli o el vi, per exemple, o fer-ho amb preus de mercats rurals; per altra banda, es diu que deflactar no fa més que repercutir les crisis amb un cert retard (Goy i Le Roy Ladurie, 1982: 785).

20 La sèrie de preus de Girona no abasta tot el període considerat. La comparació dels anys pels quals es disposa del preu de Girona, però, és molt semblant a la sèrie de preus de Barcelona (Duran, 1986: 199); és per aquesta raó que s'ha usat la sèrie barcelonina de preus per deflactar (Feliu, 1991). I s'ha deflactat any a any, no pas segons la mitjana mòbil dels preus, per considerar que interessava saber quina era la possibilitat real i efectiva de compra de blat que tenia la catedral en cada any de la corba.

21 I no ho fem amb les dades inicials de la sèrie, de 1503-1509, perquè no les tenim per a la totalitat de parròquies. Hem agafat deu anys en què no hi ha afectacions significatives sobre els arrendaments, tenint molt present la crítica, demolidora, que M. Morineau formula a Le Roy Ladurie quan compara anys de crisi del xvir amb anys de creixement de la producció agrària del segle xviII (Goy i Le Roy Ladurie, 1982: 646-649). 
tota vegada que els censos, més que els delmes proporcionals a la collita, poden suposar un llast per al creixement de la renda. És una suposició. Anem, però, per parts.

Gràfic 5. Renda deflactada de les capellanies de la seu

$(1510-1519=100)$



Font. ACG, Llibres de comptes de capellanies de la seu de Girona, 1503-1556; 1556$1615 ; 1615-1675$.

De 1509 fins a 1525, la sèrie es manté entorn de 100, que és el punt de partida, i inicia una espectacular caiguda, que arriba al mínim el 1530, quan perd la meitat dels guanys, i no es recupera fins a tornar al nivell 100 el 1543. Caldrà analitzar amb detall què passa entre 1526 i 1543 per poder explicar aquest descens, que coincideix amb una forta crisi de mortalitat a la ciutat de Girona entre 1528 i 1532, amb una punta de sobremortalitat espectacular el 1530 (Simon i Alberch, 1982: 14 i 21) en el marc més ampli de la fase depressiva de 1515-1540 (Alberch i Castells, 1985: 42-45, 73) amb episodis significatius de contagi per pesta. Aquesta acusada crisi de mortalitat també s'aprecia en les parròquies de l'Alt Empordà (Planas, 1985: 158). A partir d'aquest moment, amb una successió de petits cicles, sense canvis espectaculars, ni gaire augment, ni gaire disminució, s’arriba fins a 
1584. No hi ha un creixement continuat, prova evident que la renda real entra en una conjuntura amb poca certesa i poca expectativa per als arrendataris, d'aquí que les ofertes en la subhasta es moguin en canvis mínims en relació amb l'arrendament anterior.

Entre 1585 i 1628, la corba de les capellanies de la seu de Girona experimenta un cicle de més de quaranta anys de rendes mantingudes per sobre de 100. Això quan les rendes deflactades del Reial Patrimoni a Pals mostren a final dels anys vuitanta signes d'estancament; però és que la corba de Torroella de Montgrí està per sota de 100 des de 1550 (Duran, 1986: 213). Problemes de treballar amb unes poques sèries. ¿Quina reflecteix el Baix Empordà, la de Pals o la de Torroella de Montgrí? Poblacions veïnes, divergència en les corbes. L'aturada de l'etapa alcista, per altra banda, el 1628, té a veure amb la situació crítica dels anys 1627-1632 (Vilar, 1986: II, 328; Dantí, 1988: 213; Simon, 1992), que en la sèrie de capellanies es nota amb un any de retard perquè els arrendaments són, sovint, a tres anys. Finalment, en el període anterior a 1640, en la sèrie no s'aprecia ni prosperitat excessiva (el màxim s'assoleix el $1634 \mathrm{amb}$ 163,98), ni atonia de la renda; aturada en el creixement, sí, però sempre es manté en nivells ben superiors a cent, talment com al Vallès Oriental (Dantí, 1988: 213). Això suposaria acostar-se més a l'argumentació de Pierre Vilar per explicar la revolta de 1640 (Vilar, 1986: II, 356) com una revolta de la prosperitat, que no a la interpretació que en fa Eva Serra, segons la qual resultaria de la crisi de la renda feudal, entesa, però, com una etapa de recomposició de les forces productives capaces d'erosionar la renda feudal (Vilar, 1986: II, 228). Tot i que les dues interpretacions no són excloents: davallada de la renda feudal, per una banda, creixement de la producció agrària, per l'altra. Sembla que les capellanies de la seu van ser capaces de captar una part, almenys, d'aquest creixement agrari.

Després del tall marcat per la manca de dades, que coincideix amb el període 1652-1661, de guerres amb França, els anys posteriors són anys, inicialment, en què no s'arrenden totes les capellanies, fet que coincideix, per altra banda, amb moments de represa de l'activitat agrícola amb la pau. La veritable recuperació s'inicia en el període de 1667 a 1676, deu anys en què la corba se situa als nivells d'inici de la sèrie. Recuperació, doncs, però no pas amb seguretat, ja que hi haurà caigudes en la renda derivades de les campanyes militars franceses: la de 1684, tot i ser una guerra no declarada, va afectar 
especialment les parròquies del nord del bisbat de Girona, que, a més, coincideix amb una penúria generalitzada al Principat (Dantí, 1988: 225) i amb una important afectació sobre la mortalitat que en molts llocs supera de llarg i en molt els baptismes (Planas, 1985: 159, 163; Sánchez i Valls-Junyent, 2016-2017: 127-131); i, encara, el 1693, ara sí amb guerra declarada i ocupació efectiva del territori, quan no es poden recollir les rendes de la totalitat de les parròquies: perquè els arrendataris decideixen rescindir l'arrendament en aplicació de la clàusula de guerra, o perquè els canonges de la seu havien quedat aillats i no les van poder percebre, ${ }^{22}$ fet que, a més, coincideix amb una altra crisi de mortalitat a l'Alt Empordà els anys 1692-1696 (Planas, 1985: 159, 165). Amb tot, entre 1685 i 1705, la renda se situa en nivells de 140 i 150, amb el màxim el 1700, amb 170,46. La corba de les mitjanes mòbils, que assenyala la tendència, marca els punts més alts de tota la corba en aquests anys de final del segle Xvir. Tendència que contrasta amb la reculada del Vallès Oriental (Dantí, 1988: 216). La Guerra de Successió iniciada el 1705 torna a trencar aquesta etapa de recuperació. La guerra i la fiscalitat de guerra (imposicions militars, taxacions per càpita i redelmes sobre les universitats), un factor extern a les dinàmiques agràries, afecta el creixement de la renda de les capellanies durant els darrers quaranta anys del segle

22 Amb les dades de què disposem, no sabem amb certesa si hi ha una disminució de la renda real o si hi ha una incapacitat de la seu per cobrar la renda. Fixemnos amb les anotacions que queden en el llibre de comptes dels arrendaments de 1694. Posem alguns exemples. De la darrera terça de Porqueres s'anota: No se à pogut cobrar la tersera tersa per estar los arrendadors a la obediènsia de Spanya y no voler-hi anar los núncios. A Sant Esteve ça l'Ull tampoc no s'ha pogut cobrar la darrera terça, i a Sant Pere Despuig, ni la segona, ni la tercera. A Vilamalla, l'arrendament va ser renunciat el $1694 \mathrm{i}$, s'escriu lacònicament: en est any los fruyts d'esta capellania són estats devastats per la armada y pedragada. A la parròquia veïna de Siurana passa una cosa semblant: en esta capellania est any no s'i cullirà cosa perquè la armada à devastat molt. En acabar la relació de capellanies arrendades el 1694 hi ha una nota aclaridora de quina era la situació: Nota. Que de totas aquellas capellanias que no se à cobrat cosa y de altras falta a cobrar part, que.s troban los llochs de ditas capellanias a la obediènsia de Spanya, se té per cert que lo senyor bisbe y senyors canonges que s troban en la obediènsia de Spanya àn cobrats los fruits y tersos que faltan a cobrar, del qual se'n porà fer averiguació, quant Déu nos concedesca la pau, lo que ara no es pot fer. El 1695 s'anota que els canonges que han quedat a la part d'Espanya han cobrat rendes pel segrest que hi ha posat la Monarquia hispànica (ACG, Comptes de capellanies, vol. 1675-1706). 
XVII; no obstant això, els anys en què no s'assoleix el punt de partida inicial de 1510-1519 són molt pocs (1676, 1677 i, per molt poc, 1683). Les guerres, doncs, dificulten la recuperació. I tot i l'adversitat que denoten les crisis de mortalitat dels anys de començament de la dècada de 1690, la corba de la renda de les capellanies marca una pujada significativa. Creixement, al cap i a la fi, que ens apareix amb bases sòlides en relació amb el conjunt de la sèrie.

En definitiva, la corba deflactada de l'agregat de les capellanies de la seu de Girona mostra un segle xvi molt menys positiu del que alguns altres estudis han apuntat. Els anys en què la sèrie es troba per sota de 100, que és la mitjana del període d'inici 1510-1519, són molts i sovintejats: en cinquanta anys no s'assoleix el punt de partida inicial de la sèrie. I és especialment complicat el llarg període de 1525 a 1542: divuit anys seguits per sota, amb anys en què la renda perd més de vint, trenta i quaranta punts (especialment delicat és el trienni 1529-1531); menys acusat és el cicle de 1548-1552, però també amb baixades de vint punts. A partir de mitjan segle, i fins a 1584, els períodes negatius són més curts, de dos i tres anys seguits, i la corba segueix remuntant. De fet, hi ha una sola tendència des de 1585 , que és a l'alça, amb períodes puntuals de retrocés: 1619 (-13 punts), 16291631 (amb -1,8, -5,8 i -12,3), per arribar a la Guerra dels Segadors $(1644,1646$ i 1651). La represa, té molt pocs anys per sota de cent. Si contemplem tota la sèrie del segle xvir: només hi ha quinze anys, $\mathrm{i}$ encara alguns per molt poc, en què no s'assoleixi la xifra inicial de cent amb què hem iniciat aquesta corba.

Si analitzem en el seu conjunt la corba, en la llarga durada, a les capellanies de la seu de Girona, l'ingrés real va ser més positiu durant la crisi del segle XviI que no ho va ser l'etapa de creixement del segle Xvi. No sabem si és per la capacitat de captar la renda o com a resultat d'un procés de creixement de la producció agrària. Els plets que dirimeix la catedral de Girona al llarg de la geografia del bisbat hi poden tenir a veure. Com també la iniciativa pagesa d'estendre la plantació d'oliveres des del final del segle XVI, amb el manteniment de la producció cerealícola i l'inici de la posada en explotació de terres ermes o poc productives per plantar vinya del darrer quart del segle XVII. Fet, aquest darrer, que suposaria estendre la iniciativa pagesa, amb canvis en l'estructura productiva, com proposa Eva Serra (Serra, 1986: 235-237) per Sentmenat i l'entorn de Barcelona (Baix Llobregat 
i Vallès Occidental), o la substitució del treball morisc a la València del ducat de Gandia que troba Manuel Ardit (Ardit, 2004: 117-121; 2016-2017). En definitiva, a la vista de la corba, sembla que la catedral de Girona va fer servir els seus advocats i els tribunals, i la via de la negociació i la concòrdia, per seguir captant la renda pagesa.

\section{RELACIÓ ENTRE LA POBLACIÓ I LA RENDA}

A fi d'acabar d'establir la relació entre la població i la corba de la renda de les capellanies, procedim a efectuar un exercici comparatiu amb l'evolució dels baptismes de diferents parròquies del bisbat de Girona. Disposem d'algunes sèries que comencen en els primers anys del segle xvi: les parròquies de la catedral i Sant Feliu de Girona (Simon i Alberch, 1982), parròquies urbanes, i les de les viles de Castelló d'Empúries (Planas, 1985) i la Bisbal d'Empordà (Portella,

Gràfic 6. Renda deflactada de les capellanies de la seu

Diferència en relació $\mathrm{amb}$ el període $(1510-1519=100)$

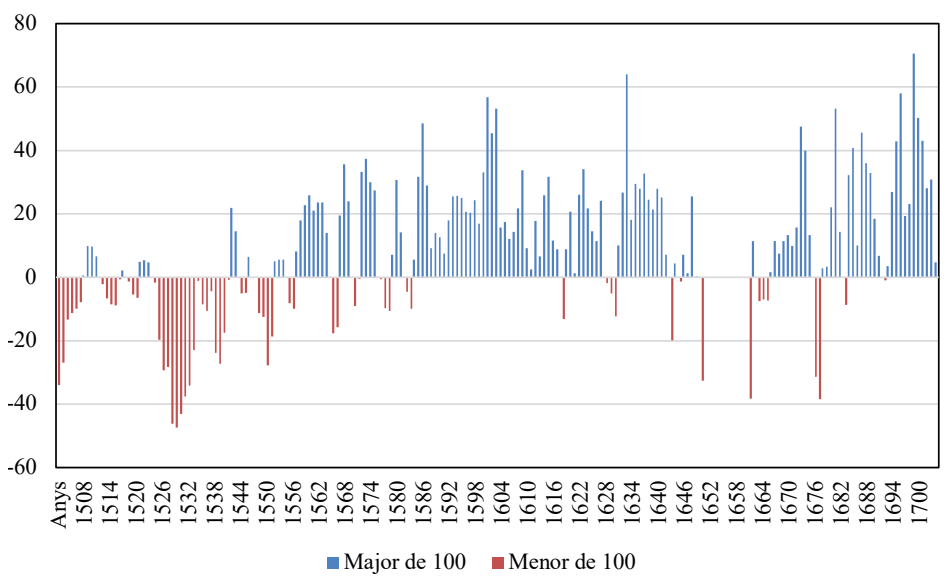

Font. ACG, Llibres de comptes de capellanies de la seu de Girona, 1503-1556; 1556$1615 ; 1615-1675$. 
1976). ${ }^{23}$ Per tal de poder comparar aquestes dades, hem establert el punt de partida en el període de 1521-1529, pel qual disposem de dades continuades de baptismes. És un punt baix, que coincideix a les parròquies de Girona amb un període de crisi de mortalitat. A fi de veure les tendències, que és el nostre propòsit, hem procedit a calcular la mitjana mòbil de set anys.

La dinàmica dels baptismes presenta comportaments diferents: especialment diferent és l'evolució de la corba de Castelló en relació amb les altres. En canvi, però, les corbes de la parròquia de la catedral, Sant Feliu i la Bisbal presenten una evolució semblant. Sabem de l'etapa de decadència per la qual passa la vila de Castelló, que queda reflectida en la corba de baptismes, i que consisteix en un procés de declivi de l'activitat manufacturera, especialment de la draperia, i una progressiva ruralització des dels primers decennis del segle XVI o fins i tot d'abans, amb un punt de no retorn de 1560 a 1590 (Colls, 2002: 171-174). Potser, també, una menor cura en la inscripció dels nounats en el registre parroquial. No ho sabem. Amb la qual cosa hem procedit a l'agregació de les corbes de les quatre parròquies.

La superposició de les dues corbes, amb els buits inevitables per la manca de dades de les dues sèries, assenyala una forta coincidència: població i renda segueixen la mateixa tendència fins a 1644, amb dues puntes marcades per la renda el 1603 i el 1637, que sobrepassa la corba de baptismes, per diferenciar-se en el període final de la sèrie de 1664 a 1702, quan, amb dents de serra, però amb tendència a l'alça, la renda de les capellanies de la seu està per sobre de la corba dels baptismes.

A la vista de la comparació de les dues corbes, que d'alguna manera ve a comprovar si la renda perd força davant el creixement de la població, la conclusió que podem extreure de les dades de què disposem ara per ara és que la renda de les capellanies s'adapta al ritme de creixement de la població durant el període 1503-1648, amb la reculada més significativa dels anys 1525-1535, quan es troba per

23 Disposem d'altres sèries publicades i estudiades, però o no tenen prou continuïtat (Caldes de Malavella, tot i que comença el 1521), o comencen tard (Sant Nicolau de Girona inicia la sèrie el 1548 i Santa Coloma de Farners, el 1588, per exemple). Per als nostres propòsits, ens cal disposar d'una sèrie que comenci el segle Xvi i com més aviat millor. 
Gràfic 7. Renda capellanies/baptismes

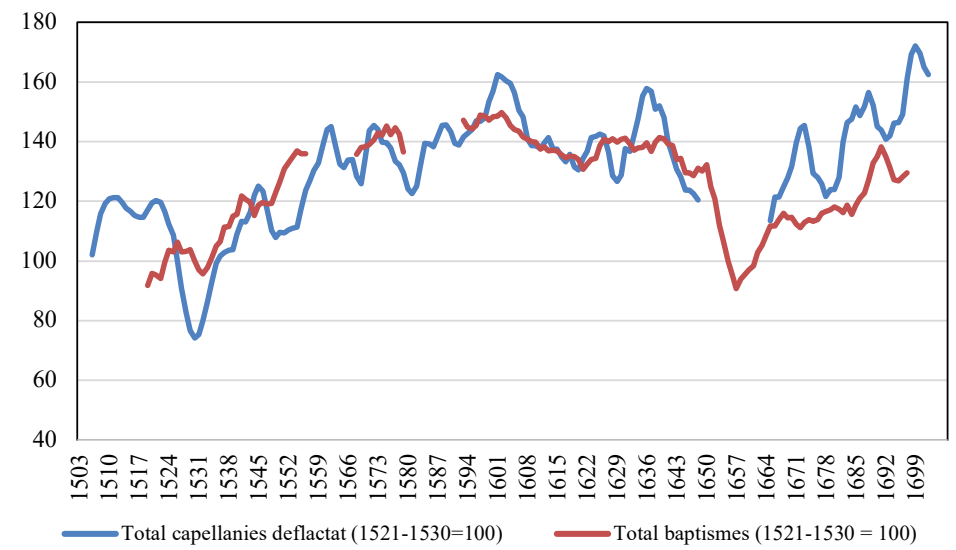

Font. ACG, Llibres de comptes de capellanies de la seu de Girona, 1503-1556; 1556$1615 ; 1615-1675$.

sota de la corba dels baptismes. La represa de la sèrie, en els darrers quaranta anys del segle XVII, mostra una recuperació de la renda per sobre del creixement dels baptismes. Les capellanies de la catedral van tenir la capacitat de seguir percebent la renda durant els segles XVI i XVII. La trajectòria coincideix amb la del Vallès Oriental fins a 1620; a partir d'aquesta data, al Vallès Oriental els baptismes es troben molt per sobre de les rendes del Vallès i Palaudàries (Dantí, 1988: 340).

Si establim la relació renda-població, en el que seria una aproximació a la taxa de sostracció per capita (Tello, 1992: 285-286), s'aprecia que es manté en la mateixa situació al llarg de la sèrie, sempre per sobre de 100: no hi ha ni una forta arrencada de la població, ni tampoc una pèrdua de capacitat de sostracció de la renda. Talment com demostra la part del gràfic elaborat per Enric Tello pel segle XVII (Tello, 1992: 308). ${ }^{24}$ No és fins al segle Xviır quan l'indicador de

24 [...] durante buena parte del siglo xvi el índice de esta renta señorial «real» se ajustaba mucho al indice de bautismos de 11 parroquias catalanas reconstruido por Jordi Nadal para el mismo periodo. A partir de 1680 las medias móviles de ambos índices se separan, y el momento inmediatamente posterior a la guerra de Sucesión acelera este proceso, acumulándose entre 1716 y 1740 hasta 30 puntos de diferencia (Tello, 1992: 290). 
Gràfic 8. Renda de capellanies/baptismes

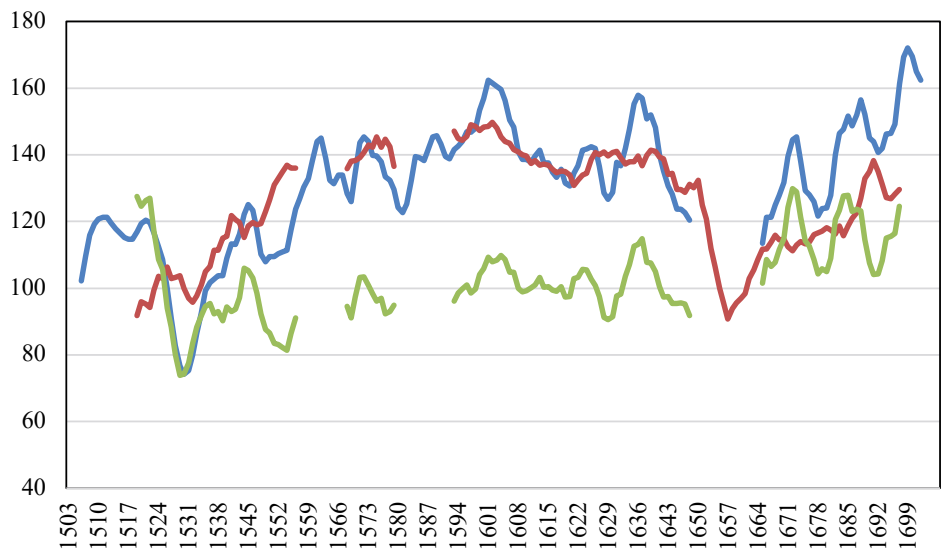

Total capellanies deflactat $(1521-1530=100) \quad$ Total baptismes $(1521-1530=100)$

Font. ACG, Llibres de comptes de capellanies de la seu de Girona, 1503-1556; 1556$1615 ; 1615-1675$.

Gràfic 9. Detracció de la renda feudal per habitant

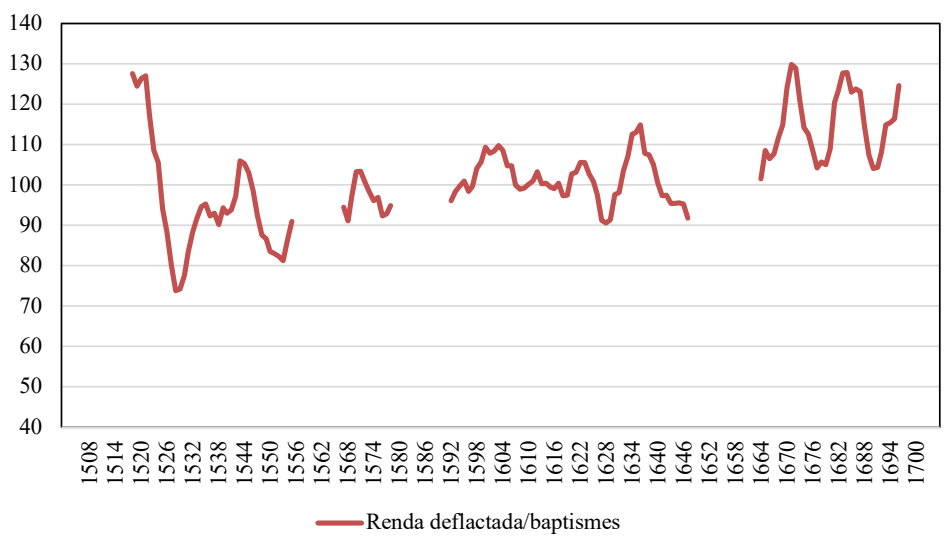

Font. ACG, Llibres de comptes de capellanies de la seu de Girona, 1503-1556; 1556$1615 ; 1615-1675$. 
baptismes es dispara per sobre de la renda a Catalunya. Al bisbat de Girona, no s'aprecien canvis significatius més enllà d'algunes petites puntes a l'alça i a la baixa: les puntes a la baixa no solen perdre més de vint punts, amb alguna excepció; i les puntes a l'alça també es mouen dins aquests paràmetres, amb quatre excepcions. La mitjana mòbil, amb l'excepció dels anys inicials de la sèrie, se situa entre 100 i 120. El que sí que sembla evident és que les capellanies de la seu de Girona no perden la seva capacitat de captar renda, menys encara en la segona meitat del segle XVII quan la renda, tot i les dificultats, es troba sempre per sobre de la corba de baptismes.

\section{Conclusió}

La corba de les capellanies de la seu de Girona no reflecteix l'oscil-lació de les collites. Això és evident quan s'arrenden les expectatives de la collita fins a tres anys vista. Si del que es tracta és d'analitzar l'ingrés pagès efectiu, no és amb aquestes dades que ens hi hem d'aproximar. Ni tampoc si volem acostar-nos a la productivitat $i$ als rendiments.

La corba de les capellanies de la seu de Girona entre 1503 i 1705, construïda a partir de l'agregació de les rendes que la seu de Girona percebia en setanta-nou parròquies del bisbat, és representativa de la geografia gironina i també ho pot ser de la tendència de les rendes d'origen agrari (en la mesura que reflecteix la renda proporcional a la collita: delmes, sobretot) i emfitèutic i feudal (pel fet de recollir els censos fixos). Hem vist en els gràfics 1, 2 i 3 la pràctica superposició de les corbes, amb l'excepció del gràfic 4 . En deflactar la corba amb els preus del blat de Barcelona, perquè els preus de Girona no abasten tot el període (i els de Barcelona tenen una forta correlació amb els de Girona), i amb l'aplicació de les mitjanes mòbils de set anys, hem aconseguit un indicador de l'evolució de la renda. La corba que en resulta reflecteix, doncs, una tendència de la renda percebuda per la seu de Girona, que és el resultat de les expectatives que tenien els arrendataris en el moment en què van optar a la subhasta. Expectatives a tres anys vista, algunes vegades a dos, però expectatives de negoci al cap i a la fi. De manera que el que acaba per percebre la catedral de Girona és la renda real, allò que podien percebre els rendistes 
que posaven en arrendament i subhasta la percepció de les rendes. Tendència de negoci, també i sobretot.

La corba mostra un creixement durant el segle XVI, menor del que altres estudis han assenyalat amb anterioritat, $\mathrm{i}$ amb un període crític molt accentuat entre 1526 i 1543 . En general, els primers cinquanta anys del segle Xvi, la renda de les capellanies de la seu de Girona presenta moltes dificultats per superar el llindar dels anys 1510-1519 que hem pres com a punt de partida. No sense algunes davallades significatives, la corba experimenta un creixement accentuat fins a 1604, quan s'alenteix el creixement, per caure en la crisi de 1628-1630. Els anys trenta torna a recuperar-se el creixement, fins que la guerra de 1640-1652 ho complica tot: la producció agrícola, però també la percepció de la renda. La dificultat de la represa dels anys seixanta és real, però també ve derivada de la font usada: tornar a posar en marxa l'engranatge dels arrendaments i la confiança en els arrendataris fa que siguin uns anys difícils per la renda. No obstant les dificultats, generals i concretades al bisbat de Girona - amb guerres i fiscalitat de guerra, males collites i crisis de mortalitat (1684, 1692-1695)—, la renda recupera els nivells de final de segle Xvi i primers anys del XVII per portar la corba al seu màxim.

Pel que fa a la taxa de detracció feudal, en el que és la relació entre creixement de la població (a partir dels baptismes) i el creixement de la renda, trobem una forta coincidència entre població i renda, excepte en el període final de la sèrie, quan la renda es troba per sobre de la corba de baptismes. El creixement de la població és, doncs, aprofitat per les capellanies de la seu de Girona per mantenir la percepció de la renda. Dilucidar les causes del creixement de la renda agrària és tot un altre exercici que necessita altres fonts.

Aquí s'ha apuntat l'evolució dels ingressos senyorials de la catedral de Girona, amb una maquinària jurídica esmolada posada al servei de la percepció de la renda. No sabem fins a quin punt pot ser extensiva a altres rendes senyorials, i a altres geografies. No sabem la seva representativitat. Aquest és un problema important de la font que hem utilitzat. 


\title{
6. DELMES, TRULLADES I PREUS DE L'OLI A MALLORCA, 1684-1835 ${ }^{1}$
}

\author{
Gabriel Jover Avellà
}

\section{Delmes, ESCRUTiNis DE COLlites I ESPECiALITZACió oleícola a Mallorca}

El delme era un «impost invariable i fix», un 10 per cent de la collita bruta, que gravava proporcionalment l'ingrés brut, però requeia sobre l'ingrés net; per això era «molt onerós e intolerable» segons David Ricardo (1984 [1817]: 150-151). La seva diabòlica naturalesa i l'àmplia difusió han estat, però, una benedicció pels historiadors de les etapes medieval i moderna. Les rendes decimals dels grans senyors feudals, particularment l'Església, s'han convertit en la font més continuada i homogènia davant d'altres microindicadors (les sèries de producció de les explotacions) o altres fonts discontínues (interrogatoris o estimes de la producció per alguns anys) — per a la reconstrucció de l'evolució del producte agrari entre els segles XIV i

1 Aquest estudi ha comptat amb l'ajut del projecte PGC2018-096350-B-I00 finançat pel Ministeri de Ciència, Innovació i Universitats. Una primera versió d'aquest text fou presentada el 26 d'octubre de 2018 a la jornada El Delme com a Font per a la Història Rural, organitzada per l'Associació d'Història Rural i el Centre de Recerca d'Història Rural de la Universitat de Girona. 
XVIII, arreu d'Europa. ${ }^{2}$ Els problemes que presenta aquesta font han estat subratllats en diversos capítols d'aquest llibre. Tanmateix, en aquest estudi es vol posar en valor l'ús dual que han fet d'aquesta font els historiadors com a proxy del producte agrari, quan eren percebudes en espècie o bé convenientment deflactades pels preus agrícoles, o com a proxy de l'ingrés senyorial.

Els estudis sobre les rendes decimals de les diferents regions de la Corona d'Aragó són un bon laboratori per destriar els usos i significats diferents d'aquesta font ${ }^{3}$. D'una banda, l'estudi de les rendes decimals ha permès retratar les grans etapes de l'expansió i diversificació agrària entre la baixa edat mitjana i la fi de l'ordre feudal a Catalunya (Duran, 1985 i 1999; Serra, 1985 i 1988; Gifre, 2012), l’Aragó (Latorre, 1989, 2010) i el País Valencià (Ardit, 2004 i 2016). Però, els delmes eren una part important de l'ingrés senyorial, la més important de fet, i un mecanisme de sostracció de l'excedent agrari que tenia un impacte social desigual, afectant més aquelles explotacions que tenien un marge de producció neta més reduït (Caminal et al., 1978; Canales, 1982 i 1985; Tello, 1992, 1995). Per això, el seu pagament fou objecte d'una tenaç resistència des d'etapes molt primerenques (Serra, 1988; Ardit, 2004; Gifre, 2012). La generalització de l'oposició al pagament dels drets feudals a final del segle XVIII acabaria deteriorant l'efectivitat de la punció i ensorrant els ingressos decimals, i el conglomerat de la renda feudal del qual n'era el component més important (Tello, 1995b, 1997; Ardit, 1977). Així, a mesura que el delme perdia efectivitat, també s'erosionava la seva fiabilitat com a indicador de l'evolució del producte agrari. Però, lluny de ser un problema, aquesta polisèmica lectura del delme pot ser una eina per entendre millor la dinàmica del creixement agrari i la distribució de la renda en les societats agràries preindustrials (Tello, 1995b).

A diferència de l'ampli ús que s'ha fet de les rendes decimals a Catalunya o al País Valencià, a l'illa de Mallorca l'interès per l'estudi de les rendes decimals com a indicadors del producte i de l'ingrés

2 Per a una discussió més detallada sobre l'ús dels ingressos decimals com a indicadors del producte agrari, vegeu el capítol primer d'Enrique Llopis Agelán i José A. Sebastián Amarilla en aquest mateix volum.

3 Per una discussió més detinguda al respecte vegeu els capítols 3, 4 i 5 d'aquest mateix llibre. 
senyorial ha sigut limitat i selectiu. Les fonts decimals han sigut àmpliament emprades pels medievalistes (López Bonet, 1983, 1989, 1990; Soto, 1991, 1997, 2014; Portella, 1993; Sastre, 1989-90, 1994, 2001, 2009, 2012; Sastre i Llompart, 2008, 2010) i altmodernistes (Vaquer Bennasar, 1987; Juan Vidal, 1987, 1988, 1989a i 1989b). Mentre els baixmodernistes (segles XVII i XVIII) han emprat excepcionalment els delmes per resseguir l'evolució d'alguns productes: el vi i els conreus de regadiu i horta (Manera, 1990 i 1992). L'interès per l'anàlisi dels delmes com a part de l'ingrés senyorial encara ha sigut més minse (Badosa, 1985). L'explicació d'aquesta prevenció en l'ús de les fonts decimals per l'etapa moderna probablement s'explica a partir de dos factors. D’una banda, la formació dels grans patrimonis agraris i la gran explotació (en domini útil) de l'aristocràcia i la dinàmica que imposà en el món rural, han centrat l'atenció en la renda de terra, el mercat de treball, la crisi dels drets de propietat de la noblesa i els canvis econòmics, menystenint el paper de la renda feudal en la crisi del vell ordre (Romero, 1983 i 1989; Suau i Moll, 1979 i 1986; Manera, 2001; Morey, 1999) ${ }^{4}$. En segon lloc, la disponibilitat d'una rica documentació estadística elaborada per les autoritats del regne de Mallorca des del segle xv fins al xIX, els anomenats escrutinis o manifests de les collites — una estimació del volum físic de les principals produccions agràries-, ha permès als historiadors prescindir de la documentació decimal (Manera, 2001).

A mitjan segle $\mathrm{xv}$, si no abans, les autoritats del reialme desenvoluparen una nova política frumentària (Juan Vidal, 1976, 1978). El nucli d'aquesta praxi era la comparació de les necessitats de consum de la població (el nombre d'habitants multiplicat pel consum mitjà de blat) amb els manifests anuals de les collites de blat. ${ }^{5}$

$4 \quad$ La interpretació del règim feudal a l'illa proposada per Joan Romero (1983 i 1989) posa l'èmfasi en la importància de les rendes dels magnats feudals i nobles en les diferents parròquies, mentre Isabel Moll i Jaume Suau (1986) argumenten l'escassa rellevància que tenien les rendes feudals en ingressos de la noblesa de l'illa, propietària sobretot de grans possessions en domini útil. Tanmateix, cap dels dos plantejaments proposa una hipòtesi sobre el què significà la crisi del règim feudal a l'illa.

5 Els escrutinis eren una estimació de les collites dels cereals realitzada abans (escrutini incert) i després de la collita (escrutini cert), per cada parròquia. La sèrie comença a 1466 i acaba el 1835 (Juan Vidal, 1978). 
Els dèficits o superàvits en la collita de cereals constituïa el punt de partida per endegar les mesures per prevenir l'escassetat frumentària: inici dels tràmits per importar cereals; repartiments de blat; adquisició de llavors; taxació dels preus, entre d'altres (Juan Vidal, 1990; Moll, Segura, i Suau, 1983; Suau, 1984; Manera, 2001; Jover-Avellà, 2011; Garí Pallicer, 2013 i 2019). La pràctica s'estendria durant el segle $\mathrm{XVII}$ a altres produccions considerades estratègiques per l'economia de l'illa: a mitjan segle xvir s'inicià la confecció dels escrutinis dels llegums (Jover-Avellà i Manera, 2009); el 1684 s'iniciaren de forma regular els manifests de trullades d'olives (nombre de premsades) per produir oli (Suau, 1979: 573-574, 612-615; Juan Vidal, 1980: 550), ${ }^{6} \mathrm{i}$ les polítiques manufactureres proteccionistes impulsaren l'elaboració dels escrutinis de la producció de seda a final del xviI (Escartín, 1992). Pel segle XviII s'han conservat els escrutinis anuals de bestiar, que estimaven el nombre de caps reproductors i les cries de la ramaderia ovina, porcina, bovina i equina (Suau, 1979; Quintana, 1982 i 1992; Bejarano, 2001). Així mateix s'han conservat estimacions esparses de la producció de vi i altres collites (garrofes, ametlles, lli, etc.) pels segles XVIII i xix (Manera, 2001; Jover-Avellà i Manera, 2009).

L'anàlisi de l'evolució de la producció agrària a l'illa s'ha fet emprant ambdues fonts, delmes i escrutinis, de forma complementària $\mathrm{i}$ seqüencial. Els delmes s'han emprat com un indicador de la producció i l'ingrés agrari total entre el segle xiII i el xvi. A partir del segle XVI s'han emprat bàsicament les sèries d'escrutinis de les collites quan estaven disponibles (cereals, llegums, oli, seda) i, en el cas dels productes que no disposaven d'aquesta font, s'ha recorregut al delme (vi i conreus de regadiu). Però, en comptades ocasions s'ha avaluat $i$ contrastat la fiabilitat d'aquestes dues tipologies documentals (Jover-Avellà i Manera, 2009). El propòsit d'aquest estudi és mesurar i discutir la fiabilitat de les rendes decimals i dels escrutinis de les collites per a una de les produccions més importants de l'illa: l'oli. Des del segle xvir més d'un $50 \%$ de la producció total d'oli era exportada als mercats exteriors (Manera, 1999); els olivars ocupaven més del $15 \%$ de les terres cultivades segons les estimacions d'inicis del segle

$6 \quad$ S'han conservat algunes estimacions esparses de les collites d'olives i de la producció d'oli de final del segle XVI i inicis del XVII; vegeu HabsburgoLorena (1959: 98-100) i Juan Vidal (1980: 521). 
XIX (Suau, 1991); la producció d'oli representava una cinquena part del producte agrícola brut a mitjan segle XviII (Jover-Avellà i Manera, 2009), i l'impost sobre l'oli, el vectigal, era el principal ingrés fiscal de la Hisenda reial al segle XviII (Daviu, 1983; Pascual, 2013 i 2018). No debades, com deia un il.lustre coetani: el aceite es el nervio de los caudales públicos (Juan Vidal, 1980: 548).

L'estudi s'articula en els apartats següents. A l'apartat 2, presentarem alguns dels trets agrosocials del model d'especialització oleícola, per oferir un context històric a la informació que proporcionen les sèries de delmes i escrutinis de les collites. A l'apartat 3 es presentaran les fonts emprades: els escrutinis de les collites d'olives (manifests de trullades), els preus de l'oli confeccionats a partir de les compres dels convents en el mercat de Palma, i finalment, les rendes del delme de l'oli del capítol de la catedral de Mallorca. En cada subapartat es farà una primera anàlisi de la seva naturalesa. L'apartat quart tracta de contrastar la fiabilitat i el significat històric dels diferents indicadors, des d'una doble perspectiva: estructural a l'apartat $4.1 \mathrm{i}$ cronològica a l'apartat 4.2. A l'apartat cinquè s'ofereix una primera interpretació de l'evolució de la producció i els ingressos oleícoles entre 1550 i 1830. Lanàlisi es centrarà en el comportament dels delmes i els manifests, com a proxies del producte i de l'ingrés del sector, però també com a espais de fricció socioeconòmica i indicadors de les transformacions agroclimàtiques. Les conclusions destaquen que el delme de l'oli planteja nombrosos problemes com a indicador físic de la producció olivarera, però sembla un bon indicador dels ingressos i la distribució de la renda en el sector olivarer. Finalment, l'estudi proposa mantenir la diferenciació analítica entre l'evolució del producte i l'ingrés del sector oleícola per tal d'entendre les inèrcies i els canvis que es produïren, i particularment per explicar la crisi que afectaria l'olivar i l'exportació d'oli des de final del segle xvirI.

\section{TRETS DEL MODEL D'ESPECIALITZACIÓ OLEÍCOLA}

A l'illa, com en el conjunt de la Mediterrània, el conreu de l'olivera tenia una antiga tradició i uns contorns agroecològics definits (Grigg, 2002). No ens ha d'estranyar, doncs, que des de l'antiguitat el conreu de l'olivera estigui profusament documentat a l'illa (Gil-Sánchez et 
al., 2003: 78-123). Ara bé, com palesen els estudis sobre la conquesta i colonització feudal del segle XIII el conreu de l'olivera s'havia concentrat a l'eix central de la serra de Tramuntana (Soto, 1997). No seria fins als segles XV i Xvi que s'estendria des de la serra cap el Raiguer i més tard a la serra de Llevant (Juan Vidal, 1989a, 1989b). Al segle XVII l'especialització oleícola estava plenament consolidada: la Serra de Tramuntana produïa més del $80 \%$ de l'oli de l'illa. Diversos factors de caràcter agroecològic i socioeconòmic concorrerien en la formació d'aquest peculiar model d'especialització (Bisson, 1977; Grau, 1983).

En primer lloc, les zones olivareres (serra de Tramuntana i Llevant, Raiguer i turons occidentals de Palma) compartien uns trets agroecològics similars. Els olivars s'assentaven sobre els suaus pendents que facilitaven el drenatge del sòl, l'altitud propiciava els contrastos tèrmics estacionals que afavorien la floració de l'olivera i una pluviometria relativament elevada afavoria collites abundants encara que molt irregulars (Bisson, 1977: 178-181, 213-224; Gil, Manuel i Diaz-Fernández, 2003: 41-49, 78-123). Per expandir-se sobre els vessants més rostos de les serres, consolidar les plantacions i modular l'erosió hídrica, es construïren terrasses fins als 700 metres d'altitud (Bisson, 1977: 179-180; Carbonero, 1992, 2002; Pérez, 2012; Villalonga, 2012; Jover-Avellà, 2013a). Contràriament, les condicions agroclimàtiques dels districtes del Pla i el Migjorn no eren tan propícies pel conreu de l'olivera. En el primer, el predomini de sòls argilosos dificultava l'evacuació de l'excés d'aigua, i en el segon eren la pobresa dels sòls, l'escassa pluviometria i l'elevada temperatura mitjana els que actuaven com a factors limitants de la producció oleícola (Jover-Avellà i Pons, 2012: 172-176).

En segon lloc, durant el segle Xvir l'oli tingué un destacat protagonisme en la petita globalització de commodities mediterrànies (Aymard, 1987; Divitiis, 1997; Ramón-Muñoz, 2000; Moore, 2010;). L'oli era demandat per les grans urbs atlàntiques (Londres, Amsterdam, Sevilla) i mediterrànies (Alacant, Barcelona, Marsella) com a input per les llars domèstiques (il-luminació, cosmètics, sabó, etc.) i les empreses manufactureres (cardat de la llana, lubricació de la maquinària, etc.). Així, Mallorca a mitjan segle XviI s'havia convertit en un precoç enclavament exportador d'oli: més de la meitat de la producció d'oli eixia cap als mercats atlàntics i mediterranis (Juan Vidal, 1980; Bibiloni, 1995; Vaquer Bennasar, 2017; Manera, 
1988, 1999). Per tant, la demanda exterior actuava com a motor i incentiu de l'especialització olivarera, un recurs que permetia pagar les importacions de blat i altres béns, i obtenir un cert superàvit que nodria el consum de luxe de les classes benestants (Manera, 1999).

En tercer lloc, l'especialització olivarera mallorquina fou un model atípic a les regions mediterrànies, on predominaven les explotacions mitjanes de caràcter familiar (Cobos, 2006; Infante, 2014). A les serres de Tramuntana i Llevant s'havien consolidat des del segle XV la gran propietat i la gran explotació, anomenada possessió (Bisson, 1977: 214-220; Suau, 1991; Tello et al., 2018). La major part de les grans possessions oleícoles eren propietat de la noblesa terratinent, rics comerciants i terratinents vilatans (Moll i Suau, 1979; Montaner i Morey, 1989; Bibiloni, 1992 i 1995: 329-332; Manera, 1988: 77-85), que per la seva explotació contractaven mà d'obra assalariada (Grau, 1983; Jover-Avellà i Pujades-Mora, 2017b, 2020a).

Així, a la segona meitat del segle xvir es congrià un model d'especialització agrícola que durà fins ben entrat el segle XIX caracteritzat per la producció d'olis de baixa qualitat per abastir el mercat internacional de greixos vegetals (Bibiloni, 1992; Vaquer Bennasar, 2017). Els ingressos del sector depenien sobretot del volum de producció i de les exportacions, mentre que els preus de l'oli estaven fixats pel mercat internacional (Jover-Avellà, 2020). Per tant, les rendes dels terratinents i els guanys dels arrendataris depenien del volum de la collita i dels preus fixats en el mercat internacional. Per augmentar els seus ingressos, els arrendataris (marge de guany) $i$ els terratinents (renda de la terra) havien de modular la intensitat del treball (maneig del sòl) i l'esmerç. Per això, empraven massivament les reserves de treball barat: dones i infants, per reduir els costos (Grau i Tello, 1985; Jover-Avellà, 2014; Jover-Avellà i Pujades-Mora, 2017 i 2020). El sistema entomava les pressions externes (descens dels preus, caiguda de la demanda o crisis agroclimàtiques perllongades) cap a dintre, comprimint els costos de producció i congelant l'esmerç. Quan aquestes condicions s'invertien en les etapes expansives - augment de la demanda i alça dels preus - el conreu s'expandia i s'incrementava l'esmerç en la millora de les installlacions i del conreu (Villalonga, 2012; Jover-Avellà, 2013 i 2020). Tanmateix, el zenit d'aquesta especialització s'inicià a final del segle XVIII (Morey Molina, 2016), quan aparegueren nous competidors, nous olis vegetals, i s'imposaren innovacions 
tècniques que milloraven l'eficiència en el premsat de l'oliva (Mazzoti, 2004; Infante, 2014; Ramón-Muñoz, 2005 i 2013).

\section{LES FONTS: ELS MANIFESTS DE TRULLADES D'OLIVES,} ELS PREUS DE COMPRA DELS CONVENTS DE PALMA I ELS delmes de l'oli del CAPítol de la CATedral de Palma

El propòsit d'aquest apartat és avaluar la fiabilitat de les fonts decimals. La hipòtesi de partida és que els escrutinis de les trullades d'olives són la font més fiable, i per tant han de servir per contrastar la fiabilitat de la resta de sèries. Per això, començarem per testar si els escrutinis de les collites d'olives eren una estimació versemblant de la producció oleícola. A continuació seguirem amb la presentació de les sèries de preus, i finalment les dels delmes. La discussió sobre la interpretació de les fonts es deixa per l'apartat següent.

\subsection{Trullades d'olives, registre del vectigal i producció i exportació d'oli}

Els manifests de les trullades d'olives foren implementats per les autoritats del regne per estimar la producció d'oli. La base del càlcul era el nombre de trullades - premsades a les tafones- que es podien fer amb la collita esperada. Per aquesta tasca les autoritats locals triaven alguns experts, entre els quals hi havia els arrendataris i majorals de les possessions, els consellers (després regidors) de les viles i els rectors de les parròquies. La collita s'estimava prenent en consideració l'experiència passada, el volum de la floració (maigjuny), el nombre d'oliveres i el seu rendiment segons l'any (règim de pluges), i el nombre de bigues de les tafones que hi havia a la parròquia $^{7}$. Els escrutinis de cada vila s'enviaven per correu a Palma

$7 \quad$ Els plecs dels manifests elaborats per cada vila i conservats a l'Arxiu Capitular de Mallorca (ACM) expliquen aquesta mecànica. Les butlletes indicaven el nombre de trullades esperades. En les seves missives, en què reportaven al capítol l'estimació de les trullades esperades, també informaven sobre quina era la situació de la maduració del fruit, i de la necessitat que els delmers acudissin en prestesa per vigilar la recollida i el premsat de les olives, i evitar el frau (ACM 17128, f. 38, Rector d'Andratx, 1768). Els manifests de 
on es confeccionaven els manifests o estims de les trullades d'olives per tota l'illa. ${ }^{8}$ A partir d'aquesta informació les autoritats estimaven la producció d'oli (en quartans) i les necessitats de consum de Mallorca i Palma (Juan Vidal, 1980: 525, 544-545) amb el propòsit de prevenir els aldarulls (Suau, 1984), i negociar els preus dels arrendaments dels drets fiscals o decimals, i avaluar els ingressos fiscals de la Hisenda del reialme (Daviu, 1983; Pascual, 2013, 2018). Per tant, tot i que s'ha pressuposat que els escrutinis són uns bons a indicadors del producte, de la mateixa manera que s'ha procedit amb el delme, cal contrastar la seva fiabilitat.

Les dades publicades per Josep Juan Vidal (1980) presenten algunes llacunes notables pels anys compresos entre 1702 i 1760, i els dos primers decennis del segle XIX. Els llibres de manifests de collites conservats a l'Arxiu Capitular permeten reconstruir la sèrie per a la primera meitat del segle XVIII, excepte pels anys 1702 i 1704, ${ }^{9} \mathrm{i}$ les dades compilades per Guillem Montis (1801-1812) permeten emplenar els buits de $1810 \mathrm{i} 1811 .{ }^{10}$ Tot i així, persisteixen llacunes pels anys $1702,1704,1813$ i 1815, i pel període $1821-1823 .{ }^{11}$ El gràfic 1 sintetitza les dades corresponents a les diferents fonts. La superposició de les sèries mostra que no hi ha dissonàncies rellevants entre les dades anuals de les diferents fonts, excepte en alguns anys a causa dels errors en les sumes de les quantitats que reportaven els manifests de cadascuna de les viles, o bé a causa del fet que en els registres del capítol hi mancava el manifest d'alguna parròquia.

les trullades es troben als registres ACM 14984, 16451, 16469, 16476, 17126, 17127 i 17128.

8 Els batlles de cada vila enviaven les estimacions de la producció a l'Ajuntament de Palma. Els oficials de la Hisenda feien càlculs més precisos per traduir el nombre de trullades en quartans d'oli segons els rendiments mitjans d'aquell any pel conjunt de l'illa. Vegeu els informes de la producció dipositats a l'Arxiu del Regne de Mallorca (ARM), D (Diputació)-1109, D-1234 i D-1302.

9 Sobre els delmes del Reial Patrimoni vegeu ARM, RP (Reial Patrimoni) 2130, i pels del capítol de la catedral, ACM 16467.

10 ARM, Arxiu Marques de la Torre (AMT), Montenegro, 127-M.

11 Les dades de 1821 a 1823 no es troben perquè es va prohibir elaborar els escrutinis de collites durant el Trienni Liberal. Durant aquells anys, la resistència al pagament dels delmes a l'illa fou molt intensa, i la recaptació, extremadament problemàtica (Valenciano, 2018: 101-102). 
Les noves fonts permeten construir una sèrie de manifests de les trullades quasi contínua entre 1684 i 1835 . Ara bé, la sèrie planteja

Gràfic 1. Manifests de les trullades d'olives segons les diferents fonts. Valors expressats en nombre de trullades

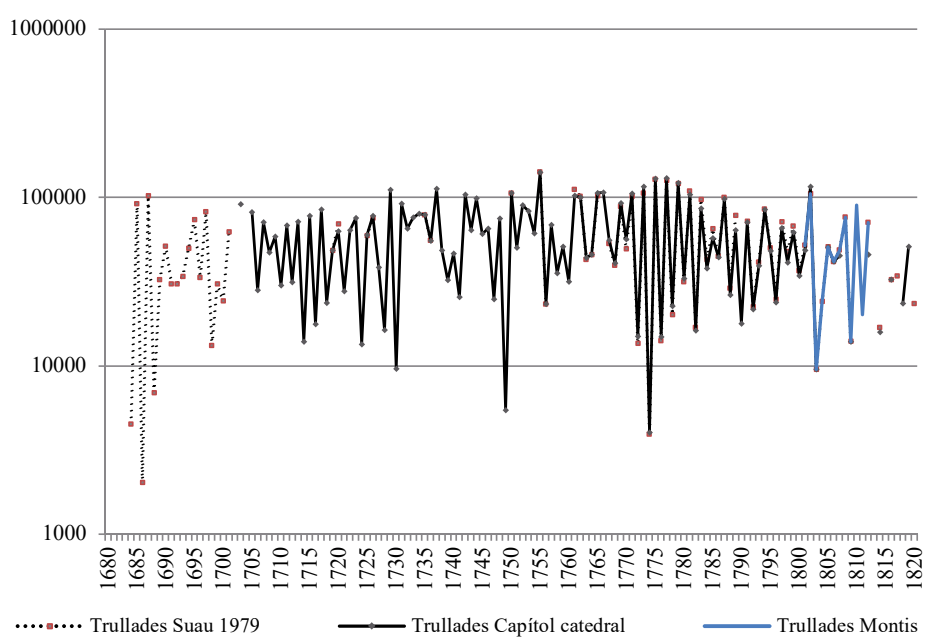

Fonts. Citades a les notes 7, 8 i 9.

alguns problemes. Primerament, persisteixen algunes llacunes, especialment pel segle XIx; en segon lloc, el nombre de trullades no expressa directament la producció total d'olives, sinó aquella part destinada a la producció d'oli, perquè una part de la producció d'olives no arribava a la tafona, sinó que era consumida directament per la població (olives conservades amb oli o sal); finalment, el nombre de trullades no expressa ni els quilograms de les olives premsades ni la producció d'oli resultant. Per tant, per transformar les trullades en la producció total bruta d'olives (quilograms o quintars) o en oli (litres) calen algunes operacions que exigeixen establir supòsits versemblants sobre quin era el consum d'olives, el nombre de quilograms d'olives que eren necessaris per cada trullada i el rendiment en oli de les olives premsades. 
Pel que respecta a les llacunes de la sèrie són susceptibles d'esmena. L'estimació del nombre de trullades dels anys 1702, 1704, 1813 i 1815 s'ha fet a partir de la interpolació del nombre de trullades estimades sobre la informació dels delmes de l'oli del Reial Patrimoni i el capítol de la catedral. ${ }^{12}$ Pel que fa al consum d'olives, les fonts del segle XVIII ofereixen poca informació. Els interrogatoris agraris dels segles XIX i Xx indiquen que entorn d'un 2-5\% de la producció total d'olives era destinada al consum alimentari. ${ }^{13}$ Pels propòsits d'aquest estudi podem prescindir d'aquesta fracció del producte. La resposta a la tercera qüestió, el volum d'olives emprades en cada trullada (premsada), planteja una major complexitat. Primerament, perquè el volum o pes de les olives emprades a cada trullada depenia de la potència de les bigues de les tafones i del pes dels fruits. Fins a començaments del segle xıx la majoria dels trulls compartien unes característiques tècniques similars i empraven entorn de 140-180 quilograms d'olives per a cada trullada, amb un rendiment mitjà en la transformació de les olives en oli d'entorn del 20-22 \%. ${ }^{14} \mathrm{La}$ major dificultat en el càlcul de l'oli obtingut rau precisament en aquestes dues darreres transformacions, per dues raons: d'una banda, perquè la transformació de la trullada en quartans d'oli (1 quartà equival a 4,16 litres) mostrava elevades oscil-lacions interanuals i locals (Grau, 1983: 161-172); i, d'altra banda, les dades esparses dels segles XVI-XIX mostren canvis importants en l'evolució de les collites i dels rendiments. A final del segle xvi Joan Binimelis a la

12 El nombre de trullades dels anys sense informació s'ha calculat a partir de l'índex del delme obtingut sobre la mitjana dels delmes dels 6 anys anteriors, després s'ha transformant aquest índex en el nombre de trullades per l'any corresponent. El mètode és senzill però fiable, atesa l'elevada correlació de les fluctuacions entre ambdues variables, com es veurà en el proper apartat. Per fer aquesta operació s'han emprat els delmes dels anys de 1811 a 1823; vegeu ACM 16555 i 16556, i ARM Reial Patrimoni (RP) 1330.

13 El consum d'olives al segle xx s'estimava entre el 2 i el $5 \%$ segons diferents fonts; vegeu Vallcanera i Esteban (2010: 61-68), el Avance estadístico agrario de la provincia de Baleares de 1922 i Genovard (1989: 124).

14 A mitjan segle xix en cada trullada es trituraven de 12 a 18 barcelles d'olives segons Habsburgo-Lorena (1987: 173), Francisco Satorras (1888) i Andreu Estarellas (1973: 161-163); aquestes magnituds suposaven entorn de 140 quilograms o 180 litres d'olives per trullada. Vegeu també una exhaustiva anàlisi d'aquestes qüestions sobre l'interrogatori de 1850 a Elena Grau (1983: 161-172). 
seva Descripció particular de l'illa de Mallorca e viles estimava el rendiment dels centres productors en 20-25 quartans per trullada; ${ }^{15} \mathrm{i}$ a la segona meitat del segle XVII els rendiments dels anys bons podien assolir els 18-22 quartans d'oli per trullada (Jover-Avellà i PujadesMora, 2017b/2020b: 86). Al segle xviII els rendiments eren inferiors, s'estimaven entre els 6 quartans i els 16 quartans (Juan Vidal, 1980: 544-545). En el primer terç del segle xIx els oficials públics calculaven els rendiments entre 6 i 11 quartans la trullada, ${ }^{16}$ i l'estadística de 1850 proporciona uns rendiments encara més baixos, entre 6 i 9 quartans/ trullada (Habsburgo-Lorena, 1959: 98-100; Estarellas, 1971: 163; Grau, 1983: 161-172). Per tant, és probable que entre els segles XVI i XIX s'hagués produït un descens en els rendiments mitjans de les trullades, però també que les fluctuacions de les collites haguessin moderat la seva intensitat, tal com diagnosticava l'arxiduc HabsburgoLorena (1959: 98-100).

Així doncs, el mètode correcte per calcular la producció d'oli seria multiplicar el nombre de trullades pel pes de les olives per trullada i pel rendiment mitjà de l'oli (quilograms oliva/litres oli) de cada any. Però només disposem d'informació sobre els rendiments mitjans per alguns anys. Per evitar aquests problemes al llarg d'aquest estudi emprarem les trullades transformades en nombres índexs per comparar-ne l'evolució amb altres variables. Només quan sigui necessari convertir les premsades d'olives en producció d'oli, utilitzarem un rendiment mitjà d'11 quartans per trullada, que era el rendiment que s'emprava comunament al segle XVIII (Juan Vidal, 1980: 540-549) ${ }^{17}$.

Per contrastar la fiabilitat dels manifests de les trullades com a indicador de la producció oleícola, els compararem amb els altres dos

15 Citem per l'edició de Juli Moll i Gómez de la Tía: Joan Binimelis Descripció particular de l'illa de Mallorca e viles, Publicacions de la Universitat de València i l'Institut Cartogràfic de Catalunya, [1593] 2014, p. 365, 574, 590, 595 i 771.

16 ARM, D-1109 pels anys 1825 a 1830.

17 Essent conscients de que l'oscil-lació del producte oleícola anual era procíclica: els rendiments eren elevats els anys d'esplet (bones collites) i migrats quan la collita era escassa; per tant, tendien a accentuar la intensitat de la fluctuació de la collita. Per tant, això implicaria que l'oscilllació del producte en oli fos major que la reflectida per les trullades. 
registres obtinguts de fonts diferents (quadre 1). La primera font és el vectigal de l'oli que era un impost que gravava l'oli que entrava a Palma. El registre anotava totes les entrades físiques d'oli (mesurades en quartans) destinades al consum o a l'exportació; a més, anotava el nom i cognoms de la persona que feia el pagament (propietaris, arrendataris, delmers), així com també l'entrada d'olis exempts d'aquest impost (Daviu, 1983; Riera, 1985). La segona font són les exportacions d'oli del port de Palma, l'única dàrsena oficialment habilitada per aquesta activitat. Els registres de duanes anotaven el volum en quartans d'olis exportats (Bibiloni, 1992).

Quadre 1. Relació entre les sèries de trullades, exportacions i entrades d'oli del vectigal a Palma

\begin{tabular}{ccccc} 
Períodes & $\begin{array}{c}\text { Anys amb } \\
\text { informació }\end{array}$ & $\begin{array}{c}\text { Exportacions oli } \\
\text { quartans }\end{array}$ & $\begin{array}{c}\text { Trullades olives } \\
\text { en quartans }\end{array}$ & $\begin{array}{c}\text { Vectigal oli } \\
\text { quartans }\end{array}$ \\
\hline $1684-1703^{2}$ & 12 & 347.874 & 490.339 & \\
\hline $1717-1787^{3}$ & 6 & 381.607 & 795.096 & 589.492 \\
\hline $1792-1804$ & 14 & 273.941 & 549.520 & 376.762 \\
\hline Períodes & & $\begin{array}{c}\text { \% Exportacions/ } \\
\text { trullades }\end{array}$ & $\begin{array}{c}\text { \% Vectigal/ } \\
\text { trullades }\end{array}$ & $\begin{array}{c}\text { \% Exportacions/ } \\
\text { vectigal }\end{array}$ \\
\hline $1684-1703$ & 12 & 70,9 & & 64,7 \\
\hline $1750-1755$ & 6 & 48,0 & 74,1 & 72,7
\end{tabular}

Notes: 1: El rendiment d'1 trullada d'olives s'ha estimat en 11 quartans; 2: Període 1684-1703: dades de les exportacions dels anys 1684, 1687-1690 i 1697-1703; 3 : Període 1717-1787: disposem de les dades de les exportacions i les trullades pels anys $1715,1717,1720,1754,1768$ i 1787 , mentre que les dades del vectigal només estan disponibles pels anys 1754, 1768, 1787.

Font. Per les exportacions s'han emprat els llibres de duanes estudiats per Manera $(1988,1999)$ i Bibiloni $(1995: 62)$; les sèries de trullades procedeixen de les fonts citades al gràfic 1, i els registres del vectigal, de Juan Vidal (1980) i Daviu (1983).

Els resultats mostren una certa coherència. L'estimació de la producció en trullades d'onze quartans, en els tres períodes estudiats, és sempre superior als olis entrats a Palma (\% vectigal/trullades) i al volum d'exportació (\% exportacions/trullades). Així, podríem dir que la major part de la producció, entorn del $70 \%$ al segle XVII 
i quasi el $50 \%$ en el xvinI, es destinava a l'exportació (indicadors $\%$ exportacions/trullades i \% exportacions/vectigal). Entorn d'un terç de la producció de l'illa era consumit fora de Palma i dos terços entraven a Palma (\% vectigal/trullades); d'aquests dos terços d'oli que entraven a Palma, se'n destinava a l'exportació entre el 64 i el $72 \%$ (\% exportacions/vectigal). Les diferències entre els quocients dels tres períodes s'han d'explicar per factors que tenen a veure amb les mostres, desiguals i migrades, però també amb els canvis que es produïren en el sector entre els segles XVII i XIX. D'una banda, el descens de la producció i l'exportació d'olis al darrer terç del segle XVIII; i de l'altra, els canvis en els rendiments de la producció i el maneig dels olivars, dos aspectes encara poc estudiats. Aquestes qüestions seran objecte de discussió a l'apartat 4 d'aquest capítol.

La producció d'oli de Mallorca havia d'abastar les necessitats de la població i, alhora, col-locar-se en els mercats internacionals; ara bé, les dades compleixen aquests dos requisits de forma versemblant? El quadre 2 intenta testar aquesta qüestió mitjançant la comparació entre

Quadre 2. Manifests de les trullades d'olives i estimació de les necessitats de consum d'oli dels habitants de Mallorca

\begin{tabular}{|c|c|c|c|c|c|c|c|}
\hline 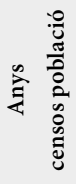 & 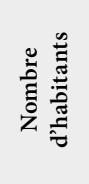 & 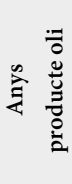 & 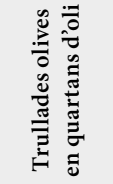 & 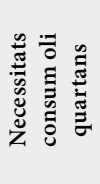 &  & 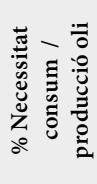 &  \\
\hline \multirow[t]{4}{*}{1769} & 124.033 & 1766 & 1.181 .400 & 215.052 & 1766 & 18,20 & 7,2 \\
\hline & & 1772 & 164.494 & 264.000 & & & \\
\hline & & 1773 & 1.277 .122 & 264.000 & & & \\
\hline & & 1774 & 44.374 & 278.748 & $1772-74$ & 54,29 & $8,2-9$ \\
\hline \multirow[t]{3}{*}{$1784 / 7$} & 136.917 & 1791 & 1.200 .000 & 240.000 & & & \\
\hline & & 1792 & 157.290 & 288.000 & $1791-92$ & 38,90 & 7,3 \\
\hline & & 1796 & 272.888 & 264.000 & & & \\
\hline 1797 & 140.699 & 1797 & 788.546 & 276.000 & $1796-97$ & 50,87 & 8,2 \\
\hline
\end{tabular}

Fonts. Quadre 1. Les dades de població són dels anys 1767, 1784/1787 i 1797; vegeu Juan Vial (1989, 1996), Segura i Suau (1984) i Manera (2001). Per les fonts sobre l'estimació de la producció d'oli citades al gràfic 1 i sobre les necessitats de consum d'oli, vegeu Juan Vidal (1980: 540-549). 
la producció i les necessitats de consum de l'oli de la població de l'illa. El panell de l'esquerra ofereix les dades de població obtingudes dels censos, la producció d'oli estimada (trullades d'olives multiplicades per 11 quartans) i les necessitats totals de consum d'oli calculades per les autoritats. El panell de la dreta mostra la proporció que representaven les necessitats de consum respecte de la producció, i el consum mitjà d'oli per habitant en els períodes pels quals disposem de dades (necessitats de consum / població). L'estimació del consum d'oli feta per les autoritats era d'entorn de 7-9 litres per habitant i any, una mitjana que no s'allunya gaire dels càlculs elaborats per altres regions en el mateix període. ${ }^{18}$

La primera columna del panell de la dreta palesa que fins i tot en els períodes de collites més crítiques (1766, 1791-1792), la producció era suficient per atendre les necessitats de l'illa. En part, això era degut a la gestió dels excedents acumulats en els anys de collites excel-lents (1774). La intervenció en el mercat, la regulació de les exportacions i la gestió de les reserves acumulades en els dipòsits, públics i privats, permetia garantir el consum de la població en anys de collites pèssimes (1772 i 1773), i destinar a l'exportació una part important de la producció, àdhuc en els anys més dolents (1766).

Podem concloure que les estimacions de la producció d'oli fetes per les autoritats (trullades d'olives) eren versemblants, i resulten un indicador robust de la producció d'oli a l'illa. Per tant, poden ser emprades com a test o testimoni per avaluar la fiabilitat d'altres fonts, i particularment les sèries dels delmes de l'oli.

18 A Mallorca el consum dels homes adults (soldats i mariners) en el segle XVII s'ha calculat en 10-12 litres per any (Vaquer Bennasar, 1988: 743-744; Pujol, 1996); pel final del segle XVıII les estimacions són més elevades i poden assolir els 20 litres/any (Manera, 2001: 78-80; Molina, 2003: 148). Tanmateix, aquestes estimacions s'han fet sobre el consum d'homes adults. El consum d'oli d'un home adult per aquests segles s'ha estimat entorn de 14-15 litres/ any, la meitat destinada a aliment i l'altra meitat per a il.luminació i altres usos. Per a la totalitat de la població, incloses dones i infants, les xifres de consum per càpita oscillen entre els 6 i els 10 litres per persona/any (González-Mariscal, 2015; Romero, 2018; Andrés i Lanza, 2019). 


\subsection{Els preus de l'oli: els llibres d'administració dels convents de palma}

El Banc de l'oli era el mercat on es venien la major part dels excedents oleícoles que entraven a Palma procedents dels arrendaments decimals i de la producció de les possessions o dels petits productors. La venda es feia a la menuda, a l'engròs o per exportar (Daviu, 1983; Riera, 1985; Bibiloni, 1992, 1995). El preu d'aquest bé era un vector d'informació clau per a tots aquells agents interessats en el seu tràfic, i que volien negociar amb les collites de l'any o especular amb les reserves que restaven als dipòsits després d'una collita bona o extraordinària. Els administradors dels impostos registraven als llibres del vectigal les quantitats, qualitats (baixos, climes, novell o vell) i els preus dels olis que es negociaven diàriament al mercat (Riera, 1985). Per tant, com en totes les mercaderies, hi havia molts preus en funció de la qualitat, quantitat, els costos de transport i els impostos que gravaven el producte. Per a construir una sèrie de preus cal tenir presents aquestes diferències i escollir aquella categoria que s'acosti al que podríem denominar el producte de consum majoritari, estàndard. En el nostre cas, l'oli comú, allunyat dels olis fins, destinats a usos molt exclusius, per exemple a la farmàcia o la cosmètica, o dels olis més gruixuts (climes, morques) destinats a fer sabó, a la manufactura de la llana o a la lubricació dels rodaments (Bibiloni, 1992; Muendel, 1995).

La demanda de les institucions eclesiàstiques de l'època s'acosta a aquests requisits. Els convents i els hospitals eren els més grans i regulars compradors de queviures als mercats urbans $i$, per tant, ofereixen certes garanties de continuitat i homogeneitat per a la confecció de les sèries de preus (Vilar, 1966; Feliu, 1991). A Mallorca, el convent de Santo Domingo de Palma era el més gran de la ciutat i de l'illa (Ferrer Flórez, 2001). El convent posseïa una petita explotació oleícola al terme de Palma: son Cigala. Durant els segles Xvir i Xviı la seva producció només proporcionava una petita part de les necessitats de consum del convent (1.000-1.700 litres). ${ }^{19}$ L'oli es destinava a satisfer les necessitats de consum de la comunitat —entre frares, sacerdots,

19 De mitjana produïa 410 quartans (1.706 litres), el $35 \%$ dels quals es destinava al consum dels treballadors de la mateixa possessió; el $24 \%$, al consum del convent, i el 41 \% era venut al mercat; vegeu ARM, C-193 (ARM, C-186, C-192). 
llecs, novicis i servei domèstic eren més d'un centenar de persones (Juan Vidal, 1989c: 34-35)—, la il-luminació de l'església, les cel-les dels monjos i altres dependències del convent, subministrar oli pel consum dels treballadors de les explotacions agràries que tenia la institució, i fer sabó i altres usos menors. ${ }^{20}$ Per satisfer aquestes necessitats els administradors del convent compraven al mercat durant la segona meitat del segle Xviı entorn de 4.000 litres d'oli cada any, i entorn de 6.000 a la primera meitat del xviII.

Les compres eren acuradament comptabilitzades en els llibres de rebudes $i$ despeses generals, ${ }^{21}$ i des de mitjan segle XVII es registraven en uns llibres de despesa anomenats extraordinaris. ${ }^{22}$ Durant la primera meitat del segle Xvir les anotacions són esparses i tenen una periodicitat quadrimestral o semestral. Entre 1663 i 1757 la informació és molt minuciosa, les anotacions del volum i dels preus tenien una periodicitat setmanal o mensual. Tanmateix, entre 1705 i 1732 hi ha una llacuna documental, i la sèrie torna a ser completa entre 1735 i 1757. A partir d'aquesta data el volum i els preus de compres d'oli pràcticament desapareixen dels manuals de despesa. La raó és que el 1743 el convent comprà una extensa explotació agrària anomenada son Frau al terme de Marratxí. La possessió produïa de mitjana entre 5.000 i 6.000 litres anuals d'oli. Així, a partir de 1753 l'oli de Son Frau juntament amb la producció de la petita explotació de son Cigala abastaven amb escreix les necessitats de consum de la comunitat, i proporcionaven un excedent per vendre al mercat local o àdhuc exportar-los als mercats de Barcelona i Marsella. ${ }^{23}$

Per tal de completar les llacunes dels llibres de comptes de Santo Domingo s'han buidat els llibres d'administració dels convents

20 Llibre de comptes de les collites (1743-1787): ARM, C-193.

21 Vegeu els llibres de compres d'oli ARM, C (Convents)-136 (1619-1659), C-200 (1638-1667), C-132 (1662-1680), C-136; C-189; C-132; AH, C-133; C-141; AH, C-3762.

22 Llibres extraordinaris de despesa: C-1749; C-186; C-192 AH.

23 La possessió fou comprada el 1743, però entre el 1743 i el 1753, es mantingué arrendada. L'explotació mitjançant parceria s'inicià el 1752, Llibre de comptes de les collites (1743-1787): ARM, C-193. 
del Carme (1643-1757), ${ }^{24}$ Socors (1667-1815) ${ }^{25}$ i Montisión (15871742), ${ }^{26}$ i els de l'Hospital General (1755-1773). ${ }^{27}$ La informació que proporcionen aquestes institucions permet reforçar les sèries de Santo Domingo amb una major densitat de dades per any, i completar les sèries pels períodes 1590-1662, 1706-1734 i 1756-1810. Per aquestes institucions només s'han recollit els preus mensuals de l'oli corrent o nou, que constituïa més del $90 \%$ de les compres, deixant fora de la sèrie els preus dels olis qualificats com a baixos, climes o vell (emprats per lubricar rodaments, morcar $^{28}$ les ovelles, fer sabó, etc.), i tampoc els olis més fins destinats a usos de la farmàcia del convent. Ara bé, mentre que les dades del convent de Santo Domingo tenien una periodicitat setmanal o mensual, les anotacions de les compres de la resta de convents s'agrupaven en unes poques partides anuals. Per tant, si bé les dades reflecteixen el preu mitjà anual de les compres, no permeten fer una anàlisi estacional de les compres i dels preus de l'oli.

Per tal de verificar la fiabilitat de les sèries de preus dels convents, les hem comparat amb les de la Societat Econòmica Mallorquina d’Amics del País (SEMAP). La SEMAP recollí setmanalment els preus de l'oli, i de la resta de queviures, del mercat de Palma entre 1779 i 1808, distingint entre el preu baix i l'alt. ${ }^{29}$ La comparació dels preus corrents de l'oli d'ambdues sèries mostra un ajust notable. Les minses diferències entre els nivells de preus dels convents respecte de la SEMAP en el període inflacionari final podrien atribuir-se al mètode en el càlcul de la mitjana dels preus en cada cas. Mentre que la sèrie de la SEMAP recull la mitjana de tots els preus dels diferents olis (inclosos els de baixa qualitat), la dels convents només incorpora

24 Convent del Carme: C-524; C-526; C-542.

25 Convent del Socors: C-1477; C-1652; C-689; C-701; C-708; C-712; C-769 i AH (Arxiu Històric)-6146.

26 Convent de Montisión: C-1418; C-1525; C-1651; C-1936/4; C-399; C-401; C-416; C-133.

27 A l'ARM, Hospital General de Palma (H): H-357 i H-358; i altres comptes de convents sense identificar: C-1058; C-1065.

28 Morcar: modisme d'emmorcar: untar les ovelles d'un suc compost de vinagre, oli, ceba marina, pebre coent i almangra, perquè no hi vagin les mosques vironeres a picar-les (Mall.) (https://dcvb.iec.cat/).

29 Preus de l'oli obtinguts del Semanario Económico de la SEMAP, 1779-1820 (ARM). 
Gràfic 2. Preus nominals de l'oli: registre de la Societat Econòmica Mallorquina d'Amics del País (SEMAP) i dels convents. Mitjanes anuals, valors expressats a preus corrents, sous per quartà



Fonts. Llibres de despeses dels convents citats a les notes de la 16 a la 22.

la del preu pel consum domèstic (aliments, il-luminació, etc.), per això probablement el preu mitjà és una mica més elevat, endemés, cal recordar que aquest preu incorporava els costos de transport $\mathrm{i}$ intermediació, i els impostos que en gravaven la venda (Juan Vidal, 1980; Daviu, 1983). Eren els preus de compra, i no de venda en origen del producte; per tant, poden introduir distorsions quan són emprats com a deflactors de les sèries d'ingressos monetaris (salaris o rendes familiars), incloses les del delme de l'oli que tractarem a continuació (Andrés Ucendo, 2011, 2017; Andrés Ucendo i Lanza García, 2013, 2019).

\subsection{La distribució del delme a Mallorca i el delme de l'oli del capítol de la catedral de Palma}

Mallorca constituí una de les noves fronteres d'expansió feudal de la Corona catalanoaragonesa. El 1095 una butlla pontifícia obria una intensa pugna per la distribució del delme entre els diferents magnats i l'Església en els nous territoris conquerits als infidels (Puigvert, 1992: 117-125). Els conflictes es resolgueren amb uns nous pactes 
entre els diferents magnats per a la distribució del delme en les noves colònies feudals (Burns, 1966; Ardit, 1993: 79-107). La conquesta de Mallorca (1229-1232) encetà una llarga pugna entre els magnats feudals, el monarca i l'Església de l'illa per la distribució del delme.

El 1315 el monarca - el primer magnat feudal de l'illa i un dels majors partícips en la captació de les rendes decimals- imposà un gran pacte a la resta de senyors jurisdiccionals i institucions eclesiàstiques que perdurà fins a l'abolició del sistema feudal (Campaner, 1984: 1, 21-24, 41-42; López Bonet, 1988: 117-118; Sastre, 1990: 247-248, 2001). Els acords de 1315 (quadre 3) establien que en els territoris sota domini dels barons porcioners (el primer estrat feudal) i senyors de cavalleria - petites senyories amb jurisdicció baixa infeudades pel monarca o els barons - la meitat de tots els delmes serien pel baró o senyors (50\%), i la resta es distribuí entre el monarca (12,5\%), el bisbe (6,75\%), capítol de Mallorca (6,75\%) i la parròquies (25\%). ${ }^{30}$ Mentre que en els dominis de reialenc la distribució seria del 37,5 \% per al monarca, 18,5 \% per al bisbe de Mallorca, un 18,5\% per al capítol de la catedral, i el $25 \%$ restant per a les parròquies (Juan Vidal, 1987, 1989a, 1989b). ${ }^{31}$ Els documents elaborats per les institucions eclesiàstiques el 1773 reflecteixen la pervivència d'aquells pactes de 1315. Per últim, la taxa de detracció decimal variava força d'un producte a l'altre: el $10 \%$ sobre els cereals, el $9 \%$ del vi (no delmaven els raïms), i el $8 \%$ de l'oli (les olives no

30 Vegeu del mateix document: la parte de el Rector y Beneficio no padece mengua de detrimento ni disminucion la sufren el Rey y las del Obispo y Cavildo... solo queda la quarta parte para S. M. Obispo y Cavildo, de suerte que el número diez y sies arriba expresado el Señor de la Cavalleria percive ocho, el Rector y Beneficio quatro el Rey dos y el Obispo y Cavildo otros dos. Vegeu ARM, Reial Acord (RA), 1774, lligall 1, número 8, f. 20.

31 Vegeu se advierte que dividiendose los diezmos comunes, que aquí llaman de realengos donde no hay cavallerias separandose la quarta parte para el rector y quanto a los tres restantes se hacen dos partes la una percive su Magestat y la otra se hacen dos partes entre el Obispo y Cavildo. [...] Poniendo el exemplo de que haya diez y seis quarteras de grano diez y seis cargas de vino, ó, Aceite de Diezmo. De la diez y seis quarteras o cargas et alia percive el Rector, y beneficio, ó quarto quatro y de la doce restantes percive la parte de S.M. seis, tres, tres el obispo y tres el Cavildo. Una part dels delmes que estava aplicada a los Rectores y Curas de cada una de les parròquies, es dedicava als beneficis que hi havia en aquestes parròquies, i la major part s'havia agregat al capítol, seminari o altres comunitats eclesiàstiques. Vegeu ARM, RA, 1774, 1, número 8, f. 19-19v. 
delmaven), emperò era la mateixa per a tots els perceptors (Juan Vidal, 1987: 156-158; 1989a: 167; 1989b: 170).

Quadre 3. Distribució percentual de les rendes decimals segons els pactes de 1315, reproduïts el 1773

$\begin{array}{cccc}\text { Porcioners delme } & \text { Domini reial } & \text { Domini barons } & \text { Domini cavalleries } \\ \text { Barons } & & 50,0 & \\ \text { Cavallers } & & & 50,0 \\ \text { Monarca } & 37,5 & 12,5 & 12,5 \\ \text { Bisbe } & 18,8 & 6,3 & 6,3 \\ \text { Capítol } & 18,8 & 6,3 & 6,3 \\ \text { Rector i benefici } & 25,0 & 25,0 & 25,0 \\ & 100,0 & 100,0 & 100,0\end{array}$

FonTs. Dades sobre la distribució del delme entre magnats, senyors i Església a Juan Vidal (1989: 812). Les dades originals procedeixen de l'expedient elaborat pel bisbe de Mallorca el 1774 sobre el delme: ADM, CCLR, Llibre II-173; i ARM, RA, lligall 1 , expedient 8 .

Ara bé, aquestes proporcions eren una unitat de compte perquè el procés de feudalització no havia estat uniforme. Les unitats polítiques i fiscals (universitats) i religioses (parròquia) de l'illa se superposaven, i els termes de les parròquies actuaven com a districtes decimals; però els dominis feudals sovint no coincidien amb els districtes parroquials (Montaner, 1986; Moll i Suau, 1986). Així, la distribució del delme en cada parròquia presentava resultats força complexos. La fragmentació territorial dels dominis senyorials; les diferents distribucions dels delmes segons el tipus de domini feudal (reial o senyorial); l'apropiació dels quarts i de les primícies per alguns senyors laics i eclesiàstics, i les donacions reials a l'Església havien provocat una distribució calidoscòpica del delme a cada parròquia (Romero, 1983 i 1989).

La figura 1 expressa la diversitat en la seva distribució en una mostra de 16 parròquies segons els comptes de 1773. La distribució s'ha calculat sobre el valor monetari del delme que cada perceptor rebia respecte del total. A la part superior de la figura s'han disposat 
Figura 1. Distribució del delme en diferenets parròquies de Mallorca. Percentatges sobre els valors monetaris del delme



Fonts. Les dades procedeixen de Romero (1989: 365-381).

les parròquies que estaven sota domini d'un únic baró, en aquest cas el bisbe de Barcelona. El baró detenia el seu domini sobre la totalitat de les parròquies d'Andratx i Calvià, i compartia el delme amb el monarca i l'Església de Mallorca amb unes proporcions molt semblants a les acordades per aquests dominis a 1315. La imatge s'embolica quan passem a aquelles parròquies, com Muro, en què el domini baronial (comte d'Empúries i bisbe de Girona) era compartit amb petites senyories que encongien la participació en el delme del monarca i de l'Església. També a les parròquies —en el centre de la figura-, on els magnats feudals havien infeudat nombroses cavalleries, la distribució del delme s'aparta del cànon, perquè reduïen la participació del monarca i de l'Església en la recaptació decimal. 
Novament, la distribució del delme se simplifica en la part baixa de la figura; en les parròquies de reialenc, el delme es repartia segons el cànon de 1315: el monarca, amb un 37,5 \%; el bisbe i el capítol de Mallorca, amb un 37,5 \%, i el rector amb el $25 \%$ restant. Per tant, el conjunt dels delmes es distribuïa de forma desigual a cadascuna de les parròquies, i sobre cadascun dels productes la punció era diferent (López Bonet, 2008).

El capítol de la catedral era doncs un dels grans partícips en la distribució del delme i una de les institucions més influents del reialme (García Pérez, 2014, 2017, 2018). El capítol captava de mitjana entorn del 12-14 \% dels delmes de l'illa, i els delmes constituïen més del $80 \%$ dels ingressos totals, i el delme de d'oli representava entorn del $15 \%$ dels ingressos totals (Juan Vidal, 1989b: 814). ${ }^{32}$ Per això, des de l'etapa medieval el capítol va gestionar de forma autònoma, meticulosa i amb criteris homogenis les seves rendes decimals. La pulcritud en la gestió i els comptes derivava de l'estricta supervisió que exercia el mateix Col-legi de Canonges. Perquè eren aquests ingressos, i bàsicament els ingressos decimals, els que es destinaven a pagar les despeses i els salaris dels membres del capítol.

Al segle XIv el capítol havia gestionat directament les seves rendes decimals, però ràpidament aquest sistema fou substituït per l'arrendament en espècie, oli, i després en diner (Sastre, 1994 i 2001; Juan Vidal, 1989b; Portella, 1993; Sastre i Llompart, 2008; Dols Martorell, 2014). Des del segle xvi la pràctica comuna en la gestió del delme de l'oli, excepte en alguns anys excepcionals, era la següent: els delmes eren subhastats abans de la collita de l'oliva (setembre) cada any per a cadascun dels districtes decimals. En la majoria dels casos aquests districtes coincidien amb els termes d'una parròquia, però alguns districtes integraven diverses parròquies veïnes on la producció oleícola era escassa (Artà i Mancor, Campanet i Sa Pobla, Pollença i Alcúdia). En el llibre manual s'anotaven el preu de venda de l'esplet per a cadascuna de les parròquies, noms i cognoms dels arrendataris i els fiadors, així com els pagaments realitzats fins a satisfer l'import acordat. El sistema de gestió canviava

32 Comptes generals del capítol dels anys 1670 a 1682: ACM 14989, 16465 i 16466; i dels anys 1772, 1777 i 1785: ACM 2904. 
quan les collites eren escasses o pèssimes. Els anys de collita molt escassa el capítol subhastava conjuntament tots els delmes de l'oli de l'illa (1609, 1615, 1625, 1627, 1646, 1653, 1657 i 1671). Encara que, en alguns anys de pèssimes collites $(1659,1661,1673,1680,1682$ i 1686), tot i que el valor dels delmes no arribava al centenar de lliures - quan la mitjana del segle Xviı era d'entorn de 2.000 lliures-, es mantingueren els arrendaments parroquials o, en alguns casos, s'agrupaven diverses parròquies veïnes en un sol arrendament. ${ }^{33}$ També fou rematat conjuntament tot el delme de l'oli de l'illa el 1651, però aquell fou any d'esplet $i$, per tant, els motius eren uns altres que no apareixen explicitats en la documentació. El resum dels ingressos dels arrendaments decimals, per producte i parròquia, s'anotava cada any en un manual d'ingressos i despeses. ${ }^{34} \mathrm{I}$, finalment, els llibres dels fruyts de la Mesa Capitular resumien el conjunt d'ingressos (delmes, préstecs, censos, censals, drets sobre el domini directe, arrendaments de terres, etc.) i despeses (càrregues que pesaven sobre el capítol, els drets que pagaven al monarca, excusada, i després el novè, administració del patrimoni), i la distribució de l'ingrés net entre els diferents canonges. ${ }^{35}$

La continuïtat d'aquest sistema es trencà en el decenni de 1740. A partir de llavors sovint el delmes eren arrendats en grans paquets que integraven diverses viles a companyies de comerciants; i alguns anys els delmes foren gestionats directament pel capítol. ${ }^{36}$ En aquests anys el capítol desplegava tota la seva capacitat de gestió per recollir els delmes de les parròquies, transportar-los a Palma, i vendre el seu producte al Banc de l'oli a l'engròs, o organitzar-ne l'exportació, i en altres ocasions organitzar la venda a la menuda entre les tenderes de

33 ACM 14950 (1624-1629), 14951 (1627-1651), 14952 (1630-35), 14953 (1636-1647), 14954 (1640-45), 14955 (1646-1650), 14956 (1646-1650), 14957 (1651-1656), 14958 (1657-1663), 14959 (1664), 14960 (1673-1682) i 14961 (1683-1691).

34 Resums de les rendes decimals per cadascuna de les parròquies i productes: ACM 16458 (1567-1581), 14985 (1585-1631), 16423(1665-1670) i 14989 (16751681).

35 Els resums dels comptes anuals es troben a ACM, Llibres dels Fruits 2896 a 2908.

36 Pels anys citats, a ACM 2901 a 2908. 
la ciutat. ${ }^{37}$ En el llibre de comptes de l'oli s'hi anotava el producte de la venda final i les despeses que ocasionava l'administració i comercialització del producte (collecta dels delmes, el seu transport a Palma i els impostos que el gravaven). Finalment, els ingressos nets es destinaven al pagament dels drets que el monarca tenia sobre la punció decimal, l'excusat i més tard el novè ${ }^{38}$

Per tant, la sèrie del delme de l'oli s'ha confeccionat a partir del valor monetari del preu pagat per l'arrendament del delme quan era subhastat, o del valor del producte net de la venda del delme un cop descomptades les despeses derivades de la seva gestió (transport, salaris i impostos sobre la comercialització). S'han exclòs els redelmes, quarts o préstecs que responien a altres conceptes ${ }^{39}$. Ara bé, aquesta sèrie, ¿podrà considerar-se un bon indicador del producte? ¿ $\mathrm{O}$ solament podrà ser considerada com l'ingrés brut del perceptor del delme? Caldrà ser prudents en el seu ús i en la interpretació històrica de la seva evolució, com mostrarem en els propers apartats.

\section{RESUlTATS: PROXIES DE LA PRODUCCIÓ I DELS INGRESSOS OLEÍCOLES}

El propòsit d'aquest apartat és fer una anàlisi de la fiabilitat creuada de les fonts presentades. Les sèries que tractarem poden dividir-se en dos conjunts. Primer, aquelles que poden qualificar-se de proxies del producte oleícola físic: els manifests de les trullades d'olives (simplificant, trullades olives), el quocient entre el delme nominal i els preus de l'oli, que anomenarem, en endavant, producte decimal en quartans, i els registres del vectigal de l'oli: els registres de les entrades d'oli a Palma que eren objecte de venda al mercat urbà o destinades a l'exportació. El segon conjunt serien les proxies que atenyen l'ingrés

37 Per exemple el 1772 l'oli fou distribuït entre les botigueres que venien l'oli a la menuda, vegeu ACM, 2904.

38 Per exemple en els anys 1772, 1775 i 1785 en els llibres dels fruits es detallava la distribució de les rendes i els guanys amb la venda de l'oli entre els partícips: ACM 2904.

39 La mateixa comptabilitat del capítol diferenciava aquests conceptes i els anotava separadament. 
del sector oleícola: primerament, els preus de l'oli; segonament, els delmes nominals (l'ingrés nominal dels propietaris del delme), i finalment, la transformació de les trullades d'olives multiplicades per 11 quartans i pels preus de l'oli, que podem considerar una estimació del valor monetari de producció total d'oli, i expressen els ingressos del sector. A partir de l'anàlisi d'aquestes variables es discutiran tres aspectes que fan referència a la interpretació de les fonts decimals, a l'evolució del producte oleícola i a la distribució de la renda en el sector olivarer.

\subsection{Delmes, escrutinis i vectigal de l'oli: una anàlisi estructural}

Per l'anàlisi del comportament estructural de les variables considerades s'ha triat un estadístic descriptiu simple: el coeficient de correlació. Els coeficients de correlació (en endavant, CR) s'han calculat per períodes de 50 anys per centrar els arguments més en l'anàlisi de les fonts que no en els canvis en les conjuntures històriques, que seran tractades posteriorment, tot i que aquest darrer punt no sempre es podrà defugir.

Les primeres tres columnes del quadre 4 presenten les relacions entre els indicadors del producte decimal en quartans, les trullades d'olives, els delmes nominals i el vectigal de l'oli, les proxies de la producció física. Els índexs de correlació entre el producte decimal en quartans, trullades d'olives i vectigal, i els delmes nominals són positius, molt elevats i similars en tots els períodes $(0,88-0,96)$. Així, els resultats dels CR poden interpretar-se, d'una banda, com que els delmes són bons indicadors de la fluctuació de les collites d'olives i de la producció d'oli. I, de l'altra, que la fluctuació de la collita era determinant en la fixació del preu de l'arrendament dels delmes i del volum de producte comercialitzat en el mercat de Palma (trullades olives / vectigal oli).

La correlació amb el retard d'un any (-1) entre les mateixes variables capta l'efecte de l'alternança de producció típica de l'olivar, com bé coneixien els coetanis (Juan Vidal, 1980: 523). L'alternança en la producció era deguda a la complexa relació inversa que s'estableix entre el creixement de la nova branca (en la qual creixien els rovells 
Quadre 4. Índexs de correlació entre els diferents indicadors de la producció i dels ingressos de l’oli

\begin{tabular}{|c|c|c|c|c|c|c|}
\hline &  & 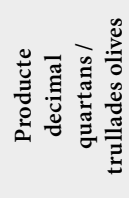 & 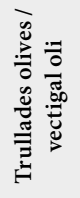 & 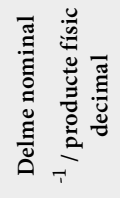 &  & 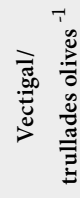 \\
\hline $1601-1650$ & 0,937 & & & $-0,470$ & & \\
\hline $1651-1700$ & 0,974 & 0,903 & & $-0,803$ & $-0,665$ & \\
\hline $1701-1750$ & 0,882 & 0,919 & 0,917 & $-0,449$ & $-0,468$ & $-0,269$ \\
\hline $1751-1800$ & 0,907 & 0,917 & 0,836 & $-0,585$ & $-0,531$ & $-0,260$ \\
\hline
\end{tabular}

Nota. Trullades: pel període 1651-1700 només es consideren els anys de 1684 a 1700; vectigal: pel període 1701-1750, només es prenen els anys 1732-1750.

FonTs. Gràfics 1, 2 i notes de la 33 a la 36.

i es produiria la floració l'any següent) i la càrrega d'olives de l'any (la floració i fructificació de l'any). Així, com més gran era la collita menys augmentava la branca que donaria fruit l'any següent; per tant, després d'una bona collita era d'esperar que n'hi hagués una de mediocre o dolenta (Barranco, 2008: 135-156). Les condicions climàtiques - temperatura i pluviometria - podien afavorir 0 comprometre les collites esperades. L'escassetat de pluges i l'aridesa podien perjudicar, en els mesos d'estiu i tardor, la fructificació i la maduració de les olives, i podien destruir fins al $80 \%$ dels fruits (drupes) que s'havien desenvolupat durant l'any. També les nevades intenses podien destruir les branques productives, $\mathrm{i}$ les gelades seques acabar amb la collita i l'arbre (Pansiot i Rebour, 1961: 19-21). Per tant, aquests factors climàtics extrems podien accentuar la tradicional alternança de producció de les collites de l'olivera. Finalment, les fluctuacions de les collites podien ser atenuades, parcialment, mitjançant una menor o major intensificació en el maneig del sòl i de l'arbre - cavar, abonar, llaurar, podar- (Grau, 1983; Barranco et al., 2008: 158-161).

El resultat és en tots els casos una relació negativa que indica la persistència de l'alternança en la producció. Tanmateix, la intensitat d'aquesta alternança va canviar al llarg dels segles XVII i XVIII. En la segona meitat del segle XVII els índexs de correlació entre delme 
nominal / valor producte decimal $(-0,80)$ i producte decimal quartans / trullades olives $(-0,66)$ foren molt més elevats que a la primera meitat del segle Xvir i del segle XVIII. A la segona meitat del segle XviII tornen a repuntar els índexs de correlació pels mateixos indicadors, encara que amb una intensitat menor (-0,58 i - 0,53 respectivament). En canvi, la correlació entre les trullades d'olives i el vectigal de l'oli manté el signe negatiu, però és molt feble al llarg del segle XviıI $(-0,26)$. Caldrà tenir presents aquests canvis en les relacions entre les variables en la discussió sobre la interpretació de l'evolució de les sèries.

El quadre 5 s'apropa a la complexa relació entre les collites, els ingressos i els preus en el sector oleícola. El quadre s'ha dividit en dos panells: el 5a es presenta el CR entre les dades de la producció i els preus en any agrícola (Jover-Avellà, 2013b, 2015; Jover-Avellà i Pujades-Mora, 2020b); el quadre inferior (5b) introdueix un retard d'un any en els preus. El propòsit es captar l'efecte que podia tenir la producció de l'any (5a) i l'emmagatzemament de les reserves d'oli sobre els preus l'any següent (5b).

El panell superior mostra la relació negativa esperada en tots els casos: les males collites induïen una alça dels preus en els mesos posteriors a la collita. Les correlacions entre les trullades d'olives i el producte físic decimal amb els preus de l'any són estretes i estables, encara que molt baixes. D’altra banda, la relació del delme nominal i els preus és negativa però minsa, mentre que la relació del valor del producte oleícola amb els preus és de signe negatiu, però manté un índex de correlació més elevat, especialment al segle XVIII $(-0,62$ i -0,60). La correlació entre els preus i el vectigal d'oli presenta un resultat negatiu i més robust $(-0,67 \mathrm{i}-0,54)$ que l'observat en les proxies productives de les trullades d'olives i el producte físic decimal $( \pm 0,3$ 04). Mentre que les dues darreres expressen la producció, el vectigal reflecteix aquella part de la producció que entrava a Palma per ser comercialitzada en el mercat urbà (pel consum de la població o per l'exportació); per tant, efectivament condicionava la formació de preus al mercat. Els resultats del panell inferior (5b) - quan introduïm el retard d'un any, i, per tant, mesurem l'efecte de la producció d'oli sobre els preus de l'any posterior- són poc significatius i presenten notables diferències entre elles i entre períodes. Encara que sigui feble, hi ha una tendència que mereix ser remarcada: les correlacions 
Quadre 5. Índexs de correlació entre els indicadors dels ingressos, la producció i els preus de l'oli

\begin{tabular}{|cccccc}
\multicolumn{5}{|c}{ Quadre 5a. Índexs de correlació sobre les dades en any agrícola, de setembre a agost, per } \\
producció i preus \\
$\begin{array}{c}\text { Delme } \\
\text { nominal/ } \\
\text { preus oli } \\
\text { AA }\end{array}$ & $\begin{array}{c}\text { Producte } \\
\text { físic decimal } \\
\text { / preus oli } \\
\text { AA }\end{array}$ & $\begin{array}{c}\text { Trullades } \\
\text { olives / } \\
\text { preu oli AA }\end{array}$ & $\begin{array}{c}\text { Vectigal oli / } \\
\text { preu oli AA }\end{array}$ & $\begin{array}{c}\text { Valor } \\
\text { producte oli / } \\
\text { preus oli AA }\end{array}$ \\
\hline $1601-1650$ & $-0,089$ & $-0,394$ & & \\
\hline $1651-1700$ & $-0,258$ & $-0,423$ & $-0,333$ & $-0,488$ \\
\hline $1701-1750$ & $-0,011$ & $-0,406$ & $-0,395$ & $-0,675$ & $-0,627$ \\
\hline $1751-1800$ & $-0,080$ & $-0,421$ & $-0,303$ & $-0,544$ & $-0,608$
\end{tabular}

Quadre 5b. Índexs de correlació sobre les dades amb un any de retard de la producció respecte dels preus $(-1)$

\begin{tabular}{|c|c|c|c|c|c|}
\hline & $\begin{array}{c}\text { Delme } \\
\text { nominal }^{-1} \\
/ \text { preus oli }^{\text {AA }}\end{array}$ & $\begin{array}{l}\text { Producte físic } \\
\text { decimal }^{-1} / \\
\text { preus oli AA }\end{array}$ & $\begin{array}{c}\text { Trullades } \\
\text { olives / } \\
\text { preus oli } \\
\text { AA }\end{array}$ & $\begin{array}{c}\text { Vectigal oli }^{-1} / \\
\text { preus oli AA }\end{array}$ & $\begin{array}{l}\text { Valor } \\
\text { producte oli }^{-1} \\
\text { / preus oli AA }\end{array}$ \\
\hline $1601-1650$ & 0,014 & $-0,128$ & & & \\
\hline $1651-1700$ & 0,136 & 0,008 & 0,043 & & $-0,155$ \\
\hline $1701-1750$ & 0,206 & $-0,146$ & $-0,066$ & 0,057 & $-0,320$ \\
\hline $1751-1800$ & 0,053 & $-0,295$ & $-0,171$ & $-0,356$ & $-0,502$ \\
\hline
\end{tabular}

Nota. Trullades: pel període 1651-1700 només es consideren els anys de 1684 a 1700; vectigal: pel període 1701-1750, només es prenen els anys 1732-1750. AA: any agrícola de setembre a agost.

FonTs. Gràfics 1, 2 i notes de la 21 a la 29.

entre els preus, el producte físic decimal, les trullades d'olives i els ingressos del sector (valor estimat de la producció d'oli) mostren un augment progressiu de la correlació negativa al llarg del període.

La comparació de l'anàlisi de correlació de la producció i els preus de l'oli al mercat de Palma planteja interessants contrastos amb una anàlisi similar feta amb les sèries de producció i preus dels cereals pels mateixos segles (Moll i Suau, 1985: 276; Jover-Avellà, 2011: 64). En primer lloc, l'escassa significació de les correlacions preus/producte de l'oli contrasten amb els elevats CR obtinguts entre els preus i la producció de blat. Per tant, sembla que es tractava de dos mercats 
amb comportaments diferents. Malgrat que l'illa, i particularment Palma, comprava una part del blat en el mercat internacional, la relació entre preus i producció en els cereals era negativa i elevada. Per tant, podem interpretar que la producció de blat de l'illa tenia un pes molt significatiu en la determinació dels preus en el mercat interior (Manera, 2001; Garí Pellicer, 2019). No succeïa el mateix, com mostra el quadre 5, en el mercat de l'oli.

Els preus en el mercat de Palma depenien poc, sembla, del volum de les collites d'olives de l'illa. Això era degut a diferents factors. Primerament, les exportacions representaven entorn del $60 \%$ al segle XVII i entorn del $50 \%$ al xviı de la producció total d'oli (Bibiloni, 1995; Manera, 1999); per tant, la cotització de l'oli en el mercat de Palma estava possiblement subjecta més estretament als canvis en el mercat internacional, que no pas a l'oferta i demanda domèstiques (Jover-Avellà, 2020). A més, l'oli no tenia un paper equivalent al del blat en les dietes de l'època, podia ser substituït per la ingesta d'altres greixos animals (llard de porc), i per ço l'elasticitat preu-demanda possiblement era menor que la del blat (Vaquer Bennasar, 1988: 743-744, 763-765; Pujol Beltrán, 1996: 375-376; Manera, 2001: 7881). D'altra banda, l'oli era un producte que es podia emmagatzemar durant llargs períodes i tenia usos alternatius. Si els olis novells podien abastir el consum domèstic (alimentació, il-luminació), els olis més vells (baixos, climes i morques) podien emprar-se per altres usos com ara fer sabó o lubricar els rodaments. Per això, les reserves d'oli dipositades en els safareigs i les collites de l'any constituïen l'oferta real que comptava en el mercat. La gestió de les collites de l'any i les reserves dels dipòsits era l'oferta total d'oli que les autoritats prenien en consideració per prendre les seves decisions sobre la política a seguir (taxar els preus o prohibir les exportacions) per tal de garantir l'abastament del mercat local (Juan Vidal, 1980; Bibioni, 1995; Manera, 1999).

La presa en consideració d'aquestes variables potser milloraria la nostra comprensió del funcionament del mercat de l'oli, i en particular dels preus. Tanmateix, no podem descartar canvis importants en la pròpia estructura del mercat al llarg dels segles XVII i XVIII. L'augment de la proporció d'oli venut en el mercat de Palma que es palesava en el quadre 1, la disminució de la proporció d'oli exportat respecte de la producció total (Manera, 1999), i la progressiva convergència de 
les correlacions entre les collites - l'oli venut al mercat i els preus de l'oli quan introduïm el retard d'un any que reflecteix el quadre $5 b-$, podrien significar que durant el segle xvinI els preus de l'oli depenien cada cop més de l'oferta de l'illa, i estaven menys sotmesos a les pressions dels mercats internacionals. Caldrà, doncs, prendre en consideració els resultats d'aquesta anàlisi per comprendre alguns dels canvis que es produïren en les fluctuacions i en les tendències de la producció oleícola de l'illa al llarg dels segles XVI-XIX.

\subsection{Conjuntures i tendències de la producció oleícola}

En aquest apartat s'ofereix una anàlisi descriptiva de les fluctuacions i tendències de les proxies del producte i ingressos del sector oleícola. Els resultats es presenten en quatre gràfics en nombres índexs per tal de facilitar la comparació entre les sèries. Els gràfics $3 \mathrm{i}$ 4 mostren en nombres índexs els valors anuals de les sèries decimals i de les trullades d'olives. Els gràfics 5 i 6 sintetitzen les tendències dels diferents indicadors: preus, rendes decimals i trullades d'olives, en nombres índexs de les mitjanes mòbils d'11 anys entorn del valor central. L'any escollit com a base 100 és el 1690; per dos motius: primer perquè és un període de relativa calma després d'una etapa d'intenses crisis productives; i segon, perquè és el punt de coincidència entre les sèries de delmes i preus, i les de les trullades que comencen el 1684.

El gràfic 3 mostra l'evolució de les rendes decimals nominals i en producte decimal en quartans sobre una gràfica semilogarítmica per atenuar la intensitat de les fluctuacions. La sèrie s'ha empalmat amb les dades del segle xvi del capítol de la catedral publicades per Josep Juan Vidal (1989b). El gràfic 4 aporta una mirada més minuciosa pel que respecta a les oscillacions del producte decimal en quartans i les trullades d'olives entre 1684 i 1820 . Als anys en què la collita era pràcticament nul-la (nihil, diu el document), és a dir, en què els delmes no s'arrendaren o el seu preu era insignificant (vegeu l'apartat 3.3), se'ls ha assignat el valor 1, per evitar deixar buits.

Ambdós gràfics mostren una plena superposició d'ambdues corbes fins a mitjan segle XVIII. A patir d'ací la sèrie del producte decimal en quartans palesa un creixent desacoblament respecte dels valors nominals i de la corba de les trullades d'olives. Les desviacions en 
les trajectòries s'eixamplen a partir de 1790 . Tornarem sobre aquest punt més endavant.

Pel que fa a la intensitat de les fluctuacions, les sèries mostren tres etapes ben diferenciades. La primera comprendria un llarg període entre 1550 i 1690 dominat per intenses fluctuacions de les collites i ingressos, en el qual sovintejaven els anys amb collites pèssimes o nul.les. Dintre d'aquesta llarga etapa destaca el període entre 1651 i 1690 caracteritzat per una oscil-lació extremadament intensa de les collites, en què les anyades de producció nul.la o molt escassa eren freqüents. El segon període abasta de 1690 a 1770, en què les fluctuacions interanuals dels delmes (gràfic 3) i les trullades (gràfic 4) s'atenuen i les greus crisis productives tendeixen a espaiar-se en el temps. En el tercer període, entre 1770 i 1820, reapareixen intenses crisis de subproducció oleícola, encara que d'una intensitat inferior a les del segle XVII, i les tres corbes, els delmes nominals, el producte decimal en quartans i les trullades palesen una creixent divergència

Gràfic 3. Delmes nominals i en producte físic (delme nominal/ preus oli) de l'oli del Capítol de la catedral de Mallorca

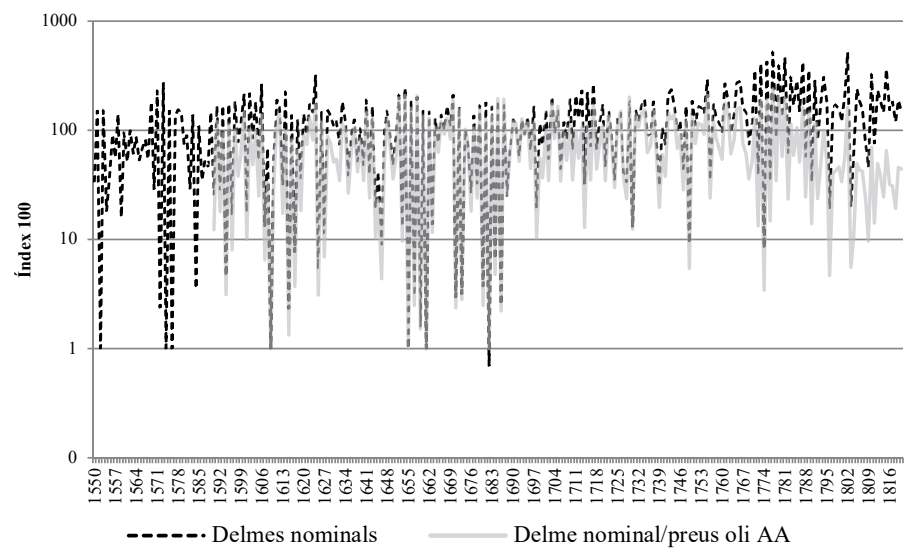

Nota. Valors en nombres índexs, 100= mitjana mòbil 11 anys entorn de 1690 .

FonTs. Notes de la 21 a la 29. 
Gràfic 4. Trullades d'olives i producte físic decimal (delme/preus oli)

1000

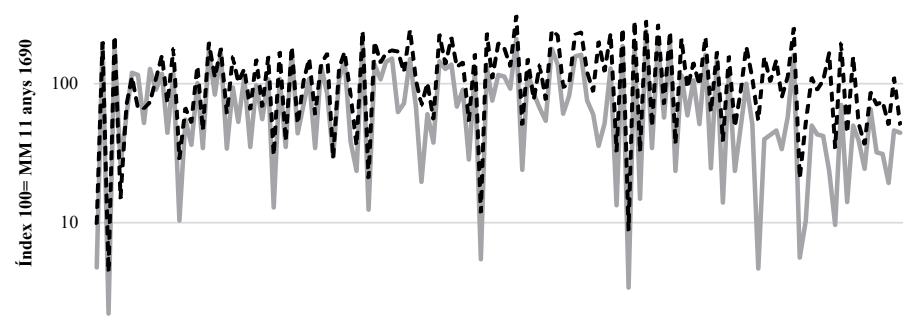



Delme nominal/preus oli AA _ - - Trullades olives

NотA. Valors en nombres índexs, $100=$ mitjana 11 anys entorn de 1690.

Fonts. Gràfic 1 i notes de la 21 a la 29.

Gràfic 5. Evolució dels indicadors de la producció d'oli



Nota. Índexs de les mitjanes mòbils 11 anys. Índex 100=1690

FonTs. Gràfics 1, 2 i notes de la 21 a la 29. 
Gràfic 6. Evolució dels indicadors del valor de la producció oleícola

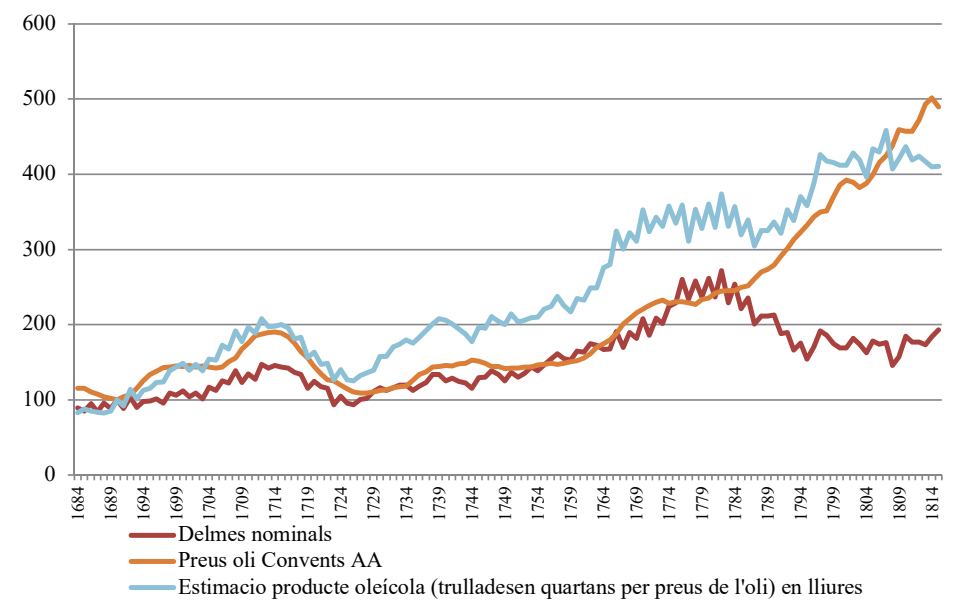

Nota. Índexs de les mitjanes mòbils 11 anys. Índex 100=1690.

Fonts. Gràfics 1, 2 i notes de la 21 a la 29.

a partir de 1780. La cronologia d'aquests desacoblaments entre les sèries es copsarà millor en els gràfics següents.

El gràfic 5 mostra l'evolució de la producció d'oli que dibuixen ambdues proxies del producte físic entre 1590 i 1815. En primer lloc, cal subratllar el que s'insinuava en el gràfic 4: existeix un clar desacoblament entre les sèries de les trullades d'olives i les del producte decimal en quartans. La sèrie del producte decimal en quartans no mostra la recuperació de la producció que palesa la sèrie de trullades d'olives després de 1690, i especialment després de la Guerra de Successió (1706-1715). Des de llavors s'obre una distància creixent entre ambdós indicadors del producte, especialment durant la fase expansiva del segle XviII. Però també permet una primera caracterització de l'evolució de la producció oleícola entre el segle Xvi i el XIX. L'expansió oleícola es produí en forma d'una successió d'onades que s'encavalcaven, solcades per profundes crisis que es perllonguen un seguit d'anys. La primera embranzida arrenca a mitjan segle XVI i assoleix un primer màxim productiu entorn de 1624. Aquesta conjuntura expansiva és seguida d'una profunda i llarga crisi durant 
els decennis de 1630 a 1640. La represa es caracteritza per una intensa fluctuació de les collites (gràfic 3); tanmateix el producte mig assoleix les cotes més elevats del segle XVII en els decennis de 1660 i 1670, per tornar a endinsar-se en una greu crisi en els decennis de $1680 \mathrm{i}$ 1690. Entre 1690 i 1770 s'obre una llarga etapa d'expansió oleícola, caracteritzada per una atenuació de les fluctuacions de les collites. La llarga etapa de creixement del set-cents es tanca amb una greu i persistent crisi que abasta el darrer terç del segle Xvin i primers decennis del xix, que tindrà una recuperació incompleta durant el segon quart del segle xix (Morey i Molina, 2016).

El gràfic 6 compara l'evolució dels índexs dels ingressos del sector a partir de tres indicadors: el delme nominal, el valor de la producció total d'oli a Mallorca (trullades transformades amb un rendiment d'11 quartans i multiplicades pels preus) i els preus de l'oli del mercat de Palma. Novament, cal fer dos tipus de consideracions. Els delmes nominals de l'oli se separen clarament del valor de la producció oleícola de l'illa entorn de 1700 . Aquesta bretxa s'incrementa lentament entre 1720 i 1770 . A partir de 1780 i fins a 1815 la bretxa s'obre de forma dramàtica. Òbviament, aquesta bretxa fou el resultat, d'una banda, de la disminució de la producció oleícola observada en el gràfic 5. Però també cal remarcar que les rendes decimals tingueren un creixement anèmic. El preu dels arrendaments tenia dificultats per ajustar-se a l'increment interanual dels preus, especialment quan comença l'intens període inflacionari del darrer quart del segle XVIII. Aquest doble llast de les rendes decimals, respecte del producte (gràfic 5) i dels preus (gràfic 6), explica el seu desacoblament també respecte de l'augment dels ingressos totals del sector, la variable valor de la producció oleícola.

L'anàlisi descriptiva de les variables suggereix dues conclusions provisionals. Les rendes decimals són un bon indicador per a l'anàlisi de les fluctuacions de la producció; ara bé, presenten problemes com a indicadors de les tendències del producte físic i de l'ingrés del sector. Aquesta deficiència no era tècnica, sinó que, com veurem a continuació, tenia un origen social. Els desacoblaments entre les diferents corbes del producte, els preus i els ingressos oleícoles expressaven els conflictes entorn de la distribució de la renda. 


\section{DisCUSSIÓ: INDICADORS, CONFLICTES EN LA}

\section{DISTRIBUCIÓ DE LA RENDA I FACTORS AGROCLIMÀTICS EN}

\section{EL SECTOR OLEÍCOLA DURANT EL LLARG SEGLE XVIII}

A partir dels resultats obtinguts en els apartats anteriors la discussió se centrarà en dos períodes: els conflictes per la distribució de la renda i les pertorbacions agroclimàtiques pels períodes 16751720 i 1770-1800. Els canvis en els comportaments de les variables productives entre ambdós períodes, suggereix també modificacions en el maneig del cultiu de l'olivar.

Durant l'etapa 1650-1720 convergiren una intensificació de les fluctuacions (gràfic 3) i del caràcter anyívol de les collites (quadre 4), i la caiguda de la producció (gràfic 4) i exportació mitjana de l'oli (Bibiloni, 1992). La crisi olivarera del darrer terç del segle XVII estava relacionada amb les intenses sequeres i onades de fred i neu que se succeïren en aquella etapa (Pastor, 2001; Barceló Pons, 1959; Cañellas, 2006; Espino, 2015), la manifestació regional de l'anomenat mínim de Maunder (1645-1715), considerat el període més fred de la petita edat de gel (Barriendos, 1997 i 2010; Alberola Pla, 2014: 94-96, 160-178). En aquells anys la caiguda de les rendes agràries conduí a la noblesa terratinent a una profunda crisi financera que s'allargaria fins a mitjan segle XVIII: caiguda de les rendes agràries, endeutament, segrests de patrimonis, alienació de terres (Morey, 1999; Jover-Avellà, 1999, 2002 i 2014). Els problemes es complicaren amb la inflació derivada de la Guerra de Successió (1706-1715), la intensa deflació posterior (gràfic 6) i els canvis en el mercat internacional de l'oli (Manera, 1988 i 1999). La crisi de les rendes de l'aristocràcia propicià una oportunitat als mercaders per consolidar el seu protagonisme en els vessants financer (préstecs a la noblesa) i comercial (acaparar el control dels nous circuits comercials, especialment amb França i Marsella), i en la negociació dels contractes d'arrendament de les explotacions olivareres (Manera, 1984, 1996).

Les tensions també es manifestaren en la negociació de l'arrendament dels delmes de l'oli. En primer lloc, a partir de 1715 les fonts decimals palesen una creixent feblesa com a indicador de l'evolució del producte, potser no tant com a indicador de l'ingrés brut del sector (gràfics 3, 4 i 6). A l'apartat 3.3 s'ha argumentat que el sistema d'arrendament de delmes del capítol canvià en el decenni 
de 1740: els delmes s'arrendaven en la seva totalitat o en paquets que agrupaven diverses viles a companyies de mercaders. La major capacitat de negociació dels mercaders podria explicar la creixent divergència en l'evolució de les corbes del valor de la producció total i l'evolució del delme nominal (gràfic 6). La distància entre ambdues corbes es mantingué relativament estable entre les dècades de $1730 \mathrm{i}$ 1770. Durant els anys centrals del segle Xvin l'estabilitat dels preus i l'augment del producte compensaven, encara llavors, els ingressos dels perceptors de les rendes decimals com el capítol de la catedral (gràfics 5 i 6).

El segon punt de ruptura socioeconòmica està clarament dibuixat a la dècada de 1770. Les greus crisis del decenni de producció de 1770 i 1780 recorden per la seva intensitat aquelles de final del segle XVII. L'augment de la intensitat de les fluctuacions s'expressa en un repunt dels coeficients de correlació superior a les de la primera meitat del set-cents (quadre 4). Però, a diferència de 1700, la producció mitjana descendí de manera continuada fins ben entrat el segle XIX (gràfic 5). Les crisis productives d'aquells decennis foren generals a la Mediterrània. La imprevisible successió de sequeres, nevades i inundacions intenses feren pensar a alguns coetanis que el temps s'havia trastornat (Barriendos i Llasat, 2003; Alberola, 2014). Els trastorns meteorològics també foren perceptibles a Mallorca, on l'afectació no es limità solament a les collites sinó que afectà els béns fons: vinyes, fruiters i oliveres (Segura Cortes, 2002).

Els impactes climàtics tingueren lloc en un context molt complicat socialment. Malgrat la crisi productiva, l'increment dels preus compensava la davallada del producte pels productors (terratinents, arrendataris, pagesos intermedis), la corba del valor de la producció (ingressos bruts del sector) es mantingué a l'alça fins a 1800 (gràfic 6). Però l'alça dels preus no empenyia amb la mateixa força les rendes decimals. Les rendes decimals s'ensorren amb les crisis de 1772 a 1782, i no aixequen el vol amb la inflació de preus posterior. Els gràfic $5 \mathrm{i}$ 6 mostren el desacoblament entre el volum de la producció (o el seu valor monetari) i la recaptació nominal a la segona meitat del segle XVIII. El bisbe i el capítol de Mallorca eren conscients que malgrat que els ingressos s'incrementaven nominalment, cada cop es captava una proporció menor del producte agrari. Així ho expressaren en diversos memorials adreçats al monarca els anys 1735, 1768 i 1773. 
En ells es lamentaven de la desaparició d'alguns drets (els delmes sobre el baleig i espigueig, en el cas dels cereals), però sobretot es queixaven del fet que tot un conjunt de nous productes arboris i arbustius escapessin al delme: ametlles, garrofes, seda, tàperes, etc. ${ }^{40}$ Escapaven, també, als senyors directes les oliveres plantades en les petites parcel-les dels pagesos? O la fracció de la producció d'olives que restava pel consum directe s'incrementava, en detriment d'aquella destinada a la transformació en oli, més fàcilment aprehensible pels delmadors? Hi ha indicis de la resistència dels pagesos a la punció decimal, encara que poc estudiats (Romero, 1983; Vaquer Bennasar, 1987: 327-328; Montaner, 1990: 84). Alhora, que s'estenia una difusa resistència per sota, per sobre els mercaders collaven als terratinents en la negociació de la renda (Moll i Suau, 1979; Morey, 1999) i als perceptors de delmes en la negociació dels preus dels arrendaments. Els canvis en la gestió de les rendes decimals del capítol de la catedral, com ara administrar directament la recaptació del delme de l'oli i la seva comercialització, no foren suficients per remuntar aquella anèmica evolució dels ingressos decimals del principal sector exportador de l'illa.

Al darrer terç del set-cents les dificultats financeres de la corona exigiren un augment dels impostos sobre els béns de consum, i particularment sobre l'oli (Juan Vidal, 1980: 545-546; Daviu, 1983; Bejarano, 2006; Morey i Molina, 2016; Pascual, 2018). L'increment impositiu sobre la venda de l'oli contribuí a dificultar el seu despatx

40 La queixa del bisbe es concretava en no se conoce ni se paga el derecho que en Castilla llaman Primicia [...] Tampoco se paga Diezmo de las crias del ganado de bacas, Burras, Yeguas, Ganado de Cerda, gallinas, Pabos, lana seda, miel, ni Quezo y todo se paga el diezmo de corderos de el qual no se sabe el motivo, no son participantes los Rectores o Curas [...] Tampoco se paga diezmo de arbol alguno de fruta, ni de la uba de las viñas que se vende a el peso para comer, ni tampoco de toda aquella, que producen los emparrados, y sirve no solo para comer, sino tambien para hazer el vino que llaman Malbasia. Tampoco se paga diezmo de Algarrobos, ni de Alcaparras, abundando los montes de aquellas, y los sembrados de estas, que son las que se componen para vende. Pero lo mas notable es que no se pague de la Almendra, ni del mais, o trigo de Indias, haviendo tenido principio en esta Isla uno y otro fruto en el presente siglo, y el primero se va aumentando de forma, que en el dia es y cosecha considerable y se hara mucho mayor segun el Copioso numero que se va plantando cada dia, a que les excita la la livertad del diezmo. Vegeu ARM, RA, 1774, 1, número 8. 
als mercats internacionals. Primer, perquè la demanda dels mercats internacionals canviava ràpidament degut a les continues guerres entre les potències europees, i segonament, perquè l'increment dels costos, dificultava encara més la competitivitat dels pesants olis mallorquins en la franja baixa del mercat front els nous olis més fins procedents d'Itàlia i França (Boulanger, 2015). La conjunció d'aquestes pressions a final del segle XviII ajuda a capir millor alguns dels canvis observats en el descens de les exportacions i l'augment del consum interior (quadre 1 i 2), l'impuls a les saboneries (Manera, 2001), i l'inici d'un canvi en les plantacions de les possessions, on nous conreus (fruiters, garrofers i ametllers) desplaçaven els olivars de les planes cap als pendents (Morey i Molina, 2016).

El període (1690-1770) que va transcórrer entre aquestes dues etapes crítiques fou d'alguna manera excepcional. A l'apartat 4.1 s'ha insistit en l'elevada intensitat i freqüència de les fluctuacions entre 1550 i 1690, i en un creixement solcat per profundes crisis. Però tots els indicadors presentats assenyalen un canvi important entorn de 1690 . A partir de llavors es produeix un apaivagament de les fluctuacions i una reducció de la durada i periodicitat de les crisis més intenses (gràfics 4 i 5), així com una disminució del caràcter anyívol de les collites d'olives, és a dir, disminuïa la probabilitat d'una mala collita després d'una de molt bona (quadre 4). Quins foren els vectors que propiciaren aquest canvi? Les evidències de què disposem fins avui sobre el maneig de l'olivar per aquesta llarga etapa són escasses. A la segona meitat del segle XVII els llibres de comptes de les explotacions suggereixen que els terratinents es limitaven a munyir els arbres, a recollir els fruits: el volum de treball destinat al manteniment dels sòls i a l'arbre era molt reduït (Jover-Avellà i Pujades-Mora, 2020a i 2020b). A més, els processos de recollida i elaboració de l'oli havien adquirit el biaix que buscava la quantitat i no la qualitat (Bibiloni, 1992; Vaquer Bennasar, 2017). No disposem de prou evidències per comparar el sistema de conreu de $1650 \mathrm{amb}$ aquell altre, ben conegut i estudiat, de 1850, també descrit com a molt extensiu (Grau, 1983; Grau i Tello, 1985). Ara bé, l'interrogatori de 1850 s'havia confeccionat després de la greu crisi de final del segle xvin, quan s'havia iniciat la decadència productiva i comercial de l'olivar (Morey i Molina, 2016). Cal preguntar-se, doncs, si la disminució en la intensitat de les fluctuacions i l'augment de la producció entre 1690 i 1770 fou resultat 
de la introducció de millores en el maneig de l'olivar o simplement s'ha d'atribuir a un apaivagament de les pertorbacions climàtiques entre dos extrems, el mínim de Maunder (1675-1715) i la pertorbació Maldà (1770-1790). I també, si els canvis posteriors a 1770 induïren a una relaxació en la intensitat de treball destinada a l'olivar en benefici d'altres conreus (Jover, 2013b: 55-59), o bé canvis en l'assignació dels cultius: mentre els menys productius quedaren confinat a les terres de pitjor qualitat, els nous ocupaven les terres més grasses (Morey i Molina, 2016).

\section{Conclusions}

L'estudi s'ha centrat en l'anàlisi de les diferents fonts que permeten reconstruir la producció de l'oli a l'illa de Mallorca per l'etapa 15501830. L'avaluació de la fiabilitat d'aquestes fonts, com a proxies de la producció i ingressos del sector oleícola mallorquí, simplement vol establir alguns criteris sobre el seu ús i significat a l'hora d'interpretar l'evolució del sector. Les sèries de trullades d'olives són una font excepcional per conèixer l'evolució de la producció oleícola de l'illa. Tanmateix, cal fer algunes matisacions. En primer lloc, cal entendre que aquesta estimació no incloïa les olives destinades al consum, i caldria determinar amb major precisió per cada etapa quina era la seva proporció per tal d'avaluar amb més precisió la collita d'olives. Segonament, per transformar les trullades en producció d'oli cal disposar dels rendiments anuals. Malgrat aquests problemes, la font mereix molta confiança i és un bon testimoni per avaluar la fiabilitat de les fonts decimals.

La sèrie de preus dels convents capta un segment ampli del mercat, el preu de l'oli pel consum domèstic: alimentació, il-luminació, etc. Però, cal tenir en compte que queden fora d'aquesta sèrie els preus dels olis per a usos relacionats amb la manufactura, o els olis més fins que podien comprar els grups socials més rics, o que eren destinats a l'elaboració de cosmètics. Convindria completar aquesta sèrie amb els preus de venda d'oli dels productors directes, per tal de mesurar els impactes dels costos de transport i els canvis en el sistema impositiu sobre el preu de consum final al mercat de Palma. Per últim, per determinar amb quina proporció els nivells i 
les variacions dels preus de consum finals estaven condicionats per el mercat internacional, fora convenient fer una anàlisi comparativa dels peus a escala internacional.

El delme de l'oli a Mallorca com a indicador del producte oleícola planteja diversos problemes. L'arrendament del delme expressava les expectatives que generaven les collites i els preus esperats, sota unes determinades condicions de negociació, i alhora formaven part de la pugna per la distribució de la renda entre diferents sectors socials. A més, com s'ha dit, els preus estaven sotmesos a forces que desfiguraven la seva relació inversa amb el volum de les collites; per tant, la traducció dels valors nominals en valors físics esdevé problemàtica. Tanmateix, si bé no semblen un bon indicador de l'evolució del producte a llarg termini, com s'ha posat de manifest a l'apartat 4.2, si que segueixen essent una font important per entendre l'evolució i distribució dels ingressos del sector.

Finalment, l'ús combinat dels delmes de l'oli, trullades d'olives i preus de l'oli s'ha revelat extremadament útil per presentar una periodització de l'evolució de producció i la distribució de la renda en el sector oleícola. L'anàlisi de dos períodes clau en la història del conreu a l'illa, la segona meitat del segle XviI (1650-1690) i el darrer terç del XVIII (1770-1800), mostra les complexes relacions que s'establien entre els factors agroclimàtics, els canvis en els mercats internacionals, conflictes entorn de la distribució de la renda i els sistemes de conreu. Ambdós episodis plantegen preguntes que exigeixin la integració de disciplines diferents per tal d'explicar de forma pertinent els canvis en l'evolució de la producció del sector olivarer. L'anàlisi d'aquelles crisis poden aportar informació que depassa l'interès específicament històric, i ens acosten als problemes actuals dels olivars mediterranis. L'augment de la temperatura i el descens de la pluviositat afecten la floració i la collita dels olivars, i afavoreixen l'aparició de noves plagues (Xylella fastidiosa). Símptomes del canvi climàtic (ambiental) global en curs a la conca mediterrània. Els processos socioeconòmics són resultat dels conflictes socials; tanmateix, tenen lloc sobre el planeta Terra, que també té la seva història. En el futur les explicacions més reeixides dels processos històrics sorgiran de l'anàlisi de la intersecció de la coevolució dels processos humans i naturals. 
๑ :三

$<$

$>$ 


\section{Bibliogr AFiA}

ABARCA, Vanesa (2015) Campos conocidos, senderos nuevos. Población y producción agraria en Burgos, 1540-1865 (Tesi doctoral), Madrid: Universidad Complutense de Madrid.

ABARCA, Vanesa (2017) «Mortalidad y crecimiento vegetativo en la provincia de Burgos, 1650-1865", Investigaciones de Historia Económica, 13 (3), p. 153-165.

ALBERCH, Ramon; CASTELLS, Narcís (1985) La població de Girona (segles XIV-XX), Girona: Institut d'Estudis Gironins.

ALBEROLA ROMÀ, Armando (2014) Los cambios climáticos. La pequeña Edad de Hielo en España, Madrid: Cátedra.

ALBEROLA ROMÀ, Armando (1984) Jurisdicción y propiedad de la tierra en Alicante (ss. XVII $y$ XVIII), Alacant: Ajuntament d'Alacant.

ALDEA VAQUERO, Quintín (1973) «La economía de las iglesias locales en la Edad Media y Moderna», Hispania Sacra, 26, p. 27-68.

ALFONSO, Isabel (2010) «Iglesias rurales en el Norte de Castilla: una dimensión religiosa de las luchas campesinas durante la Edad Media», dins Ricardo ROBLEDO (ed.) Ramon Garrabou. Sombras del progreso. Las huellas de la historia agraria, Barcelona: Editorial Crítica, p. 27-65.

ALLEN, Robert C. (2000) «Economic structure and agricultural productivity in Europe, 1300-1800», European Review of Economic History, 3 (2), p. 1-25.

ÁLVAREZ VÁZQUEZ, José Antonio (1984) Los diezmos en Zamora (15001840), Salamanca: Universidad de Salamanca.

ÁLVAREZ-NOGAL, Carlos; PRADOS, Leandro (2007) «The Decline of Spain (1500-1850): Conjectural Estimates», European Review of Economic History, 11, p. 319-366.

ÁLVAREZ-NOGAL, Carlos; PRADOS, Leandro (2013) «The rise and fall of Spain (1270-1850)», Economic History Review, 66, p. 1-37. 
ÁLVAREZ-NOGAL, Carlos; PRADOS DE LA ESCOSURA, Leandro; SANTIAGO-CABALLERO, Carlos (2016) «Spanish agriculture in the little divergence», European Review of Economic History, 20 (4), p. $452-477$.

ANDRÉS UCENDO, José Ignacio (2011) «Fiscalidad y precios en Castilla en el siglo XVII: los precios del vino en Madrid, 1606-1700», Revista de Historia Económica - Journal of Iberian and Latin American Economic History, 29 (2), p. 269-298.

ANDRÉS UCENDO, José Ignacio (2017) «La fiscalidad municipal en Castilla en el siglo xviI: el caso de Madrid», Cuadernos de Historia Moderna, 42 (2), p. 615-627.

ANDRÉS UCENDO, José Ignacio; LANZA GARCÍA, Ramón (2013) «Impuestos municipales, precios y salarios reales en la Castilla del siglo Xvir: el caso de Madrid», Hispania, 73 (243), p. 161-192.

ANDRÉS UCENDO, José Ignacio; LANZA GARCÍA, Ramón (2020) «Prices and wages in Segovia, 1571-1807)», Revista de Historia Económica Journal of Iberian and Latin American Economic History, 38 (2) 221-248.

ANES ÁLVAREZ, Gonzalo (1970) Las crisis agrarias en la España moderna, Madrid, Taurus.

ANES, Gonzalo; LE FLEM, Jean-Paul (1965) «Las crisis del siglo xviI: producción agrícola, precios e ingresos en tierras de Segovia», Moneda y Crédito, 93, p. 3-55.

ARDIT, Manuel (1975) «Contribución al estudio del movimiento de las rentas de la tierra en el País Valenciano en el siglo XVIII (1707-1800)», Cuadernos de Historia, 5, p. 337-417.

ARDIT, Manuel (1977) Revolución liberal y revuelta campesina. Un ensayo sobre la desintegración del régimen feudal en el País Valenciano (17931840), Barcelona: Ariel.

ARDIT, Manuel (1987) «Expulsió dels moriscos i creixement agrari al País Valencià», Afers, 5/6, p. 273-316.

ARDIT, Manuel (1989) «Recaudación y fraude diezmal en el siglo xviII valenciano», dins Antonio Miguel BERNAL (ed.) Estructuras agrarias y reformismo ilustrado en la España del siglo XVIII, Madrid: Ministerio de Agricultura, Alimentación y Medio Ambiente, p. 391-410.

ARDIT, Manuel (1993) Els homes i la terra del País Valencià (segles XVIXVIII), Barcelona: Curial. 
ARDIT, Manuel (1996) «Agricultura e industria rural en el siglo xviII», dins Joaquín AZAGRA, Enric MATEU i Javier VIDAL (ed.) De la sociedad tradicional a la economía moderna. Estudios de historia valenciana contemporània, Alacant: Instituto Alicantino de Cultura Juan GilAlbert, p. 62-76.

ARDIT, Manuel (2004) Creixement econòmic i conflicte social. La foia de Llombai entre els segles XIII $i$ XIX, Catarroja-Barcelona: Editorial Afers.

ARDIT, Manuel (2016) Els homes i la terra al País Valencià (segles XVI-XVIII), Catarroja-Barcelona: Editorial Afers [la primera edició és de 1993].

ARDIT, Manuel (2016-2017) «La crisi del segle Xviı al País Valencià i Catalunya», Recerques, 72-73, p. 105-118.

ARDIT, Manuel (2018) «The Agrarian Model of Valencian Moriscos», dins Thomas F. GLICK, Antonio MALPICA, Fèlix RETAMERO i Josep TORRÓ (ed.) From Al-Andalus to the Americas (13th-17th Centuries). Destruction and Construction of Societies, Leiden: Brill, p. 228-258.

ARNOUX, Mathieu (2010) «Pour une économie historique de la dîme», dins Roland VIADER (ed.) La dîme dans l'Europe médiévale et moderne, Tolosa: Presses Universitaires du Mirail, p. 145-159.

ARNOUX, Mathieu (2012a) Le temps des laboureurs. Travail, ordre social et croissance en Europe (XI ${ }^{\mathrm{e}}-\mathrm{XIV} \mathrm{V}^{\mathrm{e}}$ siècle), París: Éditions Albin Michel.

ARNOUX, Mathieu (2012b) «Des fruits et des hommes», dins Michel LAUWERS (ed.) La dîme, l'église et la société féodale, Turnhout: Brepols Publishers, p. 591-605.

AYLLÓN, Carlos (2010) «Estructura parroquial en el sureste de Castilla a fines de la Edad Media», Medievalismo, 20, p. 173-202.

AYMARD, MAURICE (1987) «Fernand Braudel, the Mediterranean, and Europe», Mediterranean Historical Review, 2 (1), p. 102-114.

BADOSA I COLL, Elisa (1983) «Explotació agrícola i contractes de conreu (1670-1840). Les finques del clergat de Barcelona», Estudis històrics $i$ documents dels arxius de protocols, 12, p. 7-535.

BARRANCO, Diego (2008) El cultivo del olivo, Madrid: Mundi-Prensa Libros.

BARRIENDOS, Mariano (1997) «Climatic variations in the Iberian Peninsula during the late Maunder Minimum (AD 1675-1715): an analysis of data from rogation ceremonies», The Holocene, 7 (1), p. 105-111. 
BARRIENDOS, Mariano (2010) «Les variations climatiques dans la péninsule Ibérique: l'indicateur des processions $\left(\mathrm{XVI}^{\mathrm{e}}-\mathrm{XIX}^{\mathrm{e}}\right.$ siècle)», Revue d'histoire moderne et contemporaine, 57 (3), p. 131-159.

BARRIENDOS, Mariano; LLASAT, Maria del Carmen (2003) «The case of the Maldá' anomaly in the western Mediterranean basin (AD 17601800): an example of a strong climatic variability», Climatic Change, 61 (1-2), p. 191-216.

BARRIO GOZALO, Maximiliano (1981-1982) «Perfil socioeconómico de una élite de poder. I: los obispos de Castilla la Vieja, 1600-1685", Anthologica annua, 26/27, p. 71-138.

BARRIO GOZALO, Maximiliano (1982) Estudio socioeconómico de la Iglesia en Segovia en el siglo XVIII, Segovia: Caja de Ahorros de Segovia.

BARRIO GOZALO, Maximiliano (1983) «Los diezmos y primicias en la diócesis de Segovia en el siglo xviII», Cuadernos de Investigación Histórica, 7, p. 133-146.

BARRIO GOZALO, Maximiliano (1983-1984) «Perfil socioeconómico de una élite de poder. II: los obispos del reino de León (1600-1840)», Anthologica annua, 30-31, p. 209-294.

BARRIO GOZALO, Maximiliano (1985) «Perfil socioeconómico de una élite de poder. III: los obispos del reino de Galicia (1600-1940)», Anthologica aпnua, 32, p. 11-108.

BARRIO GOZALO, Maximiliano (1986) «Perfil socioeconómico de una élite de poder. IV: los obispos de Castilla La Nueva y Extremadura (1600-1840)», Anthologica annua, 33, p. 159-302.

BARRIO GOZALO, Maximiliano (1987) «Perfil socioeconómico de una élite de poder. V: los obispos de Andalucía (1640-1840)», Anthologica аппиа, 34, p. 11-188.

BARRIO GOZALO, Maximiliano (1988a) «Economía de un grupo privilegiado del antiguo Régimen. Los obispos de Pamplona (15561833)», Príncipe de Viana, anejo 9. Primer Congreso General de Historia de Navarra, p. 47-59.

BARRIO GOZALO, Maximiliano (1988b) «La economía de las mitras catalanas en la segunda mitad del siglo xvili y su relación con el conjunto español: apuntes para su estudio», Pedralbes: Revista d'Història Moderna 8, (2), p. 447-458. 
BARRIO GOZALO, Maximiliano (1992) «Perfil socioeconómico de una élite de poder. VII: los obispos de Cartagena-Murcia (1556-1834)», Anthologica annua, 39, p. 103-166.

BARRIO GOZALO, Maximiliano (1996) «Perfil socioeconómico de una élite de poder de la Corona de Aragón. I: los obispos del reino de Aragón (1536-1834)», Anthologica annua, 43, p. 107-212.

BARRIO GOZALO, Maximiliano (2003) «Perfil socioeconómico de los Obispos del Reino de Valencia (1556-1834)», Anthologica annua, 50, p. 311-374.

BARRIO GOZALO, Maximiliano (2004) El Real patronato y los obispos españoles del Antiguo Régimen (1556-1834), Madrid: Centro de Estudios Políticos y Constitucionales.

BARRIO GOZALO, Maximiliano (2007) «El clero parroquial en la España moderna. Estilo de vida y aspectos socioeconómicos», Cuadernos de Investigación Histórica, 24, p. 311-341.

BARRIO GOZALO, Maximiliano (2010a) El sistema beneficial de la Iglesia española en el Antiguo Régimen, Alacant: Universidad de Alicante.

BARRIO GOZALO, Maximiliano (2010b) «Las rentas de los obispos de Cataluña en el Antiguo Régimen (1556-1837)», Manuscrits: Revista d'Història Moderna, 28, p. 143-179.

BARRIO GOZALO, Maximiliano (2011) El sistema beneficial de la Iglesia española en el Antiguo Régimen (1475-1834), Alacant: Universidad de Alicante.

BARRIO GOZALO, Maximiliano (2014) «Las rentas de los obispos de Extremadura en el Antiguo Régimen (1556-1837)», Revista de estudios extremeños, 70, p. 637-668.

BARRIO GOZALO, Maximiliano (2015) «Los obispos de Cuenca en los siglos modernos (1479-1826). Estudio socioeconómico», Cuadernos de investigación histórica, 32, p. 285-316.

BARTON, Thomas W. (2009) «Constructing a diocese in a post-conquest landscape: a comparative approach to the lay possession of tithes», Journal of Medieval History, 35, p. 1-33.

BATEMAN, Victoria (2011) «Market integration and trade in the Mediterranean, 1500-1900", Economic History Society, Working Papers, 11032 . 
BEJARANO GALDINO, Emilio (2000) Amotinamientos populares y revuelta de los privilegiados: lucha y resistencia social en Mallorca en las postrimerías del Antiguo Régimen, Palma: El Tall Editorial (vol. 34).

BEJARANO GALDINO, Emilio (2001) «El sector de la ramaderia a Mallorca al segle XVIII a través dels valors de la cabanya i dels preus carnis», Estudis d'història agrària, 14, p. 155-170.

BEJARANO GALDINO, Emilio (2006) «Cambios en el sistema impositivo de Mallorca a lo largo del siglo Xvin y sus repercusiones sociopolíticas», Mayurqa, 31, p. 275-294.

BELANDO, Remedios (1990) Realengo y señorío en el Alto y Medio Vinalopó: génesis de las estructuras de propiedad de la tierra, Alacant: Universitat d'Alacant.

BENÍTEZ SÁNCHEZ-BLANCO, Rafael (1978) «Las rentas eclesiásticas del obispado de Málaga a mediados del siglo xviI», dins Diversos Autors Actas del I Congreso de Historia de Andalucía. Andalucía Moderna (ss. XVI-XVII), vol. 1, Còrdova: Caja de Ahorros, p. 119-130.

BENITO, Pere (2003) Senyoria de la terra i tinença pagesa al comtat de Barcelona (segles XI-XIII), Barcelona: Consell Superior d'Investigacions Científiques.

BENITO, Pere (2005) «La submissió del comte Hug IV d’Empúries i de la noblesa emporitana a l'Església de Girona (1226-1229): una repercussió de la croada albigesa liderada per Lluís VIII, rei de França, a Catalunya», dins Lourdes PLANAS i COMDERRÓS Església, societat i poder a les terres de parla catalana, Valls: Coordinadora de Centres d'Estudis de Parla Catalana i Cossetània Edicions, p. 139-154.

BIBILONI AMENGUAL, Andreu (1995) El comerç exterior de Mallorca: homes, mercats $i$ productes d'intercanvi (1650-1720), Palma: El Tall Editorial.

BIBILONI AMENGUAL, Andreu (1992) Mercaders i navegants a Mallorca durant el segle XVII: l'oli com indicador del comerç mallorquí (1650-1720), Palma: El Tall Editorial.

BIDAGOR, Ramón (1933) La Iglesia propia en España: estudio históricocanónico (Anacleta Gregoriana IV), Roma: Universidad Gregoriana.

BILBAO, Luis María; FERNÁNDEZ DE PINEDO, Emiliano (1984) «La producción agrícola en el País Vasco (1537-1850)», Eusko-Ikaskuntza / Sociedad de Estudios Vascos. Cuadernos de Sección Historia-Geografía, 2, p. 84-196. 
BISSON, JEAN (1977) La terre et l'homme aux îles Baléares. Aix-enProvence: Edisud (vol. 3).

BONNASSIE, Pierre (1979-1981 [1975-1976]) Catalunya, mil anys enrera. Creixement econòmic i adveniment del feudalisme a Catalunya, de mitjan del segle $\mathrm{X}$ al final del segle XI, Barcelona: Edicions 62, 2 volums.

BOYD, Catherine E. (1952) Tithes and Parishes in Medieval Italy. The Historical Roots of a Modern Problem, Ithaca: Cornell University.

BROADBERRY, Stephen; CAMPBELL, Bruce M.; KLEIN; Alexander; OVERTON, Mark; LEEUWEN, Bas van (2015) British Economic Growth, 1270-1870, Cambridge: Cambridge University Press.

BROADBERRY, Stephen; CAMPBELL, Bruce; KLEIN, Alexander; OVERTON, Mark; LEEUWEN, Bas van (2011) «British Economic Growth, 1270-1870: an output-based approach», University of Kent School of Economics Discussion Papers, KDPE 1203.

BUENO, Santiago (2000) El derecho canónico catalán en la Baja Edad Media. La diócesis de Gerona en los siglos XIII y XIV, Barcelona: Facultat de Teologia de Catalunya.

BURGO LÓPEZ, Ma Concepción (1993) «La estructura económica del cabildo de Lugo a finales del siglo xviII", Obradorio de Historia Moderna, 2, p. 65-84.

BURNS, Robert I. (1962) «The Parish as Frontier Institution in thirteenthcentury Valencia», Speculum, 37, p. 244-251.

BURNS, Robert I. (1966) «A mediaeval income tax: the tithe in the thirteenth century kingdom of Valencia», Speculum, 41, p. 438-452.

BUYST, Erik (2011) «Towards estimates of long term growth in the southern Low Countries, c. 1500-1846», HI-POD Workshop Quantifying long run economic development, University of Warwick in Venice. Accessible a l'adreça: https://warwick.ac.uk/fac/soc/economics/seminars/seminars/ conferences/venice3/programme/buyst.pdf

CABY, Cécile (2012) «Les moines et la dîme ( $\mathrm{XI}^{\mathrm{e}}-\mathrm{XIII}^{\mathrm{e}}$ siècle): construction, enjeux et évolutions d'un débat polymorphe», dins Michel LAUWERS (ed.) La dîme, l'église et la société féodale, Turnhout: Brepols Publishers, p. 369-409.

CALDERÓN, Andrés; GARCÍA MONTERO, Héctor; LLOPIS, Enrique (2017) «New research guidelines for living standards, consumer baskets, and prices in Madrid and Mexico», dins DIVERSOS AUTORS. I prezzi 
delle cose nell'età preindustriale, Florència: Firenze University Press, p. 333-363.

CAMINAL, Montserrat; CANALES, Esteban; SOLÀ, Àngels; TORRAS, Jaume (1978) «Moviment de l'ingrés senyorial a Catalunya (1770-1835). Els arrendaments de la casa de Medinaceli», Recerques, 8, p. 51-72.

CAMPANER, Álavaro (1888[1984]) Cronicón Mayoricense, Palma: Luis Ripoll Editor.

CANAL, Josep; CANAL, Eduard; NOLLA, Josep M.; SAGRERA, Jordi (1995) «Història urbana de Girona. El monar reial del Mercadal a Girona», Annals de l'Institut d'Estudis Gironins, 35, p. 55-68.

CANALES, Esteban (1982) «Los diezmos en su etapa final», dins Gonzalo ANES (ed.) La economía española al final del Antiguo Régimen. I. Agricultura, Madrid: Alianza Editorial, p. 103-187.

CANALES, Esteban (1985) «Diezmos y revolución burguesa en España», dins Ángel GARCÍA SANZ i Ramon GARRABOU (ed.) Historia agraria de la España contemporánea (Volum 1), Barcelona: Editorial Crítica, p. 245-274.

CANALES, Gregorio (1981) «Recolección y partición de diezmos en la diócesis de Orihuela en el siglo xviII", Revista del Instituto de Estudios Alicantinos, 33, p. 103-119.

CANALES, Gregorio (1988) «Relación entre nacimientos y producción agraria (siglos XVII-XVIII) en el Bajo Segura», dins Carmen PÉREZ APARICIO (ed.) Estudis sobre la població del País Valencià: actes de les I Jornades d'Estudi sobre la Població del País Valencià: València-Alacant, 20-22 de març de 1986, València: IVEI-Alfons el Magnànim, p. 437-449.

CAÑELLAS SERRANO, Nicolau (2006) «Instal-lacions per a la recollida de neu a Mallorca. Revisió bibliogràfica», Territoris, 6, p. 67-105.

CARBONERO GAMUNDÍ, Maria A. (1992) L'espai de l'aigua: petita hidràulica tradicional a Mallorca, Palma: Consell Insular de Mallorca.

CASANOVA I TODOLÍ, Ubaldo de (1985) «El déficit alimenticio del reino de Mallorca a lo largo del s. Xvir y sus problemas de abastecimiento», Mayurqa, 21, p. 217-232.

CASANOVA I TODOLÍ, Ubaldo de (2005) Aproximación a la historia mallorquina del siglo xvII, Salamanca: Amaru Ediciones.

CASEY, James (1971) «Moriscos and the Depopulation of Valencia», Past \& Present, 50 (1), p. 19-40. 
CASEY, James (1976) «Irrigació i economia al País Valencià, 1589-1689», dins DIVERSOS AUTORS Primer Congreso de Historia del País Valenciano: celebrado en Valencia del 14 al 18 de abril de 1971. 3. Edad Moderna, València: Universitat de València, p. 281-290.

CASEY, James (1981) El Regne de València al segle XVII, Barcelona: Curial.

CASEY, James (1982) «Structure et développement de l'agriculture de Valence à l'époque Moderne, 1500-1700», dins Joseph Goy i Emmanuel Le Roy Ladurie (ed.) Prestations paysannes dîmes, rente foncière et mouvement de la production agricole à l'époque préindustrielle, París: Mouton, $\mathrm{p}$. 329-339.

CASEY, James (1987) «Què deu el País Valencià als canvis en el poblament rural del segle XvII?», Revista de Catalunya, 5, p. 84-100.

CASTAGNETTI, Andrea (1976) La pieve rurale nell'Italia padana. Territorio, organizzazione patrimoniale e vicende della pieve veronese di San Pietro di Tillida dall'alto medioevo al secolo XIII, Roma: Herder Editrice e Libreria.

CASTILLO, Álvaro (1969) «La coyuntura de la economía valenciana en los siglos XVI y XVII», Anuario de Historia Económica y Social, 2, p. 3-52.

CASTILLÓN CORTADA, Francisco (1988) «Diezmos y primicias del obispo de Lérida», Anacleta Sacra Tarraconensia, 61-62, p. 7-161.

CATAFAU, Aymat (1999) «Un inventaire des fiefs tenus pour l'évêque d'Elne (fin XII ${ }^{\mathrm{e}}$ siècle)», dins Helène DÉBAX (dir.) Les sociétés méridionales à l'âge féodal. Hommage à Pierre Bonnassie, Tolosa: Presses Universitaires du Mirail, p. 331-337.

CATAFAU, Aymat (2003) «Les évêques d'Elne, leurs fiefs et leurs vassaux, $\mathrm{XI}^{\mathrm{e}}$-XIV ${ }^{\mathrm{e}}$ siècles», dins Marie GRAU i Olivier POISSON (dir.) Elne. Ville et territoire. L'historien et l'archéologue dans sa cité. Hommage à Roger Grau, Elna: Société d'Amis d'Illiberris, p. 141-150.

CATALÁN MARTÍNEZ, Elena (1997) «El fin de un privilegio: La contribución eclesiástica a la Hacienda Real (1519-1794)», Studia historica. Historia moderna, 16, p. 177-200.

CATALÁN MARTÍNEZ, Elena (2004a) «El derecho de patronato y el régimen beneficial de la Iglesia Española en la Edad Moderna», Hispania Sacra, 56, p. 135-167.

CATALÁN MARTÍNEZ, Elena (2004b) «Seculares aragoneses después de Trento. La visita pastoral de D. Antonio Chacón a los valles del Jalón y Jiloca», Revista de Historia Jerónimo Zurita, 76-77, p. 369-397. 
CATALÁN MARTÍNEZ, Elena (2010) «La participación del bajo clero en el excedente agrario vasco y riojano (1545-1775)», Investigaciones de Historia Económica - Economic History Research, 6 (18), p. 35-36.

CATALÁN MARTÍNEZ, Elena (2013) «Parroquias y curas en el obispado de Calahorra y La Calzada (siglos XI-XVI)», Obradoiro de Historia Moderna, 22, p. 35-62.

CATALÁN MARTÍNEZ, Elena (2015) «El clero rural vasco durante la Edad Moderna» dins Rosario PORRES (coord.) Entre el fervor y la violencia. Estudios sobre los vascos y la Iglesia (siglos XVI-XVIII), Bilbao: Servicio editorial de la UPV/EHU, p. 17-56

CATALÁN MARTÍNEZ, Elena (2018) «El crecimiento del producto agrario por habitante de La Rioja en la Edad Moderna», Investigaciones de Historia Económica - Economic History Research, 14 (2), p. 69-138.

CÍSCAR, Eugenio (1977) Tierra y Señorío en el País Valenciano (1570-1620), València: Del Cenia al Segura.

CÍSCAR, Eugenio (1993) Moriscos, nobles y repobladores. Estudios sobre el siglo XVII en Valencia, València: Institució Alfons el Magnànim.

COBO, Josep M. (2006) Pagesos, peraires i teixidors al Llobregat montserratí, Barcelona: Publicacions de l'Abadia de Montserrat.

COLLS, Josep (2002) D'artesans a pagesos: l'evolució del treball en una vila de la Catalunya moderna (Castelló d'Empúries, segles XV-XVII) (Treball de recerca presentat al programa de doctorat d'Història Medieval, Moderna i Contemporània), Universitat de Girona.

CONESA, Marc (2010) «Des grains, des terres et des hommes. La dîme et la question des espaces agraires en Cerdagne (XVII ${ }^{\mathrm{e}}$-XVIII ${ }^{\mathrm{e}}$ siècles)», dins Roland VIADER (ed.) La dîme dans l'Europe médiévale et moderne, Tolosa: Presses Universitaires du Mirail, p. 257-269.

CONGOST, Rosa (1986) «Reflexions sobre la renda de la terra a la regió de Girona en l'etapa final de l'Antic Règim, 1770-1840», dins Núria SALES et al. (ed.) Terra, treball i propietat. Classes agràries i règim senyorial als Països Catalans, Barcelona: Editorial Crítica - Centre de Treball i Documentació, p. 247-277.

CONGOST, Rosa (1990) Els propietaris i els altres, Vic: Eumo Editorial.

CONSTABLE, Giles (1964) Monastic tithes. From their origins to the twelfth century, Cambridge: Cambridge University Press. 
CORREA, Jorge (1995) La Hacienda Foral Valenciana. El Real Patrimonio en el siglo XVII, Alzira: Consell Valencià de Cultura.

CUERVO FUENTE, Noemí (2015) Población y crecimiento agrario en un territorio de la España central. La provincia de Ávila (siglos XVI-XIX) (Tesi doctoral), Madrid: Universidad Complutense de Madrid.

CURIEL YARZA, Iosu (2009) La parroquia en el País Vasco-cantábrico durante la baja edad media (c. 1350-1530): organización eclesiástica, poder señorial, territorio y sociedad, Bilbao: Servicio editorial de la UPV/EHU.

DANTÍ, Jaume (1988) Terra i població al Vallès Oriental. Ėpoca moderna. El creixement demogràfic i econòmic als segles XVI $i$ XVII, Santa Eulàlia de Ronçana: Ajuntament de Santa Eulàlia de Ronçana.

DAVIU PONS, Guillem (1983) «La producció d'oli a Mallorca. Segle XVIII. Aproximació en base a la documentació fiscal», dins DIVERSOS AUTORS I Col-loqui d'història agrària: Barcelona, 13-15 d'octubre de 1978, València: Institució Alfons el Magnànim, p. 391-410.

DE JUAN, Màrius (1996) «Delme i producció agrària (1380-1412)», dins DIVERSOS AUTORS III Jornades d'Estudis Locals d'Inca, Inca: Ajuntament, p. 243-253.

DEVROEY, Jean-Pierre (2010) «Dîme et économie des campagnes à l'époque carolingienne», dins Roland VIADER (ed.) La dîme dans l'Europe médiévale et moderne, Tolosa: Presses Universitaires du Mirail, p. 37-62.

DIAGO HERNANDO, Máximo (1997) «Las iglesias propias de monasterios en la Castilla Bajomedieval. Algunos ejemplos riojanos», Hispania Sacra, 49 (100), p. 625-651.

DÍAZ DE DURANA, José Ramón (1998) «Patronatos, patronos, clérigos y parroquianos. Los derechos de patronazgo sobre los monasterios e iglesias como fuente de renta e instrumento de control y dominación de los Parientes Mayores guipuzcoanos (siglos XIV a XVI)», Hispania Sacra, 50 (102), p. 467-508.

DÍAZ DE DURANA, José Ramón; GUINOT, Enric (2010) «La dîme dans l'Espagne médiévale», dins Roland VIADER (ed.) La dîme dans l'Europe médiévale et moderne, Tolosa: Presses Universitaires du Mirail, p. 63-88.

DIVITIIS, Gigliola Pagano de (1997[1990]) English merchants in seventeenthcentury Italy, Cambridge: Cambridge University Press. 
DOLS I MARTORELL, Maria del Camí (2014) Estudi agro-econòmic de Mallorca i Menorca del 1380 al 1420 segons el delme eclesiàstic (Tesi doctoral), Palma: Universitat de les Illes Balears.

DOMÍNGUEZ ORTIZ, Antonio (1974) «Las rentas episcopales de la Corona de Aragón en el siglo xviII», dins Gabriel Tortella i Jordi Nadal (coord.) Agricultura, comercio colonial y crecimiento económico en la España contemporánea: actas del Primer Coloquio de Historia Económica de España (Barcelona, 11-12 mayo 1972), Barcelona: Ariel, p. 13-43.

DOMÍNGUEZ ORTIZ, Antonio (1981) «Un alegato de los párrocos de la diócesis toledana contra el desigual reparto de los diezmos», Hispania Sacra, 33 (68), p. 533-539.

DONÉZAR DIEZ DE ULZURUN, Javier Ma (1984) Riqueza y propiedad en la Castilla del Antiguo Régimen: la provincia de Toledo en el siglo XVIII, Madrid: Instituto de Estudios Agrarios, Pesqueros y Alimentarios, p. 468-489.

DURAN PUJOL, Montserrat y FELIU MONTFORT, Gaspar (2008): «Algunos datos para el cálculo del PIB catalán (siglos XVI-XVIII), con escepticismo», comunicación presentada a la Sesión Plenaria A1, El PIB y las macromagnitudes económicas en la España del Antiguo Régimen, del IX Congreso de la AEHE, Murcia, 10-12 de septiembre. Accessible a l'adreça: https://www.aehe.es/wp-content/uploads/2008/09/Algunosdatos.pdf

DURAN PUJOL, Montserrat (1984) Renda i producció agrària (s. XVII-XVIII) a Catalunya: l'Alt Urgell, el Tarragonès, la Conca de Barberà, el Baix Empordà (Tesi doctoral), Universitat Autònoma de Barcelona.

DURAN PUJOL, Montserrat (1985) «L'evolució de l'ingrés senyorial a Catalunya (1500-1799)», Recerques, 17, p. 7-42.

DURAN PUJOL, Montserrat (1986) «Producció i renda agrària a la Catalunya del segle XVI», dins Núria SALES et al. (ed.) Terra, treball i propietat. Classes agràries i règim senyorial als Països Catalans, Barcelona: Crítica, p. 186-213.

DURAN PUJOL, Montserrat (1999) «La llarga davallada de la renda feudal a Catalunya: un exemple», dins Albert CARRERAS, Pere PASCUAL, David REHER i Carles SUDRIÀ Homenatge a Jordi Nadal, I, Barcelona: Universitat de Barcelona, p. 412-421.

ELSAS, Moritz J. (1936/1940) Umriss einer Geschichte der Preise und Löhne in Deutschland, Leiden: Sijthoff. 
ESCARTÍN BISBAL, Joana Maria (1992) «La manufactura a Mallorca durant el segle XviII: el cas de la seda», Estudis baleàrics, 43, p. 61-81.

ESPINO LOPEZ, Antonio (2011) En la perifèria dels regnes perifèrics. Guerra $i$ defensa en la Mallorca de Carles II (1665-1700), Palma: Lleonard Muntaner Editor.

ESPINO LOPEZ, Antonio (2015) «La climatología y el negocio de la sal en la Ibiza del siglo XVII», Revista de Historia Moderna, 33, p. 243-262.

ESTARELLAS, Andreu (1971) «Olivos y almazaras de Mallorca» dins Josep MASCARÓ i PASARIUS (ed.), Historia de Mallorca vol. Iv, Palma: Editorial Miramar, p. 139-192.

FARÍAS, Víctor (1998) «La ferreria i el mas al nord-est català medieval», Quaderns del Centre d'Estudis Comarcals de Banyoles, 19, p. 29-44.

FARÍAS, Víctor (2000) «Sobre la reorganización del señorío rural y la figura del baiulus en la Catalunya del Noreste de los siglos XII y xIII», Anuario de Estudios Medievales, 30 (2), p. 887-916.

FARÍAS, Víctor (2009) El mas i la vila a la Catalunya medieval. Els fonaments d'una societat senyorialitzada (segles XI-XIV), València: Universitat de València.

FEDERICO, Giovanni; MALANIMA, Paolo (2004) «Progress, decline, growth: product and productivity in Italian agriculture, 1000-2000", Economic History Review, LVII, 3, p. 437-464.

FELIPO, Amparo (1982) «Las sisas del vino y del general de entradas tras las Cortes Valencianas de 1626», Saitabi, 32, p. 61-74.

FELIPO, Amparo (1984) «El control de la producción vinícola en el País Valenciano durante el siglo XviI: los manifiestos de 1627-1631», Estudis: Revista de Historia Moderna, 11, p. 41-82.

FELIPO, Amparo (1985) «Producción y consumo de vino en el País Valenciano durante el siglo xvII: los manifiestos de 1627-1631», Saitabi, 35, p. 127-150.

FELIU, Gaspar (1985) «El negocio de los arrendamientos de rentas señoriales: examen de un libro de cuentas», Revista de Historia Económica, III (1), p. 31-54.

FELIU, Gaspar (1990) El funcionament del règim senyorial a l'Edat Moderna. L'exemple del Pla d'Urgell, Lleida: Institut d'Estudis Ilerdencs.

FELIU, Gaspar (1991) Precios y salarios en la Cataluña moderna, Madrid: Banco de España - Servicio de Estudios. 
FELIU, Gaspar (2004) «La crisi catalana de la baja edad media: estado de la cuestión», Hispania, LXIV (2), 217, p. 435-466.

FELIU, Gaspar (2006) "La baixa edat mitjana», dins Rosa CONGOST, Maximiliano MORALES i Jaume SOBREQUÉS (coord.), Pierre Vilar i la història de Catalunya, Barcelona: Editorial Base, p. 43-69.

FELIU, Gaspar (2011) La llarga nit feudal. Mil anys de pugna entre senyors $i$ pagesos, València: Publicacions de la Universitat de València.

FERRER FLOREZ, Miguel. (2001) «Las órdenes religiosas en Mallorca a fines del siglo XviII y principios del XIX», Bolletí de la Societat Arqueològica Lul.liana: Revista d'estudis històrics, 57, p. 171-202.

FERRER, Joan (2009) Diplomatari del monestir de Sant Joan de les Abadesses (995-1273), Barcelona: Fundacio Noguera.

FERRER, Llorenç (2013) «Plantar a mitges. L'expansió de la vinya i els orígens de la rabassa morta a la Catalunya Central en el segle Xviı», Recerques, 67, p. 33-59.

FERRER, Llorenç (2016) «El crecimiento demográfico de las comarcas de Girona en el siglo xviII y los cambios hacia la transición demográfica en la primera mitad del siglo xIx», Revista de Demografía Histórica, 34 (2), p. 17-52.

FONSECA, Josué (1992) El clero en Cantabria en la Edad Moderna. Un estudio sobre la implantación de la Contrarreforma en el Norte de España, Santander: Servicio de Publicaciones de la Universidad de Cantabria.

FONTANA, Josep [COSTA, Ferran] (1966) «La pugna entorn dels delmes a les Corts catalanes del segle XVI», Nous Horitzons, 2, p. 41-45.

FOREVILLE, RAIMUNDA (1972) Lateranense IV, Vitòria: Editorial Eset.

FRADERA, Josep M. (1983) «Evolució del delme i les finances de Santa Maria de Mataró, 1727-1835», dins DIVERSOS AUTORS $1 r$ Col-loqui d'Història Agrària. Barcelona, 13-15 d'octubre de 1978, València: Institució Alfons el Magnànim / Diputació de València, p. 247-269.

FRANCESCH, Clara; APARICIO, Andrea (2017) «La familia de Roca. El monopolio familiar sobre la bailía de Sant Ponç de Fontajau», dins María ASENJO GONZÁLEZ Campo y ciudad. Mundos en tensión. Siglos XIIXV. XLIV Semana Internacional de Estudios Medievales (Estella-Lizarra, 2017), Pamplona: Nafarroako Gobernua, p. 233-246.

FREEDMAN, Paul H. (1993) Els orígens de la servitud pagesa a la Catalunya medieval, Vic: Eumo Editorial. 
FREIRE COSTA, Leonor; PALMA, Nuno; REIS, Jaime (2013) «The Great Escape? The Contribution of the Empire to Portugal's Economic Growth, 1500-1800», Working Papers in Economic History, WP 13-07, Instituto Figuerola, Universidad Carlos III de Madrid. Accesssible a l'adreça: https://ideas.repec.org/p/cte/whrepe/wp13-07.html

FUENTE CIMINO, Carla (2014) «Parroquias y diezmos en la historiografía medieval española», Historia da historiografía: International Journal of Theory and History of historiography. Ouro preto, 15, p. 89-106.

GARCÍA PÉREZ, Francisco José (2014) «El Cabildo catedralicio de Mallorca (1700-1750). Estudio de una élite de poder durante el siglo XVIII», Tiempos Modernos, 29 (2).

GARCÍA PÉREZ, Francisco José (2017) «Los canónigos de la catedral de Mallorca durante el siglo XVII», CAURIENSIA. Revista anual de Ciencias Eclesiásticas, 12, p. 407-442.

GARCÍA PÉREZ, Francisco José. (2018) «El cabildo mallorquín en la época de la Ilustración (1750-1800)» Historia. Instituciones. Documentos, 45, p. 61-87.

GARCÍA FIGUEROLA, Luis (1989) La economía del cabildo salmantino del siglo XVIII, Salamanca: Universidad de Salamanca.

GARCÍA SANZ, Ángel (1986) Desarrollo y crisis del Antiguo Régimen en Castilla la Vieja. Economía y sociedad en tierras de Segovia, 1500-1814, Madrid: Akal, $2^{\text {a }}$ edició.

GARÍ PALLICER, Miguel G. (2013) «Notas introductorias sobre el almacenamiento del cereal de la Administración en la Ciutat de Mallorca (circa 1580-1692)», Bolletí de la Societat Arqueològica Lul-liana: Revista d'estudis històrics, 69, p. 159-176.

GARÍ PALLICER, Miguel G. (2019) «Población y escasez en Palma de Mallorca durante el siglo Xviı», Revista de Demografía Histórica, 37 (1), p. 47-78.

GIFRE RIBAS, Pere (2008) «Temps de crisi i de transformacions productives (1580-1680)», dins Emili GIRALT (ed.) Història Agrària dels Països Catalans. Época Moderna, Barcelona: Fundació Catalana per a la Recerca i la Innovació, Universitats dels Països Catalans, vol. III, p. 31-53.

GIFRE RIBAS, Pere (2009) En la prehistòria dels hisendats. De senyors útils a propietaris (Vegueria de Girona, 1486-1720) (Tesi doctoral), Universitat de Girona, Facultat de Lletres (Departament de Geografia, 
Història i Història de l'Art). 2 vol. Accessible a l'adreça: http://hdl. handle.net/10803/7855

GIFRE RIBAS, Pere (2011) Delmes, censos i lluïsmes. El feudalisme tardà a la Catalunya Vella (Vegueria de Girona, s. XVI-XVII), Girona: Associació d'Història Rural de les Comarques Gironines; Centre de Recerca d'Història Rural de la Universitat de Girona; Documenta Universitaria.

GIFRE RIBAS, Pere (2012) Els senyors útils i propietaris de mas. La formació històrica d'un grup social pagès (vegueria de Girona, 1486-1730), Barcelona: Fundació Noguera.

GIFRE RIBAS, Pere (2017) «La recerca històrica en arxius patrimonials de Catalunya. Un estat de la qüestió», Bolletí de la Societat Catalana d'Estudis Històrics, XxvIII, p. 197-236.

GONZÁLEZ MARISCAL, Manuel (2015) «Inflación y niveles de vida en Sevilla durante la revolución de los precios», Revista de Historia Económica (New Series), 33 (03), p. 353-386.

GOY, Joseph (1982) «Methodology», dins Emmanuel LE Roy Ladurie i Joseph GOY (ed.) Tithe and Agrarian History from the Fourteenth to the Nineteenth Centuries. An essay in comparative history, Cambridge: Cambridge University Press, p. 3-67.

GOY, Joseph; LE ROY LADURIE, Emmanuel (coord.) (1972) Les fluctuations $d u$ produït de la dîme. Conjoncture décimale et domaniale de la fin du Moyen Âge au XvII e siècle, París, La Haia, Nova York: Éditions de l’École des Hautes Études en Sciencies Sociales, Mouton éditeur.

GOY, Joseph; LE ROY LADURIE, Emmanuel (coord.) (1982) Prestations paysannes. Dîmes, rente foncière et mouvement de la production agricole à l'époque préindustrielle, París, La Haia, Nova York: Éditions de l'École des Hautes Études en Sciencies Sociales, Mouton éditeur.

GRAU, Elena (1981) El conreu de l'olivera a Mallorca a mitjan segle XIX. Sistema de conreu, organització del treball, rendiments i productivitat segons les dades de l'Interrogatori fiscal de 1850/1 (Memòria de llicenciatura), Universitat de Barcelona (Facultat de Geografia i Història).

GRAU, Elena; TELLO, Enric (1985) «Anàlisi de la producció agrària mallorquina en els seus dos sectors fonamentals: l'oli i els cereals", Randa, 18, p. 45-91.

GRIGG, David (2002) «Olive oil, the Mediterranean and the World», GeoJournal, 53, p. 163-172. 
GUILLERÉ, Christian (1985-1986) «Ville et féodalité dans la Catalogne du bas Moyen-Âge», Estudi General, 5-6, p. 447-466.

GUILLERÉ, Christian (1990) «Criteris medievals per a l'estudi comarcal: el cas de la Selva a través de les enquestes episcopals», Quaderns de la Selva, 2, p. 85-101.

GUILLERÉ, Christian (1993-1994) Girona al segle XIV, Barcelona: Publicacions de l'Abadia de Montserrat - Ajuntament de Girona, 2 vol.

HABSBURG-LORENA, Luís Salvador (1954-1965) Las Baleares descritas por la palabra y el grabado [traducció de José Sureda Blanes], Palma: Ed. Imprenta Mossèn Alcover.

HABSBURG-LORENA, Luís Salvador (1980-1993) Las Baleares: por la palabra y el grabado [traducció de Carlos y Bárbara Sánchez-Rodrigo], Palma: El. Caja de Baleares «Sa Nostra».

HAMILTON, Earl J. (1934) American Treasure ad the Price Revolution in Spain, 1501-1650, Cambridge, MA: Harvard University Press ([1975] versió espanyola).

HAMILTON, Earl J. (1936) Money, Prices, and Wages in Valencia, Aragon and Navarre, 1351-1500, Cambridge, MA: Harvard University Press.

HAMILTON, Earl J. (1947) War and Prices in Spain, 1650-1800. Cambridge, MA: Harvard University Press ([1988] versió espanyola).

HAMILTON, Earl J. (1983) El tesoro americano y la revolución de los precios en España, 1501-1650, Barcelona: Ariel.

IBÁÑEZ, Santiago (1994) «El diezmo en la Rioja (s. XVI-XVIII)», Brocar. Cuadernos de Investigación Histórica, 18, p. 189-222.

IBÁÑ̃Z, Santiago (1999) El pan de Dios y el pan de los Hombres. Diezmos, primicias y rentas en la diócesis de Calahorra (ss. XVI-XVIII), Logronyo: Universidad de la Rioja.

IGLESIAS ORTEGA, Arturo (2012) La catedral de Santiago de Compostela y sus capitulares: Funcionamiento y sociología de un cabildo en el siglo XVI, La Corunya: Diputación de A Coruña.

INFANTE-AMATE, Juan (2014) ¿Quién levantó los olivos?: Historia de la especialización olivarera en el sur de España (ss. XVIII-XX), Madrid: Ministerio de Agricultura, Alimentación y Medio Ambiente, Centro de Publicaciones.

JACQUART, Jean (1975) «La rente foncière, inidice conjoncturel?», Revue històrique, CCLIII, p. 355-376 [Reeditat en el recull Jean JACQUART 


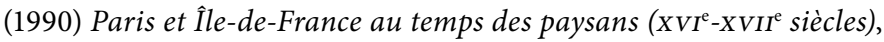
París: Publications de la Sorbonne, p. 59-80].

JOVER-AVELLÀ, Gabriel (1999) «Crisi agrària i endeutament nobiliari. La casa Gual Despuig, Mallorca, 1650-1750», Randa, 42, p. 11-46.

JOVER-AVELLÀ, Gabriel (2002) «Ingresos y estrategias patrimoniales de la nobleza durante la crisis del seiscientos. Mallorca, 1600-1750», dins Hilario CASADO ALONSO i Ricardo ROBLEDO HERNÁNDEZ (ed.) Fortuna y negocios. La formación y gestión de los grandes patrimonios (ss. $x v i-x x$ ), Valladolid: Secretariado de Publicaciones de la Universidad de Valladolid, p. 99-130.

JOVER-AVELLÀ, Gabriel (2011) «Population, Subsistence Crisis and Agrarian Change in the Island of Majorca, 1560-1650», Histoire \& Mesure, XXviI, p. 51-74.

JOVER-AVELLÀ, Gabriel (2012) «Tres notes sobre la demanda de treball assalariat a les possessions mallorquines durant el segle XVI», dins Antònia MOREY i Gabriel JOVER-AVELLÀ (ed.) Les possessions mallorquines. Passat i present, Palma: Documenta / Institut d'Estudis Baleàrics, p. 209-231.

JOVER-AVELLÀ, Gabriel (2013a) «Il fondi di Canet, 1723-1793. Investimenti ed expansuione degli oliveti ne'll isola di Maiorca», dins Rossano PAZZAGLI (ed.) Il mondo a metà. Studi storici sul territorio e l'ambiente in onore di Giuliana Biagioli, Pisa: Edizioni ETS, p. 151-168.

JOVER-AVELLÀ, Gabriel (2013b) «La difusión del trabajo asalariado infantil en la agricultura mallorquina: una aproximación a partir de los libros de cuentas de los predios oleícolas, 1700-1850», dins José María BORRÁS (ed.) El trabajo infantil en España, 1700-1950, Barcelona: Universitat de Barcelona / Icaria, p. 27-62.

JOVER-AVELLÀ, Gabriel (2014) «Després de les Noves Plantes: canvis i continuïtats a les terres de parla catalana», dins Narcís FIGUERAS i Josep SANTESMASES (ed.), Actes del IX Congrés de la CCEPC (Cervera, 21 i 22 de febrer de 2014), Barcelona: Cosetània Edicions, p. 351-368.

JOVER-AVELLÀ, Gabriel (2015) «Salarios y movilización del trabajo femenino en el olivar: Mallorca, 1650-1720», dins María Teresa ORTEGA (ed.) Jornaleras, campesinas y agricultoras: La historia agraria desde una perspectiva de género, Saragossa: Prensas Universitarias de Zaragoza, p. 43-64.

JOVER-AVELLÀ, Gabriel (2020) «Was there an agrarian crisis in the last third of the $17^{\text {th }}$ century in the Mediterranean World? The island 
of Majorca», dins Gérard BEAUR (ed.) Alternative agriculture. À reassessment, Turnhout: Brepols Publishers, p. 139-166.

JOVER-AVELLÀ, Gabriel; MANERA, Carles (2009) «Producción y productividad agrícolas en la isla de Mallorca, 1590-1860», Revista de Historia Económica - Journal of Iberian and Latin American Economic History, 27, (3), p. 463-498.

JOVER-AVELLÀ, Gabriel; PONS, Jerònia (2012) Possessions, renda de la terra i treball assalariat. L'illa de Mallorca, 1400-1660, Girona: Documenta Universitaria / Biblioteca d'Història Rural.

JOVER-AVELLÀ, Gabriel; PUJADAS-MORA, Joana M. (2020a) «Mercado de trabajo, género y especialización oleícola: Mallorca a mediados del siglo XVII», Revista de Historia Agraria, 80, p. 1-33.

JOVER-AVELLÀ, Gabriel; PUJADAS-MORA, Joana M. (2020b) «A ro de 28 sous $i$ mig oli mes, $i$ mesureta: els salaris de les collidores d'olives a Mallorca, 1645-1687», Estudis d'Història Agrària, 29, p. 65-102.

JUAN VIDAL, Josep (1976) «Las crisis agrarias y la sociedad en Mallorca durante la Edad Moderna», Mayurqa, 16, p. 87-114.

JUAN VIDAL, Josep (1978) «La evolución de la producción agrícola en Mallorca durante la Edad Moderna. Fuentes y problemas de su estudio», Moneda y crédito, 145, p. 67-69.

JUAN VIDAL, Josep (1980) «La producción de aceite en Mallorca durante la Edad Moderna y su papel en la economía mallorquina», Bolletí de la Societat Arqueolòica Lul-liana, 832-833, p. 519-552.

JUAN VIDAL, Josep (1987) «Aproximación a la conyuntura agraria mallorquina en el siglo xvi», Studia Historica: Historia Moderna, 5 (1), p. 127-139.

JUAN VIDAL, Josep (1988) «Evolución de la renta de la tierra en Mallorca durante el siglo XVI: El diezmo de la procuración real (1484-1583)» dins Homenatge al doctor Sebastià Garcia Martínez, València: Conselleria de Cultura, Educació i Ciència, 1988, p. 153-178.

JUAN VIDAL, Josep (1989a) «La distribución de los cultivos en la Mallorca del siglo xvI», Bolletí de la Societat Arqueològica Lul-liana: Revista d'estudis històrics, 45, p. 165-175.

JUAN VIDAL, Josep (1989b) «Los diezmos en la diocesis de Mallorca en el siglo XVI», Mayurqa, 22, p. 811-824. 
JUAN VIDAL, Josep (1989c) El cens de Floridablanca a les Illes Balears, 1786-1787, Palma: Miquel Font Editor.

JUAN VIDAL, Josep (1990) «Crisis de subsistències i aprovisionament blader de Mallorca durant el segle XVIII», Randa, 26, p. 103-132.

JUAN VIDAL, Josep (1996) El cens d'Aranda a Mallorca (1768-1769), Palma: El Tall Editorial.

LADERO QUESADA, Miguel Ángel (1982) El siglo Xv en Castilla: fuentes de renta y política fiscal, Barcelona: Ariel.

LATORRE CIRÍA, José Manuel (1990) «El reparto del diezmo en la diócesis de Teruel (siglo XviI)», Studium. Geografía, historia, arte, filosofía, 2, p. 27-44.

LATORRE CIRÍA, José Manuel (1992) Economía y religión. Las rentas de la catedral de Huesca y su distribución social (siglos XVI-XVIII), SaragossaOsca: Institución Fernando el Católico.

LATORRE CIRÍA, José Manuel (2010) «La evolución del producto agrario del sur aragonés durante la Edad Moderna», Investigaciones de Historia Económica, 6 (18), p. 67-101.

LAUWERS, Michel (2012b) «Pour une histoire de la dîme et du dominium ecclésial», dins Michel LAUWERS (ed.) La dîme, l'église et la société féodale, Turnhout: Brepols Publishers, p. 11-64.

LAUWERS, Michel (ed.) (2012a) La dîme, l'église et la société féodale, Turnhout: Brepols Publishers.

LAUWERS, Michel; MAZEL, Florian (2014) «Comment l'Église a confisqué la dîme», L'Histoire, 403, p. 68-74.

LE ROY LADURIE, Emmanuel (1969) «Enquêtes en cours au Centre de Recherches Historiques de l'E.P.H.E. (6 ${ }^{\mathrm{e}}$ section)», Annales, 24 (3), p. 826-832.

LE ROY LADURIE, Emmanuel (amb Marie-Jeanne Tits-Dieuaide) (1982): "Comparative study of trends", dins LE ROY LADURIE, Emmanuel and GOY, Josep (ed.) Tithe and Agrarian History from the Fourteenth to the Nineteenth Centuries. An essay in comparative history, Cambridge, Cambridge University Press, p. 71-192.

LE ROY LADURIE, Emmanuel; GOY, Joseph (1982) «Prestaciones campesinas, diezmos y tendencias de la producción agrícola en las sociedades preindustriales», dins Jerzy TOPOLSKI et al. Historia Económica: nuevos enfoques y nuevos problemas. Comunicaciones al 
Séptimo Congreso Internacional de Historia Económica, Barcelona: Crítica, p. 153-174.

LE ROY LADURIE, Emmanuel; GOY, Joseph (ed.) (1982) Tithe and Agrarian History from the Fourteenth to the Nineteenth Centuries, Londres - París: Cambridge University Press - Maison des Sciences de l'Homme.

LEMEUNIER, Guy (1976) «La part de Dieu: Recherches sur la levée des dîmes au Diocése de Carthagéne-Murcie d'après les Visitas des Tercias (XVIII-XIX)», Mélanges de la Casa de Velázquez, 12, p. 357-386.

LLIBRER ESCRIG, Inmaculada (2011) «La Catedral de Valencia como administrador general del diezmo de la diócesis. Aspectos históricos, económicos, contables y organizativos», XVI Congreso de la AECA. Nuevo modelo económico: Empresas, Mercados y Culturas, Granada, 21 a 23 de septiembre de 2011, p. 1-17. Accessible a l'adreça: http://www. aecal.org/pub/on_line/comunicaciones_xvicongresoaeca/cd/41e.pdf

LLINÀS, Joan (2010) «El castell i les muralles de Llagostera. Història i evolució del nucli antic de la població», dins Marta ALBÀ i Elvis MALLORQUÍ (coord.) Història de Llagostera. Les claus del passat, Llagostera: Ajuntament, p. 165-190.

LLOPIS AGELÁN, Enrique (2010) «La crisis económica en la España del siglo XVII: la decadencia de Castilla», dins Antoni FURIÓ (ed.) Las crisis a lo largo de la historia, Valladolid: Universidad de Valladolid, p. 46-96.

LLOPIS AGELÁN, Enrique; GONZÁLEZ MARISCAL, Manuel (2010) «Un crecimiento tempranamente quebrado: el producto agrario en Andalucía occidental en la Edad Moderna», Historia Agraria, 50, p. 13-42.

LLOPIS AGELÁN, Enrique; PÉREZ MOREDA, Vicente; SEBASTIÁN, José Antonio (2015) «Algunas sombras en el Siglo de las Luces. La sobremortalidad adulta en el interior castellano a mediados del Setecientos», dins José Luis GARCÍA RUIZ i José María ORTIZVILLAJOS (ed.) Ensayos de Historia y Pensamiento Económicos, en homenaje al Prof. Juan Hernández Andreu, Madrid: Delta Publicaciones, p. 69-82.

LLOPIS AGELÁN, Enrique, SEBASTIÁN, José Antonio.; BERNARDOS SANZ, José Ubaldo; VELASCO SÁNCHEZ, Ángel Luis; ABARCA, Vanesa (2018) «¿Descendió el producto agrario por habitante en la Europa moderna? El caso castellano», Investigaciones de Historia Económica- Economic History Research, 17 (2), p. 69-81. 
LLOPIS AGELÁN, Enrique; SEBASTIÁN, José Antonio (2019) «Aclarando tintes demasiado oscuros. La economía española en el siglo XVIII», Cuadernos Dieciochistas, 20, p. 13-68.

LLUCH, Rosa (2005) Els remences. La senyoria de l'Almoina de Girona als segles XIV $i \mathrm{XV}$, Girona: Documenta Universitaria; Associació d'Història Rural de les Comarques Gironines; Centre de Recerca d'Història Rural de la Universitat de Girona.

LLUCH, Rosa (2008) «El dia a dia d'una senyoria feudal: els manuals de comptes dels pabordes de l'Almoina del Pa (segles XIV i Xv)», dins Rosa CONGOST (ed.) Dels capbreus al registre de la propietat. Drets, títols i usos socials de la informació a Catalunya (segles XIV-XX), Girona: Documenta Universitaria; Associació d'Història Rural de les Comarques Gironines; Centre de Recerca d'Història Rural de la Universitat de Girona, p. 81-111.

LÓPEZ BONET, José F. (1983) «L'estudi del delme recaudat per la Procuració Reial de Mallorca en el segle XIV i el seu interès respecte a l'aproximació a la conjuntura agrària», Bolletí de la Societat Arqueològica Lul.liana, 39, p. 381-406.

LÓPEZ BONET, José F. (1989) «Dominis seculars, patrimoni eclesiàstic i rendes decimals a la Mallorca cristiana», Mayurqa, 22, p. 353-365.

LÓPEZ BONET, José F. (1990) La Riquesa de Mallorca al segle XIV (evolució i tendencies econòmiques), Palma: Consell de Mallorca.

LÓPEZ BONET, José F. (2008) «Para una historia fiscal de la Mallorca cristiana (siglos XIII-XIv)», Anuario de estudios medievales, 38 (1), p. 101-184.

LOPEZ NADAL, Gonçal (1986) El corsarisme mallorquí a la Mediterrània occidental, 1652-1698: un comerç forçat, Palma: Consell de Mallorca.

LORCIN, Marie Thérèse (1973) «Un musée imaginaire de la Ruse paysanne: la frau donis decimals du XIV ${ }^{e}$ au XVIII ${ }^{e}$ siècle dans la région Lyonnaise», Etudes Rurals, 5, p. 112-124.

LORING GARCÎA, Isabel (1987) «Nobleza e iglesias propias en la Cantabria altomedieval», Studia Historica. Historia Medieval, 5, p. 89-121.

MADURELL, Josep M. (1968) «La lezda de Gerona (contribución a su estudio)», Annals de l'Institut d'Estudis Gironins, 19, p. 65-106.

MALANIMA, Paolo (2003) «Measuring the Italian Economy. 1300-1861», Revista di Storia Economica, xIX, p. 265-295. 
MALANIMA, Paolo (2006) «An Age of Decline. Product and Income in Eighteenth-Nineteenth Century Italy», Revista di Storia Economica, 22 (1), p. 91-133.

MALANIMA, Paolo (2011) «The Long Decline of a Leading Economy: GPD in Central and Northern Italy, 1300-1913», European Review of Economic History, 15, p. 169-219.

MALLORQUÍ GARCÍA, Elvis (1999) «Homes, viles i masos (Cruïlles, 1319)», dins Rosa CONGOST i Lluís TO (ed.) Homes, masos, història. La Catalunya del nord-est (segles XI-XX), Barcelona: Publicacions de l'Abadia de Montserrat; Institut de Llengua i Cultura Catalanes de la Universitat de Girona, p. 43-89.

MALLORQUÍ GARCÍA, Elvis (2000) El monestir de Sant Miquel de Cruïlles a l'edat mitjana. Estudi i edició dels documents (1035-1300), la Bisbal d'Empordà: Ajuntament.

MALLORQUÍ GARCÍA, Elvis (2005) «El Sobirà de Santa Creu d'Horta (Osor): del mas medieval a la masia moderna», Quaderns de la Selva, 17, p. 81-104.

MALLORQUÍ GARCÍA, Elvis (2008) «Els veïnats: orígens i evolució d’una demarcació territorial a l'interior de les parròquies del bisbat de Girona, segles X-XIV», dins Jordi BOLÓS i Enric VICEDO (ed.) Poblament, territori i història rural, Lleida: Institut d'Estudis Ilerdencs, p. 361-394.

MALLORQUÍ GARCÍA, Elvis (2009a) «Parròquia i feudalització a la Catalunya Vella. Reflexions a partir del cas del comtat de Girona, segles IX-XI», dins Jean-Pierre BARRAQUÉ i Philippe SÉNAC (ed.) Habitat et peuplement dans les Pyrénées au Moyen Âge et à l'époque moderne, Tolosa: CNRS - Université de Toulouse-Le Mirail, p. 49-64.

MALLORQUÍ GARCÍA, Elvis (2009b) «Parròquia i societat rural al Bisbat de Girona, segles XIII-XIV», Butlletí de la Societat Catalana d'Estudis Històrics, XX, p. 277-297.

MALLORQUÍ GARCÍA, Elvis (2010a) «Masos agraris o ramaders? El cas de Cruilles i Sant Cebrià dels Alls a la primera meitat del segle XIV», dins Jordi BOLÓS, Antonieta JARNE i Enric VICEDO (ed.) Família pagesa i economia rural. VII Congrés sobre Sistemes agraris, organització social i poder local, Lleida: Institut d'Estudis Ilerdencs, p. 169-199.

MALLORQUÍ GARCÍA, Elvis (2010b) «Dues comunitats gironines: Cruilles i Riudellots de la Selva als segles XIII i xIV», dins Narcís FIGUERAS i Pep VILA (ed.) Miscelllània en honor de Josep M. Marquès, Girona: Publicacions de l'Abadia de Montserrat, p. 150-161 
MALLORQUÍ GARCÍA, Elvis (2011a) Parròquia i societat rural al bisbat de Girona, segles XIII-XIV, Barcelona: Fundació Noguera.

MALLORQUÍ GARCÍA, Elvis (2011b) El Llibre verd del bisbe de Girona (1362-1371). El delme i l'estructura feudal de la diòcesi de Girona al segle XIV, Girona: Diputació de Girona.

MALLORQUÍ GARCÍA, Elvis (2011c) «Fronteres a escala local: les parròquies del bisbat de Girona del segle XIV», Actes del congrés Fronteres: una visió des de l'Empordà, Figueres: Institut d'Estudis Empordanesos, p. 163-194.

MALLORQUÍ GARCÍA, Elvis (2012) «Parroquians contra rectors i canonges. La fixació dels costums de la parròquia de Lladó l'any 1319», Annals de l'Institut d'Estudis Empordanesos, 43, p. 85-111.

MALLORQUÍ GARCÍA, Elvis (2013) Col-lecció diplomàtica de Sant Pere de Galligants (911-1300), Barcelona: Fundació Noguera, 2 vol.

MALLORQUÍ GARCÍA, Elvis (2014a) Pagesos i homes de mar de Lloret. Estudi i edició del capbreu de la Pabordia de Novembre de 1317-1320, Lloret de Mar: Ajuntament.

MALLORQUÍ GARCÍA, Elvis (2014b) «Els masos i el paisatge de Panedes a partir del capbreu del monestir de Sant Feliu de Guíxols, 1319», dins Marta ALBÀ i Elvis MALLORQUÍ (ed.) Homes i terres. L'ordenació del paisatge agrari de Llagostera, segles XIII-XX, Llagostera: Ajuntament, p. 74-91.

MALLORQUÍ GARCÍA, Elvis (2014c) «Els delmes de la vall de Camprodon, segles X-XIV", Annals del Centre d'Estudis Comarcals del Ripollès 20122013, Ibix, 8, p. 11-30.

MALLORQUÍ GARCÍA, Elvis (2014d) «Parròquies i delmes del comtat de Besalú (segles IX-XIV): elements per a una redefinició del feudalisme català», Quaderns de les Assemblees d'Estudis, 1, p. 157-174.

MALLORQUÍ GARCÍA, Elvis (2016) «Novals i conreu de nous productes agraris al bisbat de Girona, segles XIII-XIV», Estudis d'Història Agrària, 28, p. 65-87.

MALLORQUí GARCÍA, Elvis (2017a) El delme, Girona: Diputació de Girona; Obra Social «la Caixa».

MALLORQUÍ GARCÍA, Elvis (2017b) Precepte del 844 concedit pel rei Carles el Calb al monestir de Sant Medir i Sant Genís - de Cartellà-, que al segle X esdevingué Santa Maria d'Amer. Acte de presentació (Amer, 9 de juny de 2017), Amer: Ajuntament; Departament de Cultura de la Generalitat de Catalunya; Consell Comarcal de la Selva. 
MALLORQUÍ GARCÍA, Elvis (2017c) «El castell de Dosrius a partir de l'inventari de 1315», Duos Rios, 3, p. 29-40.

MALLORQUÍ GARCÍA, Elvis (2018a) «De la parròquia a la universitat. El cas de Banyoles, segles IX-XIV», dins Gerardo BOTO, Pere FREIXAS i Jordi GALOFRÉ (ed.) Arquitectura gòtica a les terres de Girona. La construcció de l'església de Santa Maria dels Turers de Banyoles, Banyoles: Centre d'Estudis Comarcals de Banyoles, p. 13-43.

MALLORQUÍ GARCÍA, Elvis (2018b) «La Casa del Delme de Fortià. Una revisió de la història local a partir del delme», Annals de l'Institut d'Estudis Empordanesos, 49, p. 133-159.

MALLORQUÍ GARCÍA, Elvis (2020) «Els orígens de la parròquia de Blanes, 1319-1362», dins 700 aniversari de Santa Maria de Blanes (1319-2019), Blanes: Parròquia de Santa Maria de Blanes, p. 40-75.

MALLORQUÍ GARCÍA, Elvis; PRAT, Marc; SAGRERA, Jordi (2020) «La Torre Ferrana de Montfullà: la casa forta medieval dels Perafort», Acta Historica et Archaeologica Mediaevalia, 33.

MAÑARICÚA, Andrés Eliseo de (1950) Santa María de Begoña en la historia espiritual de Vizcaya, Bilbao: La Editorial Vizcaína.

MANERA ERBINA, Carles (1984) «Entorno a una familia comercial mallorquina a fines del siglo XviII: los Capo», dins Agustín RAVINA GUIMERÁ Actes del Primer Congrés d'Història Moderna de Catalunya, Barcelona, del 17 al 21 de desembre de 1984, Barcelona: Universitat de Barcelona, p. 798-806.

MANERA ERBINA, Carles (1988) Comerç i capital mercantil a Mallorca. 1720-1800, Palma: Consell Insular de Mallorca.

MANERA ERBINA, Carles (1990) «Resistir i créixer. Canvi econòmic i classes socials a la Mallorca del segle XviII», Randa, 26, p. 7-83.

MANERA ERBINA, Carles (1992) «Viticultors a Mallorca. L'avenç de la vinya el segle XVIII", Estudis d'historia agrària, 9, p. 41-71.

MANERA ERBINA, Carles (1996) «Burguesía mercantil y tardofeudalismo: notas sobre la formación del capital comercial en la Mallorca del Setecientos», dins Luis Miguel ENCISO RECIO (ed.) La burguesia española en la Edad Moderna: actas del Congreso Internacional celebrado en Madrid y Soria los días 16 a 18 de diciembre de 1991, Madrid: Secretariado de Publicaciones e Intercambio Editorial, p. 811-820. 
MANERA ERBINA, Carles (1999) «Mallorca en el planeta mediterrani. Les principals línies d'inversió del capital comercial (1700-1900)», Randa, 42, p. 81-148.

MANERA ERBINA, Carles (2001) Història del creixement econòmic a Mallorca (1700-2000), Palma: Lleonard Muntaner Editor.

MARCÓ, Xavier (2008) «La senyoria del delme de l'Almoina del Pa de la seu de Girona a Santa Cristina d'Aro al segle XV», dins Alejandro MARTÍNEZ, Neus PUIG i Montse VIADER (ed.) Les senyories a la Catalunya baixmedieval, Hostalric: Ajuntament, p. 118-131.

MARCOS MARTÍN, Alberto (1983) «De nuevo sobre los diezmos. La documentación decimal de la diócesis de Palencia: problemas que plantea», Investigaciones históricas: Época moderna y contemporánea, 4, p. 99-122.

MARQUÈS, JOSEP M. (1984) Pergamins de la Mitra (899-1687). Arxiu Diocesà de Girona, Girona: Institut d'Estudis Gironins.

MARQUĖS, JOSEP M. (1986) El cartoral de Santa Maria de Roses (segles $X$ XIII), Barcelona: Institut d'Estudis Catalans.

MARQUÈS, JOSEP M. (1993) Cartoral, dit de Carlemany, del bisbe de Girona (s. IX-XIV), Barcelona: Fundació Noguera, 2 vol.

MARQUÈS, Josep M. (1995) Escriptures de Santa Maria de Vilabertran (968-1300), Figueres: Institut d'Estudis Empordanesos.

MARQUĖS, Josep M.; MALLORQUÍ, Elvis (2019) Vilobí d'Onyar a través del capbreu de Ramon Malarç (1337-1338), Vilobí d'Onyar: Ajuntament.

MARQUÈS, JOSEP M.; PUIG, Jaume de; SERRAT, Albert (2009a) El Cartoral de Rúbriques Vermelles de Pere de Rocabertí, bisbe de Girona (1318-1324), Barcelona: Fundació Noguera.

MARQUĖS, JOSEP M.; PUIG, Jaume de; SERRAT, Albert (2009b) «Regest del protocol del notari de la cúria diocesana de Girona Pere Capmany (anys 1313-1367)», Arxiu de Textos Catalans Antics, 28, p. 265-453.

MARTÍN MARTÍN, José Luis (2005) «Beneficios y oficios del clero rural castellano (siglos XIII-Xv)», Anuario de Estudios Medievales, 32, p. 693-735.

MAS, Francesca (1988) La revolta dels Joseps. Un conflicte dels pescadors de Lloret al segle XVIII, Lloret de Mar: Club Marina Casinet. 
MAZZOTI, Massimo (2004) «Enlightened Mills. Mechanizing Olive Oil Production in Mediterranean Europe», Technology and Culture, 47, april, p. 277-304.

MELÓN JIMÉNEZ, Miguel Ángel (1987) «Los diezmos de la diócesis de Coria (1566-1773)», Studia histórica. Historia Moderna, 5, p. 177-190.

MESTRE, Antonio (1976) «La recolección de diezmos en la diócesis valenciana según la encuesta capitular de 1758», dins DIVERSOS AUTORS Primer Congreso de Historia del País Valenciano: celebrado en Valencia del 14 al 18 de abril de 1971. 3. Edad Moderna, València: Universitat de València, p. 631-642.

MIERES, Tomàs (2001) Costums de Girona (edició crítica i traducció d'Antoni Cobos), Girona: CCG Edicions; Associació d'Història Rural de les Comarques Gironines.

MOLINA DE DIOS, Ramon (2003) Treball intensiu, treballadors polivalents (Treball, salaris i cost de la vida, Mallorca 1860-1936), Palma: Govern de les Illes Balears.

MOLL BLANES, Isabel; SEGURA, Antoni; SUAU PUIG, Jaume (1983) «Les crisis de subsistències a Mallorca. Metodologia per al seu estudi», Estudis de Prehistòria, d'Història de Mayurqa i d'Història de Mallorca dedicats a Guillem Rosselló Bordoy, Palma: Museu de Mallorca, p. 304-326.

MOLL BLANES, Isabel; SEGURA, Antoni; SUAU PUIG, Jaume FERRER, Llorenç (1983) Cronologia de les crisis demogràfiques a Mallorca, segles XVIII-XIX, Palma: Institut d'Estudis Baleàrics.

MOLL BLANES, Isabel; SUAU PUIG, Jaume (1985) «Memoria explicativa del estado de la isla de Mallorca en el siglo xviıI», dins Roberto FERNÁNDEZ (ed.) España en el siglo XVIII: homenaje a Pierre Vilar, Barcelona: Crítica, p. 249-288.

MOLL BLANES, Isabel; SUAU PUIG, Jaume (1986) «Canvis i permanència de les institucions senyorials a Mallorca durant el segle XIX», dins Núria SALES et al. Terra, treball i propietat. Classes agràries i règim senyorial als Països Catalans, Barcelona: Crítica, p. 66-106.

MOLL, JULI (2014) Joan Binimelis: Descripció particular de l'illa de Mallorca e viles, València: Publicacions de la Universitat de València.

MONJAS, Lluís (2008) La Reforma eclesiàstica i religiosa de la província eclesiàstica tarraconense al llarg de la baixa edat mitjana a través dels qüestionaris de visita pastoral, Barcelona: Fundació Noguera. 
MONTANER, Pedro de (1986) «Les cavalleries mallorquines (segles XIIXVIII)», dins Núria SALES et al. Terra, treball i propietat. Classes agràries i règim senyorial als Països catalans, Barcelona: Crítica, p. 42-65.

MONTANER, Pedro de (1990) Una conspiración filipista: Mallorca, 1711, Palma: Ed. Guillermo Canals.

MONTANER, Pedro de; MOREY, Antònia (1989) «Notas para el estudio de la Mano mayor mallorquina durante los siglos Xvi y xviı», Estudis Baleàrics, 34, p. 71-89.

MOORE, Jason W. (2010) «Amsterdam is Standing on Norway, Part II: Global North Atlantic in the Ecological Revolution of the Long Seventeenth Century», Journal of Agrarian Change, 10 (2), p. 188-227.

MOREY, Antònia (1999) Noblesa i desvinculació a Mallorca als segles XVIII $i$ XIX: les Repercusions de la legislació desvinculadora sobre a els patrimonis nobiliaris, Palma: Universitat de les Illes Balears / Abadia de Montserrat.

MOREY, Antònia; MOLINA DE DIOS, Ramon (2016) «El retroceso del olivar en las Baleares: un itinerario a contracorriente de la evolución española (1800-1960)», Historia Agraria, 68, p. 71-101.

MORGADO, Arturo (1996) El estamento eclesiástico y la vida espiritual en la diócesis de Cádiz en el siglo XVII, Cadis: Servicio de publicaciones de la Universidad de Cádiz.

MORGADO, Arturo (2000) Ser clérigo en la España del Antiguo Régimen, Cadis: Servicio de Publicaciones, Universidad de Cádiz.

MUENDEL, John (1995) «Friction and lubrication in Medieval Europe: the emergence of olive oil as a superior agent», Isis, 86 (3), p. 373-393.

MUÑOZ DUEÑAS, María Dolores (1988) El diezmo en el obispado de Córdoba, Còrdova: Caja Sur.

MUÑOZ DUEÑAS, María Dolores (1994) «Las resistencias al diezmo», Hacienda Pública Española, 1, p. 155-165.

NICOLAS, Jean (1982) La Savoie au XVIII e siècle. Noblesse et bourgeoisie, París: Maloine Éditeur.

NOGUER, Tomàs; PONS GURI, Josep M. (1966-1967) «Constitucions sinodals de Girona de la primera compilació», Anales del Instituto de Estudios Gerundenses, 18, p. 49-212.

OJEDA, José (1997) El patrimonio de la catedral de Orihuela: gobierno y administración de un edificio religioso en el Antiguo Régimen, Oriola: Imprenta Oriolana Minerva. 
ORTÍ, Pere (1999) «Una primera aproximació als fogatges catalans de la dècada de 1360», Anuario de Estudios Medievales, 29, p. 747-773.

PALMA, Nuno; REIS, Jaime (2014) «Portuguese demography and economic growth, 1500-1850», Accounting for the Great Divergence Conference, The University of Warwick in Venice, 22-24 May. Acceessible a l'adreça: https://academica-e.unavarra.es/bitstream/handle/2454/24289/

ConvergenceDivergence.pdf?sequence $=1 \&$ is Allowed $=y$

PALMA, Nuno; REIS, Jaime (2019) «From Convergence to Divergence: Portuguese Economic Growth, 1527-1850», The Journal of Economic History 79 (29, p. 477-506.

PALOP, José Miguel (1977) Fluctuaciones de precios y abastecimiento en la Valencia del siglo XVIII, València: Alfons el Magnànim.

PALOP, José Miguel (1982) «El producto diezmal valenciano durante los siglos XVII y xVIII. Aproximación a su estudio», dins Joseph GOY i Emmanuel LE ROY LADURIE (ed.) Prestations paysannes dîmes, rente foncière et mouvement de la production agricole à l'époque préindustrielle, París: Mouton, p. 407-416.

PANFILI, Didier (2012) «La dîme, enjeu majeur dans la compétition entre élites laïques et ecclésiastiques (Languedoc occidental, XI ${ }^{\mathrm{e}}$-XII ${ }^{\mathrm{e}}$ siècles», dins Michel LAUWERS (ed.) La dîme, l'église et la société féodale, Turnhout: Brepols Publishers, p. 253-279.

PANSIOT, Fernand P.; REBUR, Henry (1961) Mejoramiento del cultivo del olivo, Roma: FAO.

PASCUAL RAMOS, Eduardo (2013) «La Real Hacienda del Reino de Mallorca durante la Guerra de Sucesión. Guerra y crisis del sistema económico», Cuadernos dieciochistas, 14, p. 199-232.

PASCUAL RAMOS, Eduardo (2018) «Reforma y gestión de la deuda pública. La Junta de Caudales Comunes de Mallorca (1758-1812)», Cuadernos de Historia Moderna, 43 (1), p. 231-247.

PÉREZ GARCÍA, José Manuel; ARDIT, Manuel (1988) «Bases del crecimiento de la población valenciana en la Edad Moderna», dins Carme PÉREZ APARACIO Estudis sobre la població del País Valencià: actes de les I Jornades d'Estudi sobre la Població del País Valencià: València-Alacant, 20-22 de març de 1986, València: IVEI-Alfons el Magnànim, p. 199-228.

PÉREZ PLANELLES, Francisco (1807) Plan Estatístico de la villa de Alcoy. Accessible a l'adreça (consultada el 08/07/2019): https://riunet.upv.es/ bitstream/handle/10251/20594/48_IV_2.PDF?sequence=1\&isAllowed=y 
PÉREZ ROMERO, Emilio (2009) «Un mundo inmóvil: el producto agrícola por habitante en la cuenca alta del Duero durante la Edad Moderna», Investigaciones de Historia Económica, 14, p. 69-102.

PÉREZ, Plàcid (2012) «La família Palou de Tuent, terratinents Sollerics (1550-1700)», dins Antònia MOREY i Gabriel JOVER-AVELLÀ (ed.) Les possessions mallorquines. Passat i present, Palma: Documenta / Institut d'Estudis Baleàrics, p. 159-172.

PERIS, Tomás (1995) «La evolución de la agricultura valenciana entre los siglos XV-XIX: rasgos cualitativos y problemas de cuantificación», Revista de Historia Económica - Journal of Iberian and Latin American Economic History, 13 (3), p. 473-508.

PFISTER, Ulrich (2011) «Economic growth in Germany, 1500-1850», Quantifying Long Run Economic Development Conference, University of Warwick in Venice, 22-24 March. Acceessible a l'adreça: https://www. wiwi.uni-muenster.de/wisoge/sites/wisoge/files/downloads/aktuelleProjekte/growth_venice_2011.pdf

PHELPS BROWN, Henry Phelps; HOPKINS, Sheila V. (1955) «Seven Centuries of Building Wages», Economica, 22 (87), p. 195-206.

PHELPS BROWN, E. H.; HOPKINS, S. V. (1956) «Seven Centuries of the Prices of Consumables, Compared with Builders' Wage Rates», Economica, 23 (92), p. 296-314.

PLANAS ROIG, Miquel (1985) La població de l'Alt Empordà al règim demogràfic antic (Tesi de llicenciatura), Universitat Autònoma-Lletres.

PONS GURI, JOSEP M. (1989) «Constitucions conciliars Tarraconenses (1229 a 1330)», dins Josep Maria PONS GURI, Recull d'estudis d'història jurídica catalana, Barcelona: Fundació Noguera, vol. 2, p. 223-251.

PORTELLA, Jaume (1976) «Estudi demogràfic del prelitoral gironí (segles XVI-XVIII)», Treballs d'Història. Estudis de demografia, economia $i$ societat de les comarques Gironines, Girona: Patronat Eiximenis, p. $35-62$.

PORTELLA, Jaume (1993) El negoci feudal de Mallorca (segles XIII-XV). Drets $i$ rendes de les senyories laiques i eclesiàstiques (Tesi Doctoral), Universitat Autònoma de Barcelona.

PORTELLA, Jaume; SANZ, Antoni Ll. (1985) «Reacció senyorial i resistència pagesa al domini de la catedral de Girona (segle XVIII). Notes per a una recerca», Recerques, 17, p. 141-151. 
POSTHUMUS, Nicolaas Wilhelmus (1946) Inquiry into the History of Prices in Holland, vol. I, Leiden: E. J. Brill.

POSTHUMUS, Nicolaas Wilhelmus (1964) Inquiry into the History of Prices in Holland, vol. II, Leiden: E. J. Brill.

PRIBRAM, Alfred Francis (1938) Materialien zur Geschichte der Preise und Löhne in Osterreich, Band I, Viena: Carl Ueberreuters Verlag.

PUIG, Narcís de (2003) L'armari i les pabordies de la seu de Girona durant l'Edat Moderna. Un exemple de comptabilitat senyorial (Treball de recerca), Girona: Universitat de Girona.

PUIGVERT, Xavier (1992) «La introducció del delme a la Marca d'Hispània», Acta Historica et Archaeologica Mediaevalia, 13, p. 117-125.

PUJOL BERTRAN, Antoni (1996) «Diferències en l'alimentació de la milicia a Felanitx i Pollença, segle XVII», dins DIVERSOS AUTORS XIV Jornades d'Estudis Històrics Locals, Palma: Insitut d'Estudis Baleàrics, p. 493-495

PUJOL, Marcel (2015) Un mar de conflictes. La pesca a Roses durant l'Antic Règim, 1592-1835, Roses: Ajuntament.

QUINTANA I TORRES, Antoni. (1982) «Anàlisi del grup pagès arrendatari/ propietari de bestiar al municipi de Llucmajor en el segle XviII», Estudis baleàrics, 6, p. 157-168.

QUINTANA I TORRES, Antoni (1992) «Estat general de la ramaderia mallorquina (segle XVIII)», Estudis d'historia econòmica, 1, p. 57-71.

RAMÓN-MUÑOZ, Ramon (2000) «Specialization in the international market for olive oil before World War II», dins Sevket PAMUK i Jeffrey G. WILLIAMSON (ed.) The Mediterranean Response to Globalization before 1950, Londres / Nova York: Routledge, p. 159-198

RAMÓN-MUÑOZ, Ramon (2005) «La producción y el comercio de aceite de oliva en los países del Mediterráneo (1850-1938): competencia y especialización», Mediterráneo Económico, 7, p. 329-354

RAMÓN-MUÑOZ, Ramon (2013) «Modernizing the Mediterranean OliveOil Industry, 1850s-1930s», dins Dereck J. ODDY i Alain DROUARD (ed.) The food industries of Europe in the nineteenth and twentieth centuries, Londres: Routledge, p. 71-88.

RAMOS, Juan Antonio (1980) Demografía, economía (desamortización bajo el reinado de Carlos IV) y sociedad en la comarca del Bajo Segura durante el siglo XVIII, Oriola: Caja de Ahorros de Alicante y Murcia. 
REIXACH, Albert (2019) Els usos de l'aigua a la Girona preindustrial: segle XIV - inicis del segle XVIII, Girona: Ajuntament - Institut d'Estudis Gironins.

REY CASTELAO, Ofelia (1992) «El reparto social del diezmo en Galicia», Obradorio de Historia Moderna, 1, p. 145-162.

RICARDO, David (1984 [1817]) Els principis d'economia política i tributació, Barcelona: Edicions 62/Diputació de Barcelona.

RIERA FERRER, Juan José (1985) «Aproximación al estudio del derecho del aceite», Bolletí de la Societat Arqueologica Lul-liana: Revista d'estudis històrics, 41, p. 251-258.

RIVES, Jean (1976), Dîme et société dans l'archevêché d'Auch au XVIII' siècle, Commission d'histoire économique et sociale de la Révolution française. Mémoires et documents XXII, Paris.

ROBLEDO HERNÁNDEZ, Ricardo (2002) «Quiebra de la Universidad tradicional (1790-1845)», Luís Enrique RODRÍGUEZ SAN PEDRO Historia de la Universidad de Salamanca. I. Trayectoria y vinculaciones, Salamanca: Universidad de Salamanca, p. 205-237

RODRÍGUEZ CACHO, Miguel; MELÓN JIMÉNEZ, Miguel Ángel; RODRÍGUEZ GRAJERA, Alfonso; BLANCO CARRASCO, José Pablo (2004) «Economía eclesiástica en Extremadura a finales del Antiguo Régimen: una aproximación a las rentas de la diócesis de Plasencia», Obradoiro de Historia Moderna, 13, p. 127-16.

RODRÍGUEZ LÓPEZ-BREA, Carlos (1995) «La crisis del Antiguo Régimen en el arzobispado de Toledo. El impago de diezmos (1800-1820)», dins Antonio Miguel BERNAL (ed.) Antiguo Régimen y liberalismo. Homenaje a Miguel Artola. 2. Economía y sociedad. Madrid: Alianza Editorial-Universidad Autónoma de Madrid, p. 285-293.

ROMEO, María Cruz (1986) Realengo y municipio: marco de formación de una burguesía (Alcoi en el siglo XVIII), Alacant: Institut de Cultura Juan Gil-Albert.

PÉREZ ROMERO, Emilio (2018) «Precios, salarios y carga laboral durante el siglo xviII. El caso de la villa de El Burgo de Osma (Soria)», Investigaciones de Historia Económica, 15 (2), p. 78-90.

ROMERO, Joan (1983) «Notas comparativas entre el señorío valenciano y los territorios de la antigua Corona de Aragón. Dos elementos básicos: la ausencia de población morisca en Cataluña y las Islas y la peculiaridad del modelo insular», Estudis, 10, p. 151-164. 
ROMERO, Joan (1989) «Señorio y propiedad en Mallorca en el tránsito de los siglos XVIII al XIX», dins Antonio Miguel BERNAL (ed.) Estructuras agrarias y reformismo ilustrado en la España del siglo XVIII. Actas del seminario de Segovia sobre Agricultura e Ilustración en España (14, 15 y 16 de septiembre de 1988), Madrid: Ministerio de Agricultura, Pesca y Alimentación, p. 349-365

ROSTOW, W. W. (1990) The stages of economic growth: A non-communist manifesto, Cambridge: Cambridge University Press, 1960

ROURE I AULINAS, Lluís (1984) L'Antic Règim a Mallorca. Abast de la commoció dels anys 1808-1814, Palma: Conselleria d'Educació i Cultura del Govern Balear.

RUBIO PÉREZ, Laureano (2013) «Párrocos, parroquias y concejos: el modelo parroquial leonés en el marco de las comunidades rurales y concejiles durante la Edad Moderna», Obradoiro de Historia Moderna, 22, p. 129-166.

RULLAN, Onofre (2002) La construcció territorial de Mallorca, Palma: Editorial Moll.

RUWET, Joseph (1964) «Mesure de la production agricole sous l'Ancien Régime. Le blé en pays mosan», Annales. Histoire, Sciences Sociales 19 (4), p. 625-642.

SAAVEDRA, Pegerto (2009) «El patrimonio y los ingresos de la Iglesia en la España de finales del Antiguo Régimen», dins Bernard BODINIER, Rosa CONGOST i Pablo Fernando LUNA (coord.) De la Iglesia al Estado: las desamortizaciones de bienes eclesiásticos en Francia, España y América Latina, Saragossa: Universidad de Zaragoza, Prensas Universitarias de Zaragoza, p. 45-76.

SAAVEDRA, Pegerto (2016) «El clero rural en la España moderna», dins Francisco GARCÍA GONZÁLEZ, Gerard BÉAUR i Fabrice BOUDJAABA (ed.) La historia rural en España y Francia (siglos XVIXIX), Saragossa: Prensas de la Universidad de Zaragoza, p. 339-383.

SABATÉ, Flocel (1993) «Les castlanies i la comissió reial de 1328», dins Manuel SÁNCHEZ MARTÍNEZ (comp.) Estudios sobre renta, fiscalidad y finanzas en la Cataluña bajomedieval, Barcelona: Consejo Superior de Investigaciones Científicas, p. 177-241.

SÁINZ DE RIPA, Eliseo (2001) «Los obispos de Calahorra en la Edad media (siglos VIII-XV)», dins José Ignacio DE LA IGLESIA DUARTE (coord.) Semana de estudios medievales, Nájera del 6 al 11 de agosto de 1990, Logronyo: Instituto de Estudios Riojanos, p. 37-66. 
SALES, Lluís (2014) «Suing in a local jurisdictional court in late medieval Catalonia. The case of Caldes de Malavella (1328-1369)», Continuity and Change, 29, p. 49-81.

SALES, Lluís (2018) «Masos i renda feudal en una baronia jurisdiccional. El cas de Caldes de Malavella al segle XIV", dins Jordi MORELLÓ, Pere ORTÍ i Pere VERDÉS (ed.) Renda feudal i fiscalitat a la Catalunya baixmedieval. Estudis dedicats a Manuel Sánchez Martínez, Barcelona: Consell Superior d'Investigacions Científiques - Institució Milà i Fontanals, p. 647-682.

SALES, Lluís (2019) La jurisdicció de Sabadell a la baixa edat mitjana. Edició i estudi d'un llibre de la cort del batlle (1401-1404), Girona: Associació d'Història Rural - Centre de Recerca d'Història Rural de la Universitat de Girona - Documenta Universitaria.

SALOMON, Nöel (1982) La vida rural castellana en tiempos de Felipe II, Barcelona: Ariel.

SALVADOR, Emilia (2004) «Tercios diezmos sobre la producción agraria de la huerta de Valencia en el siglo xvi. Aproximación a su naturaleza y rendimiento», Estudis d'Història Agrària, 17, p. 861-876.

SÁNCHEZ MARTÍNEZ, Manuel (1995) El naixement de la fiscalitat d'Estat a Catalunya (segles XII-XIV), Vic: Eumo Editorial.

SÁNCHEZ, Àlex; VALLS-JUNYENT, Francesc (2016-2017) «Les crisis a Catalunya en una etapa de creixement i transició (1680-1840)», Recerques, 72-73, p. 119-170

SANTAMARÍA, Álvaro (1989) Nueva Planta de gobierno de Mallorca. Enfiteusis urbana y real cabrevación, Palma: Ajuntament de Palma.

SASTRE, Florenci (1981-1984) «El pariatge de Menorca de 1301», Mayurqa, 20, p. 141-154.

SASTRE, Jaume (1989-1990) «La producción agraria de Inca, Valldemosa, Llucmajor y Montuïri según la declaración del diezmo de 1310», dins DIVERSOS AUTORS XIII Congreso de Historia de la Corona de Aragón, Palma: Institut d'Estudis Baleàrics, vol. I, p. 247-261.

SASTRE MOLL, Jaume (1994) «Rentas eclesiásticas de la isla de Menorca», Bolletí de la Societat Arqueologica Lul. liana: Revista d'estudis històrics, 50, p. 139-166.

SASTRE MOLL, Jaume (1997-1998) «L'organització de Menorca de 1301», Mayurqa, 24, p. 43-52. 
SASTRE MOLL, Jaume (2001) «Les rendes reials i de la porció de Gastó de Bearn. La seva estructura i valoració», Mayurqa, 27, p. 63-84.

SASTRE MOLL, Jaume (2009) «La producció d’oli de la villa de Sóller a la primera meitat del segle XIV (1311-1343)», dins DIVERSOS AUTORS I Jornades d'Estudis Locals de Sóller, Sóller: Ajuntament, p. 127-133.

SASTRE MOLL, Jaume (2012) «La recaptació del delme eclesiàstic de la vila d'Inca a la primera meitat del segle XIV (1328-1343)», dins DIVERSOS AUTORS XII Jornades d'Estudis Locals d'Inca, Inca: Ajuntament, p. 19-36.

SASTRE MOLL, Jaume; LLOMPART BIBILONI, Maria (2008) La Tesoreria en el reino de Mallorca durante su época de esplendor, Palma: Edicions UIB, Cas Jai

SASTRE, MOLL; Jaume; LLOMPART BIBILONI, Maria (2014) «La estructura de la documentación relativa al diezmo eclesiástico percibido por el Obispo y Cabildo de Mallorca.(Siglos xIV, xv, y xVI)», XIV Encuentro AECA, p. 23-24.

SCHÖN, Lennart; KRANTZ, Olle (2012) «The Swedish economy in the early modern period: constructing historical national accounts», European Review of Economic History, 16, p. 529-549.

SEBASTIÁN AMARILLA, José Antonio (1991) «La producción de cereales en tierras de León durante la Edad Moderna (1570-1795)», Agricultura $y$ sociedad, 59, p. 75-118.

SEBASTIÁN AMARILLA, José Antonio (1992) Agricultura y rentas monásticas en tierras de León: Santa María de Sandoval (1167-1835), Madrid: Universidad Complutense de Madrid.

SEBASTIÁN AMARILLA, José Antonio (2013) «El largo siglo xvir: crisis en España, depresión en Castilla», dins Enrique LLOPIS i Jordi MALUQUER (ed.) España en crisis. Las grandes depresiones económicas, 1348-2012, Barcelona: Pasado \& Presente, p. 59-96.

SEGURA CORTÉS, Pere Antoni (2002) «Les nevades a Mallorca en el segle XVIII: el cas de 1788», dins José Antonio GUIJARRO PASTOR (ed.). El agua y el clima, España: Publicaciones de la Sociedad Española de Climatología, p. 555-565.

SEGURA, Antoni; SUAU, Jaume (1984) «Estudi de demografia mallorquina: l'evolució de la població», Randa, 16, p. 19-62.

SERRA, Eva (1978) «Consideracions entorn de la producció i la productivitat agràries de la Catalunya del segle XVII», Estudis d'Història Agrària, 1, p. 120-153. 
SERRA, Eva (1986) «Per una cronologia i interpretació de la crisi del segle XVII», dins Núria SALES et al. Terra, treball i propietat. Classes agràries i règim senyorial als Països Catalans, Barcelona: Crítica, p. 214-246.

SERRA, Eva (1988) Pagesos i senyors a la Catalunya del segle XVII. Baronia de Sentmenat, 1590-1729, Barcelona: Editorial Crítica.

SERRA, Eva (2008) «La propietat. Mercat de la terra i evolució de la renda (segles XVI-XVII)», dins Emili GIRALT (dir.) Història Agrària dels Països Catalans. Ėpoca Moderna, Barcelona: Fundació Catalana per a la Recerca i la Innovació, Universitats dels Països Catalans, vol. III, p. 511-557.

SERRA, Eva (2013) «La crisi del segle Xvir i Catalunya», Bolletí de la Societat Catalana d'Estudis Històrics, XXIV, p. 297-315.

SIMON, Antoni; ALBERCH, Ramon (1982) «L'evolució demogràfica de Girona en els segles XVI i XVII a través dels registres parroquials», Estudi General, 2, p. 11-31.

SOLDEVILA, Xavier (2002) «La transhumància entre el Baix Empordà i el Pirineu (1270-1348)», Ibix - Annals del Centre d'Estudis Comarcals del Ripollès 2000-2001, 2, p. 107-115.

SOTO, Ricard (1991) L’ordenació de l'espai i les relacions socials a Mallorca en el segle XIII (1229-1301) (Tesi doctoral), Universitat Autònoma de Barcelona.

SOTO, Ricard (1997) «Patrimoni reial i transformacions agràries a Mallorca en el segle XIII", dins Manuel SÁNCHEZ i Antoni FURIÓ (ed.) Actes del Col.loqui Corona, Municipis i Fiscalitat a la Baixa Edat Mitjana, Lleida: Institut d'Estudis Ilerdencs, p. 555-573.

SOTO, Ricard (2014) «La vinya a Mallorca després de la conquesta catalana: un conreu de colonització feudal?», Estudis d'història agrària, 26, p. 115-132.

SUAU, Jaume (1979) La pagesia mallorquina al segle XVIII i primera meitat del XIX (Tesi doctoral), Universitat de Barcelona.

SUAU, Jaume (1984) «Escassetat i ordre social a Mallorca (1740-1760)», dins Neus ESCANDELL TUR i Ignasi TERRADAS SABORIT (ed.) Història i antropologia a la memòria d'Àngel Palerm, Barcelona: Abadia de Montserrat, p. 363-402.

SUAU, Jaume (1991) El món rural mallorquí, segles XVIII-XIX, Barcelona: Curial. 
TELLO, Enric (1992) «Renta señorial y renta de la tierra en la última etapa del antiguo régimen en Cataluña», Noticiario de Historia Agraria, 4, p. 283-314.

TELLO, Enric (1995a) «El fin de la expansión agraria en Cataluña del siglo XVIII: factores económicos y crisis social», Agricultura y sociedad, $74,109-158$.

TELLO, Enric (1995b) «El component actiu de la crisi de l'antic règim a Catalunya: la lluita per la renda entre senyors i pagesos», dins Enric VICEDO (coord.) El món rural català a l'època de la revolució liberal. Volum I. Ponències, Lleida: Edicions de la Universitat de Lleida, p.53-84.

TELLO, Enric (1997) «La conflictividad social en el mundo rural catalán, del Antiguo Régimen a la Revolución liberal, 1720-1833» Noticiario de Historia Agraria, 13, p. 89-104

TELLO, Enric; JOVER-AVELLÀ, Gabriel; MURRAY, Ivan; FULLANA, Onofre; SOTO, Ricard (2018) «From Feudal Colonization to Agrarian Capitalism in Mallorca: Peasant Endurance under the Rise and Fall of Large Estates (1229-1900)», Journal of Agrarian Change, 48, p. 483-516.

TO, Lluís (1993) «Le mas catalan du XII siècle: genèse et évolution d'une structure d'encadrement et d'asservissement de la paysannerie», Cahiers de Civilisation Médiévale, 36 (2), p. 151-177.

TO, Lluís (2005) «Le marché de la terre et la seigneurie dans la Catalogne médiévale», dins Laurent FELLER i Chris WICKHAM (ed.) Le marché de la terre au Moyen Âge, Roma: École Française de Rome, p. 479-542.

TORRES, Victor (2018) La senyoria de Palau-sator al capbreu de Pere des Miquel (1406-1408) (Treball de fi de màster), Barcelona: Universitat de Barcelona.

TORRÓ ABAD, Josep (1999) El naixement d'una colònia. Dominació $i$ resistència a la frontera valenciana (1238-1276), València: Publicacions de la Universitat de València.

TORRÓ ABAD, Josep (2009) «Vivir como cristianos y pagar como moros. Genealogía medieval de la servidumbre morisca en el reino de Valencia», Revista de Historia Moderna. Anales de la Universidad de Alicante, 27, p. 11-40.

TORRÓ GIL, Lluís (1989) «Aproximació a la producció agrícola d’Alcoi (s. XVII)», Eines. Revista Interdisciplinar, 9-10, p. 49-63.

TORRÓ GIL, Lluís (1994) Abans de la indústria: Alcoi als inicis del sis-cents, Alacant: Universitat d'Alacant. 
TORRÓ GIL, Lluís (2000) Proto-indústria i acumulació originària de capital a la vila valenciana d'Alcoi (1430-1823) (Tesi doctoral) Universitat d'Alacant.

TORRÓ GIL, Lluís (2005) «Transformaciones agrarias en el campo valenciano durante la Edad Moderna. El caso de la comarca de Alcoi (ss. XV-XVIII)», Revista de Historia Económica - Journal of Iberian and Latin American Economic History, 23 (3), p. 563-595.

TORRÓ GIL, Lluís (2019) «Protoindustria y población en una comarca textil valenciana (1600-1800)», Investigaciones de Historia Económica, 15 (1), p. 1-12.

VALDÉS, Carlos Manuel; DÍAZ-FERNÁNDEZ, Pedro; GIL-SÁNCHEZ, Luís (2003) La transformación histórica del paisaje forestal en las islas Baleares. Madrid: Ministerio de Medio Ambiente.

VALENCIANO, Valentí (2018) Petits i grans propietaris de Binissalem. Malnoms i toponimia, Palma: Editorial Disset-Institut d'Estudis Baleàrics.

VALLCANERAS, Lluis; ESTEBAN, Antoni (2010). Coma-sema. Editorial, Gorg Blau.

VAQUER BENNASAR, Onofre (1987) Una sociedad del Antiguo Régimen, Felanitx y Mallorca en el siglo XVI, volum I, Palma: edició de l'autor.

VAQUER BENNASAR, Onofre (1988) Una sociedad del Antiguo Régimen, Felanitx y Mallorca en el siglo XVI, volum II, Palma: edició de l'autor.

VAQUER BENNASAR, Onofre (2017) El comerç marítim de Mallorca a la primera meitat del segle XVII, Palma: El Tall Editorial.

VIADER, Roland (2012b) «La dîme dans l'Europe des féodalités. Rapport introductif», dins Roland VIADER (ed.) La dîme dans l'Europe médiévale et moderne, Tolosa: Presses Universitaires du Mirail, p. 7-36.

VIADER, Roland (ed.) (2012a) La dîme dans l'Europe médiévale et moderne, Tolosa: Presses Universitaires du Mirail.

VIARD, Pierre (1909) Histoire de la dîme ecclésiastique principalement en France jusqu'au décret de Gratien, Dijon: Imprimerie Jobard.

VIARD, Pierre (1912) Histoire de la dîme ecclésiastique dans le royaume de France au XII et XIII siècles, París: A Picard.

VICEDO, Enric (1986) «Propietat i renda senyorial a les terres de Lleida en el marc del procés de creixement agrari (segle XVIII)», dins Núria 
SALES et al. Terra, treball i propietat. Classes agràries i règim senyorial als Països Catalans, Barcelona: Crítica, p. 278-301.

VICEDO, Enric (1991) Les terres de Lleida i el desenvolupament català del set-cents. Producció, propietat i renda, Barcelona: Crítica.

VICEDO, Enric (2015a) «La recuperació agrària a Lleida i la seva àrea, 1670-1706», Recerques, 71, p. 59-94.

VICEDO, Enric (2015b) Pagesia, accés a la terra i desenvolupament històric. Els latifundis eclesiàstics a la Catalunya occidental plana (segles XVII$\mathrm{XX}$ ), Lleida: Pagès Editors.

VICENS, Jaume (1978 [1945]) Historia de los remensas (en el siglo XV), Barcelona: Edicions Vicens Vives.

VICIANO, Pau (2017) Més enllà de la senyoria. Mercat i impostos a la Plana de Castelló (segles XIV-XV), Catarroja: Editorial Afers.

VILA, Carmen M. (1990) «Los arrendamientos de las rentas del Real Patrimonio como indicadores económicos en la Valencia del XVII», Estudis: Revista de Historia Moderna, 16, p. 89-114.

VILAR, Pierre (1966) Catalunya dins l'Espanya moderna, Barcelona: Edicions 62.

VILAR, Pierre (1980) «Crecimiento económico y análisis histórico», dins Pierre VILAR Crecimiento y desarrollo, Barcelona: Ariel, p. 17-105.

VILLALONGA MORELL, José (2012) «Les reformes del patrimoni del marquès de Solleric a les possessions d'Alaró», dins Antònia MOREY i Gabriel JOVER-AVELLA (ed.), Les possessions mallorquines. Passat i present, Palma: Edicions Documenta-Institut d'Estudis Baleàrics, $\mathrm{p}$. 283-298.

YUN CASALILLA, Bartolomé (1994) «Proposals to Quantify Long Term Performance in the Kingdom of Castile, 1550-1800», dins Angus MADDISON i Hermann van der WEE (ed.) Economic Growth and Structural Change: Comparative Approaches over the Long Run, Milà: Università Bocconi.

ZANDEN, Jean Luiten van; LEEUWEN, Bas van (2012) «Persistent but not consistent: The growth of national income in Holland 1347-1807», Explorations in Economic History, 49, p. 119-130.

ZUCCHITELLO, Mario (2013) En mar i en terra. Una història de Tossa i la seva gent (1186-1835), Tossa de Mar: Centre d'Estudis Tossencs. 
๑ :三

$<$

$>$ 
Els autors agraeixen els comentaris i suggeriments fets pels avaluadors anònims, així com la revisió i correcció dels textos realitzada per Berta Crous. 


